\title{
Electrochemical coating of micro-structured silicon \\ for photoelectrochemical water splitting
}

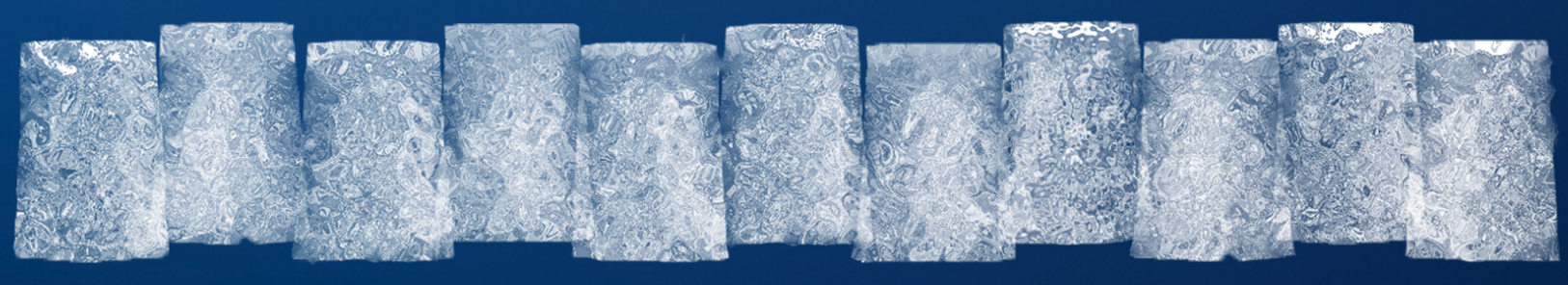

\section{Alexander Milbrat}




\section{ELECTROCHEMICAL COATING OF MICRO-STRUCTURED SILICON FOR PHOTOELECTROCHEMICAL WATER SPLITTING}

\section{Alexander Milbrat}




\section{Members of the committee:}

\section{Chairman:}

Prof. dr. ir. J.W.M. Hilgenkamp University of Twente

\section{Promotors:}

Prof. dr. G. Mul

Prof. dr. ir. J. Huskens

\section{Members:}

Prof. dr. R. van de Krol

Prof. dr. T. Jüstel

Prof. dr. J.G.E. Gardeniers

Prof. dr. J.C.T. Eijkel

Prof. dr. H.J.M. Bouwmeester

\begin{abstract}
University of Twente
University of Twente
\end{abstract}

Technische Universität Berlin

Münster University of Applied Sciences

University of Twente

University of Twente

University of Twente

The research described in this thesis was performed in a collaboration of the PhotoCatalytic Synthesis and Molecular NanoFabrication groups, both part of the MESA+ Institute for Nanotechnology at the University of Twente.
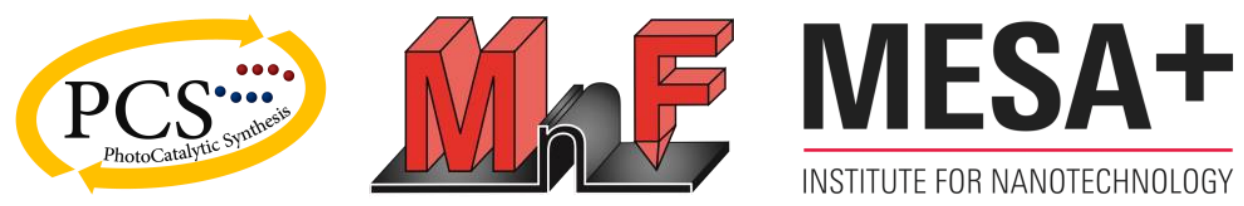

\section{Electrochemical coating of micro-structured silicon for}

\section{photoelectrochemical water splitting}

Copyright (C) 2018 Alexander Milbrat

All rights reserved. No part of this work may be reproduced by print, photocopy or any other means without prior written permission of the author.

$\mathrm{PhD}$ thesis, University of Twente, Enschede, the Netherlands

ISBN: $\quad 978-90-365-4545-7$

DOI: $\quad 10.3990 / 1.9789036545457$

Cover art: Alexander Milbrat

Printed by: Gildeprint 


\title{
ELECTROCHEMICAL COATING OF MICRO-STRUCTURED SILICON FOR PHOTOELECTROCHEMICAL WATER SPLITTING
}

\section{DISSERTATION}

\author{
to obtain \\ the degree of doctor at the University of Twente, \\ on the authority of the rector magnificus, \\ Prof. dr. T.T.M. Palstra, \\ on account of the decision of the graduation committee, \\ to be publicly defended \\ on Thursday May 3, 2018, at 16:45 h

\section{Alexander Milbrat born April 10, 1987 in Fergana, Uzbekistan}


This dissertation has been approved by the promotors:

Prof. dr. G. Mul

Prof. dr. ir. J. Huskens
University of Twente

University of Twente 


\section{Table of Contents}

Chapter 1: Introduction and motivation.......................................................1

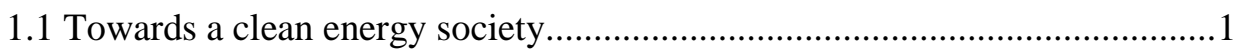

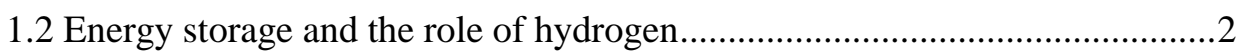

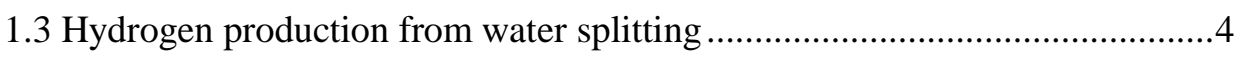

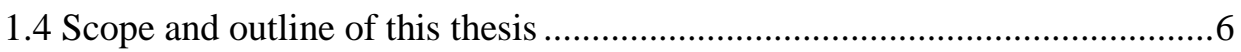

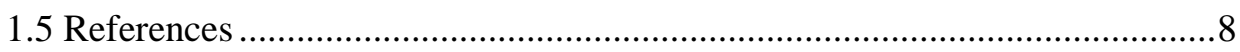

Chapter 2: Photocatalytic water splitting .........................................................13

2.1 Photocatalytic principle and material requirements .....................................14

2.2 Dual absorber particle slurry systems .......................................................16

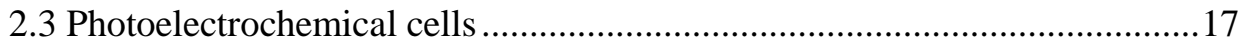

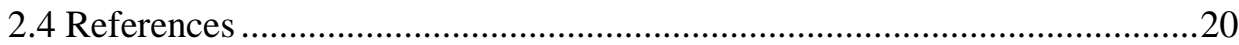

Chapter 3: Controlling the size and density of electrochemically deposited

Pt particles on $\mathrm{p}$ type $\mathrm{Si}$ by hydrogen peroxide ...............................................23

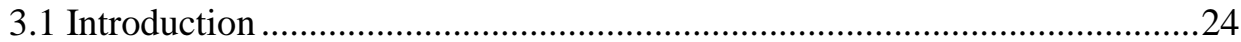

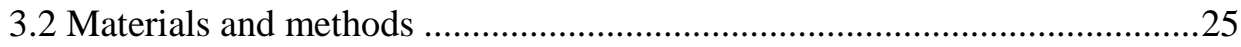

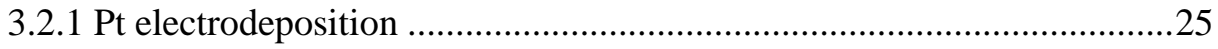

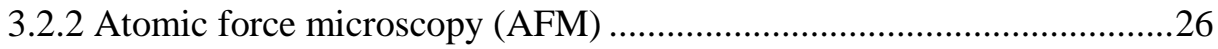

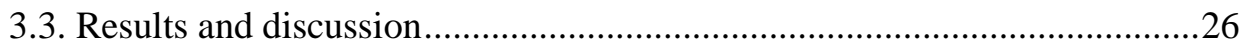

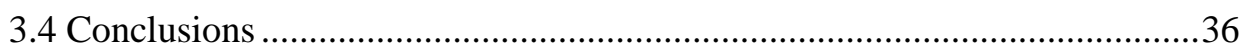

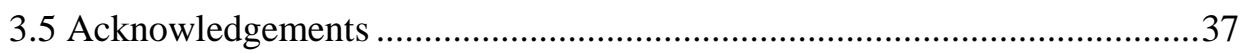

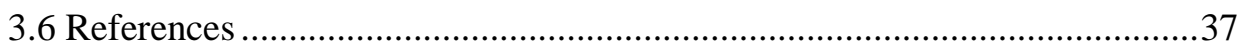

Chapter 4: Spatioselective electrochemical and photoelectrochemical functionalization of silicon microwires with axial $\mathbf{p} / \mathbf{n}$ junctions....................39

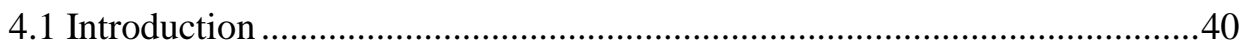

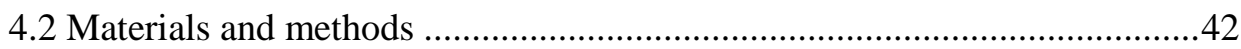

4.2.1 Fabrication of silicon microwires with axial $\mathrm{n}^{+} / \mathrm{p}$ junction.....................42

4.2.2 Electrodeposition of platinum and silver ..............................................44 
4.2.3 Scanning electron microscopy (SEM)/ energy-dispersive X-ray

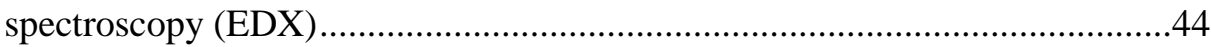

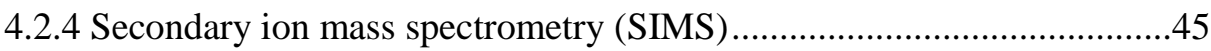

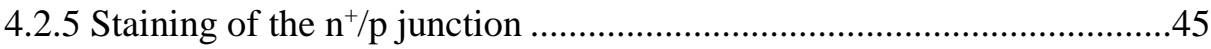

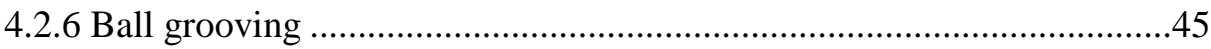

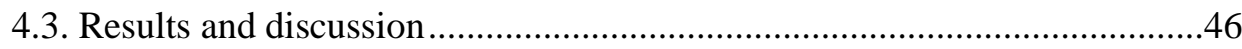

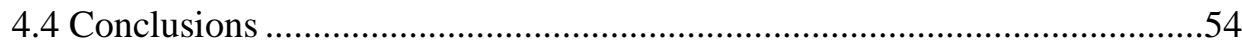

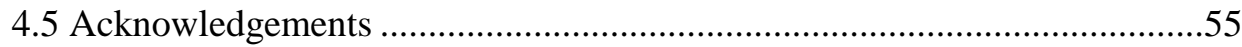

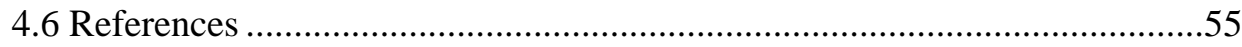

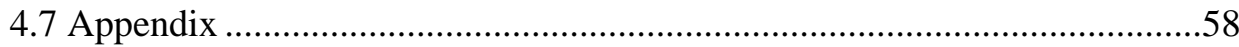

Chapter 5: $\mathrm{WO}_{3}$ photoanode deactivation during photoelectrochemical water oxidation ................................................................................................63

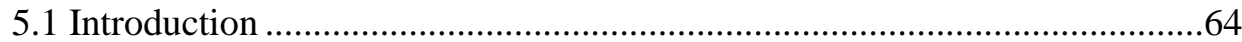

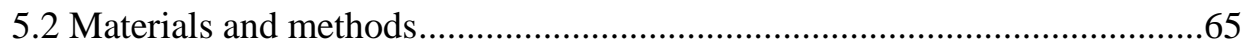

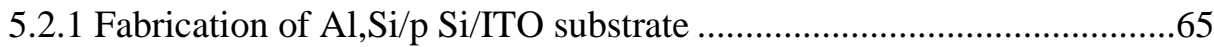

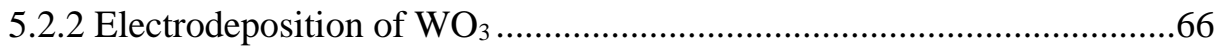

5.2.3 Photoelectrochemical measurements ...................................................66

5.2.4 Gas chromatography (GC) analysis ...................................................67

$5.2 .5 \mathrm{H}_{2} \mathrm{O}_{2}$ determination in the electrolyte …………................................6

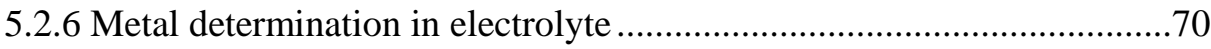

5.2.7 Scanning electron microscopy (SEM) ..................................................

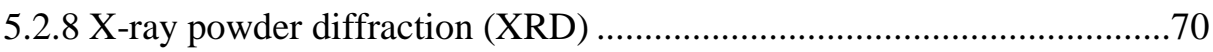

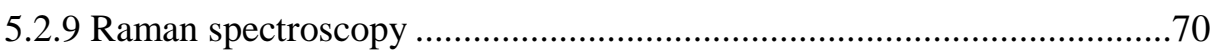

5.2.10 X-ray photoelectron spectroscopy (XPS) ……......................................

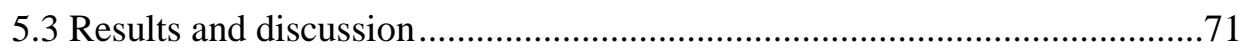

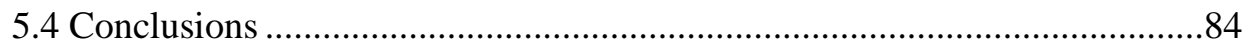

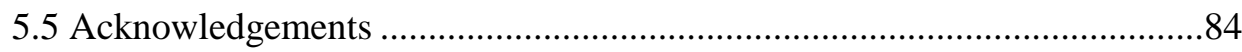

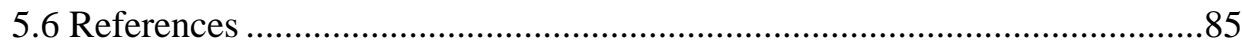

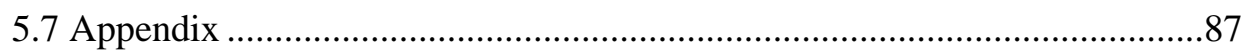

Chapter 6: Integration of molybdenum-doped, hydrogen-annealed $\mathrm{BiVO}_{4}$ on silicon microwires for photocatalytic applications .....................................101

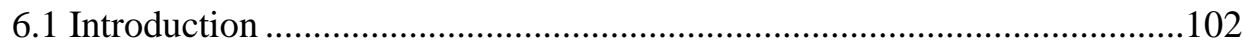

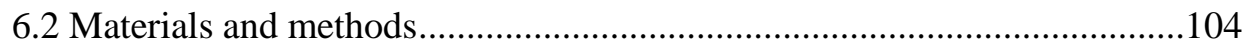




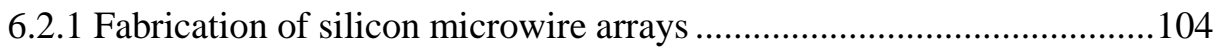

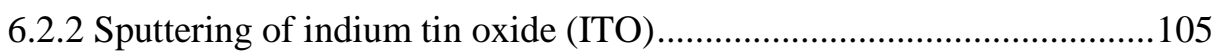

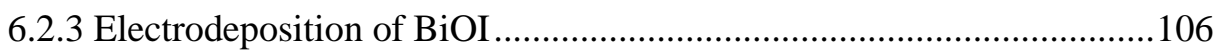

6.2.4 Synthesis of H-BiVO

6.2.5 Photoelectrochemical measurements ....................................................107

6.2.6 Scanning electron microscopy (SEM) ................................................108

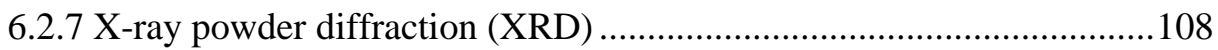

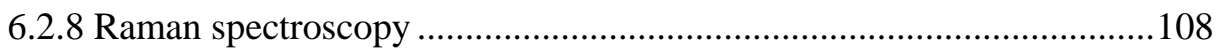

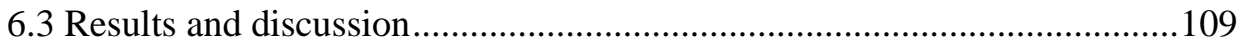

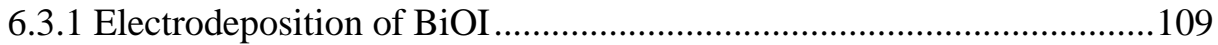

6.3.2 Transformation of $\mathrm{BiOI}$ into $\mathrm{H}-\mathrm{BiVO}_{4-\mathrm{x}}: \mathrm{Mo}$........................................117

6.3.3 Photoelectrochemical characterization .............................................119

6.3.4. Influence of Mo doping and $\mathrm{H}_{2}$ annealing .......................................126

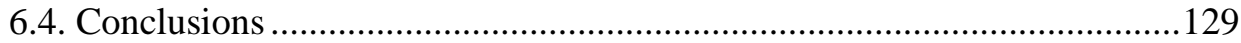

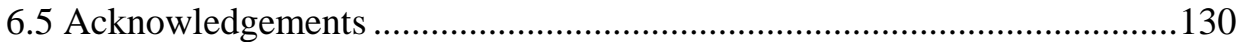

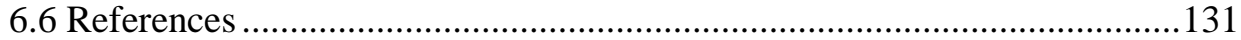

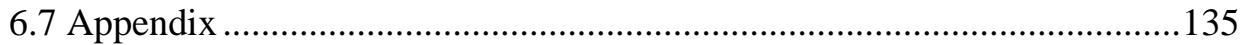

Chapter 7: Summary and perspective..................................................................141

Hoofdstuk 7: Samenvatting en perspectief ......................................................145

Acknowledgements.......................................................................................................151

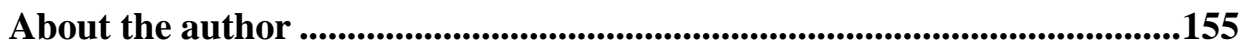




\section{Chapter 1}

Introduction and motivation

\subsection{Towards a clean energy society}

Since the beginning of the industrial revolution in the $17^{\text {th }}$ century, the worldwide economy and thus wealth is growing. ${ }^{[1]}$ However, this growth is mostly powered by fossil fuels, such as coal, natural gas and crude oil. Nowadays, fossil fuels contribute for more than $80 \%$ of the total world energy consumption, distributed over various sectors, such as electricity generation, transportation, industrial processes and heating. ${ }^{[2]}$ Through burning of fossil fuels, deforestation and changes in land use, $\mathrm{CO}_{2}$ levels in the atmosphere have increased from 280 parts per million ( $\mathrm{ppm}$ ) at the beginning of the industrial revolution by more than a third to 407 ppm today. ${ }^{[3,4]} \mathrm{CO}_{2}$ is a greenhouse gas. Its emission causes global warming which leads to rising of the sea level and longer, more intense heat waves. ${ }^{[5]}$ Also, burning fossil fuels, especially coal, increases pollution. ${ }^{[6]}$ Pollution, mainly caused by industrial emissions, vehicle exhaust and toxic chemicals, is estimated to be responsible for 9 million premature deaths in 2015, which constitutes $16 \%$ of all premature deaths worldwide. ${ }^{[6]}$

In order to significantly slow down or stop global warming and reduce pollution, humanity needs to reduce the dependence on fossil fuels by transitioning to the use of renewable energy sources. So far, the focus has been on electricity production, which accounts for about one-third of the total primary energy consumption. ${ }^{[7]}$ The numbers of installed wind power plants and photovoltaic installations are growing as these sources are becoming the cheapest energy sources on many parts of the planet. ${ }^{[8]}$ In 2016, more than half of the added global electricity generating capacity was from renewable sources ${ }^{[8]}$ and this number is increasing with decreasing prices. The learning curve for photovoltaics has caused the price for modules to decrease by $24 \%$ with each doubling of the cumulative module production over the last 36 
years. ${ }^{[9]}$ On a yearly basis, the photovoltaic module prices drop by between 5 and $7 \% \cdot{ }^{[10]}$ However, the integration of wind and photovoltaics into the existing electricity infrastructure is a challenge as their electricity output is variable and hardly controllable, and very often does not match the demand. Germany, one of the early adopters and supporters of renewable energy produced $33 \%$ of its electricity from renewable sources in 2016. ${ }^{[9]}$ But at times when a lot of wind is blowing and the sun is shining, countries like Germany experience temporary electricity overproduction, which is evident in low or negative electricity market prices and electricity export to neighboring countries (Figure 1.1). On the other hand, many conventional power plants cannot be shut down as they are needed as a backup for times when renewables cannot meet the electricity demand. This forces the authorities to subsidize conventional power plants to keep them as a backup to stabilize the grid. Thus, it is necessary to find solutions to store renewable energy and explore energy carriers which have the same ease of handling, storage and transport as fossil fuels.

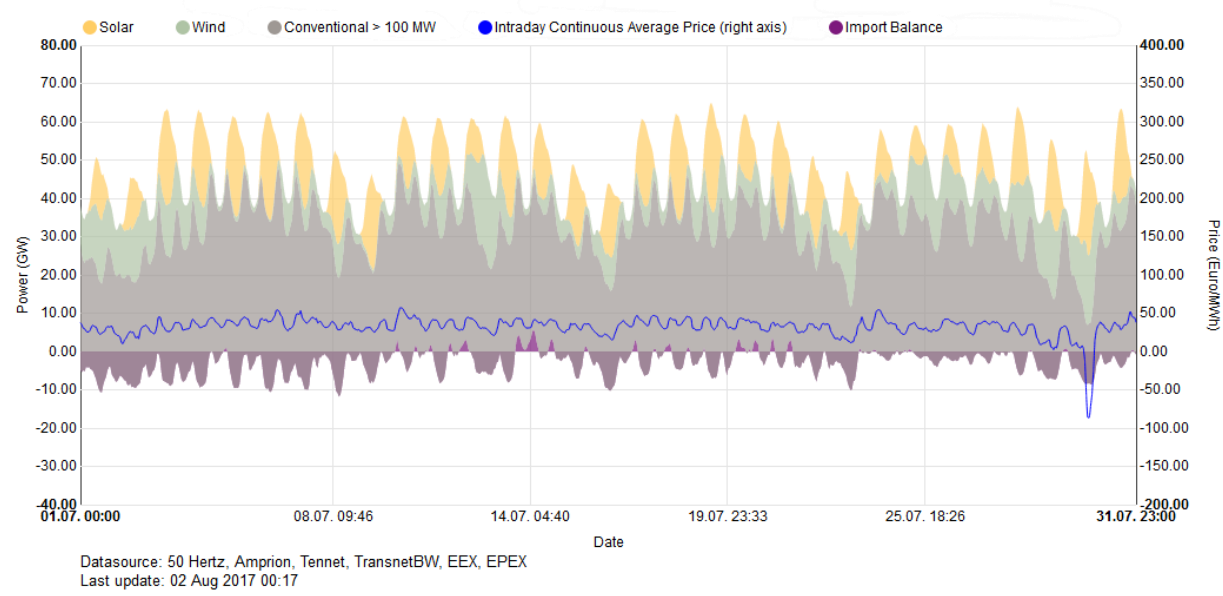

Figure 1.1 Electricity production and prices in Germany in July 2017..$^{[11]}$

\subsection{Energy storage and the role of hydrogen}

The sun provides the earth with about $120000 \mathrm{TW}$ of radiation, which is 8000 times the current annual worldwide energy consumption of about $15 \mathrm{TW} .{ }^{[12,13]}$ Covering $0.16 \%$ of the earth land with $10 \%$ efficient solar cells would be more than sufficient to meet the world's consumption rate of fossil energy. ${ }^{[13]}$ 
However, the irradiation flux at the earth's surface fluctuates with season, time of the day and weather. Also, the average amount of solar irradiation is highest at the equator and decreases towards the poles. The solar flux fluctuation over a day and a year at $50^{\circ}$ northern latitude, which represents northern Europe and roughly the border between USA and Canada, is shown in Figure 1.2. During the day-night intermittency there is a shortage of solar energy at night, and at $50^{\circ}$ northern latitude around $70 \%$ of the energy is received during the summer months (April to September). This means that solar energy received in the summer period needs to be stored for the winter period where it can be used for, for instance, heating.
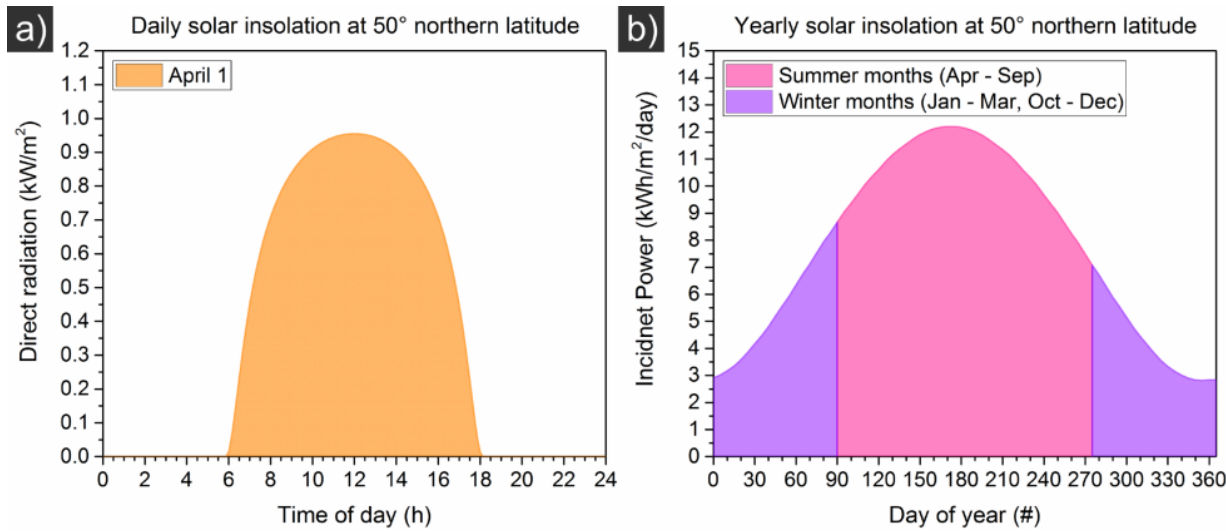

Figure 1.2 Calculated ${ }^{[14]}$ maximal solar insolation based on the equation of the sun's position at $50^{\circ}$ northern latitude for a day (a) and a year (b).

Thus, solar energy needs to be collected, transferred into other energy carriers and partially stored at various time frames and, eventually transported from the supplier to the consumer. The time frames in which energy needs to be stored range from milliseconds to a year. Electricity producers need to adjust their supply instantly to the demand in order to keep the grid stable and avoid blackouts. At time frames up to several days, surplus electricity is mostly stored in pumped hydro-energy storage systems. ${ }^{[15]}$ However, building pumped hydro storage needs large geologically suited areas and has a major local environmental impact. Also battery electricity storage with a rate of $100 \mathrm{MW}$ and a capacity of 129 MWh has been recently installed in South Australia, and more is in planning or construction around the globe. ${ }^{[16-18]}$ Along the efforts in transport electrification, the investments in batteries are increasing which has 
led to a significant price drop of more than $50 \%$ between 2013 and 2016. ${ }^{[19]}$ Also, the energy storage capacity of pumped hydro-storage, batteries and others is finite which means that very high capacities would be needed to store energy over a longer time frame than a few hours or days. Such capacities are economically not feasible as these devices generate their return via charging and discharging cycles, i.e. buying electricity when it is produced in excess and relatively cheap and selling it when the demand is higher than the supply, and electricity is relatively expensive. Instead, in order to store energy over weeks or months, technologies are needed which transfer the energy from the sun into an energy carrier which is not bound to a device and thus has no production limits.

The most energy-dense carriers are fuels. Therefore, a carrier which can function as a long-term storage is a fuel, and hydrogen is believed to be such an energy carrier or an intermediate for it. ${ }^{[7,20,21]}$ Hydrogen is used in the chemical industry, among others, for the production of ammonia and methanol and holds great promises to be used for electricity generation in fuel cells for transportation, back-up power, and grid stabilization. ${ }^{[7,20-22]}$ However, about $96 \%$ of the more than 50 million metric tons of hydrogen is produced from fossil fuels. ${ }^{[23]}$ Replacing its production from renewable sources would reduce the emission of $\mathrm{CO}_{2}$ by about 685 million metric tons as $13.7 \mathrm{~kg}$ of $\mathrm{CO}_{2}$ are emitted on average with every $\mathrm{kg}$ of $\mathrm{H}_{2}$ produced. ${ }^{[24]}$ Also, hydrogen can be further converted with $\mathrm{CO}_{2}$ and water to hydrocarbons, such as methanol, using energy from renewable sources, and these can be fed back into the existing hydrocarbon economy. ${ }^{[25]}$

\subsection{Hydrogen production from water splitting}

Hydrogen is a common building block in nature and the most abundant element on earth. It is present in water and all organic compounds including natural gas and oil. Since the hydrogen molecule is not present in the atmosphere, it needs to be extracted from one of the compounds of which water is the most sustainable source. The stoichiometric water splitting equation to gaseous 
hydrogen and oxygen is shown in Equation 1.1 in which the water can be gaseous or liquid, depending on the process conditions.

$2 \mathrm{H}_{2} \mathrm{O} \rightarrow 2 \mathrm{H}_{2}+\mathrm{O}_{2}$

$\Delta G^{\circ}=237 \mathrm{~kJ} / \mathrm{mol}$ (Eq. 1.1)

There are three major pathways to perform the splitting of water using the energy from sunlight, i.e. thermolysis, electrolysis (in combination with photovoltaics (PV) or concentrating solar power technologies (CSP)) and photo(electro)catalysis.

Direct water thermolysis into hydrogen and oxygen (Eq. 1.1) occurs at temperatures above $2000{ }^{\circ} \mathrm{C} .{ }^{[26]}$ Solar concentrated furnaces at laboratory and pilot scales have obtained a temperature up to $3500{ }^{\circ} \mathrm{C} \cdot{ }^{[27,28]}$ However, these temperatures set high requirements for the selection of refractory materials and construction of equipment and bear a considerable risk of an explosion due to the evolution of oxygen and hydrogen in the same compartment. ${ }^{[22]}$ In order to reduce process temperatures and separate hydrogen and oxygen evolution, two-step thermolytic water splitting is in development. Herein, an auxiliary chemical, such as a reduced metal oxide, sulfur-iodine or copper-chlorine, catalyzes the thermolysis. In the example of a metal oxide, an endothermic reduction is performed first in which oxygen is produced (Eq. 1.2), followed by water hydrolysis and hydrogen production (Eq. 1.3). ${ }^{[7,22]}$

$2 \mathrm{M}_{\mathrm{x}} \mathrm{O}_{\mathrm{y}} \rightarrow 2 \mathrm{M}_{\mathrm{x}} \mathrm{O}_{\mathrm{y}-1}+\mathrm{O}_{2}$

$\mathrm{M}_{\mathrm{x}} \mathrm{O}_{\mathrm{y}-1}+\mathrm{H}_{2} \mathrm{O} \rightarrow \mathrm{M}_{\mathrm{x}} \mathrm{O}_{\mathrm{y}}+\mathrm{H}_{2}$

Reported redox pairs of metal oxides include $\mathrm{Fe}_{3} \mathrm{O}_{4} / \mathrm{FeO}, \mathrm{TiO}_{2} / \mathrm{TiO}_{\mathrm{x}}$, $\mathrm{Mn}_{3} \mathrm{O}_{4} / \mathrm{MnO}, \quad \mathrm{CeO}_{2} / \mathrm{Ce}_{2} \mathrm{O}_{3}, \quad \mathrm{Co}_{3} \mathrm{O}_{4} / \mathrm{CoO}, \quad \mathrm{Nb}_{2} \mathrm{O}_{5} / \mathrm{NbO}_{2}, \quad \mathrm{In}_{2} \mathrm{O}_{3} / \mathrm{In}, \quad \mathrm{WO}_{3} / \mathrm{W}$, $\mathrm{CdO} / \mathrm{Cd}$ and others. ${ }^{[22]}$ The procedure of thermolytic water splitting, however, brings in many challenges due to high temperature heat requirements. Working fluids including water, thermal oils, molten salts, steam, air and other gases, and equipment materials of the working fluid vessel have to be able to sustain the high temperature. ${ }^{[22]}$ Especially the usage of thermal oils is problematic as they are volatile, toxic and may decompose at high temperatures. ${ }^{[22]}$ 
Electrolysis of water uses energy input from an external power source in the form of a direct current to drive the oxidation (Eq. 1.4) and reduction (Eq. 1.5) reactions of water to produce oxygen at the anode and hydrogen at the cathode, respectively.

$2 \mathrm{H}_{2} \mathrm{O} \rightarrow \mathrm{O}_{2}+4 \mathrm{H}^{+}+4 \mathrm{e}^{-}$

$E^{\circ}=1.23 \mathrm{~V}($ Eq. 1.4)

$2 \mathrm{H}^{+}+2 \mathrm{e}^{-} \rightarrow \mathrm{H}_{2}$

$E^{\circ}=0.0 \mathrm{~V}($ Eq. 1.5)

The minimum required thermodynamic potential is $1.23 \mathrm{~V}$. However, to overcome overpotentials and to drive the reaction at a sufficiently high rate, cell potentials between 1.8 and $2.4 \mathrm{~V}$ are required. ${ }^{[29]}$ The efficiencies range between 62 and $82 \%$ for alkaline and proton exchange membrane (PEM) electrolyzers. ${ }^{[29]}$ In combination with power generation efficiencies of $\sim 17 \%$ for photovoltaics ${ }^{[9]}$ overall conversion efficiencies of up to $14 \%$ can be expected for these commercially available system combinations.

Photo(electro)catalysis aims to integrate solar absorbance and electrolysis into one device which is predicted to produce hydrogen at a lower price than the combination of electrolysis and photovoltaics ${ }^{[30]}$ Herein the light absorber also acts as the electrode on which the oxidation and/or reduction reactions occur. This has the advantage that a much greater area is used for electron transfer than in electrolyzers. Thus, the current densities can be much smaller and the required overpotentials substantially lower. ${ }^{[30,31]}$

\subsection{Scope and outline of this thesis}

The research described in this thesis focuses on the development of photoelectrochemical devices for the generation of hydrogen from water splitting. In particular, it aims to utilize electrochemistry for the coating and functionalization of flat and microwire-structured silicon with metals or semiconductors.

Silicon has been chosen as a substrate because it is a nontoxic, abundant and easily available material. Silicon is the second most common element after oxygen in the earth's crust ${ }^{[32]}$ and the technology in producing highly pure silicon is established in industry due to its usage in solar cells and computer 
chips. Also, it can absorb the entire range of visible and UV light with a band gap of $1.1 \mathrm{eV}$ which is in the ideal range for a tandem arrangement with a second, wider band gap absorber. ${ }^{[33-36]}$ Also, silicon can be doped p- and n-type, and provides an additional voltage of $\sim 0.5 \mathrm{~V}$ to the photoelectrochemical system.

Electrochemistry has been used as the main deposition technique for semiconductors and metals on $\mathrm{Si}$, due to its versatility to produce a wide range of materials (such as metals, alloys, oxides, etc.) and its ability to control the nucleation and growth and thus morphology by varying the potential, the current, and/or the electrolyte composition (such as $\mathrm{pH}$, solvents, additives or reagent concentrations). Also, electrodeposition allows the coating of structured substrates, ensures a good electrical contact between substrate and deposit due to electron transfer-induced growth, is compatible with ambient conditions, and is easily scalable and inexpensive to produce commercially viable and costeffective devices.

The thesis has been structured as follows:

Chapter 2 gives a brief overview of photo(electro)chemical water splitting.

In Chapter 3, a method is presented to control the size and density of electrochemically deposited platinum particles on p-type Si by the addition of hydrogen peroxide to the electrolyte solution. Atomic force microscopy of the deposited Pt particles at various $\mathrm{H}_{2} \mathrm{O}_{2}$ concentrations gave insight into the surface area and coverage, distribution, and deposited mass of the Pt particles.

In Chapter 4, the possibility to functionalize silicon microwires with two different materials at different locations has been explored. For that purpose, an axial $\mathrm{p} / \mathrm{n}$ junction has been created in Si micropillars, and two different metals, i.e. platinum and silver, were deposited on the bottom p-type and top n-part, respectively, without the use of a masking step.

In Chapter 5, the deactivation processes of a tungsten oxide photoanode during photocatalytic water oxidation in a phosphate buffer at different $\mathrm{pH}$ were investigated. Oxygen evolution on the photoanode and hydrogen evolution on a platinum cathode were followed with high time and concentration resolution by 
a gas chromatograph. The electrolyte was tested for potentially evolved hydrogen peroxide and the amount of corroded tungsten. Scanning electron microscopy provided insight into the morphology of the photocatalyst, and Xray photoelectron spectroscopy into changes of its oxidation state.

In Chapter 6, molybdenum-doped and hydrogen-annealed bismuth vanadate was deposited on microwire-structured silicon coated with indium tin oxide. The aim was to study the influence of enhanced light absorption by the structure as well as the increase of surface area and mass of bismuth vanadate at various microwire lengths and spacings. The photocatalytic performance was evaluated by the oxidation of the hole scavenger sulfite to sulfate.

Chapter 7 provides a summary of the results described in this thesis and a perspective on photoelectrochemical water splitting.

\subsection{References}

[1] G. Clark, A Farewell to Alms - A Brief Economic History of the World, 2009.

[2] U.S. Energy Information Administration, International Energy Outlook 2017, https://www.eia.gov/outlooks/ieo/pdf/0484(2017).pdf, Sept. 14, 2017.

[3] NASA, Global Climate Change: Vital Signs of the Planet, CARBON DIOXIDE, https://climate.nasa.gov/, Nov. 30, 2017.

[4] NASA, Global Climate Change: Vital Signs of the Planet, A blanket around the Earth https://climate.nasa.gov/causes/, Nov. 30, 2017.

[5] NASA, Global Climate Change: Vital Signs of the Planet, The consequences of climate change, https://climate.nasa.gov/effects/, Nov. 30, 2017.

[6] P. J. Landrigan, R. Fuller, N. J. R. Acosta, O. Adeyi, R. Arnold, N. Basu, A. B. Baldé, R. Bertollini, S. Bose-O'Reilly, J. I. Boufford, P. N. Breysse, T. Chiles, C. Mahidol, A. M. Coll-Seck, M. L. Cropper, J. Fobil, V. Fuster, M. Greenstone, A. Haines, D. Hanrahan, D. Hunter, M. Khare, A. Krupnick, B. Lanphear, B. Lohani, K. Martin, K. V. Mathiasen, M. A. McTeer, C. J. L. Murray, J. D. Ndahimananjara, F. Perera, J. Potočnik, A. 
S. Preker, J. Ramesh, J. Rockström, C. Salinas, L. D. Samson, K. Sandilya, P. D. Sly, K. R. Smith, A. Steiner, R. B. Stewart, W. A. Suk, O. C. P. van Schayck, G. N. Yadama, K. Yumkella, M. Zhong, The Lancet, The Lancet Commission on pollution and health, 2017, DOI:10.1016/S0140-6736(17)32345-0.

[7] H. L. Tuller, Mater. Renew. Sustain. Energy 2017, 6, 3.

[8] Frankfurt School-UNEP Centre/BNEF, Global trends in renewable energy investment 2017, http://fs-unepcentre.org/sites/default/files/publications/globaltrendsinrenewableenergyin vestment2017.pdf, Apr. 2017.

[9] Fraunhofer Institute for Solar Energy Systems (ISE), PHOTOVOLTAICS REPORT, https://www.ise.fraunhofer.de/content/dam/ise/de/documents/publications/ studies/Photovoltaics-Report.pdf, Jul. 12, 2017.

[10] C. A. Rodriguez, M. A. Modestino, D. Psaltis, C. Moser, Energy Environ. Sci. 2014, 7, 3828.

[11] Fraunhofer Institute for Solar Energy Systems (ISE), Energy charts, https://www.energy-charts.de/, Dec. 9, 2017.

[12] R. E. Blankenship, D. M. Tiede, J. Barber, G. W. Brudvig, G. Fleming, M. Ghirardi, M. R. Gunner, W. Junge, D. M. Kramer, A. Melis, T. A. Moore, C. C. Moser, D. G. Nocera, A. J. Nozik, D. R. Ort, W. W. Parson, R. C. Prince, R. T. Sayre, Science 2011, 332, 805.

[13] R. M. Nault, N. S. Lewis, Basic research needs for solar energy utilization - Report on the Basic Energy Sciences Workshop on Solar Energy Utilization Argonne National Laboratory 2005.

[14] Photovoltaic Education Network, Calculation of Solar Insolation, http://www.pveducation.org/pvcdrom/calculation-of-solar-insolation, Dec. 12, 2017.

[15] E. Barbour, I. A. G. Wilson, J. Radcliffe, Y. Ding, Y. Li, Renewable Sustainable Energy Rev. 2016, 61, 421.

[16] electrec.co, Tesla completes world's largest li-ion battery system in Australia, https://electrek.co/2017/11/23/tesla-worlds-largest-li-ionbattery-system-in-australia/, Nov. 23, 2017. 
[17] World's largest battery: 200MW/800MWh vanadium flow battery - site work ongoing, https://electrek.co/2017/12/21/worlds-largest-battery200mw-800mwh-vanadium-flow-battery-rongke-power/, 21.12.2017.

[18] Electrec.co, World's largest solar+battery project announced in South Australia: 330MW of solar \& 100MW/400MWh of batteries, https://electrek.co/2017/04/11/world-largest-solar-battery-project-southaustralia/, Apr. 11, 2017.

[19] Bloomberg Technology, Tesla's Battery Revolution Just Reached Critical Mass, https://www.bloomberg.com/news/articles/2017-01-30/tesla-sbattery-revolution-just-reached-critical-mass?cmpid=BBD013017_BIZ, Jan. 30, 2017.

[20] P. C. Ghosh, B. Emonts, H. Janßen, J. Mergel, D. Stolten, Sol. Energy 2003, 75, 469.

[21] O. V. Marchenko, S. V. Solomin, Int. J. Hydrogen Energy 2015, 40, 3801.

[22] Z. Wang, R. R. Roberts, G. F. Naterer, K. S. Gabriel, Int. J. Hydrogen Energy 2012, 37, 16287.

[23] N. Armaroli, V. Balzani, ChemSusChem 2011, 4, 21.

[24] N. Z. Muradov, T. N. Veziroğlu, Int. J. Hydrogen Energy 2005, 30, 225.

[25] J. A. Herron, J. Kim, A. A. Upadhye, G. W. Huber, C. T. Maravelias, Energy Environ. Sci. 2015, 8, 126.

[26] S. Z. Baykara, Int. J. Hydrogen Energy 2004, 29, 1451.

[27] D. Riveros-Rosas, J. Herrera-Vázquez, C. A. Pérez-Rábago, C. A. Arancibia-Bulnes, S. Vázquez-Montiel, M. Sánchez-González, F. Granados-Agustín, O. A. Jaramillo, C. A. Estrada, Sol. Energy 2010, 84, 792.

[28] P. Haueter, T. Seitz, A. Steinfeld, J. Sol. Energy Eng. 1999, 121, 77.

[29] M. Carmo, D. L. Fritz, J. Mergel, D. Stolten, Int. J. Hydrogen Energy 2013, 38, 4901.

[30] R. Van de Krol, M. Graetzel, Photoelectrochemical Hydrogen Production, Vol. 1, Springer US, 2012.

[31] M. I. Hoffert, Science 2010, 329, 1292.

[32] I. Tomaszkiewicz, Journal of Thermal Analysis and Calorimetry 2001, 65, 425.

[33] J. R. Bolton, S. J. Strickler, J. S. Connolly, Nature 1985, 316, 495. 
[34] J. H. Montoya, L. C. Seitz, P. Chakthranont, A. Vojvodic, T. F. Jaramillo, J. K. Norskov, Nat. Mater. 2017, 16, 70.

[35] M. C. Hanna, A. J. Nozik, J. Appl. Phys. 2006, 100, 074510.

[36] R. T. Ross, T. L. Hsiao, J. Appl. Phys. 1977, 48, 4783. 


\section{Chapter 2}

Photocatalytic water splitting

In Chapter 1 it has been explained why the direct production of fuels from solar energy is important, and how the archetypal fuel hydrogen can be produced from water splitting. Here, we focus on the principles and requirements of a system that produces hydrogen by photocatalytic and photoelectrochemical water splitting. First, the principles of photocatalytic water splitting and the necessary requirements and characteristics of a standalone water splitting device to obtain practically applicable efficiencies are described. It is explained that the combination of two or more photoabsorbers in a Z-scheme configuration is needed in such a system. Furthermore, two different types of architectures, i.e. particle slurry-based and thin film arrangements of semiconductors on electrodes (photoelectrochemical cells), are introduced. It is shown why the targeted arrangement of photoelectrochemical cells in this thesis is superior to particle slurry approaches. 


\subsection{Photocatalytic principle and material requirements}

The photocatalytic principle of splitting water in an acidic environment into hydrogen and oxygen with an ideal single band gap material is schematically shown in Figure 2.1. When light hits a semiconductor with a greater photon energy than the band gap, a photon may be absorbed and lead to an excitation of an electron from the valence to the conduction band. The electron in the conduction band and remaining hole in the valence band may then migrate to the semiconductor surface and perform the reduction of protons to hydrogen and oxidation of water to oxygen and protons, respectively. The generated protons at the oxidation sites diffuse then to the reduction centers to close the charge flow cycle.

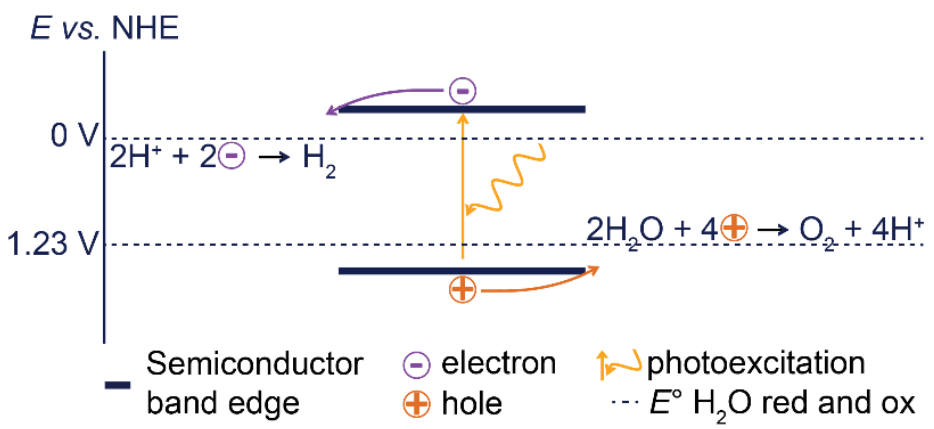

Figure 2.1 Schematic illustration of photocatalytic water splitting in an acidic environment into hydrogen and oxygen.

In order for water splitting to occur the semiconductor must meet the following minimum requirements:

- The semiconductor has to absorb photons with an energy greater than the thermodynamic water splitting potential $(1.23 \mathrm{~V})$ plus proton reduction and water oxidation overpotentials

- The band edge positions have to straddle the hydrogen and oxygen redox potentials and their overpotentials, i.e. the conduction band edge has to be more negative than the proton reduction potential and the valence band edge more positive than the oxidation potential of water

- Be stable against (photo)corrosion. 
Moreover, a practically applicable standalone water splitting photocatalyst/ photoelectrochemical device needs to have the following characteristics:

- Generate a voltage between oxidation and reduction centers of at least $1.23 \mathrm{~V}$ plus overpotentials from the interfaces of the semiconductor with the electrolyte, metals or other semiconductors in order to accelerate the migration of electrons and holes towards the surface and decrease the ratio of recombination over performance of redox reactions

- Provide efficient charge transport through the material

- Have a high light-harvesting efficiency

- Evolve hydrogen and oxygen in different compartments in order to save additional separation steps and prevent the risk of explosion

- Have a high catalytic activity (low overpotentials) towards proton reduction and water oxidation

- Be made of abundant, non-toxic and low cost materials.

To be compatible with hydrogen production from fossil fuels, the price for solar hydrogen needs to be below $\$ 4 / \mathrm{kg}$ to $\$ 2 / \mathrm{kg}^{[1,2]}$ This translates to solar-tohydrogen efficiencies of rugged and long-lived (>10 years) solar water spitting systems to 10 to $15 \% \cdot{ }^{[2,3]}$ To use as much energy from the solar spectrum as possible, William Shockley and Hans-Joachim Queisser calculated in 1961 that the optimal band gap of an ideal single p-n junction solar cell of $1.1 \mathrm{eV}$ would result in a maximum efficiency of $30 \%$ when illuminated with a blackbody spectrum of $6000 \mathrm{~K}$ surface temperature. ${ }^{[4]}$ Later, the so-called ShockleyQueisser limit was calculated to be $33.2 \%$ at a band gap of $1.34 \mathrm{eV}$ for an AM $1.5 \mathrm{G}$ spectrum which also takes light absorption and scattering in the atmosphere into account. ${ }^{[5]}$ Considering the minimum requirements for a semiconductor to split water and neglecting the energy losses from $\mathrm{H}_{2}$ and $\mathrm{O}_{2}$ evolution overpotentials and other described characteristics, a band gap of $1.34 \mathrm{eV}$ should be sufficient to drive the redox reactions. However, taking the losses into account, required single material semiconductor band gaps between 2.3 and $2.0 \mathrm{eV}$ have been proposed which result in solar-to-hydrogen efficiencies between roughly 7 and $18 \% .^{[6,7]}$ 
In order to achieve high enough practical efficiencies, two or more photon systems with two or more absorbers with smaller band gaps are required. ${ }^{[2,7,8]}$ Two strategies are presented in the literature on how to combine materials with different band gaps into a water splitting device, i.e. particle slurry-based systems, and photoelectrochemical cells. Both benefit from a Z-scheme configuration of the semiconductor materials to promote broad use of the solar spectrum and thus boost their efficiency. The Z-scheme arrangement utilizes two semiconductors with staggered band edge positions, which are by themselves not able to perform the overall water splitting reaction but have more favorable band gaps to harvest the energy from the solar spectrum more efficiently than a single semiconductor.

\subsection{Dual absorber particle slurry systems}

Figure 2.2 shows schematically the concept of a particle slurry-based system with a Z-scheme configuration and the use of a mediator. Upon illumination, electrons from both semiconductors are photoexcited into the conduction bands. Water oxidation is performed at one, and proton reduction at the other semiconductor. Only one band edge of one photocatalyst straddles the equilibrium potential of $\mathrm{O}_{2}$ or $\mathrm{H}_{2}$ and performs the corresponding reaction. The electron cycle is closed by the recombination of the photoexcited electron from the water oxidation photocatalyst with the hole of the proton reduction photocatalyst. This occurs by either the two photocatalysts having physical contact or the presence of an electron mediator, which shuttles between the two photocatalysts. In the case of a mediator, the photoexcited electrons in the water oxidation catalyst reduce the mediator which then diffuses to the proton reduction catalyst and injects an electron into its valence band. This system has the advantage that oxygen and hydrogen can be formed in different compartments when the photocatalysts are separated by a mediator permeable membrane. Typically used mediator redox couples are $\mathrm{IO}_{3}-/ \mathrm{I}^{-}$or $\mathrm{Fe}^{3+} / \mathrm{Fe}^{2+}$. [9-11] 


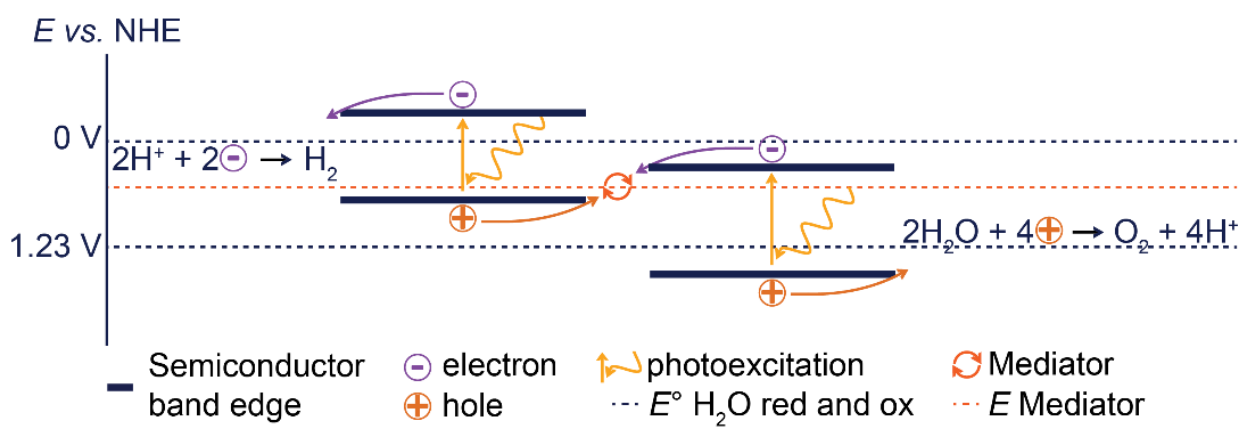

Figure 2.2 Schematic illustration of photocatalytic water splitting into hydrogen and oxygen in a Z-scheme arrangement with two semiconductor materials and a redox mediator in acidic environment.

The Z-scheme arrangement system with a mediator has been shown for, for instance, $\mathrm{Pt}$ or $\mathrm{Ru}$-loaded $\mathrm{SrTiO}_{3}: \mathrm{Rh}$ as the proton reduction photocatalyst and $\mathrm{WO}_{3}, \mathrm{BiVO}_{4}, \mathrm{BiMoO}_{6}$ or Ru-loaded $\mathrm{SrTiO}_{3}: \mathrm{Na}, \mathrm{V}$ as water oxidation photocatalyst. ${ }^{[12,13]}$ Also examples with physically connected materials have been reported. ${ }^{[14-17]}$ However, the efficiencies in Z-scheme mediator systems are low as the semiconductors also react with the mediator in the undesired direction, i.e. the water reduction photocatalyst reduces the oxidized mediator species and the water oxidation photocatalyst oxidizes the reduced form of the mediator. ${ }^{[8,9,18]}$ Also, the redox mediator may strongly absorb part of the illuminated light, reducing the light available for the photocatalysts. ${ }^{[10]}$ The Z-scheme particle systems without a mediator have the disadvantage that $\mathrm{H}_{2}$ and $\mathrm{O}_{2}$ gases evolve in the same compartment, which besides introducing the need for gas separation and bearing the risk of an explosion, also suffer from undesired back-reactions of the gases on their surfaces. In Chapter 5 we will demonstrate a loss of about 50\% in hydrogen yield, when oxygen and hydrogen are produced simultaneously in the same compartment.

\subsection{Photoelectrochemical cells}

The first photocatalytic water splitting on a semiconductor electrode was shown by Akira Fujishima and Kenichi Honda in $1972 .{ }^{[19]}$ Herein the authors constructed an electrochemical cell with a $\mathrm{TiO}_{2}$ electrode connected to a platinum black counter electrode. ${ }^{[19]}$ Figure 2.3 schematically shows the setup, without a membrane separating the two compartments. The authors described that a current 
from the platinum electrode flowed to the $\mathrm{TiO}_{2}$ electrode through the external circuit when the surface of the $\mathrm{TiO}_{2}$ was irradiated. ${ }^{[19]} \mathrm{TiO}_{2}$ fulfills the minimum requirements for a photocatalyst to perform photocatalytic water splitting. The material is stable, the band gap of $\sim 3.2 \mathrm{eV}$ is wide enough to absorb light with the required thermodynamic potential for water oxidation and reduction reactions and the band edges straddle these potentials. However, $\mathrm{TiO}_{2}$ is able to absorb only the UV part of the solar spectrum which is approximately $5 \%$ of the terrestrial solar radiation. Due to the n-type character of this semiconductor, holes are accelerated towards the $\mathrm{TiO}_{2}$ surface and photoexcited electrons towards the current conductor. ${ }^{[20-24]} \mathrm{A}$ p-type semiconductor would have shown the electron flow in the opposite direction. ${ }^{[20,23,24]}$ Therefore, also for PEC systems, incorporation of two semiconductors in a Z-scheme arrangement, is the way to go.

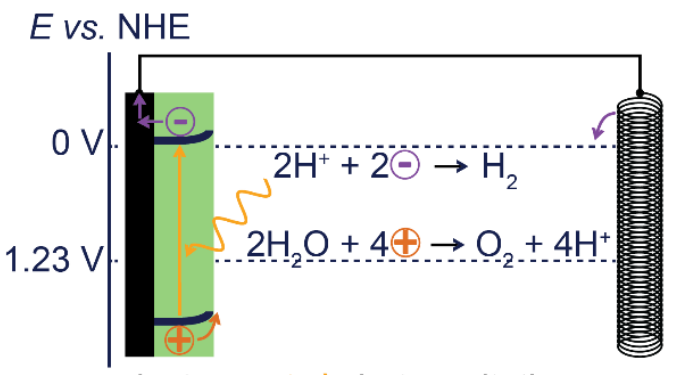

$\begin{array}{llll}\text { - Semiconductor } & \oplus \text { electron } & \uparrow \text { photoexcitation } & \text { - current conductor } \\ \text { band edge } & \oplus \text { hole } & \cdots E^{\circ} \mathrm{H}_{2} \mathrm{O} \text { red and ox }\end{array}$

Figure 2.3 Schematic illustration of a single photoabsorber photoelectrochemical cell.

Today, photoelectrochemical cells still provide the most promising configuration for practical hydrogen production from solar water splitting. $\left.{ }^{[2,}{ }^{25}\right]$ This arrangement type has the potential to fulfill not only the minimum, but all described requirements and characteristics. The list of semiconductors which are viable for the use as photoabsorbers is short. ${ }^{[26]}$ However, the construction of the photocatalytic device with electrodes instead of particle systems allows the usage of protective layers (e.g. against (photo)corrosion) and thus a selection between significantly more semiconductor candidates. ${ }^{[26,27]}$ These materials can then be chosen by taking into account their charge transport properties, abundance, high light harvesting efficiency, etc. High sunlight harvesting efficiencies can be achieved when a large-band gap material is layered in front of a small-band gap 
material, in a Z-scheme configuration. ${ }^{[28-32]}$ Herein, the short wavelength (high energy) photons will be absorbed by the top semiconductor layer (large band gap), and the long wavelength (low energy) photons will pass through and be absorbed by the underlying semiconductor layer (small band gap). Calculations, which include losses from hydrogen and oxygen evolution overpotentials and assume a $2 \mathrm{~cm}$ photon path length through an aqueous electrolyte, have shown that a maximum solar-to-hydrogen efficiency of $24.5 \%$ is possible. ${ }^{[32]}$ Accordingly, the materials have to have a band gap of $\sim 1.1$ and $\sim 1.7 \mathrm{eV} .{ }^{[32]} \mathrm{To}$ increase catalytic activity towards proton reduction or water oxidation on the photoactive electrode, catalytic layers can be applied on top of the electrode which may also decrease surface defects and thus suppress electron and hole recombination. ${ }^{[33-37]}$ The $\mathrm{H}_{2}$ and $\mathrm{O}_{2}$ evolution occur on two different electrodes which allows the ability to separate the gases in situ. To increase the voltage between the two electrodes, different doping of the materials can be applied to create an inner photovoltaic cell. Figure 2.4 shows this type of a photoelectrochemical cell with an underlying silicon $\mathrm{p} / \mathrm{n}$ junction. This design type is the basis of the research presented in Chapters 5 and 6. However, also other approaches building tandem devices exist, which for instance use a wireless design or hetero-type dual photoelectrodes. ${ }^{[20,25,26,33,38-42]}$

Evs. NHE

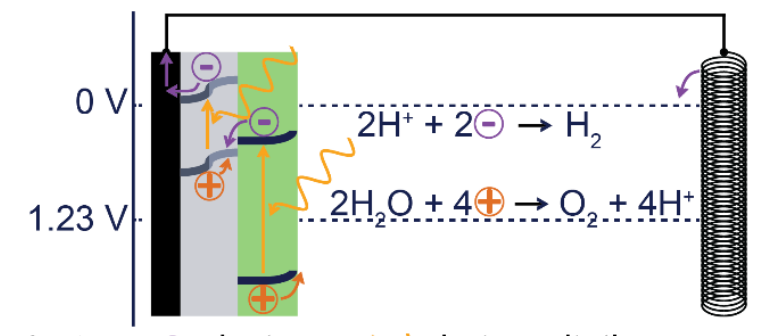

$\begin{array}{llll}\text { - Semiconductor } & \oplus \text { electron } & \uparrow \text { photoexcitation } & \text {-current conductor } \\ \text { band edge } & \oplus \text { hole } & \cdots E^{\circ} \mathrm{H}_{2} \mathrm{O} \text { red and ox } & \text { counter electrode } \\ \text { - p-Si band edge } & -\mathrm{n} \text {-Si band edge } & \end{array}$

Figure 2.4 Schematic illustration of a photoelectrochemical cell based on a dual photoabsorber.

Remarkable efficiencies have been achieved with photoelectrochemical cells. For instance, Young et al. obtained a 16.2\% solar-to-hydrogen efficiency in 2017 by creating a tandem device photocathode consisting of a gallium arsenide (GaAs) 
photovoltaic system, and a gallium indium phosphide $(\mathrm{GaInP})$ photoelectrical cell covered with a very thin aluminum indium phosphide (AlInP) and GaInP layer for reduction of surface defects and protection from corrosion. ${ }^{[32]}$ May et al. achieved $14.0 \%$ with a similar system in $2015 .{ }^{[37]}$ However, these devices are not yet practically feasible as they need improvements in long-term durability and reduction of the costs of the device. Furthermore, the usage of more abundant and non-toxic materials is desired, which is also targeted in this thesis. With abundant, non-toxic and low cost materials and preparation methods, for example, Abdi et al. obtained up to $4.9 \%$ solar-to-hydrogen efficiencies by combining cobalt phosphate-coated bismuth vanadate $\left(\mathrm{BiVO}_{4}\right)$ with a gradient tungsten doping and single- or double-junction silicon solar cells. ${ }^{[43]}$

\subsection{References}

[1] U.S. Department of Energy, Fuel Cell Technologies Office Multi-Year Research, Development, and Demonstration Plan, https://energy.gov/sites/prod/files/2015/06/f23/fcto_myrdd_production.pdf Jun., 2015.

[2] B. A. Pinaud, J. D. Benck, L. C. Seitz, A. J. Forman, Z. Chen, T. G. Deutsch, B. D. James, K. N. Baum, G. N. Baum, S. Ardo, H. Wang, E. Miller, T. F. Jaramillo, Energy Environ. Sci. 2013, 6, 1983.

[3] A. J. Bard, M. A. Fox, Acc. Chem. Res. 1995, 28, 141.

[4] W. Shockley, H. J. Queisser, J. Appl. Phys. 1961, 32, 510.

[5] S. Rühle, Sol. Energy 2016, 130, 139.

[6] M. F. Weber, M. J. Dignam, Int. J. Hydrogen Energy 1986, 11, 225.

[7] T. J. Jacobsson, V. Fjällström, M. Edoff, T. Edvinsson, Sol. Energy Mater. Sol. Cells 2015, 138, 86.

[8] A. Kudo, Pure Appl. Chem. 2007, 79, 1917.

[9] A. Kudo, Y. Miseki, Chem. Soc. Rev. 2009, 38, 253.

[10] H. Li, W. Tu, Y. Zhou, Z. Zou, Adv. Sci. 2016, 3, 1500389.

[11] K. Maeda, ACS Catal. 2013, 3, 1486.

[12] K. Hideki, H. Mikihiro, K. Ryoko, S. Yoshiki, K. Akihiko, Chem. Lett. 2004, 33, 1348. 
[13] S. Hara, M. Yoshimizu, S. Tanigawa, L. Ni, B. Ohtani, H. Irie, J. Phys. Chem. C 2012, 116, 17458.

[14] Y. Sasaki, H. Nemoto, K. Saito, A. Kudo, J. Phys. Chem. C 2009, 113, 17536.

[15] S. S. K. Ma, K. Maeda, T. Hisatomi, M. Tabata, A. Kudo, K. Domen, Chem. Eur. J. 2013, 19, 7480.

[16] W. Wang, H. Cheng, B. Huang, X. Liu, X. Qin, X. Zhang, Y. Dai, J. Colloid Interface Sci. 2015, 442, 97.

[17] A. Iwase, Y. H. Ng, Y. Ishiguro, A. Kudo, R. Amal, J. Am. Chem. Soc. 2011, 133, 11054.

[18] A. Kudo, MRS Bull. 2011, 36, 32.

[19] A. Fujishima, K. Honda, Nature 1972, 238, 37.

[20] M. Grätzel, Nature 2001, 414, 338.

[21] N. S. Lewis, Inorg. Chem. 2005, 44, 6900.

[22] N. S. Lewis, Acc. Chem. Res. 1990, 23, 176.

[23] P. Cendula, S. D. Tilley, S. Gimenez, J. Bisquert, M. Schmid, M. Grätzel, J. O. Schumacher, J. Phys. Chem. C 2014, 118, 29599.

[24] Z. Zhang, J. T. Yates, Chem. Rev. 2012, 112, 5520.

[25] M. G. Walter, E. L. Warren, J. R. McKone, S. W. Boettcher, Q. Mi, E. A. Santori, N. S. Lewis, Chem. Rev. 2010, 110, 6446.

[26] B. Seger, I. E. Castelli, P. C. K. Vesborg, K. W. Jacobsen, O. Hansen, I. Chorkendorff, Energy Environ. Sci. 2014, 7, 2397.

[27] R. Liu, Z. Zheng, J. Spurgeon, X. Yang, Energy Environ. Sci. 2014, 7, 2504.

[28] M. F. Weber, M. J. Dignam, J. Electrochem. Soc. 1984, 131, 1258.

[29] J. R. Bolton, S. J. Strickler, J. S. Connolly, Nature 1985, 316, 495.

[30] S. Hu, C. Xiang, S. Haussener, A. D. Berger, N. S. Lewis, Energy Environ. Sci. 2013, 6, 2984.

[31] H. Doscher, J. F. Geisz, T. G. Deutsch, J. A. Turner, Energy Environ. Sci. 2014, 7, 2951.

[32] J. L. Young, M. A. Steiner, H. Döscher, R. M. France, J. A. Turner, Todd G. Deutsch, Nat. Energy 2017, 2, 17028.

[33] K. Sivula, M. Gratzel, Photoelectrochemical Water Splitting: Materials, Processes and Architectures, The Royal Society of Chemistry, 2013, 83. 
[34] H. J. Lewerenz, C. Heine, K. Skorupska, N. Szabo, T. Hannappel, T. VoDinh, S. A. Campbell, H. W. Klemm, A. G. Munoz, Energy Environ. Sci. 2010, 3, 748 .

[35] C. Zachaus, F. F. Abdi, L. M. Peter, R. van de Krol, Chem. Sci. 2017, 8, 3712.

[36] M. W. Kanan, D. G. Nocera, Science 2008, 321, 1072.

[37] M. M. May, H.-J. Lewerenz, D. Lackner, F. Dimroth, T. Hannappel, Nat. Commun. 2015, 6, 8286.

[38] S. Y. Reece, J. A. Hamel, K. Sung, T. D. Jarvi, A. J. Esswein, J. J. H. Pijpers, D. G. Nocera, Science 2011, 334, 645.

[39] J. H. Kim, J.-W. Jang, Y. H. Jo, F. F. Abdi, Y. H. Lee, R. van de Krol, J. S. Lee, Nat. Commun. 2016, 7, 13380.

[40] D. G. Nocera, Acc. Chem. Res. 2012, 45, 767.

[41] C. Jiang, S. J. A. Moniz, A. Wang, T. Zhang, J. Tang, Chem. Soc. Rev. 2017, $46,4645$.

[42] J. W. Ager, M. R. Shaner, K. A. Walczak, I. D. Sharp, S. Ardo, Energy Environ. Sci. 2015, 8, 2811.

[43] F. F. Abdi, L. Han, A. H. M. Smets, M. Zeman, B. Dam, R. van de Krol, Nat. Commun. 2013, 4. 


\section{Chapter 3}

Controlling the size and density of electrochemically deposited Pt particles on p-type Si by hydrogen peroxide

Covering p-type silicon with Pt nanoparticles is of great interest for the fabrication of a photocathode for photocatalytic hydrogen production. Controlling the Pt particle size and density is essential to achieve a high catalytic activity and thereby limit the use of the precious metal. In this study, using a simple electrodeposition method (at a charge density of $20 \mathrm{mC} / \mathrm{cm}^{2}$ ), we reduced the average mean particle diameter from $302 \mathrm{~nm}$ to $60 \mathrm{~nm}$, while simultaneously increasing the particle density from 0.7 to 13.0 particles $/ \mu \mathrm{m}_{\mathrm{Si}}^{2}$ by addition of an optimized quantity of $81 \mathrm{mM} \mathrm{H}_{2} \mathrm{O}_{2}$ to the electrolyte solution. At a significantly higher $\mathrm{H}_{2} \mathrm{O}_{2}$ concentration, the deposited $\mathrm{Pt}$ mass reduced upon increasing charge density. These results suggest that at $\mathrm{H}_{2} \mathrm{O}_{2}$ concentrations of $81 \mathrm{mM}$ and below, $\mathrm{H}_{2} \mathrm{O}_{2}$ adsorbs on the nucleated $\mathrm{Pt}$ particles, thus reducing adsorption and reduction of $\mathrm{PtCl}_{6}^{2-}$ on initially formed metallic Pt particles. At high $\mathrm{H}_{2} \mathrm{O}_{2}$ concentrations, however, hydroxyl radicals, which are formed during partial $\mathrm{H}_{2} \mathrm{O}_{2}$ reduction, oxidize nucleated $\mathrm{Pt}$ particles, thus causing their cathodic dissolution, and limiting achievable Pt coverages. 


\subsection{Introduction}

Photocatalytic water splitting has the potential to contribute to hydrogen production from renewable resources. ${ }^{[1,2]}$ Silicon is a promising candidate to be used as a photocathode due to its sufficiently negative conduction band edge and an almost optimal band gap of $1.12 \mathrm{eV}$ to absorb the terrestrial solar spectrum efficiently. ${ }^{[3]}$ Moreover, silicon is a nontoxic, relatively stable, and second most abundant element on earth, and it is readily compatible with the silicon-based microelectronic and photovoltaic industry. ${ }^{[3]}$

To run the hydrogen evolution reaction (HER), silicon needs to be p-type doped to achieve favorable band bending when in contact with an aqueous electrolyte. Loading with a catalyst is necessary to reduce the overpotential for proton reduction. ${ }^{[4-6]}$ In addition, the catalyst protects the silicon surface underneath from forming electrically insulating silicon oxide, and at the same time acts as conductive channel for the electron transport to the electrolyte. ${ }^{[7]}$ The insulating silicon oxide layer is thermodynamically stable over a wide range of $\mathrm{pH}$ and potential. ${ }^{[8]}$

Platinum is one of the best electrocatalysts in acidic medium for the hydrogen evolution reaction. ${ }^{[9]}$ It has been shown that the deposition of Pt islands on $\mathrm{p}-\mathrm{Si}$ is superior to the formation of continuous films for photoelectrochemical proton reduction. ${ }^{[4,5,10]}$ When the Pt film is discontinuous, a Schottky barrier between $\mathrm{p}-\mathrm{Si}$ and the electrolyte is formed which generates a photovoltage and thus enhances $\mathrm{H}_{2}$ evolution at the Pt particles. ${ }^{[4,10]}$ In contrast, the Schottky barrier formed between Pt films and $\mathrm{p}-\mathrm{Si}$ is very low or the interface is Ohmic due to negligible differences in the work functions between $\mathrm{p}-\mathrm{Si}$ and Pt. ${ }^{[4,10]}$

However, Pt is a relatively scarce element in the earth's crust. ${ }^{[11]}$ Minimizing its deposited mass drastically reduces the cost of a solar-to-fuel device and significantly improves its optical properties by improving the transmittance of light to the silicon absorber. ${ }^{[12]}$ Nakato et al. have proposed the metal islands to have a $5 \mathrm{~nm}$ width and $20 \mathrm{~nm}$ separation distance when the saturation current density is fairly low, and a larger particle size and smaller distance for higher current densities. ${ }^{[5]}$ Thus, to manufacture a device with optimal performance it is 
essential to be able to control the size and density of the Pt particles on a nanometer scale. ${ }^{[5]}$

A scalable and low-cost technique for $\mathrm{Pt}$ particle deposition on $\mathrm{p}-\mathrm{Si}$ is electrodeposition. ${ }^{[4,13-16]}$ However, the electrochemical deposition process of $\mathrm{Pt}$ particles on $\mathrm{p}$-Si either leads to low densities, and/or to large, $\mu \mathrm{m}$ sizes when high charge densities are applied. A commonly used method to reduce the deposited particle size is to perform the deposition under illumination. ${ }^{[4,6,14,15,17]}$ Thereby, instead of the hole injection through the valence band in the dark, photoexcited electrons reduce $\mathrm{PtCl}_{6}{ }^{2-}$ via the conduction band, leading to a high amount of nucleation points. ${ }^{[14]}$ Also, pulsed electrodeposition has been employed in which a short high potential pulse induces the formation of many Pt nucleation points. ${ }^{[18]}$ However, as we will show in Chapter 4, the deposition under illumination or the application of a high potential pulse is not always desired.

Herein, we present a chemical method to reduce the electrochemically deposited Pt particle size to the low $\mathrm{nm}$ range and control their distribution density as well. To this aim, hydrogen peroxide is added to the electrolyte solution, and the influence of the $\mathrm{H}_{2} \mathrm{O}_{2}$ concentration on the obtained Pt particle morphology at variable charge density is investigated systematically.

\subsection{Materials and methods}

\subsubsection{Pt electrodeposition}

Boron-doped, p-type silicon substrates $(<100>$-oriented, resistivity $5-10 \Omega \mathrm{cm}$, $100 \mathrm{~mm}$ diameter, $525 \mu \mathrm{m}$ thickness, single-side polished, Okmetic Finland) were cleaned by immersion in $100 \%$ nitric acid $\left(\mathrm{HNO}_{3}\right)(2 \times 5 \mathrm{~min})$ and in $69 \%$ nitric acid (10 min). After quick dump rinsing in de-mineralized (DI) water, the sample was immersed in a $1 \%$ aqueous hydrofluoric (HF) acid solution for at least 1 min to remove the silicon oxide layer, washed by quick dump rinsing in de-mineralized (DI) water, spin dried, after which the backside was sputtercoated with a $1 \mu \mathrm{m}$ thick aluminum/silicon alloy (99 \% Al, $1 \% \mathrm{Si}$ ) (Oxford PL $400,7000 \mathrm{~W}$ ) to create a low resistance Ohmic contact. Subsequently, the wafer was cut into pieces of approximately $2.5 \times 2.5 \mathrm{~cm}^{2}$ and mounted into a 
custom-made single cell Teflon-based reactor with a volume of about $8 \mathrm{ml}$. The active surface area applied was $2.01 \mathrm{~cm}^{2}$ as determined by the O-ring of the reactor. A standard three-electrode system with a platinum mesh counter electrode was used. The reactor was open to the environment and a potentiostat (PAR, VersaStat 3) served as a power source. Platinum was electrodeposited potentiostatically at $-0.7 \mathrm{~V}$ vs. $\mathrm{Ag} / \mathrm{AgCl}(3 \mathrm{M} \mathrm{NaCl}$, BASi MF 2052) from an aqueous solution of $5 \mathrm{mM}$ hexachloroplatinic(IV) acid $\left(\mathrm{H}_{2} \mathrm{PtCl}_{6}\right)$ and $0.5 \mathrm{M}$ sodium sulfate $\left(\mathrm{Na}_{2} \mathrm{SO}_{4}\right)$ at room temperature. A defined amount of a hydrogen peroxide solution $\left(\mathrm{H}_{2} \mathrm{O}_{2}, \geq 35 \%\right)$ was added to a part of the $\mathrm{H}_{2} \mathrm{PtCl}_{6} / \mathrm{Na}_{2} \mathrm{SO}_{4}$ solution, prior to experiments, if needed. The measured $\mathrm{pH}$ (Hanna Instruments pH 209) of the electrolyte was 2.55 . The deposition was discontinued when the charge density amounted to either $5,10,20,40$, or $100 \mathrm{mC} / \mathrm{cm}^{2}$.

\subsubsection{Atomic force microscopy (AFM)}

Atomic force microscopy (AFM) images were taken with a Digital Instruments Nanoscope III AFM in tapping mode and a silicon cantilever at room temperature. Particle detection and analysis was performed with the software "Gwyddion v2.37" in which the baseline of the scan was corrected and the particles masked by a threshold algorithm. The software determined the mean radius of each particle which was doubled to report the mean particle diameter.

\subsection{Results and discussion}

Figure 3.1a-e shows distribution histograms overlaid with normal distribution curves, corresponding to atomic force microscopy (AFM) images of potentiostatically deposited $\mathrm{Pt}$ particles at $-0.7 \mathrm{~V}$ vs. $\mathrm{Ag} / \mathrm{AgCl}(3 \mathrm{M} \mathrm{NaCl})$ on p-type silicon. The passed charge density was varied between $5 \mathrm{mC} / \mathrm{cm}^{2}$ and $100 \mathrm{mC} / \mathrm{cm}^{2}$. Pt particles are highlighted in cyan and their average mean diameter, distribution density, specific surface area and deposited mass are plotted in Figure 3.2. The deposited Pt mass increased almost linearly between $5 \mathrm{mC} / \mathrm{cm}^{2}$ and $100 \mathrm{mC} / \mathrm{cm}^{2}$ from $13 \mathrm{mg} / \mathrm{m}^{2}{ }_{\mathrm{Si}}$ to $967 \mathrm{mg} / \mathrm{m}^{2}$ si. The stoichiometries of the two consecutive reduction reactions are shown in Equations 3.1 and 3.2.

$\mathrm{PtCl}_{6}^{2-}+2 \mathrm{e}^{-} \rightarrow \mathrm{PtCl}_{4}^{2-}+2 \mathrm{Cl}^{-} \quad E^{\circ}=0.68 \mathrm{~V}^{[19]}$ (Eq. 3.1) 
$\mathrm{PtCl}_{4}{ }^{2-}+2 \mathrm{e}^{-} \rightarrow \mathrm{Pt}(\mathrm{s})+4 \mathrm{Cl}^{-} \quad E^{\circ}=0.76 \mathrm{~V}^{[19]}$ (Eq. 3.2)

All deposited Pt mass values, except those obtained at $5 \mathrm{mC} / \mathrm{cm}^{2}$, are above theoretical values calculated assuming $100 \%$ faradaic efficiencies. We attribute this error to artefacts in assessing particle sizes using atomic force microscopy. The broadening of the AFM tip causes a broadening of the laterally measured particle size. ${ }^{[20]}$ This error increases with increasing particle height, and is consistent with our results in which the Pt mass deviation between measured and theoretical values increases with increasing passed charge density (Figure 3.2b). We expect this effect to be insignificant at particle diameters below $200 \mathrm{~nm}$. The deposited Pt mass is lower at $5 \mathrm{mC} / \mathrm{cm}^{2}$ due to Pt-catalyzed hydrogen evolution, which is favored at small Pt particle sizes. 

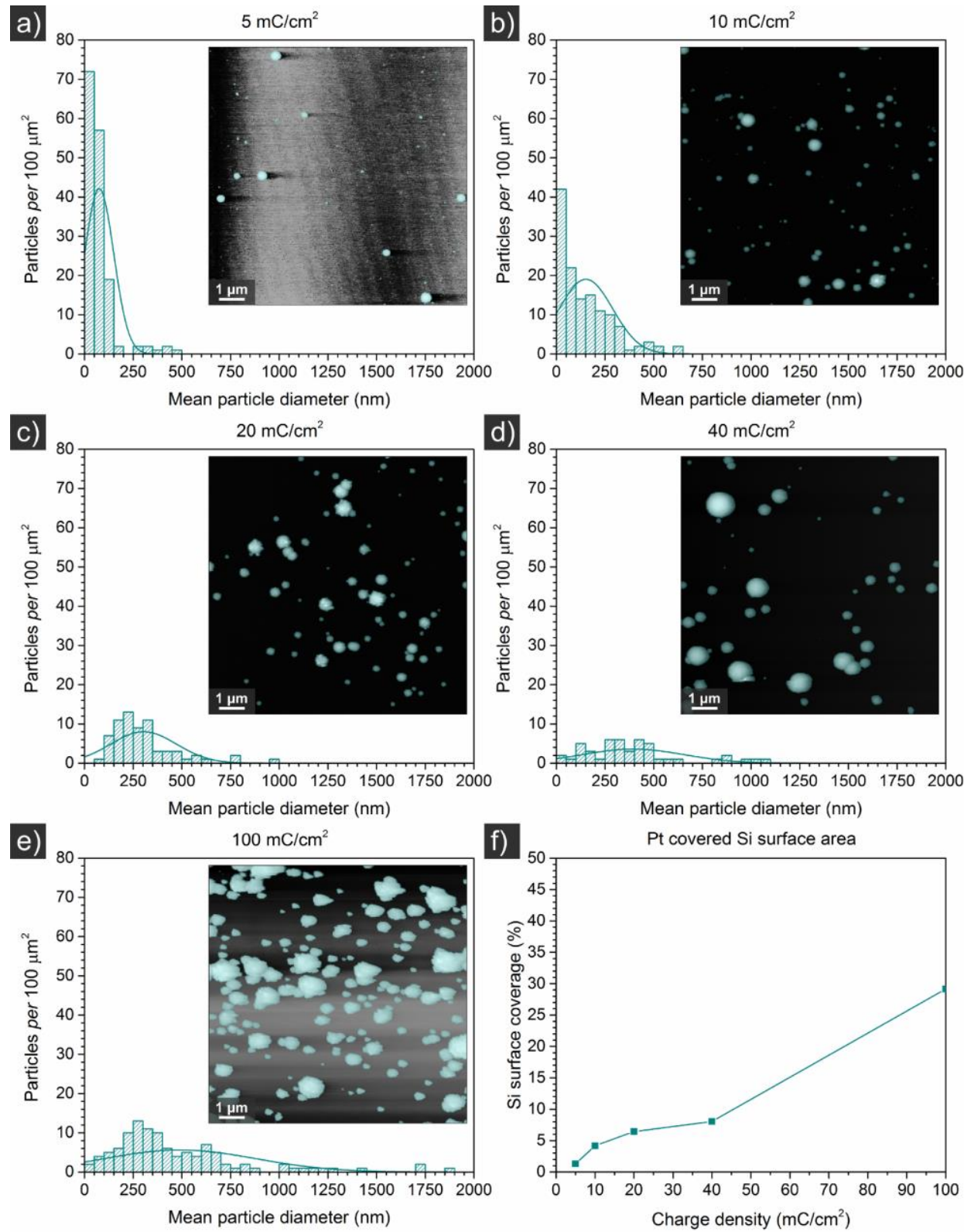

Figure 3.1 a-e) Distribution histograms with $50 \mathrm{~nm}$ bin size, normal distribution curves and inset AFM images, f) Si surface coverage of electrochemically deposited Pt particles at $-0.7 \mathrm{~V}$ vs. $\mathrm{Ag} / \mathrm{AgCl}(3 \mathrm{M} \mathrm{NaCl})$ from a $5 \mathrm{mM} \mathrm{H}_{2} \mathrm{PtCl}_{6}, 0.5 \mathrm{M} \mathrm{Na}_{2} \mathrm{SO}_{4}$ solution upon variation of the passed charge density. 

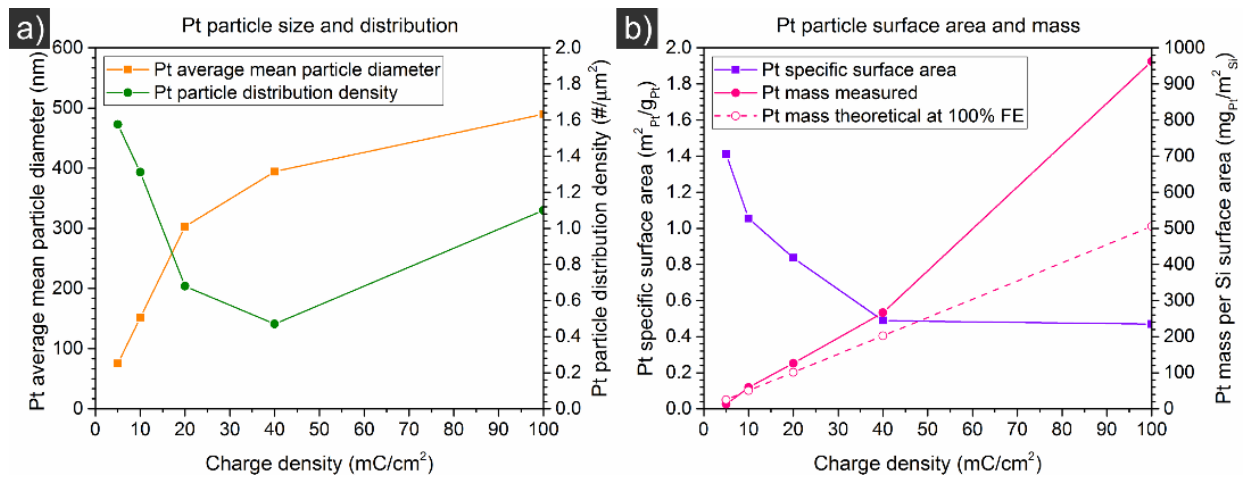

Figure 3.2 a) Average mean particle diameter and distribution density (from AFM), b) specific surface area and mass of electrochemically deposited Pt particles at $-0.7 \mathrm{~V}$ vs. $\mathrm{Ag} / \mathrm{AgCl}(3 \mathrm{M} \mathrm{NaCl})$ from a $5 \mathrm{mM} \mathrm{H}_{2} \mathrm{PtCl}_{6}, 0.5 \mathrm{M} \mathrm{Na}_{2} \mathrm{SO}_{4}$ solution upon variation of the passed charge density.

Apart from electrochemical reduction, an electroless Pt deposition on silicon is theoretically conceivable in which $\mathrm{PtCl}_{6}{ }^{2-}$ is reduced by the oxidation of silicon (Eq. 3.3).

$$
\mathrm{PtCl}_{6}^{2-}+\mathrm{Si}(\mathrm{s})+2 \mathrm{H}_{2} \mathrm{O} \rightarrow \mathrm{Pt}(\mathrm{s})+\mathrm{SiO}_{2}(\mathrm{~s})+4 \mathrm{H}^{+}+6 \mathrm{Cl}^{-}
$$

Control experiments in which we kept p-Si for a typical experiment time of $80 \mathrm{~s}$ in contact with the $\mathrm{PtCl}_{6}{ }^{2-}$-containing electrolyte solution, however, showed insignificant Pt deposition of $2.6 \times 10^{-8} \mathrm{mg} / \mathrm{m}^{2} \mathrm{Si}$. It is theoretically possible that electrochemically nucleated Pt particles accelerate the electroless Pt deposition. However, electroless Pt deposition is typically performed in a hydrofluoric acid (HF)-containing solution to etch away silicon oxide and constantly expose the silicon surface. ${ }^{[21]}$

At $5 \mathrm{mC} / \mathrm{cm}^{2}$ the majority of the particles had a mean diameter below $150 \mathrm{~nm}$ and an average mean particle diameter of $76 \mathrm{~nm}$. At increasing charge densities the particles showed an asymptotic growth and reached an average mean diameter of $490 \mathrm{~nm}$ at $100 \mathrm{mC} / \mathrm{cm}^{2}$ (Figure 3.1a-e and Figure 3.2a). The silicon surface coverage followed the same trend between $5 \mathrm{mC} / \mathrm{cm}^{2}$ and $40 \mathrm{mC} / \mathrm{cm}^{2}$ with an increase from $1 \%$ to $8 \%$, respectively (Figure 3.1f). This is in agreement with the linear Pt mass, and thus volume, increase as the particles grow in a three-dimensional, semi-spherical shape. Only the surface coverage at $100 \mathrm{mC} / \mathrm{cm}^{2}$ seems to deviate from this trend which may be attributed to the AFM 
artefacts of large particles and the highest mismatch between theoretical and deposited Pt mass. Simultaneously, the Pt particle distribution density exponentially decreased from 1.6 particles $/ \mu \mathrm{m}_{\mathrm{Si}}^{2}$ at $5 \mathrm{mC} / \mathrm{cm}^{2}$ to 0.5 particles $/ \mu \mathrm{m}_{\mathrm{Si}}^{2}$ at $40 \mathrm{mC} / \mathrm{cm}^{2}$ and then increased to 1.1 particles $/ \mu \mathrm{m}^{2} \mathrm{Si}$ at $100 \mathrm{mC} / \mathrm{cm}^{2}$ (Figure 3.2a). This is consistent with the exponential decrease of the Pt surface area from $1.41 \mathrm{~m}^{2} / \mathrm{g}$ at $5 \mathrm{mC} / \mathrm{cm}^{2}$ to $0.47 \mathrm{~m}^{2} / \mathrm{g}$ at $100 \mathrm{mC} / \mathrm{cm}^{2}$ (Figure $3.2 b)$ since small particles have a higher surface-to-volume ratio. The decrease in specific surface area and the reduction of particle density with increased passed charge density, show that existing particles tend to grow while formation of new nucleation points is limited.

The results are in good agreement with the Volmer-Weber island growth mechanism. ${ }^{[13,22]}$ After nucleation, Pt particles tend to grow larger instead of forming further nucleation points, implying that the overpotential for the reduction of $\mathrm{PtCl}_{6}{ }^{2-}$ is lower at the $\mathrm{Pt}$ surface than on the Si surface. ${ }^{[13,22]}$ Thereby, platinum catalyzes its own deposition. The optically observed particle distribution is spatially completely random and is in agreement with many models. ${ }^{[13,22]}$ Particles that are located closely together coalesce during growth and thus reduce particle density.

To suppress particle growth and enhance nucleation, we added between 0 and $845 \mathrm{mM}$ hydrogen peroxide $\left(\mathrm{H}_{2} \mathrm{O}_{2}\right)$ to the electrolyte solution and performed the potentiostatic electrodeposition, until a charge density of $20 \mathrm{mC} / \mathrm{cm}^{2}$ was reached (Figure 3.3a-e and Figure 3.4a). The Si surface coverage dropped exponentially from $6.4 \%$ to $0.5 \%$ between 0 and $845 \mathrm{mM} \mathrm{H}_{2} \mathrm{O}$, with an exception at $81 \mathrm{mM}$ $\mathrm{H}_{2} \mathrm{O}_{2}$, in which the surface coverage was $4.8 \%$. The average mean particle diameter decreased first from $304 \mathrm{~nm}$ at $0 \mathrm{mM} \mathrm{H}_{2} \mathrm{O}_{2}$ to $60 \mathrm{~nm}$ at $81 \mathrm{mM} \mathrm{H}_{2} \mathrm{O}_{2}$, and barely changed at higher $\mathrm{H}_{2} \mathrm{O}_{2}$ concentrations. The specific surface area increased with increasing $\mathrm{H}_{2} \mathrm{O}_{2}$ concentration from $0.8 \mathrm{~m}^{2} / \mathrm{g}$ at $0 \mathrm{mM} \mathrm{H}_{2} \mathrm{O}_{2}$ to $4.4 \mathrm{~m}^{2} / \mathrm{g}$ at $845 \mathrm{mM} \mathrm{H}_{2} \mathrm{O}_{2}$ with the strongest increase to $3.6 \mathrm{~m}^{2} / \mathrm{g}$ at $81 \mathrm{mM} \mathrm{H}_{2} \mathrm{O}_{2}$. The particle distribution density fluctuated between 0.2 particles $/ \mu \mathrm{m}^{2} \mathrm{Si}$ and 1.0 particles $/ \mu \mathrm{m}_{\mathrm{Si}}^{2}$ in $0 \mathrm{mM}, 15 \mathrm{mM}, 412 \mathrm{mM}$ and $845 \mathrm{mM} \mathrm{H}_{2} \mathrm{O}_{2}$, but is high at $81 \mathrm{mM} \mathrm{H} \mathrm{O}_{2}\left(13.0\right.$ particles $\left./ \mu \mathrm{m}_{\mathrm{Si}}^{2}\right)$. The Pt mass dropped exponentially from $126.1 \mathrm{mg} / \mathrm{m}^{2}$ Si to $1.4 \mathrm{mg} / \mathrm{m}^{2} \mathrm{Si}$, with a linear $\mathrm{H}_{2} \mathrm{O}_{2}$ increase from $0 \mathrm{mM}$ and 
$845 \mathrm{mM}$, whereas the theoretically deposited Pt maximum is $101.1 \mathrm{mg} / \mathrm{m}^{2} \mathrm{Si}$ (Figure 3.4b).
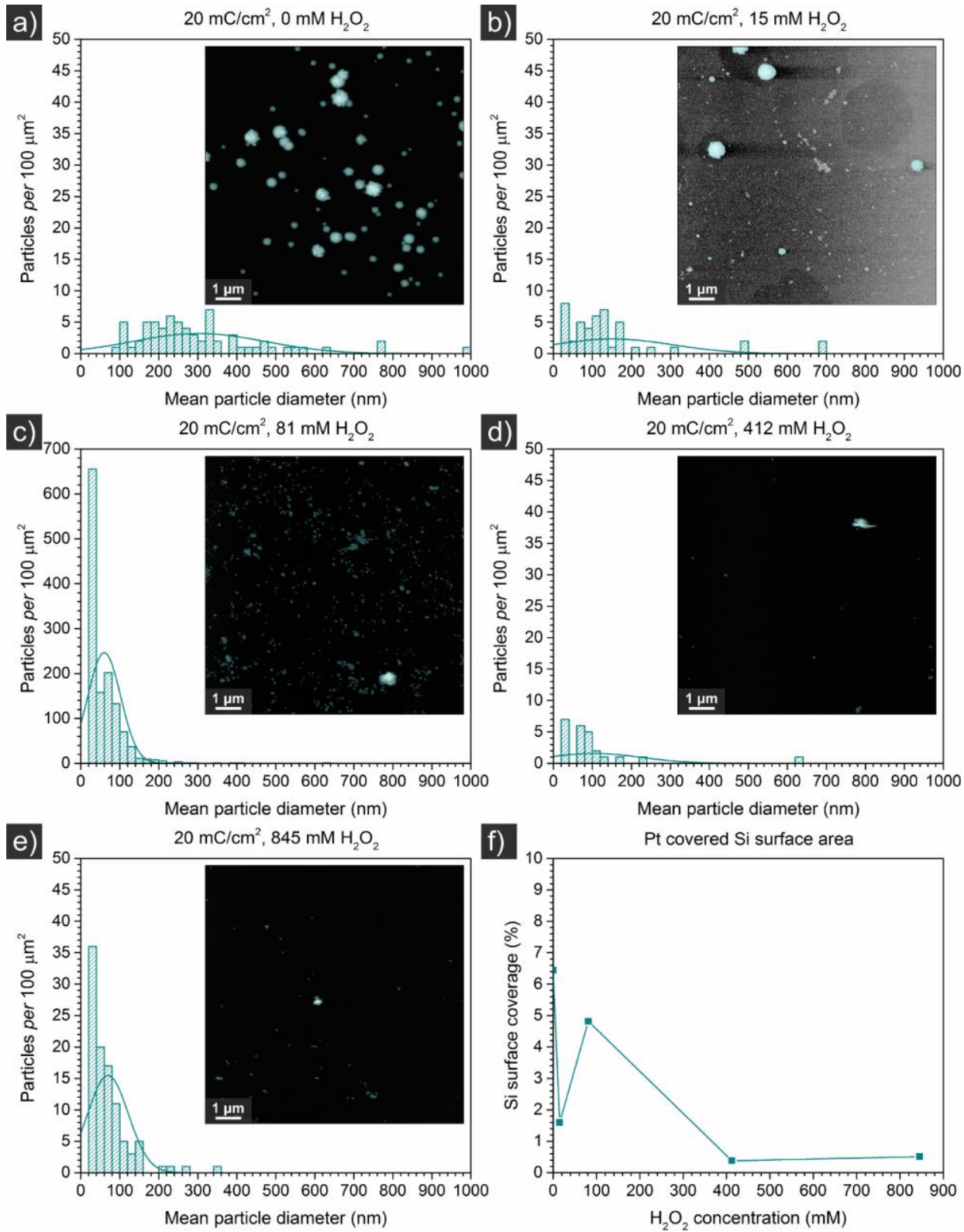

Figure 3.3 a-e) Distribution histograms with $20 \mathrm{~nm}$ bin size, normal distribution curves and inset AFM images, f) Si surface coverage of electrochemically deposited Pt particles at $-0.7 \mathrm{~V}$ vs. $\mathrm{Ag} / \mathrm{AgCl}(3 \mathrm{M} \mathrm{NaCl})$ and $20 \mathrm{mC} / \mathrm{cm}^{2}$ from a $5 \mathrm{mM} \mathrm{H}_{2} \mathrm{PtCl}_{6}, 0.5 \mathrm{M} \mathrm{Na}_{2} \mathrm{SO}_{4}$ solutions at varying $\mathrm{H}_{2} \mathrm{O}_{2}$ concentrations. Note the different y-axis scale in c). 

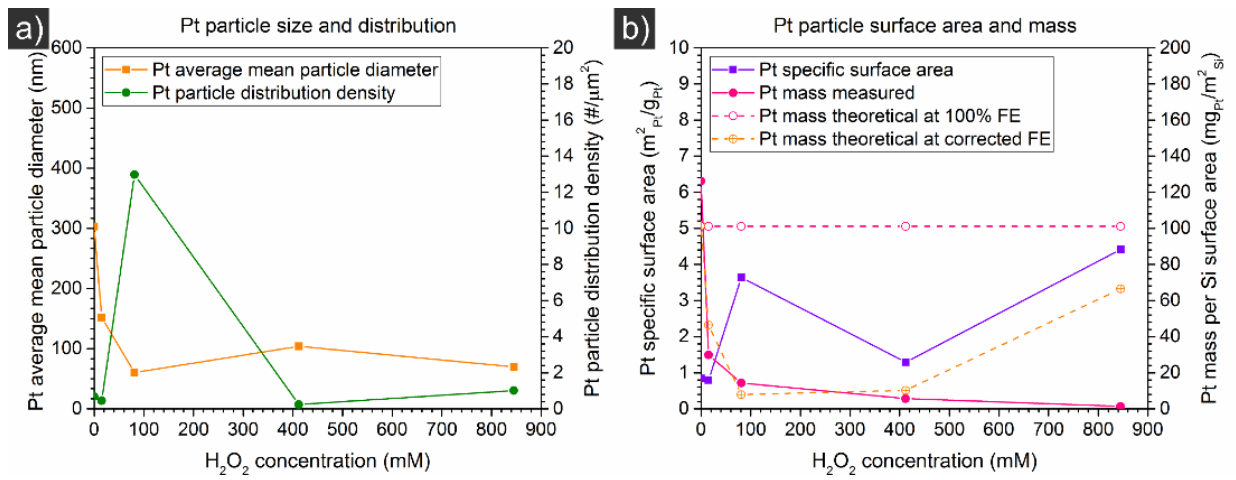

Figure 3.4 a) Average mean particle diameter and distribution density (from AFM), b) specific surface area and mass of electrochemically deposited Pt particles at $-0.7 \mathrm{~V}$ vs. $\mathrm{Ag} / \mathrm{AgCl}(3 \mathrm{M} \mathrm{NaCl})$ from $5 \mathrm{mM} \mathrm{H}_{2} \mathrm{PtCl}_{6}, 0.5 \mathrm{M} \mathrm{Na}_{2} \mathrm{SO}_{4}$ solutions at varying $\mathrm{H}_{2} \mathrm{O}_{2}$ concentrations, at a charge density of $20 \mathrm{mC} / \mathrm{cm}^{2}$. Faradaic efficiencies (FE) were corrected by estimating the current from $\mathrm{H}_{2} \mathrm{O}_{2}$ reduction.

Besides the catalysis of Pt deposition, nucleated Pt particles also catalyze the reduction of $\mathrm{H}_{2} \mathrm{O}_{2}$ to water (Equation 3.4). ${ }^{[23]}$

$\mathrm{H}_{2} \mathrm{O}_{2}+2 \mathrm{H}^{+}+2 \mathrm{e}^{-} \rightarrow 2 \mathrm{H}_{2} \mathrm{O}$ $E^{\circ}=1.78 \mathrm{~V}^{[19]}($ Eq. 3.4)

This causes a competitive and thermodynamically more favorable reduction of $\mathrm{H}_{2} \mathrm{O}_{2}$ on Pt surfaces, which is seen by increased current densities in the deposition current-time curves (Figure 3.5). The current density was highest at a $\mathrm{H}_{2} \mathrm{O}_{2}$ concentration of $81 \mathrm{mM}$. This correlates well with the observed exceptionally high Pt particle density, Si surface coverage and specific surface area found at this $\mathrm{H}_{2} \mathrm{O}_{2}$ concentration. The parasitic current from $\mathrm{H}_{2} \mathrm{O}_{2}$ reduction is approximately the difference in current between $\mathrm{Pt}$ deposition in $\mathrm{H}_{2} \mathrm{O}_{2}$-free and $\mathrm{H}_{2} \mathrm{O}_{2}$-containing solutions. Thus the amount of charges used for $\mathrm{H}_{2} \mathrm{O}_{2}$ reduction is the integrated area in the current density graph between the curves of $\mathrm{H}_{2} \mathrm{O}_{2}$ containing and $\mathrm{H}_{2} \mathrm{O}_{2}$-free deposition. To estimate the $\mathrm{Pt}$ mass at corrected faradaic efficiencies (FE), we have integrated the current density curves of the deposition from $\mathrm{H}_{2} \mathrm{O}_{2}$-free electrolytes until the time used for deposition in $\mathrm{H}_{2} \mathrm{O}_{2}$ containing electrolytes. The current densities at $0 \mathrm{mM} \mathrm{H}_{2} \mathrm{O}_{2}$ and $845 \mathrm{mM} \mathrm{H}_{2} \mathrm{O}_{2}$ crossed after $33 \mathrm{~s}$ of deposition time. In this case we integrated the graph of the current density in $845 \mathrm{mM} \mathrm{H} \mathrm{H}_{2} \mathrm{O}_{2}$ solution between $33 \mathrm{~s}$ and the end of the experiment. Resulting Pt masses match well with the measured mass up to a $\mathrm{H}_{2} \mathrm{O}_{2}$ concentration of $412 \mathrm{mM}$ (Figure 3.4b). At a concentration of $845 \mathrm{mM} \mathrm{H}_{2} \mathrm{O}_{2}$ a 
large deviation, i.e. only $2 \%$ of the theoretical Pt amount after FE correction was found. This is attributed to a mechanistic change in the deposition process which we investigated in further experiments.

The deposition of Pt particles at a passed charge density of $5 \mathrm{mC} / \mathrm{cm}^{2}$ without addition of $\mathrm{H}_{2} \mathrm{O}_{2}$ and at $20 \mathrm{mC} / \mathrm{cm}^{2}$ with addition of $81 \mathrm{mM} \mathrm{H}_{2} \mathrm{O}_{2}$ led to similar deposited masses of $13 \mathrm{mg} / \mathrm{m}^{2}$ Si and $14 \mathrm{mg} / \mathrm{m}^{2}$ Si, respectively. At the same time, the mean particle diameter decreased by $20 \%$ from $75.4 \mathrm{~nm}$ to $60.0 \mathrm{~nm}$, the distribution density increased by a factor 8.2 from 1.58 particles $/ \mu \mathrm{m}^{2}{ }_{\mathrm{Si}}$ to 13.0 particles $/ \mu \mathrm{m}^{2}{ }_{\mathrm{Si}}$, the specific surface area by a factor of 2.6 from $1.41 \mathrm{~m}^{2} / \mathrm{g}$ to $3.63 \mathrm{~m}^{2} / \mathrm{g}$ and the silicon surface coverage by a factor 3.7 from $1.3 \%$ to $4.8 \%$. In the $\mathrm{H}_{2} \mathrm{O}_{2}$ concentration range between $0 \mathrm{mM}$ and $81 \mathrm{mM} \mathrm{H}_{2} \mathrm{O}_{2}$ the equilibrium between $\mathrm{Pt}$ particle growth and nucleation shifts towards nucleation, by adsorption of $\mathrm{H}_{2} \mathrm{O}_{2}$ on the nucleated Pt particles, thus suppressing the adsorption of $\mathrm{PtCl}_{6}^{2-}$.

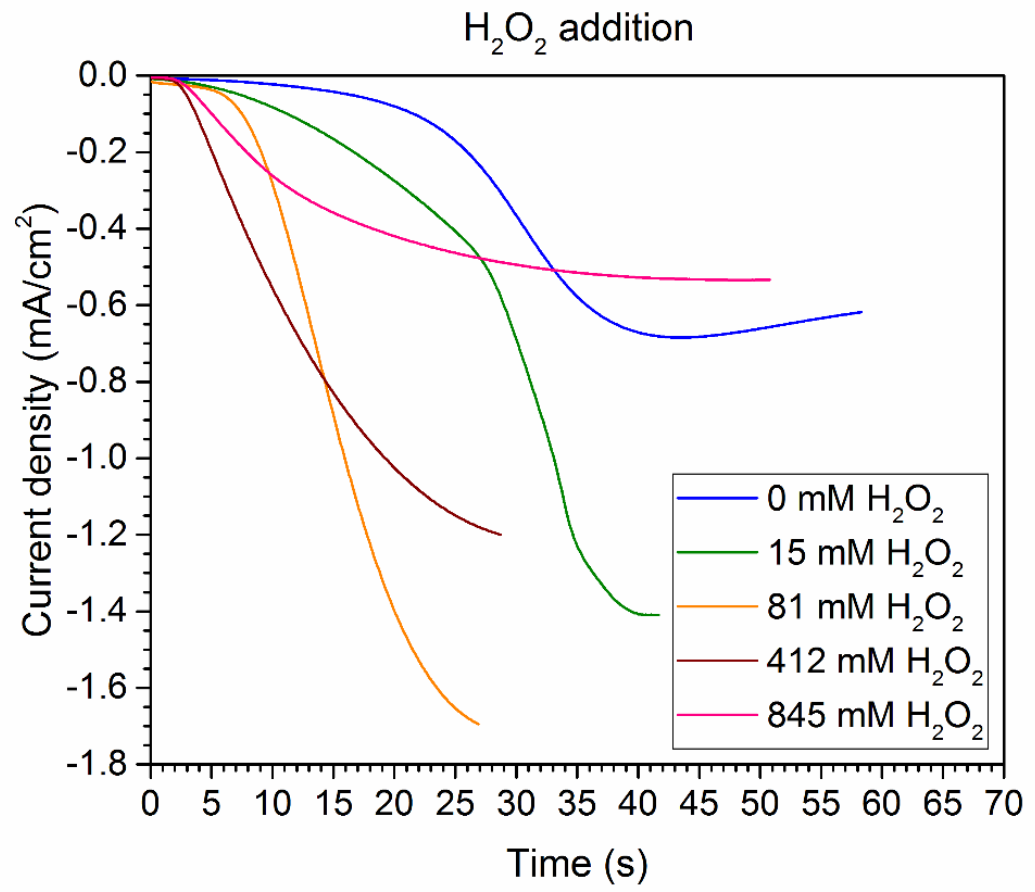

Figure 3.5 Current density vs. time curves of potentiostatically deposited Pt particles at $0.7 \mathrm{~V}$ vs. $\mathrm{Ag} / \mathrm{AgCl}(3 \mathrm{M} \mathrm{NaCl})$ from a $5 \mathrm{mM} \mathrm{H}_{2} \mathrm{PtCl}_{6}, 0.5 \mathrm{M} \mathrm{Na}_{2} \mathrm{SO}_{4}$ solutions at varying $\mathrm{H}_{2} \mathrm{O}_{2}$ concentrations, at a charge density of $20 \mathrm{mC} / \mathrm{cm}^{2}$. 
To understand the influence of $\mathrm{H}_{2} \mathrm{O}_{2}$ on Pt particle growth and distribution density at higher $\mathrm{H}_{2} \mathrm{O}_{2}$ concentrations than $81 \mathrm{mM}$, we performed the Pt deposition in a $845 \mathrm{mM} \mathrm{H} \mathrm{H}_{2} \mathrm{O}_{2}$ solution and varied the deposition charge density between $80 \mathrm{mC} / \mathrm{cm}^{2}$ and $150 \mathrm{mC} / \mathrm{cm}^{2}$. Remarkably, the silicon surface coverage remained fairly constant at $0.7 \%$ (Figure 3.6e), while the deposited Pt mass dropped from $0.60 \mathrm{mg} / \mathrm{m}^{2}$ Si to $0.23 \mathrm{mg} / \mathrm{m}^{2}$ Si. The Pt particle distribution density decreased with increasing charge density from 16.0 particles $/ \mu \mathrm{m}_{\text {Si }}^{2}$ to 7.7 particles $/ \mu \mathrm{m}^{2}$ S. The mean particle diameter increased from $24 \mathrm{~nm}$ to $32 \mathrm{~nm}$ (Figure 3.6a-d and Figure 3.7a), and the specific surface area increased from $13.2 \mathrm{~m}^{2} / \mathrm{g}$ to $30.9 \mathrm{~m}^{2} / \mathrm{g}$ (Figure $3.7 b)$.

The large Pt mass decreases $\left(61.7 \%\right.$ at charge densities of $80 \mathrm{mC} / \mathrm{cm}^{2}$ to $150 \mathrm{mC} / \mathrm{cm}^{2}$ and $83.0 \%$ at $20 \mathrm{mC} / \mathrm{cm}^{2}$ to $150 \mathrm{mC} / \mathrm{cm}^{2}$ ) at increased charge densities indicate that electrons cause a $\mathrm{H}_{2} \mathrm{O}_{2}$-induced corrosion of $\mathrm{Pt}$ at high $\mathrm{H}_{2} \mathrm{O}_{2}$ concentrations.

In literature, cathodic Pt dissolution in acidic media has been observed to occur through anodic and irreversible formation of surface oxide during cyclic voltammetry scans. ${ }^{[24-26]}$ Under purely cathodic conditions, when no anodic potential is applied, corrosion was reported after Pt had been exposed to air and thus formed an oxide layer. ${ }^{[27]}$ From these reports we can derive the dissolution mechanism of $\mathrm{Pt}$ particles at $\mathrm{H}_{2} \mathrm{O}_{2}$ concentrations above $412 \mathrm{mM}$. Potentiostatically supplied electrons induce a Fenton's reagent-type reaction in which hydroxyl radicals are formed by a partial reduction of $\mathrm{H}_{2} \mathrm{O}_{2}$ (Eq. 3.5).

$\mathrm{H}_{2} \mathrm{O}_{2}+\mathrm{e}^{-} \rightarrow \mathrm{OH}^{-}+\cdot \mathrm{OH}$

These highly oxidative hydroxyl radicals oxidize the Pt particle surface and cause their cathodic dissolution. Platinum oxide is a worse $\mathrm{H}_{2} \mathrm{O}_{2}$ reduction catalyst than metallic platinum, ${ }^{[28]}$ thus explaining the current reduction during potentiostatic deposition at $\mathrm{H}_{2} \mathrm{O}_{2}$ concentrations of $412 \mathrm{mM}$ and above (Figure 3.5). 

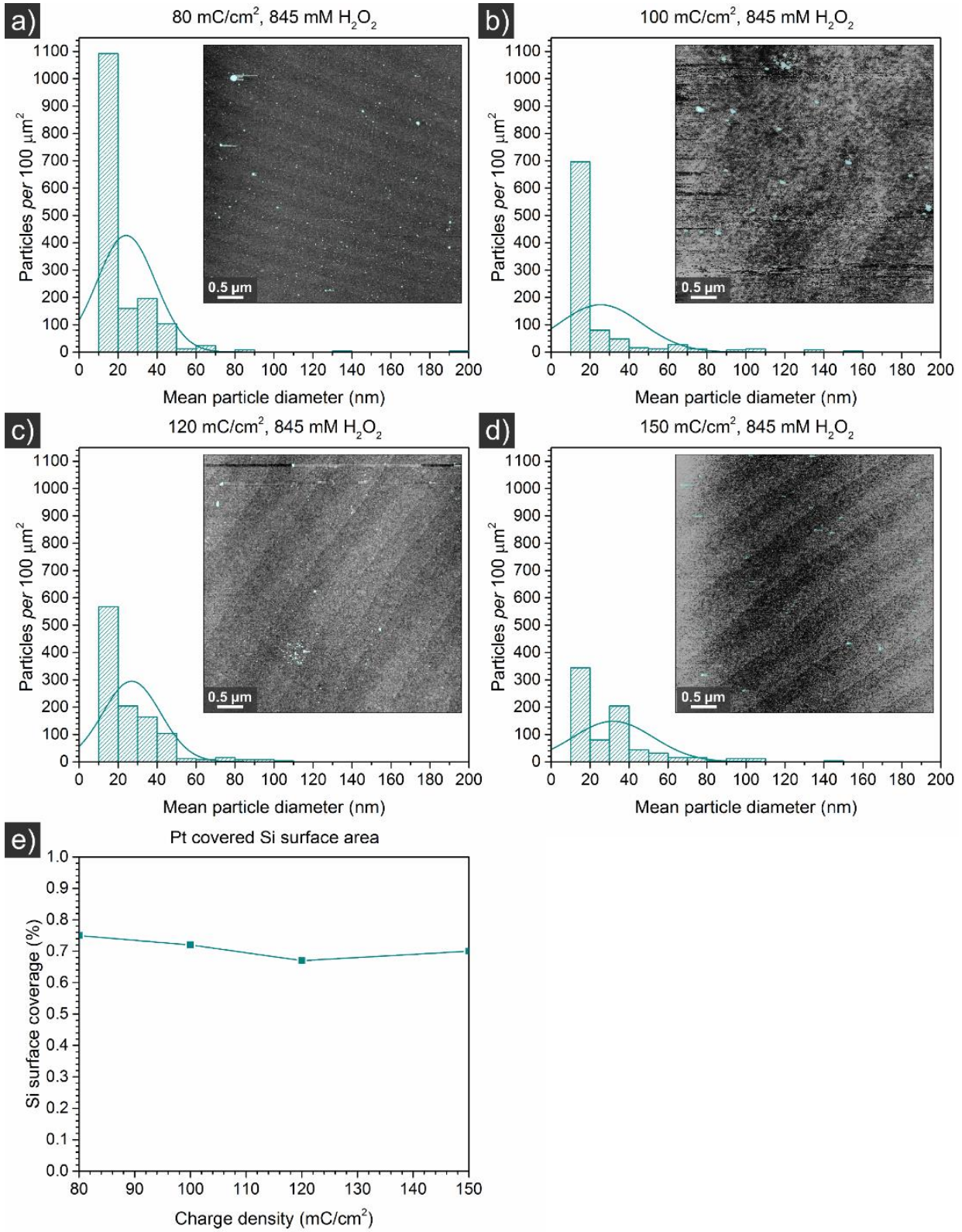

Figure 3.6 a-d) Particle distribution histograms with $10 \mathrm{~nm}$ bin size, normal distribution curves and inset AFM images, e) Si surface coverage of electrochemically deposited $\mathrm{Pt}$ particles at $-0.7 \mathrm{~V}$ vs. $\mathrm{Ag} / \mathrm{AgCl}(3 \mathrm{M} \mathrm{NaCl})$ from a $5 \mathrm{mM} \mathrm{H}_{2} \mathrm{PtCl}_{6}, 0.5 \mathrm{M} \mathrm{Na}_{2} \mathrm{SO}_{4}$ and $845 \mathrm{mM} \mathrm{H}_{2} \mathrm{O}_{2}$ solution upon variation of the passed charge density. 

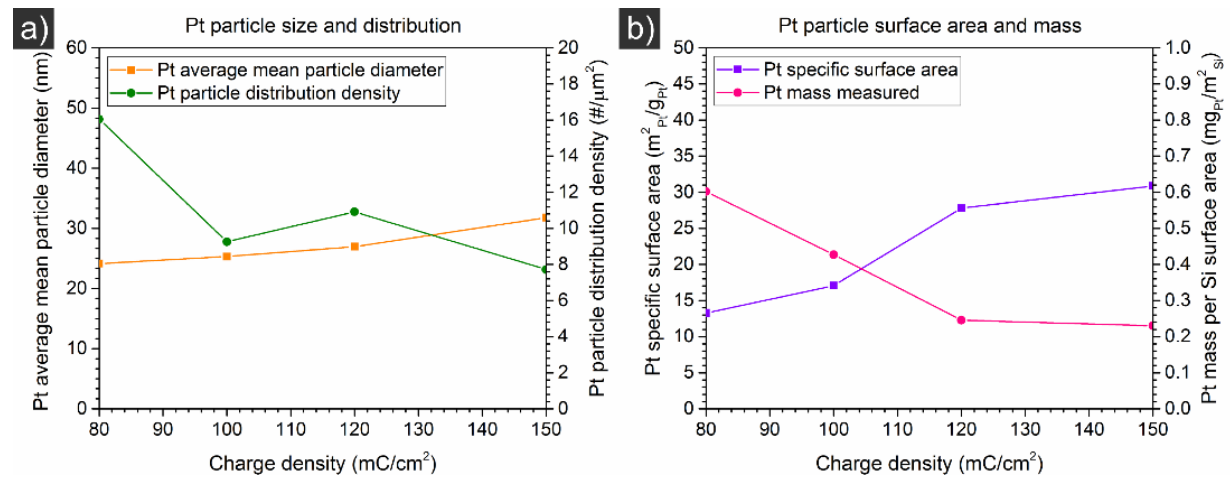

Figure 3.7 a) Average mean particle diameter and distribution density (from AFM), b) specific surface area and mass of electrochemically deposited $\mathrm{Pt}$ particles at $-0.7 \mathrm{~V}$ vs. $\mathrm{Ag} / \mathrm{AgCl}(3 \mathrm{M} \mathrm{NaCl})$ from a $5 \mathrm{mM} \mathrm{H}_{2} \mathrm{PtCl}_{6}, 0.5 \mathrm{M} \mathrm{Na}_{2} \mathrm{SO}_{4}$ and $845 \mathrm{mM} \mathrm{H}_{2} \mathrm{O}_{2}$ solution upon variation of the passed charge density.

\subsection{Conclusions}

In conclusion, the size and density of electrochemically deposited Pt particles can be easily manipulated and adjusted by the addition of hydrogen peroxide to the electrolyte solution, and by variation of charge densities passed through the cell. Our results suggest that the dominating deposition mechanism depends on the $\mathrm{H}_{2} \mathrm{O}_{2}$ concentration and could be completely revealed by in situ studies. We assume that when $81 \mathrm{mM} \mathrm{H}_{2} \mathrm{O}_{2}$ or less is added, $\mathrm{H}_{2} \mathrm{O}_{2}$ adsorption on nucleated particles dominates, thus preventing $\mathrm{Pt}$ growth by suppressing $\mathrm{PtCl}_{6}{ }^{2-}$ adsorption and consecutive reduction to metallic platinum. At concentrations of $412 \mathrm{mM}$ and above, we assume high hydroxyl radical concentrations are created by partial $\mathrm{H}_{2} \mathrm{O}_{2}$ reduction, which presumably induce $\mathrm{Pt}$ surface oxidation and cathodic dissolution.

These results provide a synthetic means to optimize size and density of $\mathrm{Pt}$ particles for high solar-to-hydrogen efficiency of silicon-based photocathodes, as well as cost-effective production with a simple and scalable electrodeposition technique. Also, the understanding of $\mathrm{Pt}$ corrosion in a $\mathrm{H}_{2} \mathrm{O}_{2}$-containing or (unintentionally) $\mathrm{H}_{2} \mathrm{O}_{2}$-developing environment, such as in fuel cells and electrolyzers, may lead to rational measures for improvements of their stability. 


\subsection{Acknowledgements}

Thimo te Molder is greatly acknowledged for discussions and practically performing the experiments within the scope of a Bachelor assignment.

\subsection{References}

[1] M. G. Walter, E. L. Warren, J. R. McKone, S. W. Boettcher, Q. Mi, E. A. Santori, N. S. Lewis, Chem. Rev. 2010, 110, 6446.

[2] J. Turner, G. Sverdrup, M. K. Mann, P.-C. Maness, B. Kroposki, M. Ghirardi, R. J. Evans, D. Blake, Int. J. Energy Res. 2008, 32, 379.

[3] K. Sun, S. Shen, Y. Liang, P. E. Burrows, S. S. Mao, D. Wang, Chem. Rev. 2014, 114, 8662.

[4] C. U. Maier, M. Specht, G. Bilger, Int. J. Hydrogen Energy 1996, 21, 859.

[5] Y. Nakato, H. Tsubomura, Electrochim. Acta 1992, 37, 897.

[6] R. N. Dominey, N. S. Lewis, J. A. Bruce, D. C. Bookbinder, M. S. Wrighton, J. Am. Chem. Soc. 1982, 104, 467.

[7] J. A. Aguiar, N. C. Anderson, N. R. Neale, J. Mater. Chem. A 2016, 4, 8123.

[8] M. Pourbaix, Atlas of Electrochemical Equilibria in Aqueous Solutions, 2, National Association of Corrosion Engineers, Houston, Texas 1974.

[9] C. C. L. McCrory, S. Jung, I. M. Ferrer, S. M. Chatman, J. C. Peters, T. F. Jaramillo, J. Am. Chem. Soc. 2015, 137, 4347.

[10] Y. Nakato, H. Yano, S. Nishiura, T. Ueda, H. Tsubomura, J. Electroanal. Chem. Interfacial Electrochem. 1987, 228, 97.

[11] P. C. K. Vesborg, T. F. Jaramillo, RSC Adv. 2012, 2, 7933.

[12] A. Heller, D. E. Aspnes, J. D. Porter, T. T. Sheng, R. G. Vadimsky, J. Phys. Chem. 1985, 89, 4444.

[13] G. Oskam, J. G. Long, A. Natarajan, P. C. Searson, J. Phys. D: Appl. Phys. 1998, 31, 1927.

[14] Y. L. Kawamura, T. Sakka, Y. H. Ogata, J. Electrochem. Soc. 2005, 152, C701.

[15] M. Aggour, K. Skorupska, T. Stempel Pereira, H. Jungblut, J. Grzanna, H. J. Lewerenz, J. Electrochem. Soc. 2007, 154, H794.

[16] Y. Liu, D. Gokcen, U. Bertocci, T. P. Moffat, Science 2012, 338, 1327. 
[17] M. Szklarczyk, J. O. M. Bockris, J. Phys. Chem. 1984, 88, 1808.

[18] L. Qiao, M. Zhou, Y. Li, A. Zhang, J. Deng, M. Liao, P. Xiao, Y. Zhang, S. Zhang, J. Electrochem. Soc. 2014, 161, H458.

[19] W. M. Haynes, CRC Handbook of Chemistry and Physics, 91st Edition, Taylor \& Francis Group, 2010.

[20] P. C. Braga, D. Ricci, Atomic Force Microscopy: Biomedical Methods and Applications, Humana Press, 2004.

[21] P. Gorostiza, R. Díaz, F. Sanz, J. R. Morante, J. Electrochem. Soc. 1997, 144, 4119.

[22] L. Guo, G. Oskam, A. Radisic, P. M. Hoffmann, P. C. Searson, J. Phys. D: Appl. Phys. 2011, 44, 443001.

[23] D. A. MacInnes, J. Am. Chem. Soc. 1914, 36, 878.

[24] S. Cherevko, A. R. Zeradjanin, A. A. Topalov, N. Kulyk, I. Katsounaros, K. J. J. Mayrhofer, ChemCatChem 2014, 6, 2219.

[25] P. Jovanovič, A. Pavlišič, V. S. Šelih, M. Šala, N. Hodnik, M. Bele, S. Hočevar, M. Gaberšček, ChemCatChem 2014, 6, 449.

[26] A. A. Topalov, I. Katsounaros, M. Auinger, S. Cherevko, J. C. Meier, S. O. Klemm, K. J. J. Mayrhofer, Angew. Chem. Int. Ed. 2012, 51, 12613.

[27] S. Cherevko, J. Electroanal. Chem. 2017, 787, 11.

[28] E. Sitta, A. M. Gómez-Marín, A. Aldaz, J. M. Feliu, Electrochem. Commun. 2013, 33, 39. 


\section{Chapter 4}

\section{Spatioselective electrochemical and photoelectrochemical functionalization of silicon microwires with axial $\mathrm{p} / \mathrm{n}$ junctions}

Dually and spatioselectively functionalized silicon and other semiconductor nano to microwires with an axial homo- or heterojunction possess unique properties for the design of next generation devices and systems with novel functions. In this work, we present a powerful method of selectively functionalizing $\mathrm{Si}$ microwire surfaces by utilizing the nature of an axial $\mathrm{p} / \mathrm{n}$ junction placed into the microwires. Stepwise electrochemical functionalization in light and dark was used to address the top or bottom selectively. First, we demonstrated the concept experimentally by the selective reduction of platinum on p-type and silver on $\mathrm{n}$-type silicon microwires with an axial $\mathrm{p} / \mathrm{n}$ junction on different samples. Subsequently, the reactions were combined, resulting in a dual functionalized microwires with an axial p/n junction, as confirmed by HR-SEM and EDX. The junction depletion layer remained unmodified which allowed its visualization and comparison with theoretical calculations.

This chapter has been adapted from: A. Milbrat, R. Elbersen, R. Kas, R. M.

Tiggelaar, H. Gardeniers, G. Mul, J. Huskens, Adv. Mater. 2016, 28, 1400 


\subsection{Introduction}

Semiconductor wires and wire arrays of nano- to micrometer sizes have unique optical, electronic, electrochemical, thermal, mechanical and magnetic properties, ${ }^{[1]}$ which make them attractive structures for electronic, sensor, photonic, thermoelectric, photovoltaic, photoelectrochemical and battery applications. ${ }^{[1-5]}$ In order to tailor the wire properties for a target application, in most cases functionalization is required, for example, by deposition of catalysts, ${ }^{[6]}$ additional semiconductors, ${ }^{[7]}$ grafting with organic molecules ${ }^{[8]}$ or polymers. ${ }^{[9]}$ These modifications are commonly performed across the entire surface of the wires. Janus-type wires on the other hand, with differently functionalized top and bottom segments, may provide access to new types of devices or improve the functionality of existing ones. ${ }^{[10]}$ For instance, many applications, such as sensors, ${ }^{[11]}$ tunnel field-effect transistors, ${ }^{[12-14]}$ light-emitting diodes, $\left.{ }^{[15}, 16\right]$ photovoltaics ${ }^{[17-19]}$ and photonics, ${ }^{[15,20]}$ require or would benefit from an axial homo- or heterojunction and electrical communication between the segments with e.g. different catalytic or surface properties. The ability to create semiconductor wires and wire arrays with axial heterostructures has been demonstrated $^{[11-16,}$ 18] and the feasibility of creating bi-functionalized semiconductor wires and wire arrays has been reported previously for their use in photocatalysis ${ }^{[21-23]}$ and microfluidics, ${ }^{[24,25]}$ or as superhydrophobic surfaces ${ }^{[26]}$. However, a combination of heterostructured wires with functionalized surfaces is rare, mainly because their preparation is complex and requires several steps. So far, bi-functionalized wires have been created by physically masking the part of the wire that was to remain unmodified. ${ }^{[21-23,26]}$ Typically, wires are embedded completely in a polymeric material first, which is then subsequently etched back to expose parts of the wires for further functionalization. This masking process makes it difficult to control the functionalization boundary precisely, reproducibly, and homogeneously across an array, which is particularly important for, for example, axially heterostructured wires where a small misalignment could lead to failure of the device.

Herein, we show a method for the direct and spatioselective bi-functionalization of semiconductor microwires, employing the different electronic properties of an 
axial junction in the dark and under illumination. As an example of the concept, we have studied silicon microwires with an axial $\mathrm{n}^{+} / \mathrm{p}$ junction.

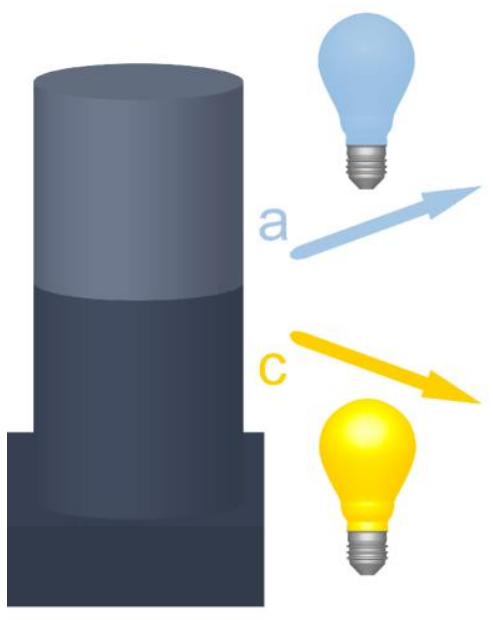

light on light off
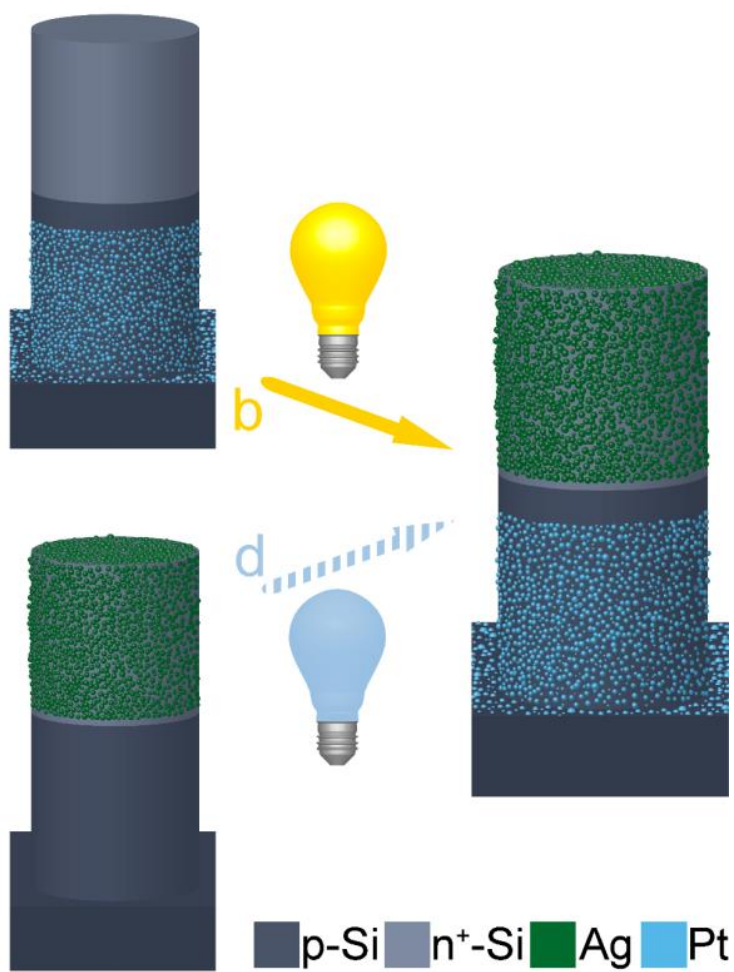

Figure 4.1 Schematic illustration of the spatioselective functionalization process of silicon microwires with an axial $\mathrm{n}^{+} / \mathrm{p}$ junction: an initial silicon microwire (left) is functionalized by the electrochemical deposition of Pt in the dark on the p-Si part (a) and of $\mathrm{Ag}$ under illumination on the $\mathrm{n}^{+}-\mathrm{Si}$ part (b, c). Sequential deposition of Pt and Ag leads to a bi-functionalized silicon microwire (right) in which a depletion zone is visible between the functionalized areas. Step (d) provides an optional, but here unexplored, route.

Figure 4.1 schematically shows the concept. It starts from a silicon microwire that has an axial $\mathrm{n}^{+} / \mathrm{p}$ junction, prepared by the $\mathrm{n}$-doping of a flat $\mathrm{p}$-base wafer followed by dry etching to create the microwires. The junction induces diode-like behavior upon application of a negative potential to the p-region, preventing electrons to pass from bottom to top. This allows the selective functionalization of the bottom segment by reductive electrodeposition, which is tested here by the electrodeposition of $\mathrm{Pt}$ nanoparticles from a hexachloroplatinic acid precursor solution (Figure 4.1a). Under illumination, the junction promotes the migration 
of electrons to the $\mathrm{n}^{+}-\mathrm{Si}$ surface, and allows the selective functionalization of that surface, which is demonstrated here by the electrodeposition of silver (Figure $4.1 \mathrm{~b} / \mathrm{c}$ ). The holes accumulated in the p-Si part either recombine with electrons supplied by an external source, i.e., by applying a negative bias to the base silicon, or migrate to the $\mathrm{p}-\mathrm{Si}$ surface likely causing its oxidation. Performing both functionalization steps consecutively results in dually and spatioselectively functionalized arrays of microwires. As Figure 4.1 indicates, we observed (see below) an unmodified band between the functionalized segments in the final wires, attributed to a depletion zone around the junction. We provide here analytical data and theory to explain this phenomenon.

\subsection{Materials and methods}

\subsubsection{Fabrication of silicon microwires with axial $n^{+} / p$ junction}

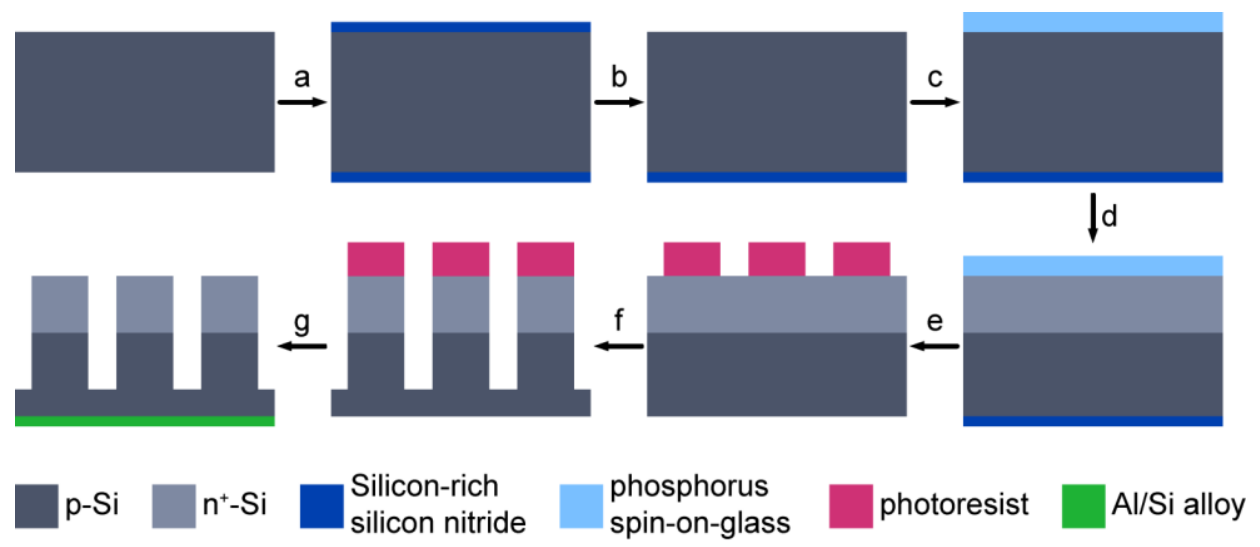

Figure 4.2 Schematic illustration of the synthesis of silicon microwires with axial $\mathrm{n}^{+} / \mathrm{p}$ junctions. a) Low pressure chemical vapor deposition (LPCVD) of silicon-rich silicon nitride ( $\mathrm{SiRN}$ ) on p-type silicon substrates. b) Removal of SiRN from the front side by reactive ion etching (RIE). c) Spin coating of phosphorus spin-on-glass (P-SOG) at $6000 \mathrm{rpm}$ for $30 \mathrm{~s}$. d.) Thermal phosphorus drive-in at $1100^{\circ} \mathrm{C}$ for $60 \mathrm{~min}$. e) Definition of microwire arrays by standard UV-lithography. f) cryogenic $\left(-100^{\circ} \mathrm{C}\right)$ deep reactive ion etching (DRIE). g) removal of photoresist and silicon oxide and sputtering of aluminum/silicon alloy $(99 \% \mathrm{Al}, 1 \% \mathrm{Si})$.

Figure 4.2 schematically shows the fabrication of silicon microwires with axial $\mathrm{n}+/ \mathrm{p}$ junction. Boron-doped, $\mathrm{p}$-type silicon substrates $(<100\rangle$-oriented, resistivity 5-10 $\Omega \mathrm{cm}, 100 \mathrm{~mm}$ diameter, $525 \mu \mathrm{m}$ thickness, single-side polished, Okmetic Finland) were cleaned by immersion in $100 \%$ nitric acid $\left(\mathrm{HNO}_{3}\right)(2 \times 5 \mathrm{~min})$ and 
in 69\% nitric acid (15 min), followed by quick dump rinsing in de-mineralized (DI) water, immersion in a $1 \%$ aqueous hydrofluoric (HF) acid to remove the formed oxide shell and another quick dump rinsing cycle. After spin drying the wafers, $100 \mathrm{~nm}$ thick silicon-rich silicon nitride (SiRN) was deposited using low pressure chemical vapor deposition (LPCVD) on both sides of the wafer, removed from the front side with reactive ion etching (Adixen AMS100DE; octafluorocyclobutane $\left(\mathrm{C}_{4} \mathrm{~F}_{8}\right)$ and methane $\left.\left(\mathrm{CH}_{4}\right)\right)$, followed by an oxygen plasma treatment and piranha cleaning (mixture of concentrated sulfuric acid and 30\% aqueous hydrogen peroxide, $3: 1(\mathrm{v} / \mathrm{v}), 20 \mathrm{~min})$ to remove any contamination (i.e. fluorocarbon traces from the DRIE-process). Subsequently, the front side was covered by a phosphorus spin-on-glass (P-SOG, Filmtronics P509), spun at 6000 rpm for $30 \mathrm{~s}$, and annealed at $1100{ }^{\circ} \mathrm{C}$ for $60 \mathrm{~min}$. The remaining P-SOG and SiRN layers were removed by immersion in buffered hydrogen fluoride $(1: 7$, BHF) for $10 \mathrm{~min}$, washed with DI water and dried with a nitrogen flow. By means of standard UV-lithography, six $2 \times 2 \mathrm{~cm}^{2}$ areas with an array of microwires (specifications: diameter $4 \mu \mathrm{m}$, spacing $2 \mu \mathrm{m}$, hexagonally stacked with a packing density of 35\%) were defined in photoresist (Olin 907-17), and postbaked for $10 \mathrm{~min}$ at $120^{\circ} \mathrm{C}$ after exposure and development. The photoresist acted as a mask layer during cryogenic $\left(-100^{\circ} \mathrm{C}\right)$ deep reactive ion etching (DRIE; Adixen AMS100SE, $1000 \mathrm{~W})$ of silicon, using sulfur hexafluoride $\left(\mathrm{SF}_{6}\right.$, $200 \mathrm{sccm})$ for etching silicon and $\mathrm{O}_{2}(30 \mathrm{sccm})$ for passivating the sidewalls. The height of the wires was determined by the etch duration, which was set to $2 \mathrm{~min}$, resulting in wire heights of approximately $7 \mu \mathrm{m}$. After etching, the photoresist mask was stripped off with oxygen plasma, followed by piranha cleaning (20 min), rinsing with DI water and drying with nitrogen. Prior to selective electrodeposition experiments, the sample was immersed in $1 \%$ aqueous hydrofluoric (HF) acid solution for at least $1 \mathrm{~min}$ to remove the silicon oxide shell, washed by quick dump rinsing in de-mineralized (DI) water, spin dried, after which the backside was sputter-coated with a $1 \mu \mathrm{m}$ thick aluminum/silicon alloy (99\% Al, 1\% Si) (Oxford PL 400, $7000 \mathrm{~W}$ ) to create a low resistance Ohmic contact. 


\subsubsection{Electrodeposition of platinum and silver}

Platinum was deposited on the bottom p-Si segments from an aqueous solution of $5 \mathrm{mM}$ hexachloroplatinic(IV) acid $\left(\mathrm{H}_{2} \mathrm{PtCl}_{6}\right)$ and $0.5 \mathrm{M}$ sodium sulfate $\left(\mathrm{Na}_{2} \mathrm{SO}_{4}\right)$, potentiostatically at $-0.7 \mathrm{~V}$. Charge densities of $130 \mathrm{mC} \mathrm{cm}^{-2}$ were supplied. Silver was deposited on the top $\mathrm{n}-\mathrm{Si}$ segments from an aqueous solution of $1 \mathrm{mM}$ silver nitrate $\left(\mathrm{AgNO}_{3}\right)$ and either $0.5 \mathrm{M} \mathrm{Na}_{2} \mathrm{SO}_{4}, 0.005 \mathrm{M} \mathrm{H}_{2} \mathrm{SO}_{4}$ or $0.5 \mathrm{M} \mathrm{H}_{2} \mathrm{SO}_{4}$ as the electrolyte, with a measured $\mathrm{pH}$ (Hanna Instruments $\mathrm{pH} 209$ ) of 5.3, 2.4 and 0.6 , respectively. Voltages applied were $-0.1 \mathrm{~V},+0.1 \mathrm{~V}$ and $+0.3 \mathrm{~V}$. The deposition was discontinued when the charge density amounted to $25 \mathrm{mC} \mathrm{cm}^{-2}$ or after $10 \mathrm{~min}$ when no external potential was applied. A solar simulator with a $300 \mathrm{~W}$ xenon lamp and an air mass 1.5 global filter was used as a light source for experiments performed under illumination. The intensity of the simulated sunlight was adjusted to 2 suns $\left(200 \mathrm{~mW} / \mathrm{cm}^{2}\right)$ with a standard reference silicon solar cell and partially cut off at $570 \mathrm{~nm}$ with a cut-on filter (Newport) to avoid significant homogeneous photodecomposition of $\mathrm{AgNO}_{3}$ in solution by shorter wavelengths. ${ }^{[23]}$ The custom-made Teflon-based reactors with a volume of about $8 \mathrm{ml}$ were equipped with an optical glass window and were open to the environment. Active surface areas applied were $3.14 \mathrm{~cm}^{2}$ for platinum and $0.28 \mathrm{~cm}^{2}$ for silver deposition, respectively, as determined by the O-rings of the reactors. A standard three-electrode system with a platinum mesh counter electrode was used in experiments with applied potential. When no external potential was applied, a two-electrode system was constructed in which the reference electrode was connected to the platinum counter mesh. The potential was set to $0 \mathrm{~V} v s$. open circuit in these cases. A potentiostat (PAR, VersaStat 4) served as a power source. All applied potentials are reported versus a $\mathrm{Ag} / \mathrm{AgCl}$ (3 M NaCl, BASi MF-2052) reference electrode, and all electrochemical experiments were performed at room temperature.

\subsubsection{Scanning electron microscopy (SEM)/ energy-dispersive X-ray spectroscopy (EDX)}

High-Resolution Scanning Electron Microscopy (HR-SEM) images were taken with a Phillips FEI XL30 FEG-ESEM with a Secondary Electron (SE) detector or FEI Sirion FEG-SEM with a Through the Lens Detector (TLD), operated at 
typical acceleration voltages of $10 \mathrm{kV}$. HR-SEM in combination with EnergyDispersive X-ray spectroscopy (EDX) mapping was performed with a MERLIN FEG HR-SEM with an inlens SE detector and an EDX Spectrometer, and a $80 \mathrm{~mm}^{2}$ detector.

\subsubsection{Secondary ion mass spectrometry (SIMS)}

Secondary ion mass spectrometry (SIMS) depth profiles of flat silicon specimen with $\mathrm{n}^{+} / \mathrm{p}$ junctions were determined with a Cameca IMS $6 f$ ion microprobe, operated in positive mode. $\mathrm{An}_{2}{ }^{+}$ion beam with the impact energy of $7.5 \mathrm{keV}$ was rastered over a $250 \times 250 \mu \mathrm{m}^{2}$ area of which's center a $30 \mu \mathrm{m}$ diameter circle was analyzed. Secondary ions ${ }^{31} \mathrm{P}^{+}$and ${ }^{28} \mathrm{Si}_{2}{ }^{+}$as reference were detected. Oxygen flooding was applied to enhance the positive ion yield. Experimental crater depth was measured by optical profilometry ( $\pm 5 \%$ accuracy) and used for depth scale calibration. Quantification was based on a P reference implant ( $\pm 10 \%$ accuracy).

\subsubsection{Staining of the $n^{+} / p$ junction}

Staining of specimen with prepared $\mathrm{n}^{+} / \mathrm{p}$ junction was performed according the procedure described in the patent of Roman and Wilson ${ }^{[1]}$, whereby, $\mathrm{n}^{+}-$and p-type silicon is etched at different rates. Chromium(VI) oxide $\left(\mathrm{CrO}_{3}\right)(99.9 \%$, Sigma-Aldrich) and DI water were mixed in a ratio of 1 to $3(\mathrm{w} / \mathrm{w})$, following an addition of a $50 \%$ aqueous HF solution (10 vol\% of the starting solution). Subsequently, specimen were immerged into this mixture for a given amount of time, rinsed with DI water and dried with a stream of nitrogen.

\subsubsection{Ball grooving}

By means of a rotating stainless steel ball with a diameter of a $60 \mathrm{~mm}$, a groove was made on a flat specimen with $\mathrm{n}^{+} / \mathrm{p}$ junction. A diamond paste was applied to the ball to enhance grooving rate with which a few seconds were sufficient to expose the junction. Subsequently, the samples were cleaned with ethanol. 


\subsection{Results and discussion}

Figure 4.3a shows platinum particles, electrodeposited in the dark, selectively on the p-type base and bottom segments of the axially doped silicon microwires. Clearly, the top $\mathrm{n}^{+}$-type segments have remained unmodified. A control experiment, performed at identical electrochemical conditions but applied to $\mathrm{p}$-Si microwires without phosphorus $\mathrm{n}^{+}-\mathrm{Si}$ top segments, yielded completely covered microwires (Figure 4.3b). This confirms that the electron flow to the $\mathrm{n}^{+}-\mathrm{Si}$ top parts is prevented in the dark by the diode properties of the axially doped microwires. The metal was deposited as particles and not as a continuous film, which is consistent with the theory of Volmer-Weber island growth. ${ }^{[27]}$ In both samples shown in Figure 4.3, the density of the particles is higher at the top of the functionalized segment compared to the bottom, which is tentatively attributed to a diffusion limitation of the precursor in between the microwires at these densely packed arrays. A control experiment in which the distance between the pillars was increased from $2 \mu \mathrm{m}$ to $16 \mu \mathrm{m}$ shows optically significantly less inhomogeneity (Figure 4.10, Appendix).
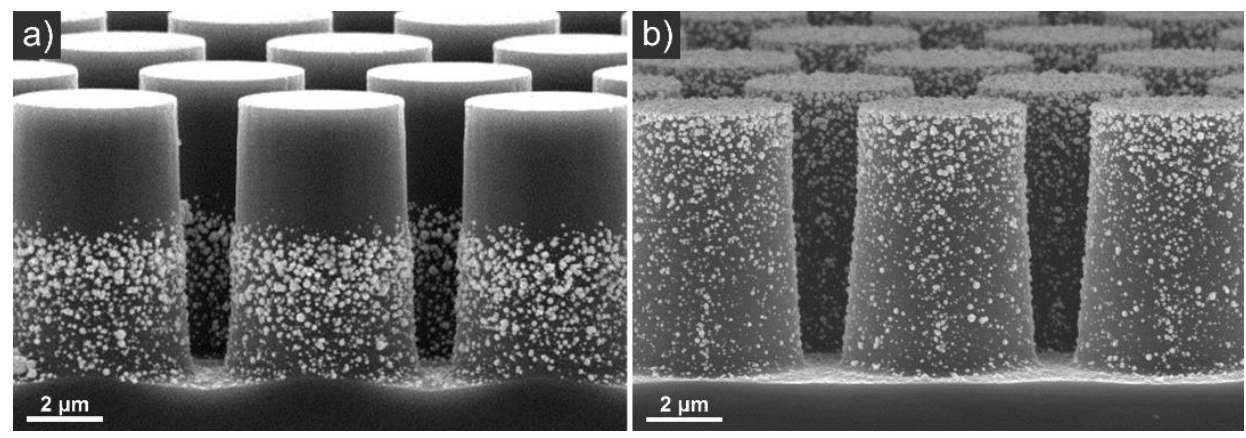

Figure 4.3 Cross-sectional SEM images of a) Si microwires with a $\mathrm{n}^{+} / \mathrm{p}$ junction and $\mathrm{b}$ ) $\mathrm{p}-\mathrm{Si}$ microwires after the electrodeposition of $\mathrm{Pt}$ particles at $-0.7 \mathrm{~V}$ vs. $\mathrm{Ag} / \mathrm{AgCl}$ $(3 \mathrm{M} \mathrm{NaCl})$ and $130 \mathrm{mC} \mathrm{cm}^{-2}$ in the dark from a solution of $5 \mathrm{mM} \mathrm{H}_{2} \mathrm{PtCl}_{6}$ and $0.5 \mathrm{M}$ $\mathrm{Na}_{2} \mathrm{SO}_{4}$.

Figure 4.4 shows silver particles, electrodeposited selectively on the top $\mathrm{n}^{+}-\mathrm{Si}$ segments (Figure 4.4a) under illumination in $0.5 \mathrm{M} \mathrm{H}_{2} \mathrm{SO}_{4}$ electrolyte and at an applied potential of $+0.3 \mathrm{~V}$, and semi-selectively on the p-type base and bottom segments of the axially doped silicon microwires (Figure 4.4b) in the dark at $-0.3 \mathrm{~V}$. Selective photo-supported electrodeposition of silver on the top of the wires at the $\mathrm{n}^{+}-\mathrm{Si}$ segments was achieved in all used electrolytes (high 
concentration of $\mathrm{Na}_{2} \mathrm{SO}_{4}$ and low and high concentrations of sulfuric acid) and applied potentials (no external potential, $+0.3 \mathrm{~V},+0.1 \mathrm{~V}$ and $-0.1 \mathrm{~V} v s . \mathrm{Ag} / \mathrm{AgCl}$ $(3 \mathrm{M} \mathrm{NaCl})$ ). Some deposition of silver on the bottom p-Si segments was observed in few cases (Figure 4.12, Appendix). Electrodeposition of Ag on p-Si in the dark was not as selective as that of Pt. Besides major Ag deposition on the bottom $\mathrm{p}$-Si segments, minor deposition on the top $\mathrm{n}^{+}$-Si segments (Figure 4.4b) was observed. We assume that the formation of a Schottky junction between $\mathrm{Ag}$ and $\mathrm{p}$-Si close to the $\mathrm{n}^{+} / \mathrm{p}$ junction caused a leak of electrons through the $\mathrm{n}^{+} / \mathrm{p}$ junction by a partial overlap of both junction depletion layers. Thus, an Ohmic contact between semiconductor wire segments and the functionalized material is likely important to achieve high selectivity in functionalization in the dark.
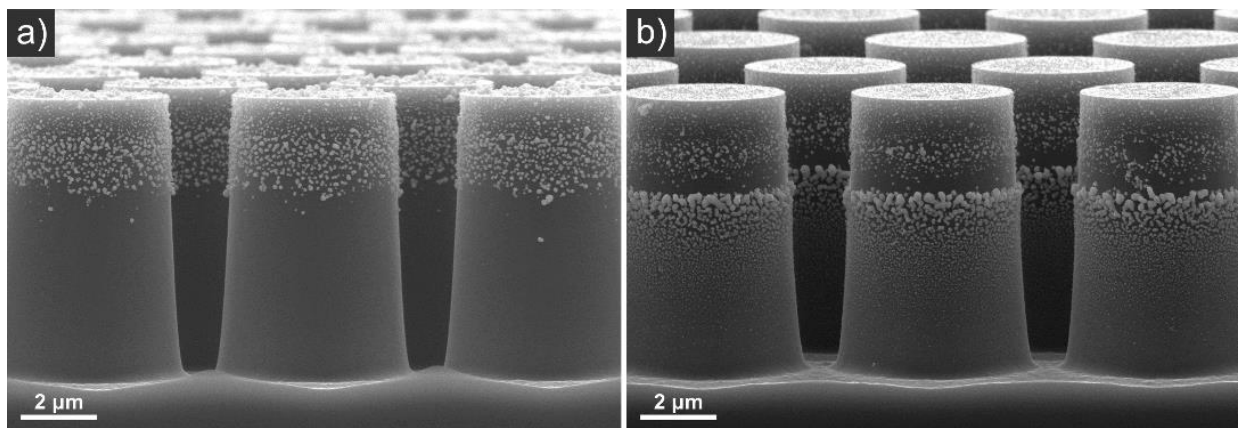

Figure 4.4 Cross-sectional SEM images of Si microwires with an axial $\mathrm{n}^{+} / \mathrm{p}$ junction after the electrodeposition of Ag particles at $25 \mathrm{mC} \mathrm{cm}^{-2}$ from a solution of $1 \mathrm{mM} \mathrm{AgNO}_{3}$ and $0.5 \mathrm{M} \mathrm{H}_{2} \mathrm{SO}_{4}$ at a) $+0.3 \mathrm{~V}$ under illumination and b) $-0.3 \mathrm{~V} \mathrm{vs.} \mathrm{Ag} / \mathrm{AgCl}(3 \mathrm{M} \mathrm{NaCl})$ in the dark.

To realize dually functionalized silicon microwires, we first performed the electrodeposition of platinum in the dark, followed by an immersion of the sample into a $1 \%$ aqueous HF solution (30s), and subsequently conducted the photo-induced electrodeposition of silver. This order (Figure 4.1, steps a-b) is necessary in this case, because Ag is galvanically replaced by Pt from the Pt precursor solution otherwise (Figure 4.11, Appendix). The reverse order (Figure 4.1, steps c-d) is therefore only possible when the second metal deposited is less noble than the first. Figure 4.5 shows cross-sectional SEM images of such bi-functionalized silicon microwires with an axial $n^{+} / p$ junction. The presence of silver on the top parts and platinum on the bottom parts of the microwires, shown in Figure 4.5a, was confirmed by SEM/EDX mapping (Figure 4.5b). The areas 
of a silicon microwire covered by Ag or Pt particles as a function of position from the pillar top was analyzed (Figure 4.13, Appendix), and the deposition boundary of silver was observed at $2.4 \mu \mathrm{m}$ and that of platinum at $3.3 \mu \mathrm{m}$ from the top of the microwire (Figure 4.5c and Figure 4.13, Appendix). In between the metalcovered areas, the microwires exhibit an unmodified band with a width of approx. $0.9 \mu \mathrm{m}$. In the following these observations will be discussed in more detail.
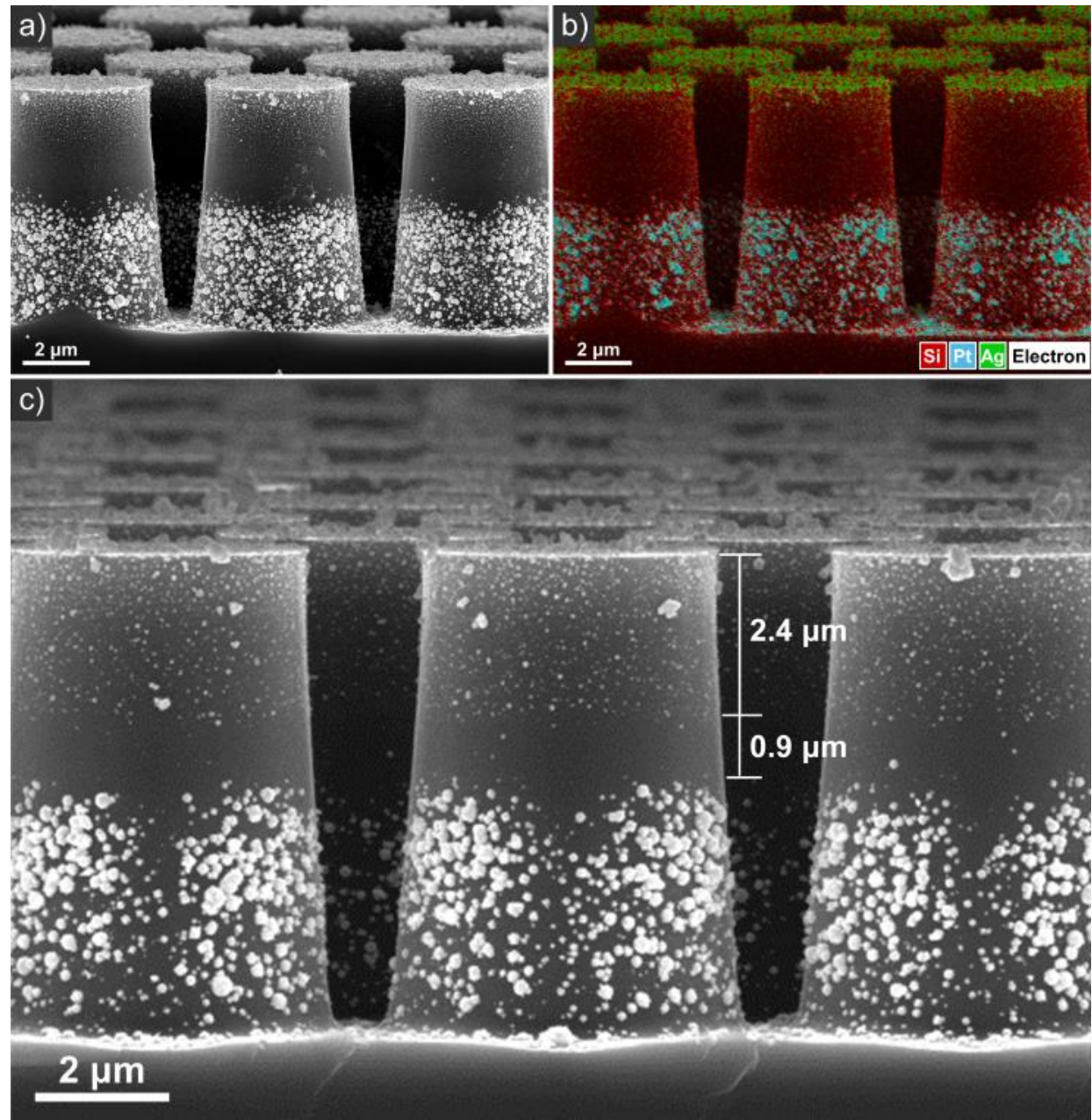

Figure 4.5 Cross-sectional SEM images $(a, c)$ and SEM/EDX mapping (b) of $\mathrm{Si}$ microwires with an axial $\mathrm{n}^{+} / \mathrm{p}$ junction after the electrodeposition of $\mathrm{Pt}$ particles at $-0.7 \mathrm{~V}$ vs. $\mathrm{Ag} / \mathrm{AgCl}(3 \mathrm{M} \mathrm{NaCl})$ and $130 \mathrm{mC} \mathrm{cm}^{-2}$ in the dark from a solution of $5 \mathrm{mM} \mathrm{H}_{2} \mathrm{PtCl}_{6}$ and $0.5 \mathrm{M} \mathrm{Na}_{2} \mathrm{SO}_{4}$, followed by the electrodeposition of $\mathrm{Ag}$ particles at $25 \mathrm{mC} \mathrm{cm}^{-2}$ under illumination from a solution of $1 \mathrm{mM} \mathrm{AgNO}_{3}$ in a,b) $0.005 \mathrm{M} \mathrm{H}_{2} \mathrm{SO}_{4}$ electrolyte at $-0.1 \mathrm{~V}$ vs. $\mathrm{Ag} / \mathrm{AgCl}(3 \mathrm{M} \mathrm{NaCl})$ and c) $0.5 \mathrm{M} \mathrm{Na}_{2} \mathrm{SO}_{4}$ electrolyte at $+0.3 \mathrm{~V}$ vs. $\mathrm{Ag} / \mathrm{AgCl}(3 \mathrm{M}$ $\mathrm{NaCl})$. 
The mechanism of the concept of dual functionalization of axially doped microwires and the occurrence of the unmodified band in between the metalcovered areas can be explained using the theory of a $\mathrm{p} / \mathrm{n}$ junction. Figure $4.6 \mathrm{a}$ shows band edges of a p-and highly n-doped silicon with its Fermi levels. Connecting the $\mathrm{p}$ - and n-type parts results in an electron flow from filled states in the $\mathrm{n}$-Si conduction band to empty states in the $\mathrm{p}$-Si valence band until the Fermi level of both silicon types equalizes. A depletion layer is thus formed, and this causes bending of the $\mathrm{p}-\mathrm{Si}$ and $\mathrm{n}-\mathrm{Si}$ bands (Figure 4.6b). The depleted areas in $\mathrm{n}$-Si and p-Si become positively and negatively charged, respectively. Due to the higher doping level of $\mathrm{n}-\mathrm{Si}$, the depletion layer penetrates mostly into $\mathrm{p}-\mathrm{Si}$.

\section{a}
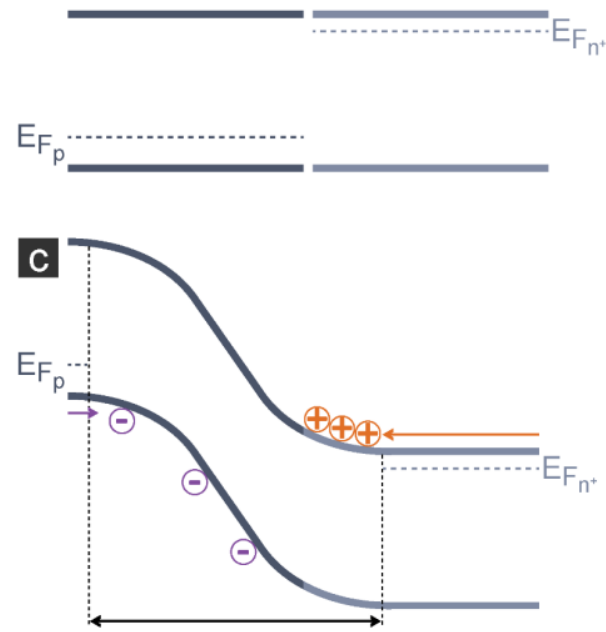

- p-Si band edge $\quad E_{F_{p}} \cdots p$-Si Fermi level

$-\mathrm{n}^{+}-\mathrm{Si}$ band edge

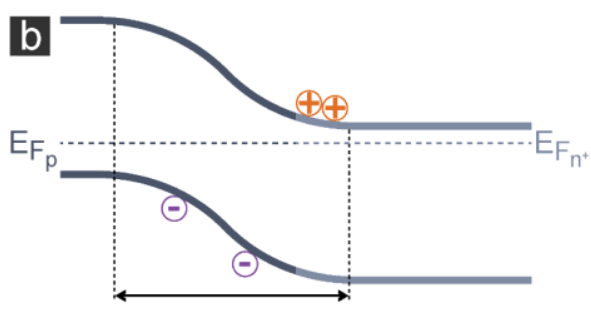

d

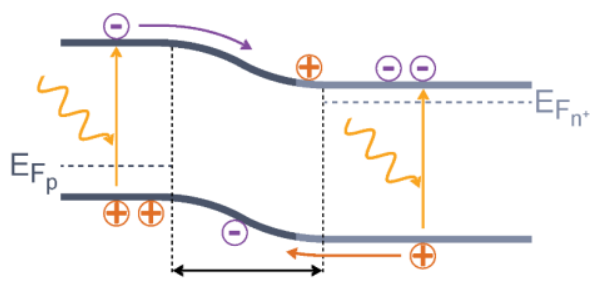

$\odot$ electron $\leftrightarrow$ depletion layer

$\oplus$ hole

Lip photoexcitation

Figure 4.6 Schematic illustration of $\mathrm{n}^{+} / \mathrm{p}-\mathrm{Si}$ band diagrams a) before contact, $\mathrm{b}$ ) in contact at equilibrium, c) reverse-biased, d) under illumination.

The orientation of the diode in our concept is such that it is reverse-biased when the base is put at a negative potential. Consequently, the potential barrier in the junction prevents a significant amount of electrons to pass the junction in the dark (Figure 4.6c). These electrons, supplied by an external source, occupy the empty states in the p-Si valence band and thereby enlarge the depletion layer into the bulk or migrate to the surface of the p-type semiconductor, where they induce its 
selective functionalization, i.e. the electrodeposition of platinum. We assume that in this case only electrons outside of the depletion layer are available for the reduction of Pt precursor at the silicon surface.

Upon illumination, photoexcited electrons drift across the junction from the $\mathrm{p}-\mathrm{Si}$ conduction band into the $\mathrm{n}^{+}-\mathrm{Si}$ conduction band while holes migrate from the $\mathrm{n}^{+}-\mathrm{Si}$ valence band to the $\mathrm{p}-\mathrm{Si}$ valence band due to the induced electric field. This diminishes the width of the depletion layer and leads to an accumulation of electrons in the $\mathrm{n}^{+}$-type part and of holes in the p-type material (Figure 4.6d). These accumulated electrons on the $\mathrm{n}^{+}-\mathrm{Si}$ side are subsequently used for the regioselective deposition of silver.

We hypothesize that the unmodified band originates from the depletion layer of the $\mathrm{n}^{+} / \mathrm{p}$ junction. The depletion layer width $(W)$ of an abrupt $\mathrm{n}^{+} / \mathrm{p}$ junction under equilibrium conditions, is given by Equation 4.1 including 4.2:

$$
\begin{gathered}
W=\sqrt{\frac{2 \varepsilon\left(N_{D}+N_{A}\right) \phi_{b i}}{q N_{D} N_{A}}} \\
\phi_{b i}=\frac{k_{B} T}{q} \ln \left(\frac{N_{D} N_{A}}{n_{i}^{2}}\right)
\end{gathered}
$$

in which $\varepsilon$ is the permittivity of the material $\left(1.034 \times 10^{-10} \mathrm{AsV}^{-1} \mathrm{~m}^{-1}\right.$ for $\left.\mathrm{Si}\right), N_{D}$ and $N_{A}$ are the donor and acceptor densities $\left(\mathrm{m}^{-3}\right), \phi_{b i}$ is the built-in potential (V), $q$ is the unit charge $\left(1.602 \times 10^{-19} \mathrm{C}\right), k_{B}$ is Boltzmann's constant $\left(1.3806 \times 10^{-23} \mathrm{JK}^{-}\right.$ $\left.{ }^{1}\right), T$ is the absolute temperature $(\mathrm{K})$ and $n_{i}$ is the intrinsic carrier concentration $\left(1.0 \times 10^{16} \mathrm{~m}^{-3}\right.$ at $300 \mathrm{~K}$ for $\left.\mathrm{Si}\right)$. The boron doping level, $N_{A}$, of the base wafer of the specimen was determined $\left(1.4 \times 10^{21} \mathrm{~m}^{-3}\right)$ by measuring its sheet resistance. The calculated depletion layer width depends only slightly on the heavily doped material. Based on secondary ion mass spectroscopy (SIMS) data of a phosphorus-doped specimen (Figure 4.7) we used $N_{D}$ doping levels in the range of $10^{22} \mathrm{~m}^{-3}$ to $10^{24} \mathrm{~m}^{-3}$ for calculations. Consequently, the expected depletion layer width in equilibrium ranges from $0.828 \mu \mathrm{m}$ to $0.841 \mu \mathrm{m}$, respectively. Any influences of the silicon/electrolyte junction and changes of the depletion layer width upon an applied reverse bias in the dark or under illumination are not considered, due to the unknown $I R$ drop caused by electron flow from $\mathrm{p}$-Si to the solution in the dark and to $\mathrm{n}^{+}$-Si under illumination. The values for the width of 
the depletion layer obtained by this simplified model correspond well with experimental observations of the width of the deposition-free zone, for which typically values of $0.9 \mu \mathrm{m}$ (Figure $4.5 \mathrm{c}$ ) were observed.

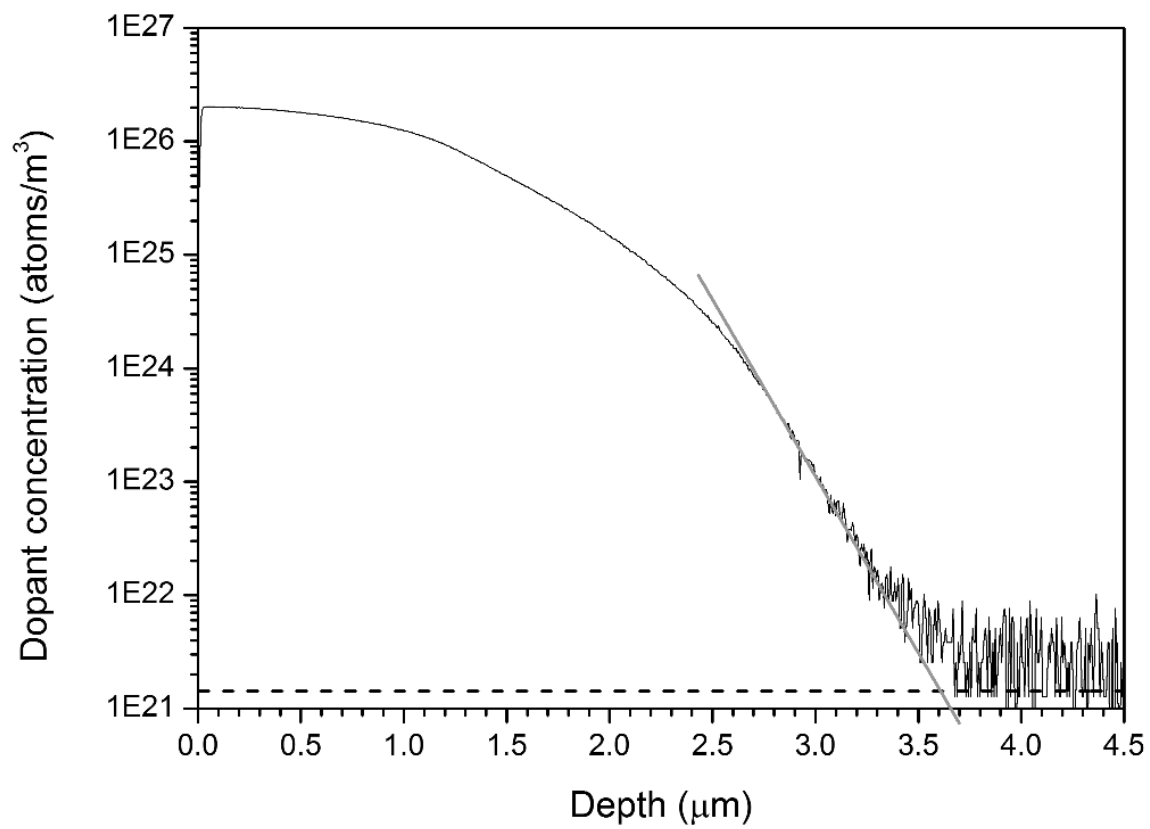

Figure 4.7 Secondary ion mass spectroscopy (SIMS) depth profile of the phosphorus dopant concentration in a boron-doped base silicon specimen with a concentration of $1.4 \times 10^{21}$ atoms $\mathrm{m}^{-3}$ (dashed line). The junction position is determined by extrapolation of the linear regime towards boron background doping concentration. Analyzed specimen is identical to the sample in Figure 4.5c.

According to the theory given above, the depletion layer is expected to penetrate mostly into the low-doped p-region, and therefore the junction should be positioned close to the top of the metal-free zone of the wires. In more quantitative detail, the estimated penetration depth of the depletion layer into the $\mathrm{n}^{+}$-Si side $\left(W_{n}\right)$ is in the range of $0.104 \mu \mathrm{m}$ to $0.001 \mu \mathrm{m}$, while the depths at the p-Si side $\left(W_{p}\right)$ amount to $0.724 \mu \mathrm{m}$ to $0.840 \mu \mathrm{m}$, using $N_{D}$ values of $10^{22} \mathrm{~m}^{-3}$ and $10^{24} \mathrm{~m}^{-3}$, respectively, calculated using the Equations 4.3 and 4.4:

$$
\begin{aligned}
& W_{n}=\frac{N_{A} W}{N_{A}+N_{D}} \\
& W_{p}=\frac{N_{D} W}{N_{A}+N_{D}}
\end{aligned}
$$


Based on the observed photoelectrochemical deposition of Ag at the top $2.4 \mu \mathrm{m}$ of the wires (Figure 4.5c), the junction is expected to be positioned at about the same height from the top of the microwires. To locate the junction position experimentally, we performed SIMS measurements (Figure 4.7), ball-grooving and staining of the junction of a doped flat wafer in $\mathrm{CrO}_{3} / \mathrm{HF}$ aqueous solution (Figure 4.8), and wet etching by the same staining solution of a microwired sample with an axial junction (Figure 4.9). The results are different: SIMS, ball-grooving and staining, and a diffusion model for predicting the doping profile at the drive-in settings used here ${ }^{[28]}$ indicate the junction to be located at approx. $3.6 \mu \mathrm{m}$ from the top. In contrast, wet etching of the doped microwires shows a transition at approx. $2.2 \mu \mathrm{m}$ from the top (Figure 4.9). In the latter case, however, a transition becomes visible due to a higher etch rate of $\mathrm{n}^{+}$-Si compared to $\mathrm{p}$-Si. Consequently, a small fraction is etched from the microwire top, suggesting that the transition is close to the Ag boundary at $2.4 \mu \mathrm{m}$ from microwire tops. However, this may not necessarily correspond with the position of the junction. Most data indicate therefore that the junction position is deeper than indicated by the position of the metal-free deposition band. The boundary of silver deposition in the dark was observed at the same location as for deposition under illumination, i.e. at $2.4 \mu \mathrm{m}$ from the microwire top (Figure 4.4). This is in stark contrast to the dark deposition of Pt (Figure 4.5). The difference in position of deposition between the two metals is not clear. We speculate that it might be due to electronic effects in the microwires. The formation of a Schottky contact between $\mathrm{Ag}$ and $\mathrm{p}-\mathrm{Si}$, of which the depletion layer partially overlaps with the $\mathrm{n}^{+} / \mathrm{p}$ junction, may reduce the $\mathrm{n}^{+} / \mathrm{p}$ junction depletion layer width at the microwires surface, thereby allowing Ag deposition up to the junction in the dark. Furthermore, silver deposition on the depletion layer of the $n^{+} / p$ junction may be caused by the attraction of the positively charged $\mathrm{Ag}^{+}$ions in solution to the negatively charged depleted layer in $\mathrm{p}-\mathrm{Si}$ (Figure 4.6b). In contrast, platinum ions are present as negatively charged $\left[\mathrm{PtCl}_{6}\right]^{2-}$ complexes ${ }^{[29]}$ and are repelled by the depleted layer in $\mathrm{p}-\mathrm{Si}$. 

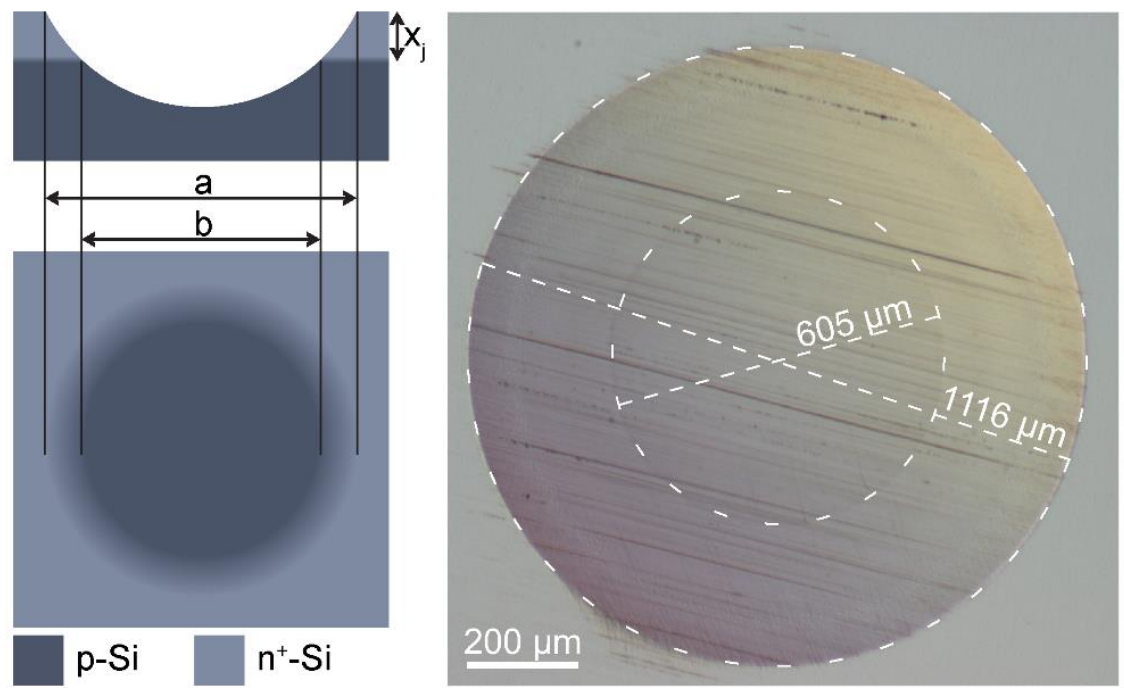

Figure 4.8 Determination of a junction depth by ball-grooving and staining. Schematic illustration of a cross-section and top-view of a stained groove on a flat surface (left) and optical microscopy image of a flat silicon sample with a $\mathrm{n}^{+} / \mathrm{p}$ junction after ball-grooving and staining in aqueous $\mathrm{CrO}_{3} / \mathrm{HF}$ solution for $25 \mathrm{~s}$ (right). The junction depth $\left(\mathrm{x}_{\mathrm{j}}\right)$ can be calculated by $x_{j}=\frac{a^{2}-b^{2}}{8 R}$ in which $\mathrm{R}$ is the radius of the ball $(30000 \mu \mathrm{m})$.

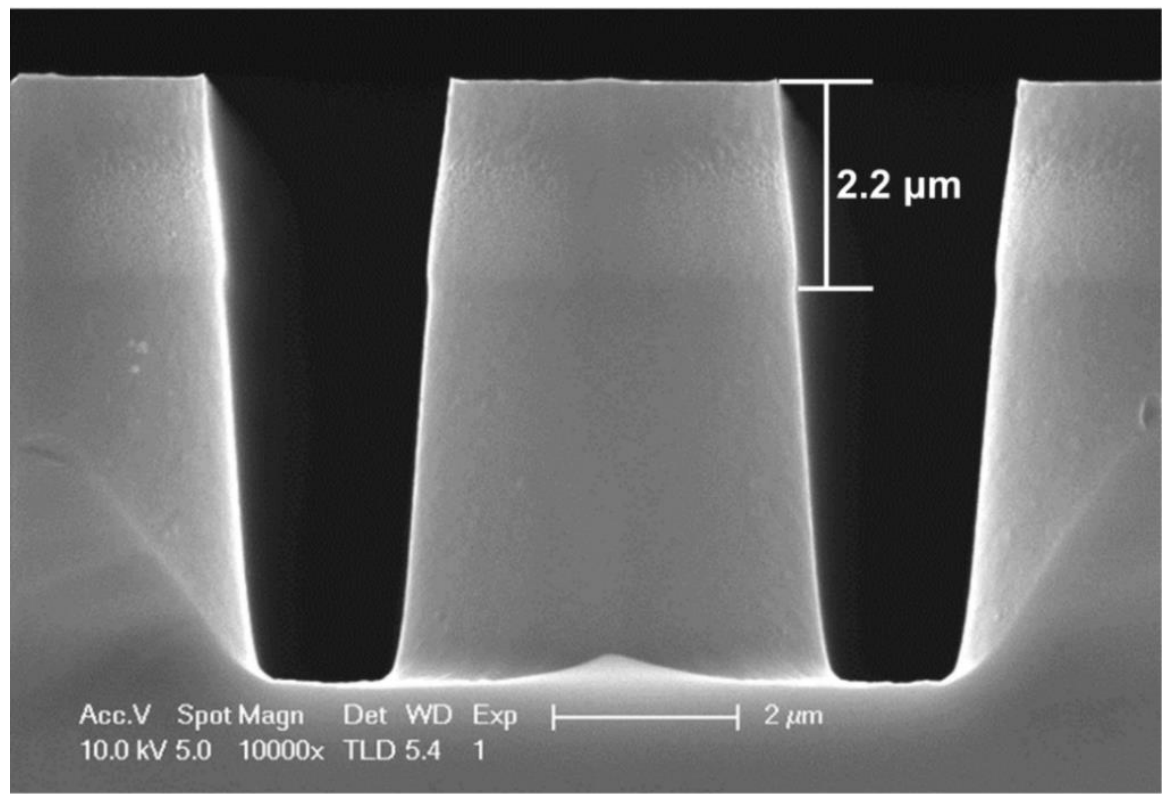

Figure 4.9 Cross-sectional SEM image of silicon microwires with an axial $\mathrm{n}^{+} / \mathrm{p}$ junction stained in $\mathrm{CrO}_{3} / \mathrm{HF}$ aqueous solution for $2 \mathrm{~min}$. 
To test whether the unmodified band is also observed when both deposition steps on the top and bottom segments of the axially doped wires are performed with the same metal, Pt deposition was performed under illumination. The same concentrations and electrochemical parameters were chosen as for deposition in dark. The applied potential of $-0.7 \mathrm{~V}$ vs. $\mathrm{Ag} / \mathrm{AgCl}(3 \mathrm{M} \mathrm{NaCl})$ is sufficiently negative to overcompensate the provided potential of the $\mathrm{n}^{+} / \mathrm{p}$ junction under illumination (Figure 4.14, Appendix) and thus deposition occurred on both top $\mathrm{n}^{+}-\mathrm{Si}$ and bottom p-Si segments simultaneously (Figure 4.15, Appendix). The particles deposited under illumination were much finer than in the dark, which is in agreement with literature. ${ }^{[30]}$ Two deposition boundaries were observed, at $2.3 \mu \mathrm{m}$ and $3.4 \mu \mathrm{m}$ from the top, with an unmodified band of $1.1 \mu \mathrm{m}$ in between (Figure 4.15, Appendix). The unmodified band is somewhat wider than for the Pt-Ag dually functionalized microwires. This can be attributed mainly to a higher applied reverse bias during deposition. Notably, the position of the metal-free zone is the same as for the bimetallic microwires, and the discrepancy with the data on the position of the junction remains, and cannot be attributed to the use of $\mathrm{Ag}$ or the two-step process used for the bimetallic wires. All in all, we conclude that the width of the metal-free band of the dually functionalized microwires corresponds well with the width of the depletion zone, but that the positions do not. The latter requires further investigation with different metals, different order of deposition steps, and different precursor ion charges, as well as modeling, to elucidate possible electronic effects.

\subsection{Conclusions}

In conclusion, we have developed a new method to spatioselectively functionalize semiconductor wires that have an axial $\mathrm{p} / \mathrm{n}$ junction, by exploiting the differences in electronic nature of differently doped segments in the dark and under illumination. We have demonstrated separate functionalization of the $\mathrm{n}^{+}$- and p-type segments of silicon microwires, as well as the combined dual functionalization, with electrochemically deposited platinum particles and photoelectrochemically deposited silver particles, respectively. The presence of an unmodified band between Pt particles deposited in the dark and $\mathrm{Ag}$ or Pt deposited under illumination has been observed. The position of the band relative 
to the junction depth is not fully clear, but its width agrees well with the width of the depletion zone around the junction. The finding of this phenomenon may help to improve fundamental understanding of interfaces between semiconductors, metals and electrolytes.

The here developed fabrication concept is highly selective, relatively simple and can potentially be applied to wires or wire arrays with semiconductorsemiconductor axial diode heterojunctions or metal-semiconductor Schottky junctions. Besides reductive electrodeposition of metals, any other reductive or electron-induced reaction, such as electrochemical grafting with organic molecules is potentially possible. Also, oxidative or electron-poor surface reactions are conceivable if an inverted junction is constructed and care is taken to prevent semiconductor surface oxidation. Thus, we believe that our method has great potential to improve the ability of creating micro-sized structures with complex compositions and engineer multifunctional devices and systems with new functions.

\subsection{Acknowledgements}

Rick Elbersen is acknowledged for discussions, preparation of microwires and assistance in (photo)electrochemical metal deposition. Roald Tiggelaar and Recep Kas are thanked for discussions, Robert Meijer for technical support, Mark Smithers for performing EDX imaging, and Philips Innovation Services in Eindhoven for SIMS analysis.

\subsection{References}

[1] N. P. Dasgupta, J. Sun, C. Liu, S. Brittman, S. C. Andrews, J. Lim, H. Gao, R. Yan, P. Yang, Adv. Mater. 2014, 26, 2137.

[2] E. L. Warren, H. A. Atwater, N. S. Lewis, J. Phys. Chem. C 2013, 118, 747.

[3] F. Patolsky, C. M. Lieber, Mater. Today 2005, 8, 20.

[4] A. I. Hochbaum, P. Yang, Chem. Rev. 2010, 110, 527.

[5] Y. Cui, Q. Wei, H. Park, C. M. Lieber, Science 2001, 293, 1289.

[6] Y. M. A. Yamada, Y. Yuyama, T. Sato, S. Fujikawa, Y. Uozumi, Angew. Chem. Int. Ed. 2014, 53, 127. 
[7] M. R. Shaner, K. T. Fountaine, S. Ardo, R. H. Coridan, H. A. Atwater, N. S. Lewis, Energy Environ. Sci. 2014, 7, 779.

[8] M. Y. Bashouti, K. Sardashti, S. W. Schmitt, M. Pietsch, J. Ristein, H. Haick, S. H. Christiansen, Prog. Surf. Sci. 2013, 88, 39.

[9] N. Gao, W. Zhou, X. Jiang, G. Hong, T.-M. Fu, C. M. Lieber, Nano Lett. 2015, 15, 2143.

[10] A. Walther, A. H. E. Müller, Chem. Rev. 2013, 113, 5194.

[11] Z. Jiang, Q. Qing, P. Xie, R. Gao, C. M. Lieber, Nano Lett. 2012, 12, 1711.

[12] A. M. Ionescu, H. Riel, Nature 2011, 479, 329.

[13] C.-Y. Wen, M. C. Reuter, J. Bruley, J. Tersoff, S. Kodambaka, E. A. Stach, F. M. Ross, Science 2009, 326, 1247.

[14] A. L. Vallett, S. Minassian, P. Kaszuba, S. Datta, J. M. Redwing, T. S. Mayer, Nano Lett. 2010, 10, 4813.

[15] M. Hocevar, G. Immink, M. Verheijen, N. Akopian, V. Zwiller, L. Kouwenhoven, E. Bakkers, Nat. Commun. 2012, 3, 1266.

[16] J. Motohisa, Y. Kohashi, S. Maeda, Nano Lett. 2014, 14, 3653.

[17] B. Tian, T. J. Kempa, C. M. Lieber, Chem. Soc. Rev. 2009, 38, 16.

[18] M. Yao, N. Huang, S. Cong, C.-Y. Chi, M. A. Seyedi, Y.-T. Lin, Y. Cao, M. L. Povinelli, P. D. Dapkus, C. Zhou, Nano Lett. 2014, 14, 3293.

[19] J. D. Christesen, X. Zhang, C. W. Pinion, T. A. Celano, C. J. Flynn, J. F. Cahoon, Nano Lett. 2012, 12, 6024.

[20] M. S. Gudiksen, L. J. Lauhon, J. Wang, D. C. Smith, C. M. Lieber, Nature 2002, 415, 617.

[21] C. Liu, J. Tang, H. M. Chen, B. Liu, P. Yang, Nano Lett. 2013, 13, 2989.

[22] S. W. Boettcher, E. L. Warren, M. C. Putnam, E. A. Santori, D. TurnerEvans, M. D. Kelzenberg, M. G. Walter, J. R. McKone, B. S. Brunschwig, H. A. Atwater, N. S. Lewis, J. Am. Chem. Soc. 2011, 133, 1216.

[23] Y. Qu, L. Liao, R. Cheng, Y. Wang, Y.-C. Lin, Y. Huang, X. Duan, Nano Lett. 2010, 10, 1941.

[24] T. Wang, H. Chen, K. Liu, S. Wang, P. Xue, Y. Yu, P. Ge, J. Zhang, B. Yang, ACS Applied Materials \& Interfaces 2015, 7, 376.

[25] T. Wang, H. Chen, K. Liu, Y. Li, P. Xue, Y. Yu, S. Wang, J. Zhang, E. Kumacheva, B. Yang, Nanoscale 2014, 6, 3846. 
[26] L. Mammen, K. Bley, P. Papadopoulos, F. Schellenberger, N. Encinas, H.J. Butt, C. K. Weiss, D. Vollmer, Soft Matter 2015, 11, 506.

[27] L. Guo, G. Oskam, A. Radisic, P. M. Hoffmann, P. C. Searson, J. Phys. D: Appl. Phys. 2011, 44, 443001.

[28] M. Uematsu, J. Appl. Phys. 1997, 82, 2228.

[29] C. R. K. Rao, D. C. Trivedi, Coord. Chem. Rev. 2005, 249, 613.

[30] Y. L. Kawamura, T. Sakka, Y. H. Ogata, J. Electrochem. Soc. 2005, 152, C701. 


\subsection{Appendix}

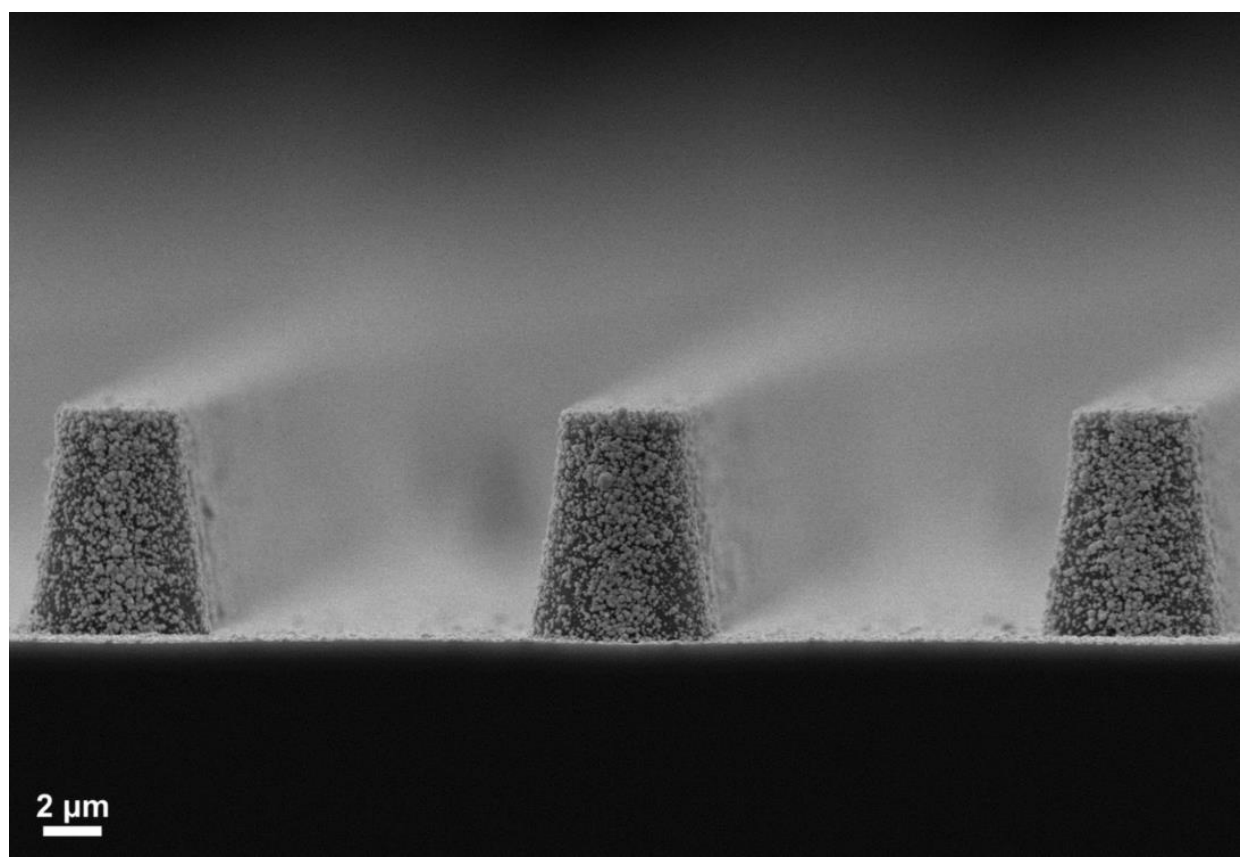

Figure 4.10 Cross-sectional SEM images of $\mathrm{p}$-Si microwires with a $16 \mu \mathrm{m}$ spacing after the electrodeposition of $\mathrm{Pt}$ particles at $-0.7 \mathrm{~V}$ vs. $\mathrm{Ag} / \mathrm{AgCl}(3 \mathrm{M} \mathrm{NaCl})$ and $130 \mathrm{mC} / \mathrm{cm}^{2}$ in the dark from a solution of $5 \mathrm{mM} \mathrm{H}_{2} \mathrm{PtCl}_{6}$ and $0.5 \mathrm{M} \mathrm{Na}_{2} \mathrm{SO}_{4}$.
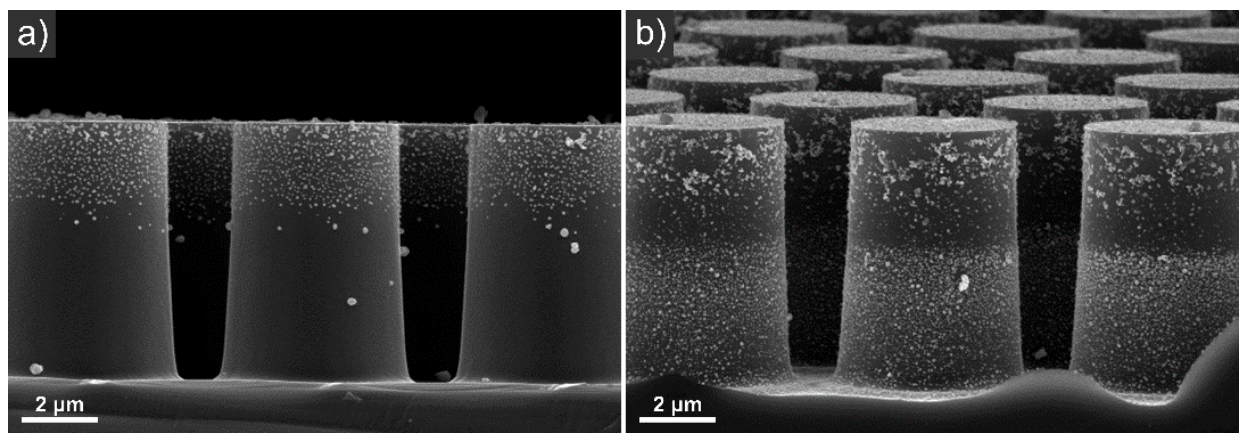

Figure 4.11 Cross-sectional SEM images of photo-supported electrodeposited Ag particles on top of $\mathrm{n}^{+}$segments of silicon microwires with an axial $\mathrm{n}^{+} / \mathrm{p}$ junction at $25 \mathrm{mC} \mathrm{cm}^{-2}$ from a solution of $1 \mathrm{mM} \mathrm{AgNO}_{3}$ and $0.5 \mathrm{M} \mathrm{H}_{2} \mathrm{SO}_{4}$ a) before and b) after $\mathrm{Pt}$ electrodeposition at $-0.7 \mathrm{~V}$ vs. $\mathrm{Ag} / \mathrm{AgCl}(3 \mathrm{M} \mathrm{NaCl})$ and $130 \mathrm{mC} \mathrm{cm}^{-2}$ in the dark from a solution of $5 \mathrm{mM} \mathrm{H}_{2} \mathrm{PtCl}_{6}$ and $0.5 \mathrm{M} \mathrm{Na}_{2} \mathrm{SO}_{4}$. 


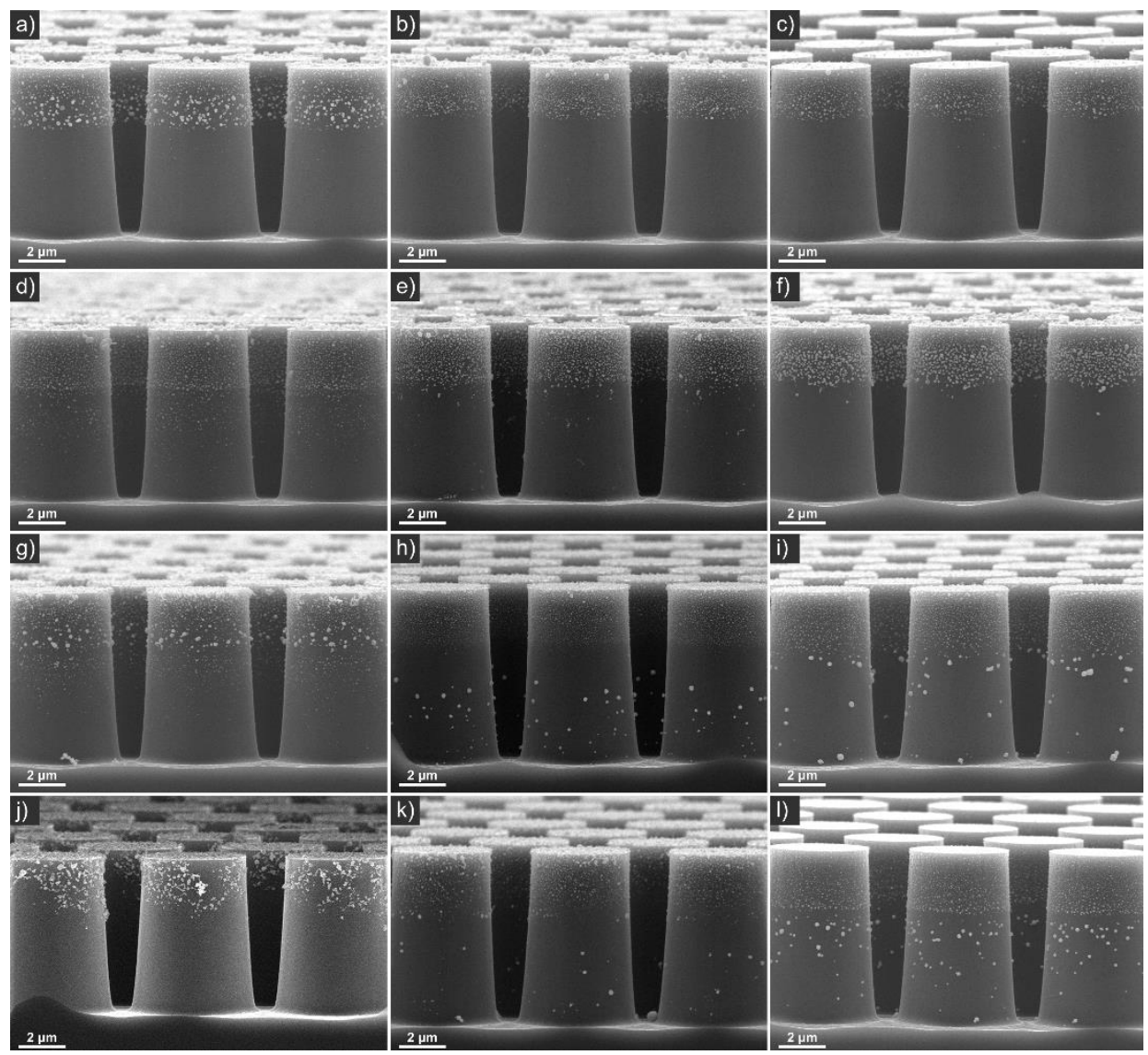

Figure 4.12 Cross-sectional SEM images of silicon microwires with axial $\mathrm{n}^{+} / \mathrm{p}$ junction after photo-supported $\mathrm{Ag}$ particles electrodeposited on top $\mathrm{n}^{+}$segments from a $1 \mathrm{mM}$ $\mathrm{AgNO}_{3}$ and $0.5 \mathrm{M} \mathrm{Na}_{2} \mathrm{SO}_{4}$ (left column, images a, d, g and $\mathrm{j}$ ), $0.005 \mathrm{M} \mathrm{H}_{2} \mathrm{SO}_{4}$ (middle column, images b, e, h, k) or $0.5 \mathrm{M} \mathrm{H}_{2} \mathrm{SO}_{4}$ (right column, images $\mathrm{c}, \mathrm{f}, \mathrm{i}, \mathrm{l}$ ) electrolytes at no applied external potential (first row, images a, b, c), $+0.3 \mathrm{~V}$ (second row, images d, e, f) $+0.1 \mathrm{~V}$ (third row, images $\mathrm{g}, \mathrm{h}, \mathrm{i}$ ) and $-0.1 \mathrm{~V}$ (fourth row, images $\mathrm{j}, \mathrm{k}, \mathrm{l}$ ). Applied potentials are vs. a $\mathrm{Ag} / \mathrm{AgCl}(3 \mathrm{M} \mathrm{NaCl})$ reference electrode. or $0 \mathrm{~V}$ vs. open circuit. Reaction was discontinued when passed charge densities reached $25 \mathrm{mC} \mathrm{cm}^{-2}$ at an applied potential or after $10 \mathrm{~min}$ at no external potential. 


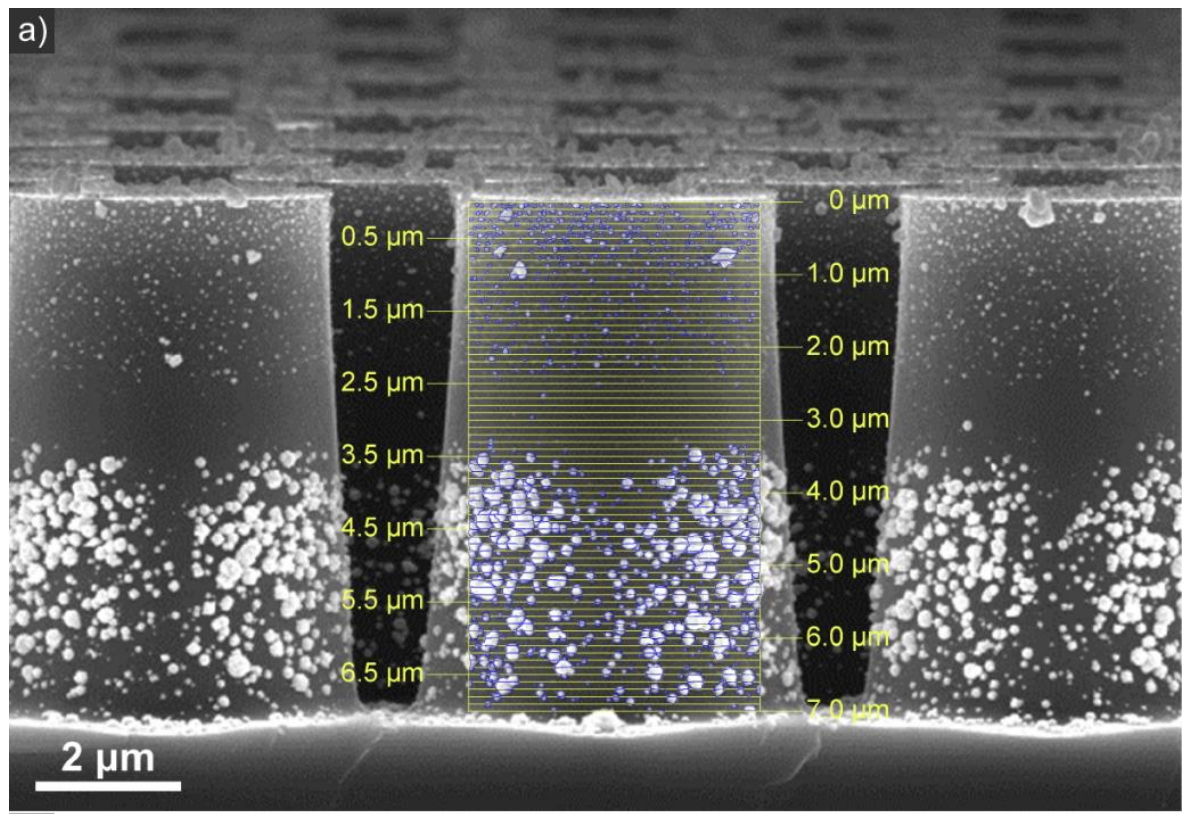

b)

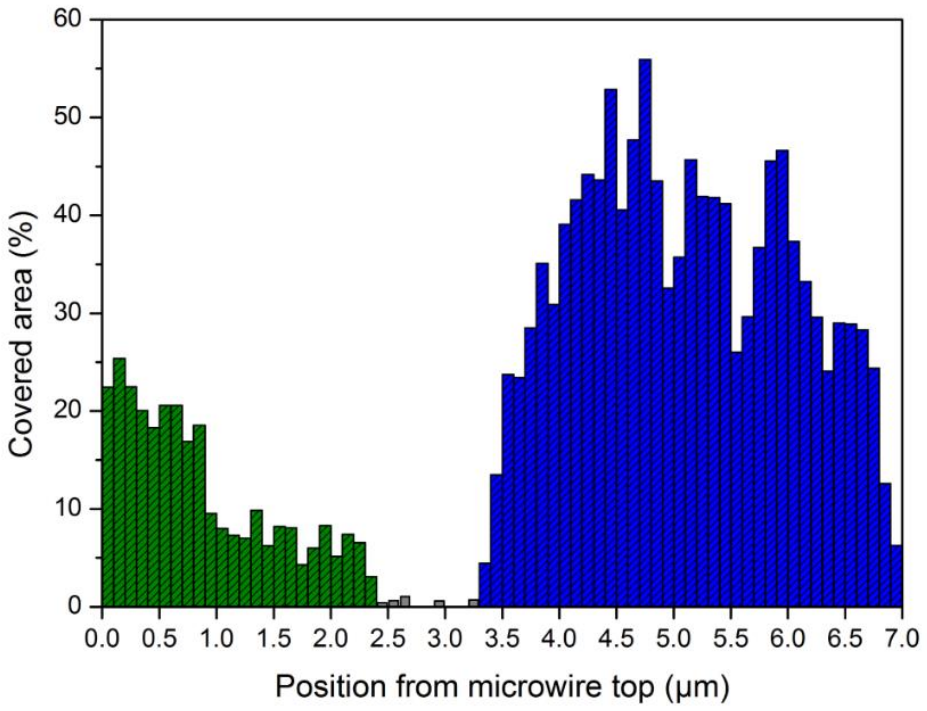

Figure 4.13 Analysis of covered area by metal particles along the microwire length. a) Rasterized cross-sectional SEM image of electrodeposited Pt particles in dark conditions on bottom p-Si segments and photo-supported electrodeposited Ag particles on top $\mathrm{n}^{+}-\mathrm{Si}$ segments of silicon microwires with an axial $\mathrm{n}^{+} / \mathrm{p}$ junction. The image is identical to Figure $4 \mathrm{c}$. Each raster is $0.1 \mu \mathrm{m}$ long and $4.0 \mu \mathrm{m}$ wide. Metal particle area was determined manually with the image processing program ImageJ. Obtained results are represented in the histogram b). Green bars correspond to $\mathrm{Ag}$, blue bars to Pt and gray bars to Pt or Ag particles. 


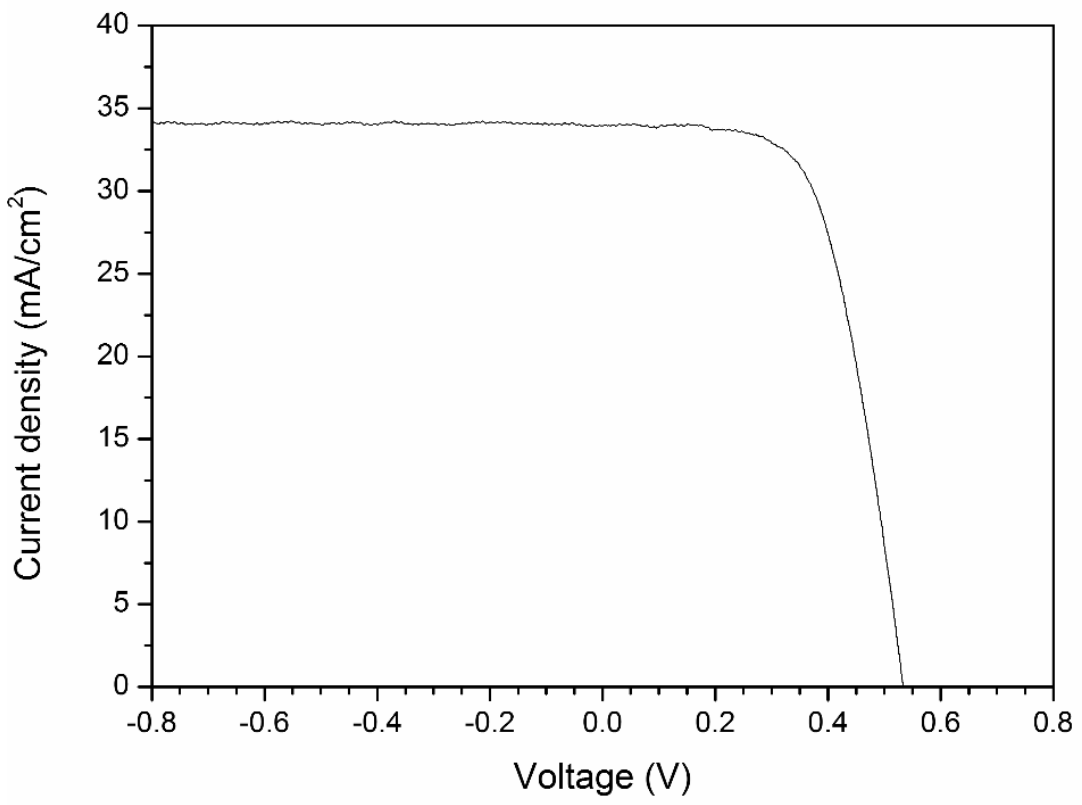

Figure 4.14 Current-voltage characteristics of a flat silicon specimen with a $\mathrm{n}^{+} / \mathrm{p}$ junction under illumination. Identical intensities ( 2 suns $\left(200 \mathrm{~mW} / \mathrm{cm}^{2}\right.$, AM 1.5) partially cut off with a $570 \mathrm{~nm}$ cut-on filter) were used as for photo-supported electrodeposition experiments.

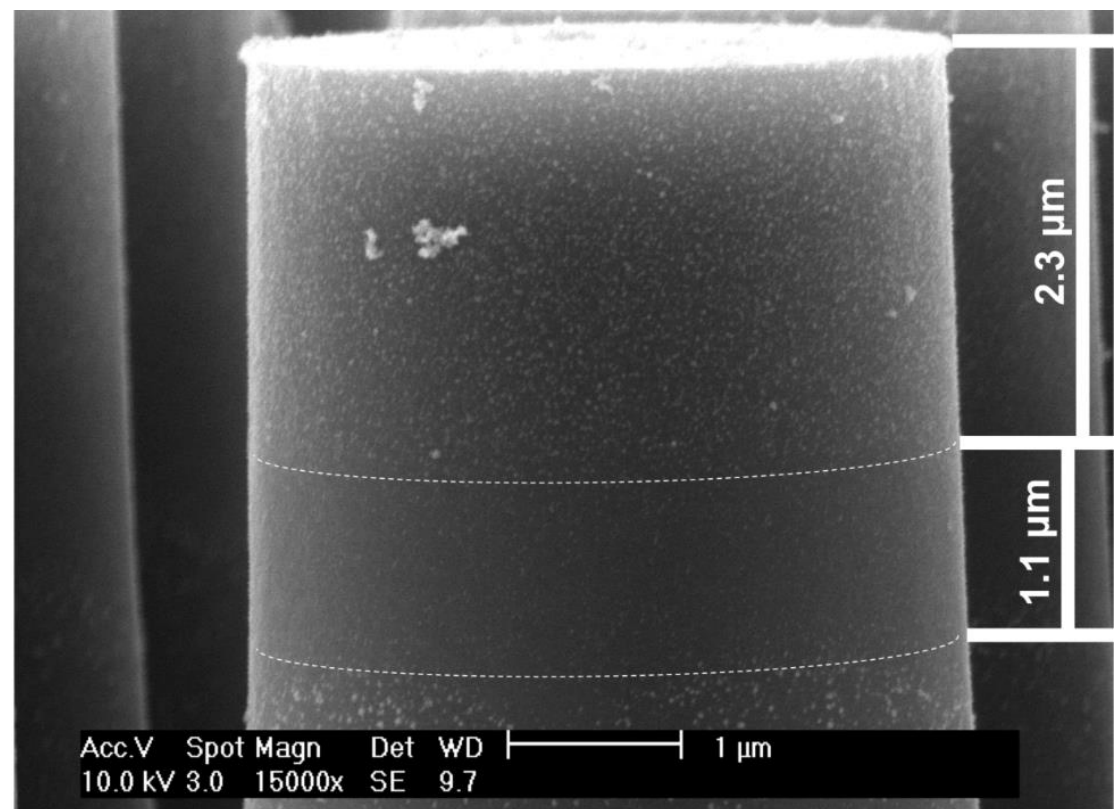

Figure 4.15 Cross-sectional SEM image of electrodeposited $\mathrm{Pt}$ particles under illumination at $-0.7 \mathrm{~V} v$ s. $\mathrm{Ag} / \mathrm{AgCl}(3 \mathrm{M} \mathrm{NaCl})$ from a solution of $5 \mathrm{mM} \mathrm{H}_{2} \mathrm{PtCl}_{6}$ and $0.5 \mathrm{M} \mathrm{Na}_{2} \mathrm{SO}_{4}$. 


\section{Chapter 5}

\section{$\mathrm{WO}_{3}$ photoanode deactivation during photoelectrochemical water oxidation}

$\mathrm{WO}_{3}$ photoanodes typically lose most of their photocatalytic activity within minutes to hours of operation in a photo-electrochemical cell, whereas lifetimes of 20 or more years are required for practical applications. Herein, we have investigated potential factors for this deactivation in (buffered) aqueous inorganic phosphate solutions as a function of $\mathrm{pH}$. The rate of the photocurrent decay was strongest in a solution of $\mathrm{pH} 1.0$, followed by $\mathrm{pH} 7.4, \mathrm{pH} 3.0$ and $\mathrm{pH}$ 5.0. At $\mathrm{pH}$ 7.4, morphology changes were observed in SEM images, and tungsten was found in the electrolyte, explaining deactivation. At lower $\mathrm{pH}$ the deactivation mechanism was different and was most significant at $\mathrm{pH}$ 1.0. Tungsten dissolution at $\mathrm{pH} 1.0$ and 3.0 was negligible. XPS results confirmed the surface of $\mathrm{WO}_{3}$ had altered insignificantly. At $\mathrm{pH} 1.0$ the deactivation was permanent and could neither be recovered by an interruption of illumination and applied bias, nor by rinsing with high-purity water and resting in air. At pH 3.0 and 5.0 a partial recovery induced by these interruptions was observed. We assume that the deactivation of $\mathrm{WO}_{3}$ photoanodes is due to a loss of number and/or activity of catalytic sites in the material with respect to water oxidation. This might be caused by the formation of peroxo species on the $\mathrm{WO}_{3}$ surface, although significant amounts of $\mathrm{H}_{2} \mathrm{O}_{2}$, potentially formed by incomplete water oxidation, were not detected in solution. 


\subsection{Introduction}

A promising, inexpensive and environmentally benign photoanode material for the oxidation of water is monoclinic $\mathrm{WO}_{3}{ }^{[1-3]}$ It has a single crystal electrical conductivity ranging between $10 \Omega^{-1} \mathrm{~cm}^{-1}$ to $10^{-4} \Omega^{-1} \mathrm{~cm}^{-1},{ }^{[4-6]}$ depending on stoichiometry, thus inherently good electron transport properties $\left(\sim 12 \mathrm{~cm}^{2} \mathrm{~V}^{-1} \mathrm{~s}^{-1}\right)$, a hole diffusion length of about $150 \mathrm{~nm},{ }^{[6]}$ and a reported indirect band gap between $2.6 \mathrm{eV}$ and $2.8 \mathrm{eV}^{[7-9]}$. Such band gap allows the absorption of light in the blue range of the visible spectrum. This translates to a theoretical solar to hydrogen efficiency of $4.8 \%$ and can be further increased by staging it with an additional lower band gap absorber, such as silicon. ${ }^{[10-12]}$

To be commercially applicable, a solar energy device has to operate for at least 20 years without a significant efficiency loss. However, $\mathrm{WO}_{3}$ photoanodes lose most of their photoactivity within minutes to hours of operation. Its reason is not fully understood. It has been proposed that competing oxidation reactions at the surface occur. ${ }^{[13-15]}$ The valence band edge position of $\mathrm{WO}_{3}$ is located at $2.97 \mathrm{~V}$ $v s$. NHE at $\mathrm{pH}=0^{[16]}$ and is thus sufficiently positive not only for the desired complete oxidation of water to $\mathrm{O}_{2}$ and $\mathrm{H}^{+}$(Eq. 5.1), but also for various other reactions, such as the formation of $\mathrm{H}_{2} \mathrm{O}_{2}$ (Eq. 5.2) or oxidation of the electrolyte. ${ }^{[13-15]}$ For instance, sulfates have been shown to oxidize to persulfates or chlorides to chlorine gas. ${ }^{[14,15]}$

$$
\begin{array}{ll}
2 \mathrm{H}_{2} \mathrm{O} \rightarrow \mathrm{O}_{2}+4 \mathrm{H}^{+}+4 \mathrm{e}^{-} & E^{\circ}=1.23 \mathrm{~V} \text { (Eq. 5.1) } \\
2 \mathrm{H}_{2} \mathrm{O} \rightarrow \mathrm{H}_{2} \mathrm{O}_{2}+2 \mathrm{H}^{+}+2 \mathrm{e}^{-} & E^{\circ}=1.78 \mathrm{~V} \text { (Eq. 5.2) }
\end{array}
$$

Best results to improve the long-term photocatalytic performance of $\mathrm{WO}_{3}$ photoanodes were achieved by treatment with hydrogen ${ }^{[17]}$ or covering the surface with a water oxidation catalyst such as $\mathrm{Co}-\mathrm{Pi},{ }^{[18]} \mathrm{IrO}_{2}{ }^{[19]}$ or $\mathrm{MnO}_{\mathrm{x}}{ }^{[20]}$. In the case of $\mathrm{Co}-\mathrm{Pi}$ and $\mathrm{IrO}_{2}$ rather thick layers were needed to achieve full protection and high oxygen yield. Such catalyst layers are unfavorable if $\mathrm{WO}_{3}$ is to be coupled with a lower band gap absorber, as they absorb the incident light either partially or completely. Thus, the origin of photocurrent loss of $\mathrm{WO}_{3}$ photoanodes during photocatalytic water oxidation needs to be found and 
$\mathrm{WO}_{3}$ photoanode deactivation during photoelectrochemical water oxidation

understood in order to stabilize the material and to provide long-term stability for dual- or multiple-junction-based $\mathrm{WO}_{3}$ systems.

Herein, we systematically examine the stability and performance of $\mathrm{WO}_{3}$ photoanodes in a potassium phosphate (KPi) buffer solution at $\mathrm{pH}$ 1.0, 3.0, 5.0 and 7.4 by measuring time-resolved oxygen and hydrogen evolution, $\mathrm{H}_{2} \mathrm{O}_{2}$ formation, and dissolution of tungsten into the electrolyte. Furthermore, possible changes of the surface morphology and composition, in particular the oxidation of $\mathrm{W}^{5+}$ surface sites, have been analyzed and evaluated.

\subsection{Materials and methods}

\subsubsection{Fabrication of Al,Si/p-Si/ITO substrate}

Highly boron-doped, p-type silicon substrates $(<100>$-oriented, resistivity $0.010 \Omega \mathrm{cm}-0.025 \Omega \mathrm{cm}, 100 \mathrm{~mm}$ diameter, $525 \mu \mathrm{m}$ thickness, single-side polished, Okmetic Finland) were cleaned by immersion in $100 \%$ nitric acid $\left(\mathrm{HNO}_{3}\right)(2 \times 5 \mathrm{~min})$ and in $69 \%$ nitric acid $(10 \mathrm{~min})$, followed by quick dump rinsing in de-mineralized (DI) water, immersion in a $1 \%$ aqueous hydrofluoric (HF) acid for at least $1 \mathrm{~min}$ to remove the formed oxide shell, washing by quick dump rinsing in de-mineralized (DI) water and spin drying. Subsequently, the backside was sputter-coated with a $1 \mu \mathrm{m}$ thick aluminum/silicon alloy (99\% $\mathrm{Al}$, $1 \% \mathrm{Si}$ ) (Oxford PL 400, $7000 \mathrm{~W}$ ) to create a low resistance Ohmic contact. Then, the front side was coated with indium tin oxide (ITO) in a home built reactive magnetron sputtering system (TCOater) in direct current (DC) mode, using a $90 \mathrm{wt} \% \mathrm{In}_{2} \mathrm{O}_{3}-10 \mathrm{wt} \% \mathrm{SnO}_{2}$ (99.99\%) target of 4.00 inch diameter. A DC power of $100 \mathrm{~W}$ was applied. The distance between the target and the substrate was kept at $44 \mathrm{~mm}$ and the substrate was rotated at $5 \mathrm{rpm}$ during the whole deposition process. The reactor chamber was pumped down to a base pressure of $5.0 \times 10^{-7}$ mbar prior to sputtering and a mix of $40 \mathrm{sccm} \mathrm{Ar}$ and $1 \mathrm{sccm} \mathrm{O} \mathrm{O}_{2}(99.5 \%)$ was introduced as reactive gas, and an $\operatorname{Ar}(99.99 \%)$ flow of $20 \mathrm{sccm}$ as sputtering gas, respectively. The process pressure was $5.0 \times 10^{-7} \mathrm{mbar}$ and the substrate temperature during deposition was maintained at $20^{\circ} \mathrm{C}$. Before ITO was sputtered on the wafer, a pre-sputtering was carried out under the same conditions for $1 \mathrm{~min}$ with a shutter covering the substrate. The deposition time was $5 \mathrm{~min}$. 
The ITO deposition rate was found to vary from $7 \mathrm{~nm} / \mathrm{min}$ in the center to $6 \mathrm{~nm} / \mathrm{min}$ at the edge on the horizontal part of the wafer.

\subsubsection{Electrodeposition of $\mathrm{WO}_{3}$}

The $\mathrm{WO}_{3}$ electrodeposition procedure was derived from the publication of Hill et $a l .{ }^{[15]} \mathrm{A} 0.1 \mathrm{M}$ peroxo-tungstic acid plating solution was made by first adding $1.838 \mathrm{~g}$ tungsten powder $(12 \mu \mathrm{m}, 99.9 \%$, Sigma Aldrich) in a $100 \mathrm{ml}$ volumetric flask. Then $3 \mathrm{ml}$ high-purity water (Millipore, MilliQ, $\mathrm{R}=18.2 \mathrm{M} \Omega \mathrm{cm}$ ), a small Teflon covered stirring bar and $6 \mathrm{ml}$ hydrogen peroxide solution $(\geq 35 \%$, Sigma Aldrich) were added and the flask was hanged into a cold water bath. Under stirring, the tungsten powder was dissolved completely overnight. To decompose excess of $\mathrm{H}_{2} \mathrm{O}_{2}$, a platinum mesh, which was platinized to further increase the decomposition rate, was added and stirred in the room temperature water bath. With our platinized Pt mesh, optimal time was 20 hours. To the resulting clear pale yellow solution $55.5 \mathrm{~g}(\bumpeq 50 \mathrm{ml})$ ethylene glycol ( $\geq 99.5 \%$, Sigma Aldrich) was added and the flask was filled up with high-purity water. After vigorous stirring, the solution was transferred to a glass jar while the platinized Pt mesh was removed. The jar was slowly heated to $45^{\circ} \mathrm{C}$ under stirring in a water bath. On each sample four layers were deposited potentiostatically in 2 subsequent potentials of $-0.6 \mathrm{~V}$ and $0.2 \mathrm{~V}$ for $60 \mathrm{~s}$ each $v s$. $\mathrm{Ag} / \mathrm{AgCl}(3 \mathrm{M} \mathrm{NaCl}$, BASi MF 2052) reference electrode. The custom-made Teflon-based reactor with a volume of about $8 \mathrm{ml}$ and a platinum mesh counter electrode was heated to $45^{\circ} \mathrm{C}$ in a water bath. A potentiostat (PAR, VersaStat 3) served as a power source for electrodeposition. The active silicon/ITO surface area was $3.14 \mathrm{~cm}^{2}$ as defined by the O-ring. After the deposition of each layer, the substrate was rinsed with high-purity water for $2 \mathrm{~min}$, gently blow-dried with an air gun and dried in a preheated oven at $120{ }^{\circ} \mathrm{C}$ for $30 \mathrm{~min}$ after deposition of layer 1 to 3 or annealed at $500{ }^{\circ} \mathrm{C}$ for $2 \mathrm{~h}$ at a heating rate of $2{ }^{\circ} \mathrm{C} / \mathrm{min}$ after deposition of layer 4 .

\subsubsection{Photoelectrochemical measurements}

Photoelectrochemical measurements of individual electrodes were performed in a custom-made Teflon-based reactor with a volume of about $8 \mathrm{ml}$ which was either connected to a gas chromatograph (GC) or open to the environment. 
Illumination occurred through a quartz glass window and $25 \mathrm{~mm}$ electrolyte (front-side illumination), and the incident beam was perpendicular to the specimen surface. A solar simulator (ABET technologies model 10500 low cost solar simulator, $5 \mathrm{~cm}^{2}$ beam area) with an air mass (AM) 1.5 spectrum was used as a light source. The intensity of the simulated sunlight was adjusted to 1 sun $\left(100 \mathrm{~mW} / \mathrm{cm}^{2}\right)$ with a standard reference silicon solar cell. The measurements were performed in a standard three-electrode setup with a platinum mesh counter electrode and a $\mathrm{Ag} / \mathrm{AgCl}$ (3 M NaCl, BASi MF 2052) reference electrode at room temperature. The reference electrode has a potential $\left(E_{\mathrm{Ag} / \mathrm{AgCl}}^{\mathrm{o}}\right)$ of $+0.209 \mathrm{~V}$ with respect to the standard hydrogen electrode (SHE) and was confirmed with a new $\mathrm{Ag} / \mathrm{AgCl}$ (3 M NaCl, BASi MF 2052) master reference electrode before measurements. All voltages reported were calculated versus the reversible hydrogen electrode (RHE) using the following Equation 5.3:

$E_{\mathrm{RHE}}=E_{\mathrm{Ag} / \mathrm{AgCl}}^{o}+0.059 \mathrm{~V} \times \mathrm{pH}+E_{\mathrm{Ag} / \mathrm{AgCl}}$

A $0.1 \mathrm{M}$ potassium phosphate (KPi) buffer solution with a $\mathrm{pH}$ of $1.0,3.0,5.0$ or 7.4 served as the electrolyte. $\mathrm{K}_{2} \mathrm{HPO}_{4}$ and $\mathrm{KH}_{2} \mathrm{PO}_{4}$ amounts were calculated with the Henderson-Hasselbalch equation, dissolved in high-purity water in a volumetric flask and precisely $\mathrm{pH}$ adjusted with concentrated $\mathrm{H}_{3} \mathrm{PO}_{4}$ or $\mathrm{KOH}$ solutions. A potential of $1.23 \mathrm{eV}$ vs. RHE was applied during photoelectrochemical measurements in which a potentiostat (PAR, VersaStat 3) served as a power source. The active surface areas were $1.13 \mathrm{~cm}^{2}$ as determined by the O-ring.

Electrochemical control experiments were performed with a Pt sputter coated highly doped silicon wafer by applying a current density of $1 \mathrm{~mA} / \mathrm{cm}^{2}$ in a $0.1 \mathrm{M}$ KPi solution ( $\mathrm{pH}$ 3.0) without (control 1) and with (control 2) saturated sodium persulfate $\left(\mathrm{Na}_{2} \mathrm{~S}_{2} \mathrm{O}_{8}\right)$.

\subsubsection{Gas chromatography (GC) analysis}

The gas composition during the photocatalytic reaction was measured with a highly sensitive gas chromatograph (CompactGC Interscience) equipped with a Pulsed Discharge Detector which allows the simultaneous detection of $\mathrm{H}_{2}, \mathrm{O}_{2}$ and $\mathrm{N}_{2}$. The headspace volume of the reactor was roughly $1 \mathrm{ml}$ and the electrolyte 
was constantly purged with helium $(7 \mathrm{~N})$ at a rate of $10 \mathrm{ml} / \mathrm{min}$. The gas composition was sampled by a $50 \mu \mathrm{l}$ loop, inserted onto a Q-bond column to remove $\mathrm{H}_{2} \mathrm{O}$ followed by a Molsieve $5 \AA$ column to separate the gaseous components.

Prior to the start of the experiment, the reactor including the sample and electrolyte was purged with helium $(10 \mathrm{ml} / \mathrm{min})$ for $1.5 \mathrm{~h}$ in the dark. The amount of oxygen leaked-in into the reactor was estimated by the leak-in of nitrogen and subtracted from the measured value. The correction factor was calculated from the $\mathrm{O}_{2} / \mathrm{N}_{2}$ ratio determined in the dark prior to the start of the experiment.

\subsection{5 $\mathrm{H}_{2} \mathrm{O}_{2}$ determination in the electrolyte}

After the photocatalytic measurements, part of the electrolyte was immediately taken and analyzed for the presence of peroxo species. Two methods, the permanganate method and the LabAssay ${ }^{\mathrm{TM}}$ Glucose method were utilized. Both procedures were derived from the publication of Daskalaki et al. ${ }^{[21]}$

In the permanganate method, $1 \mathrm{ml}$ of concentrated $\mathrm{H}_{3} \mathrm{PO}_{4}$ (85 wt.\%, Sigma Aldrich) was added to $2 \mathrm{ml}$ electrolyte solution and stirred in a small glass vial. Then, $100 \mu \mathrm{l}$ of a $20 \mathrm{mM} \mathrm{KMnO}_{4}$ standard solution (ACS reagent, $\geq 99.0 \%$, Sigma Aldrich) and $2 \mathrm{ml}$ of high-purity water were added and the solution stirred vigorously. Finally, the solution absorption was measured at $525 \mathrm{~nm}$ with a UV-Vis spectrophotometer (Thermo Scientific, Evolution 600). Always, two experiments were run in parallel of which one had $1 \mathrm{ml}$ of used sample electrolyte solution from the photocatalytic measurement and the other fresh reference electrolyte solution. The purpose of the reference solution was to eliminate any lamp intensity variation between preparing the standard curve and the sample measurement. The absorption intensity of the sample solution was adjusted by the factor of the deviation between reference solution and $20 \mathrm{mM} \mathrm{KMnO}_{4}$ calibration solution. For the calibration, solutions with $\mathrm{KMnO}_{4}$ concentrations of $20,16,12,8,4,1.6,0.8,0.4,0.16,0.08$ and $0.00 \mathrm{mM}$ (high-purity water) were prepared by diluting the $20 \mathrm{mM} \mathrm{KMnO}_{4}$ standard solution. The standard curves in different electrolyte $\mathrm{pH}$ are plotted in Figure 5.1a. All glassware was treated with aqua regia (mixture of nitric acid and hydrochloric acid), rinsed well with high-purity water and dried prior of use to remove all oxidizable substances. The 
amount of $\mathrm{H}_{2} \mathrm{O}_{2}$ in electrolyte solution was calculated according to the stoichiometry of the redox reaction 5.4.

$5 \mathrm{H}_{2} \mathrm{O}_{2}+2 \mathrm{MnO}_{4}^{-}+6 \mathrm{H}^{+} \rightarrow 5 \mathrm{O}_{2}+2 \mathrm{Mn}^{2+}+8 \mathrm{H}_{2} \mathrm{O}$

$\mathrm{H}_{2} \mathrm{O}_{2}$ is known to reduce $\mathrm{MnO}_{4}{ }^{-}$in an acidic solution which leads to a decrease in $\mathrm{MnO}_{4}{ }^{-}$concentration in solution and thus its absorption.
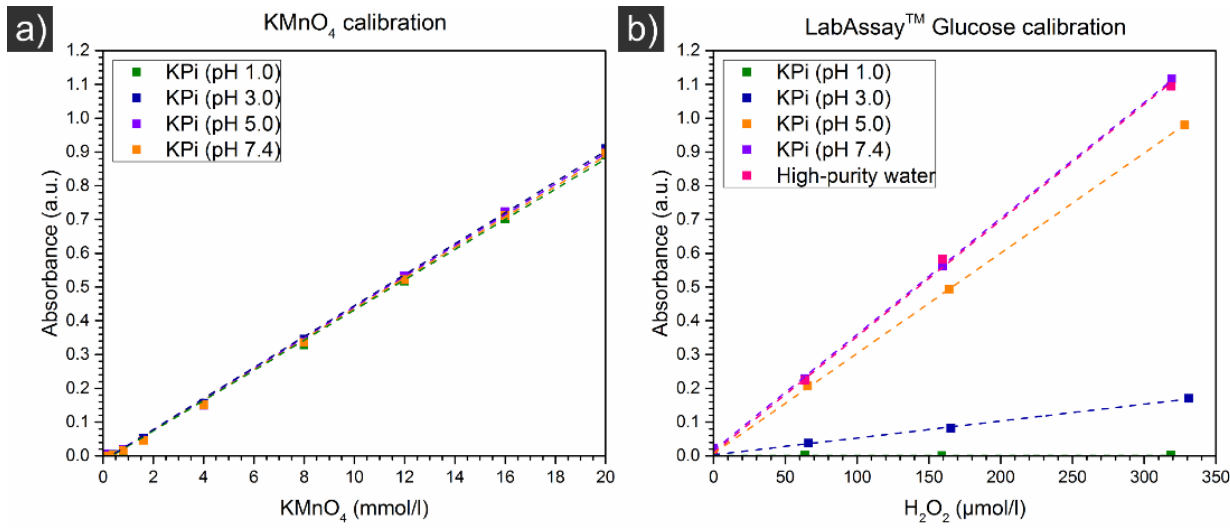

Figure 5.1 Standard calibration curves of the a) $\mathrm{KMnO}_{4}$ method and b) LabAssay ${ }^{\mathrm{TM}}$ Glucose method.

In the LabAssay ${ }^{\mathrm{TM}}$ Glucose method, the reagent was prepared by mixing 1 vial of Chromogen reagent with $150 \mathrm{ml}$ of buffer solution from the kit and kept always in the fridge in the dark. To determine the $\mathrm{H}_{2} \mathrm{O}_{2}$ concentration, $1 \mathrm{ml}$ of the reagent was added to $3 \mathrm{ml}$ of electrolyte solution in a small glass vial which was then transferred to a $37{ }^{\circ} \mathrm{C}$ warm water bath and kept there for $300 \mathrm{~s}$ under gentle stirring. Finally, the solution absorption was measured at $505 \mathrm{~nm}$ with a UV-Vis spectrophotometer (Thermo Scientific, Evolution 600). Also here, always 2 experiments were run in parallel of which one had $3 \mathrm{ml}$ of used sample electrolyte solution from the photocatalytic measurement and one fresh reference electrolyte solution. The reference solution was used as a blank to determine the background absorption. For the calibration, solutions of $\mathrm{H}_{2} \mathrm{O}_{2}$ (purum p.a., $\geq 35 \%$, Sigma Aldrich) diluted 2.500x, 10.000x, 50.000x, 100.000x, 250.000x with the electrolyte solution and pure electrolyte solution were used. The exact amount of $\mathrm{H}_{2} \mathrm{O}_{2}$ in these solutions was determined with the permanganate method. The standard curves in different electrolyte $\mathrm{pH}$ are plotted in Figure 5.1b. 


\subsubsection{Metal determination in electrolyte}

Metal traces in the electrolyte after photoelectrochemical measurements were determined with a Perkin Elmer 8300dv inductively coupled plasma optical emission spectrometer (ICP-OES) at wavelengths of $207.912 \mathrm{~nm}$ and $239.708 \mathrm{~nm}$.

\subsubsection{Scanning electron microscopy (SEM)}

High-resolution scanning electron microscopy (HR SEM) images were taken with a FEI Sirion FEG SEM with a Through the Lens Detector (TLD), operated at acceleration voltages of $10 \mathrm{kV}$.

\subsubsection{X-ray powder diffraction (XRD)}

X-ray diffraction patterns were determined with a Bruker D2 PHASER XRD using $\mathrm{Cu} \mathrm{K} \alpha$ radiation at an acceleration voltage of $30 \mathrm{kV}$. The reference used to determine the monoclinic phase of $\mathrm{WO}_{3}$ was JCPDS no. 43-1035.

\subsubsection{Raman spectroscopy}

Raman spectra were collected at ambient conditions by using a Bruker SENTERRA Raman Spectrometer equipped with a $532 \mathrm{~nm}$ laser and a cooled CCD detector. Measurements were performed at $10 \mathrm{~mW}$ laser power intensity and integration times of $2.0 \mathrm{~s}$.

\subsubsection{X-ray photoelectron spectroscopy (XPS)}

X-ray photoelectron spectroscopy measurements were performed using Quantera SXM (scanning XPS microprobe) from Physical Electronics equipped with an $\mathrm{Al}$ $\mathrm{K} \alpha$ monochromatic $(1486.6 \mathrm{eV}) \mathrm{X}$-ray source. The X-ray beam diameter had a radius of $200 \mu \mathrm{m}$ and $50 \mathrm{~W}$ power. The chamber was pumped down to a base pressure below $5 \times 10^{-10}$ Torr and operated at a pressure of $\sim 3 \times 10^{-8}$ Torr. The analyzed spectra are averages of three single measurements at different locations on the sample. A Shirley-type background was subtracted from the spectrum prior to peak deconvolution and the energy scale was calibrated against adventitious carbon binding energy of $284.8 \mathrm{eV}$. 
$\mathrm{WO}_{3}$ photoanode deactivation during photoelectrochemical water oxidation

\subsection{Results and discussion}

Photoanodes were prepared by the cathodic electrodeposition of $\mathrm{WO}_{3}$ films on a p-Si/ITO substrate from a peroxotungstic acid/ethylene glycol solution, followed by annealing at $500{ }^{\circ} \mathrm{C}$ in air. The deposition was performed in four steps in which a thin $\mathrm{WO}_{3}$ layer was grown, subsequently rinsed with high-purity water for $2 \mathrm{~min}$, gently blow-dried with an air gun and dried at $120^{\circ} \mathrm{C}$ for $30 \mathrm{~min}$. The division of the deposition in four steps was necessary to avoid cracking, flake formation, lift off and thus loss of electrical contact to the substrate upon dehydration. ${ }^{[14,22]}$ Every step consisted of a $60 \mathrm{~s}$ deposition at $-0.6 \mathrm{~V} v$ s. $\mathrm{Ag} / \mathrm{AgCl}$ ( $3 \mathrm{M} \mathrm{NaCl}$ ) followed a $60 \mathrm{~s}$ anodization at $0.2 \mathrm{~V}$ vs. $\mathrm{Ag} / \mathrm{AgCl}(3 \mathrm{M} \mathrm{NaCl})$. The coating had a blue color after the cathodic deposition step which is attributed to a d-d transition of partially formed $\mathrm{W}^{5+}$ in the film. ${ }^{[15]}$ The blue color disappeared during the following anodization step. After annealing, the resulting films were smooth, $2.8 \mu \mathrm{m}$ thick, and porous, and they adhered well to the substrate (Figure $5.2 \mathrm{c}, \mathrm{d}, \mathrm{e})$.

The XRD pattern (Figure 5.2a) of the $\mathrm{WO}_{3}$ layers after calcination shows that the phase is purely monoclinic with highly crystalline particles. The crystallites have a mean size of $47 \mathrm{~nm}$ as calculated from the Scherrer equation using 0.94 for the shape factor. The Raman spectrum (Figure 5.2b) also indicates a high crystallinity with well-resolved peaks and confirms the presence of the monoclinic $\mathrm{WO}_{3}$ phase by following the vibration assignments of Daniel et al. ${ }^{[23]}$ Also here, no coexistence of the hexagonal phase, which is the second stable $\mathrm{WO}_{3}$ phase at room temperature, was observed. However, a small fraction of $\mathrm{WO}_{3}$ was found to be hydrated. ${ }^{[23]}$ Furthermore, weak peaks at $292 \mathrm{~cm}^{-1}, 348 \mathrm{~cm}^{-1}, 418 \mathrm{~cm}^{-1}$ and $577 \mathrm{~cm}^{-1}$ indicate that a small amount of $\mathrm{WO}_{3-\mathrm{x}}$ with $\mathrm{W}^{5+}$ was present. ${ }^{[24]}$ No peaks are observed at frequencies higher than $1000 \mathrm{~cm}^{-1}$ which indicates that the samples presented in this chapter are free of hydrocarbon impurities. This is particularly important as the oxidation of hydrocarbons on the photoanode surface could contribute to parasitic photocurrents by producing oxidized hydrocarbons or $\mathrm{CO}_{2}$. In our initial experiments we rinsed the electrodes for a few seconds with high-purity water instead of 2 min after every electrodeposition step and annealed them for $1 \mathrm{~h}$ instead of $2 \mathrm{~h}$ at $500{ }^{\circ} \mathrm{C}$. In these samples we observed a much lower oxygen yield, hydrocarbon peaks in the chromatogram 
and photocurrent densities of around $1 \mathrm{~mA} / \mathrm{cm}^{2}$ which were significantly higher than the values presented in this chapter. Typically, photoanodes are characterized in literature based on their photocurrents without analyzing the composition of gases. Their results may also have too high reported photocurrents since competing hydrocarbon oxidation is thermodynamically more favorable than water oxidation.

a)

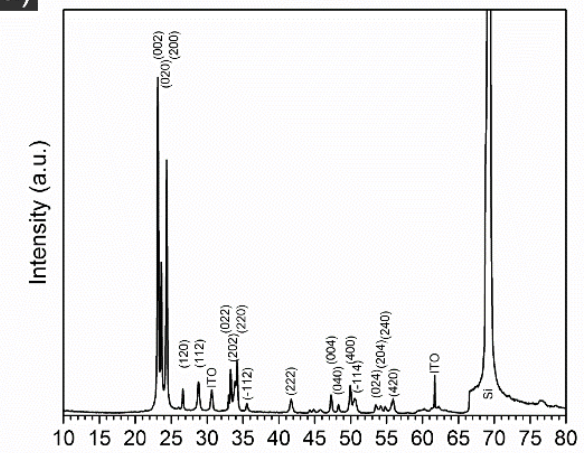

$2 \theta\left({ }^{\circ}\right)$

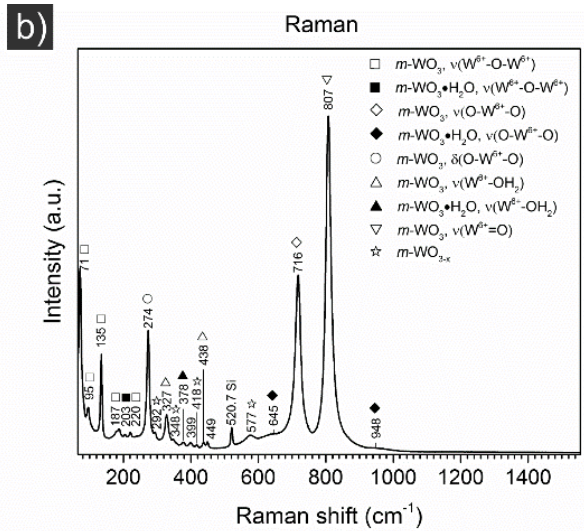

d)

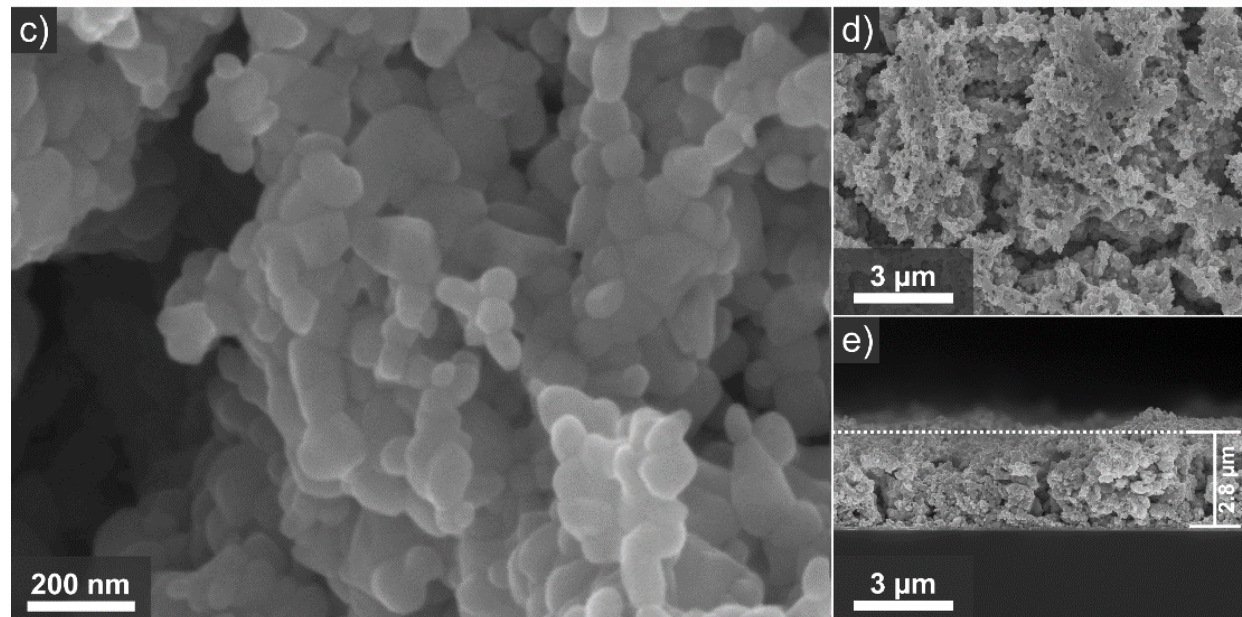

Figure 5.2 a) XRD pattern, b) Raman spectrum, c, d) top view SEM image and e) cross-sectional SEM image of a $\mathrm{WO}_{3}$ photoanode after electrodeposition and thermal annealing.

Figure 5.3 shows chronoamperometry measurements and corresponding $\mathrm{H}_{2}$ and $\mathrm{O}_{2}$ evolution of $\mathrm{WO}_{3}$ photoanodes under simulated $100 \mathrm{~mW} / \mathrm{cm}^{2} \mathrm{AM} 1.5$ solar illumination in $0.1 \mathrm{M}$ potassium phosphate (KPi) buffer solution with a $\mathrm{pH}$ of 1.0, 3.0, 5.0 and 7.4 at an applied bias of $1.23 \mathrm{~V} v s$. RHE over $5 \mathrm{~h}$ followed by shutting 

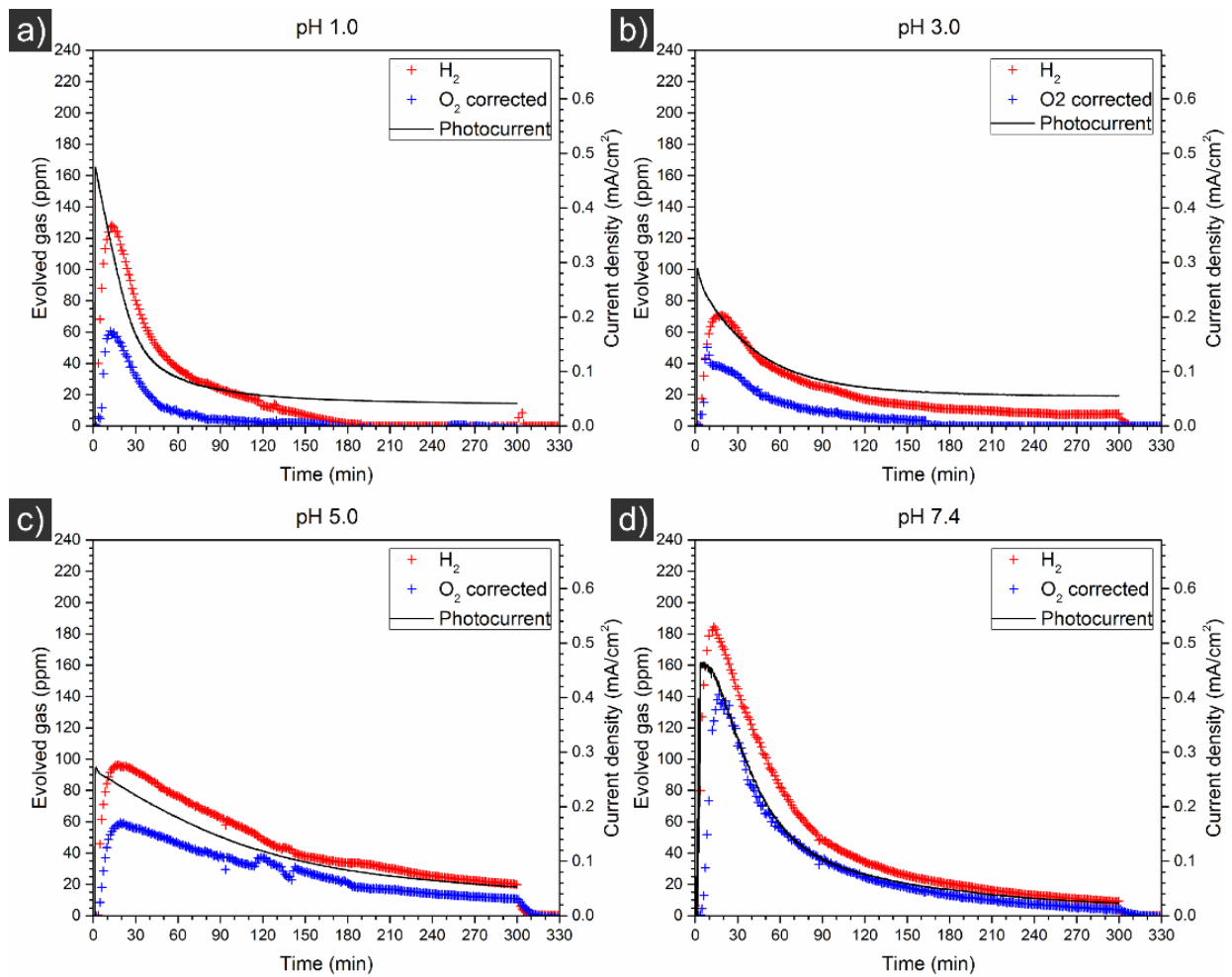

Figure 5.3 Photocurrent stability tests of $\mathrm{WO}_{3}$ photoanodes at $1.23 \mathrm{~V} v s$. RHE in $0.1 \mathrm{M}$ KPi buffer at a pH of a) 1.0 , b) 3.0, c) 5.0 and d) 7.4 under $100 \mathrm{~mW} / \mathrm{cm}^{2} \mathrm{AM} 1.5$ simulated solar illumination. $\mathrm{H}_{2}, \mathrm{O}_{2}$ and $\mathrm{N}_{2}$ gases were collected by a constant He purge of $10 \mathrm{ml} / \mathrm{min}$ through the reactor, separated with a GC and detected with a Pulsed Discharge Detector. The leak-in of $\mathrm{O}_{2}$ into the reactor was estimated from the measured amount of $\mathrm{N}_{2}$ and subtracted from the total $\mathrm{O}_{2}$ amount. The two vertical axes are aligned such that the current density represents the theoretical amount of $\mathrm{O}_{2}$ produced at the photoanode assuming $100 \%$ faradaic efficiency.

off the applied potential for $0.5 \mathrm{~h}$. Shorter reaction times of $0.5 \mathrm{~h}, 1 \mathrm{~h}$ and $2 \mathrm{~h}$ are shown in the Appendix (Figure 5.12, 5.15 and 5.18). Both $\mathrm{H}_{2}$ and $\mathrm{O}_{2}$ production followed the current densities with a slight delay of roughly $8 \mathrm{~min}$ at a lower level than theoretically calculated. The delay between produced and detected gases is attributed to the $70 \mathrm{~s}$ measurement processing time of the GC and saturation of the electrolyte with $\mathrm{H}_{2}$ and $\mathrm{O}_{2}$. The initial photocurrent density ranged between $0.35 \mathrm{~mA} / \mathrm{cm}^{2}$ and $0.60 \mathrm{~mA} / \mathrm{cm}^{2}$ in $\mathrm{pH} 1.0,0.22 \mathrm{~mA} / \mathrm{cm}^{2}$ and $0.33 \mathrm{~mA} / \mathrm{cm}^{2}$ in solution of $\mathrm{pH} 3.0,0.27 \mathrm{~mA} / \mathrm{cm}^{2}$ and $0.47 \mathrm{~mA} / \mathrm{cm}^{2}$ in $\mathrm{pH} 5.0$ and $0.22 \mathrm{~mA} / \mathrm{cm}^{2}$ and $0.46 \mathrm{~mA} / \mathrm{cm}^{2}$ in $\mathrm{pH} 7.4$ across all experiments. The observed high fluctuations in the starting photocurrent does not allow a reliable judgement but 
suggests that the electrolyte $\mathrm{pH}$ does not have a systematic influence on the starting photocurrent of $\mathrm{WO}_{3}$ photoanodes. The origin of these fluctuations is not known. All presented samples in this chapter were from the same batch and did not show any fluctuation during electrodeposition of $\mathrm{WO}_{3}$ on ITO-covered silicon substrates (Figure 5.21, Appendix). The relative rate of the photocurrent decay was the strongest at $\mathrm{pH} 1.0$, followed by $\mathrm{pH} 7.4, \mathrm{pH} 3.0$ and $\mathrm{pH} 5.0$, when compared at normalized photocurrent densities (Figure 5.11, Appendix). The photocurrent density seemed to level off to a plateau value at $0.04 \mathrm{~mA} / \mathrm{cm}^{2}$ in $\mathrm{pH} 1.0$ and at $0.05 \mathrm{~mA} / \mathrm{cm}^{2}$ in $\mathrm{pH} 3.0$ without contributing to measurable oxygen production, while the photocurrent at $\mathrm{pH} 5.0$ and $\mathrm{pH} 7.4$ seemed to keep decreasing towards zero. The accumulated amounts of $\mathrm{H}_{2}$ and $\mathrm{O}_{2}$ over time of
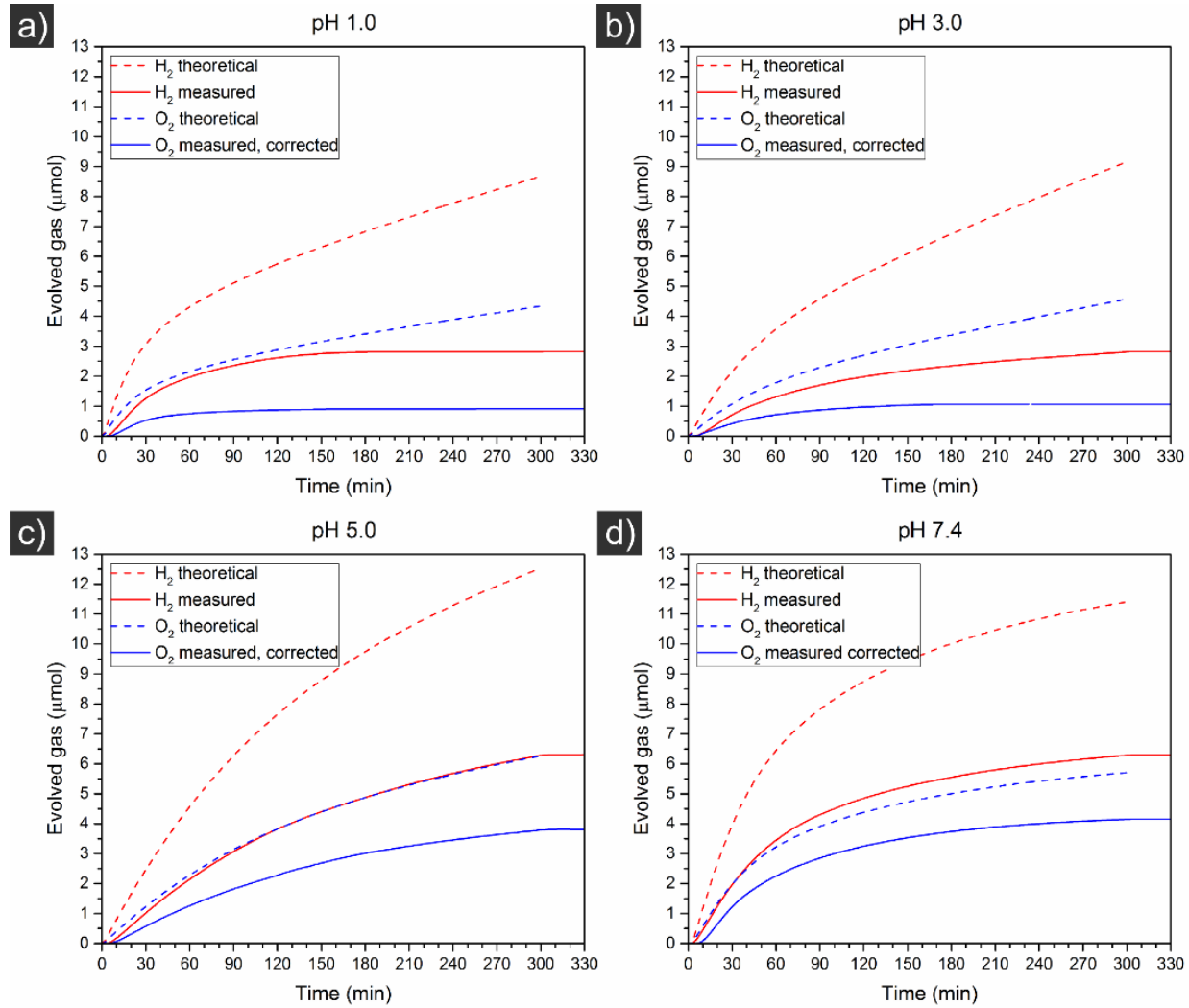

Figure 5.4 Integrated $\mathrm{H}_{2}$ and $\mathrm{O}_{2}$ gas production over time of $\mathrm{WO}_{3}$ photoanodes operated at $1.23 \mathrm{~V}$ vs. RHE in $0.1 \mathrm{M} \mathrm{KPi}$ buffer at a $\mathrm{pH}$ of a) 1.0, b) 3.0, c) 5.0 and d) 7.4 under $100 \mathrm{~mW} / \mathrm{cm}^{2} \mathrm{AM} 1.5$ simulated solar illumination. The leak-in of $\mathrm{O}_{2}$ into the reactor was estimated based on the measured amount of $\mathrm{N}_{2}$ and subtracted from the total $\mathrm{O}_{2}$ amount. Theoretical amounts were calculated from charge passed through the electrodes. 

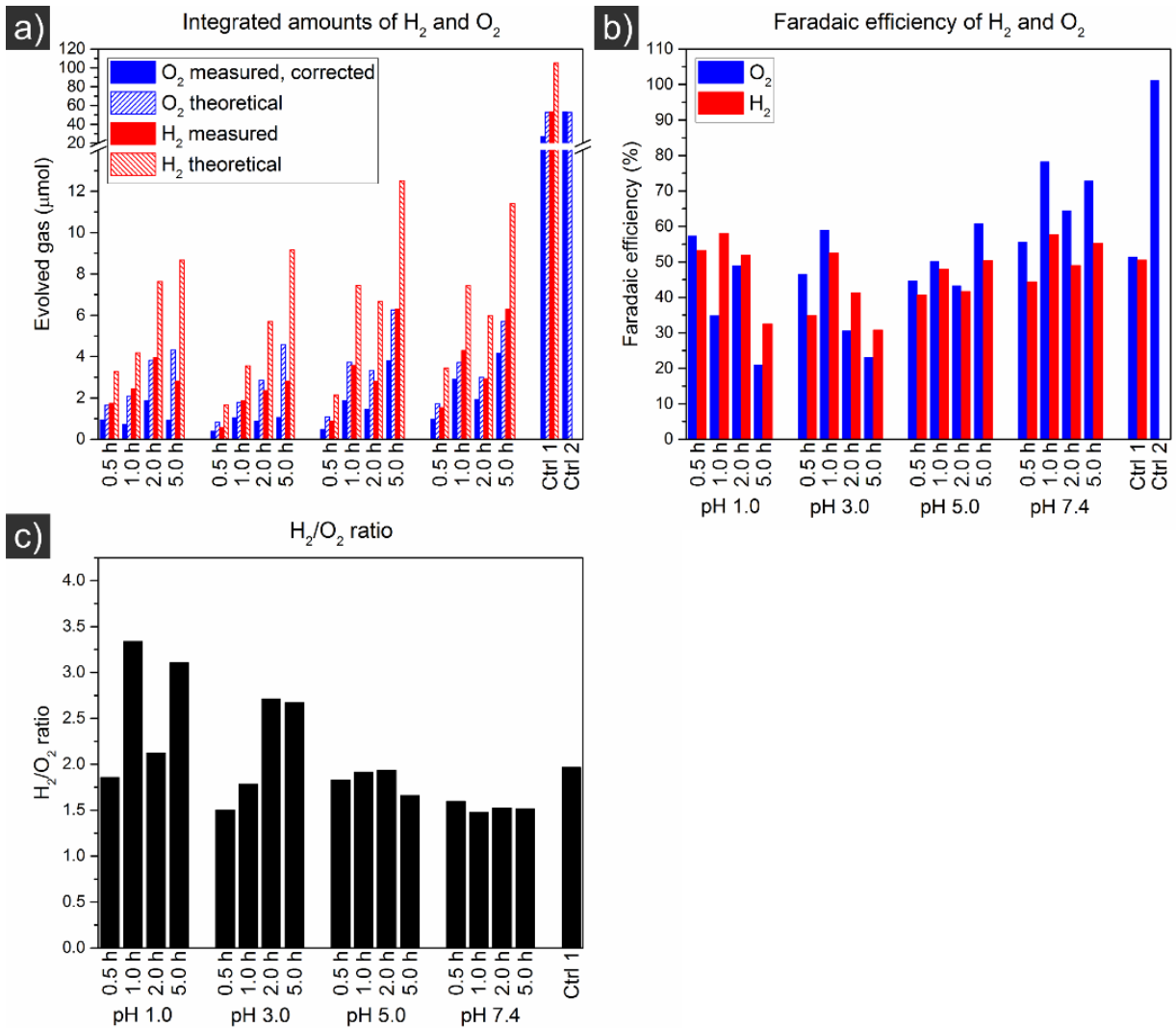

Figure 5.5 Analysis of $\mathrm{H}_{2}$ and $\mathrm{O}_{2}$ gas evolution from water splitting by $\mathrm{WO}_{3}$ photoanodes operated at $1.23 \mathrm{~V} v s$. RHE in $0.1 \mathrm{M} \mathrm{KPi}$ buffer at a $\mathrm{pH}$ of 1.0, 3.0, 5.0 and 7.4 under $100 \mathrm{~mW} / \mathrm{cm}^{2}$ AM 1.5 simulated solar illumination and $\mathrm{Pt}$ anode control experiments operated at $1 \mathrm{~mA} / \mathrm{cm}^{2}$ in a $0.1 \mathrm{M} \mathrm{KPi}$ buffer of $\mathrm{pH} 3.0$ without (Ctrl 1) and with (Ctrl 2) the saturation with sodium persulfate $\left(\mathrm{Na}_{2} \mathrm{~S}_{2} \mathrm{O}_{8}\right)$. a) Integrated amounts of $\mathrm{H}_{2}$ and $\mathrm{O}_{2}, \mathrm{~b}$ ) their faradaic efficiency and c) their ratio.

these measurements are shown in Figure 5.5a after the full reaction times, and in Figure 5.4 and the Appendix (Figure 5.13, Figure 5.16 and Figure 5.19) in a timeresolved fashion. All oxygen amounts were corrected for oxygen leak-in into the reactor. The $\mathrm{O}_{2}$ leak-in flux was estimated from the parallel leak-in of $\mathrm{N}_{2}$. The correction factor was calculated from the $\mathrm{O}_{2} / \mathrm{N}_{2}$ ratio determined in the dark prior to the start of the experiment. The maximum total amounts of gases produced were $4.2 \mu \mathrm{mol} \mathrm{O}_{2}$ and $6.3 \mu \mathrm{mol} \mathrm{H}_{2}$ at $\mathrm{pH} 7.4$ at a reaction time of $5 \mathrm{~h}$. However, no major trend in $\mathrm{O}_{2}$ and $\mathrm{H}_{2}$ production was observed at different $\mathrm{pH}$. The faradaic efficiency across all individual single point measurements (Figure 5.5b) 
was $49.4 \% \pm 16.5 \%$ for $\mathrm{O}_{2}$ and $46.4 \% \pm 8.7 \%$ for $\mathrm{H}_{2}$ with an $\mathrm{H}_{2} / \mathrm{O}_{2}$ ratio (Figure $5.5 \mathrm{c})$ at the stoichiometric value of $2.0 \pm 0.6$ over all samples.

In our experiments, a single cell reactor with no physical separation between working and counter electrode was used which allows the back-reaction, i.e. oxidation of $\mathrm{H}_{2}$ at the $\mathrm{WO}_{3}$ photoanode and reduction of $\mathrm{O}_{2}$ at the platinum cathode. To quantify these reactions, we have performed two experiments in which we exchanged the $\mathrm{WO}_{3}$ photoanode by a Pt-covered highly doped silicon wafer anode and performed galvanostatic water splitting at $1 \mathrm{~mA} / \mathrm{cm}^{2}$ in a $0.1 \mathrm{M}$ KPi solution ( $\mathrm{pH}$ 3.0) without (control 1) and with (control 2) saturated sodium persulfate $\left(\mathrm{Na}_{2} \mathrm{~S}_{2} \mathrm{O}_{8}\right)$. The persulfate anion is reduced to sulfate at $2.05 \mathrm{~V} v s$. NHE (Eq. 5.5) and thus acts as a sacrificial electron acceptor to prevent $\mathrm{H}_{2}$ production at the cathode.

$\mathrm{S}_{2} \mathrm{O}_{8}{ }^{2-}+2 \mathrm{e}^{-} \rightarrow 2 \mathrm{SO}_{4}^{2-} \quad E^{\circ}=2.05 \mathrm{~V}$ (Eq. 5.5)

Figure 5.6 shows the evolved (Figure 5.6a, c) and integrated (Figure 5.6b, d) $\mathrm{H}_{2}$ and $\mathrm{O}_{2}$ over time for these controls. Results when no persulfate was added and $\mathrm{H}_{2}$ and $\mathrm{O}_{2}$ evolved in parallel in the reactor (Figure 5.6a, b) were found to be similar to the $\mathrm{WO}_{3}$ photoanode. The yield for $\mathrm{O}_{2}$ was $27.1 \mu \mathrm{mol}$ or $51.4 \%$ and for $\mathrm{H}_{2} 53.2 \mu \mathrm{mol}$ or $50.5 \%$ (Figure 5.5). When $\mathrm{H}_{2}$ evolution was suppressed by saturation with sodium persulfate, the $\mathrm{O}_{2}$ yield was $53.2 \mu \mathrm{mol}$ or $101.1 \%$, following almost exactly the theoretically calculated values over time (Figure 5.6d). This means that neither in the first control experiment in which no persulfate was added nor in the $\mathrm{WO}_{3}$ photoanodes tests oxygen was reduced at the Pt counter electrode in the reactor. Instead, the loss of around 50\% faradaic efficiency is due to $\mathrm{H}_{2}$ oxidation. Oxidation of $\mathrm{H}_{2}$ at the anode reduces both the total detected amount of $\mathrm{H}_{2}$ and produced $\mathrm{O}_{2}$ proportionally. With the average detected $\mathrm{H}_{2} / \mathrm{O}_{2}$ ratio of 2:1 we assume that oxygen evolution and hydrogen evolution would occur with $100 \%$ faradaic efficiency when gas cross-over is prohibited by a membrane between the anode and the cathode compartment. 

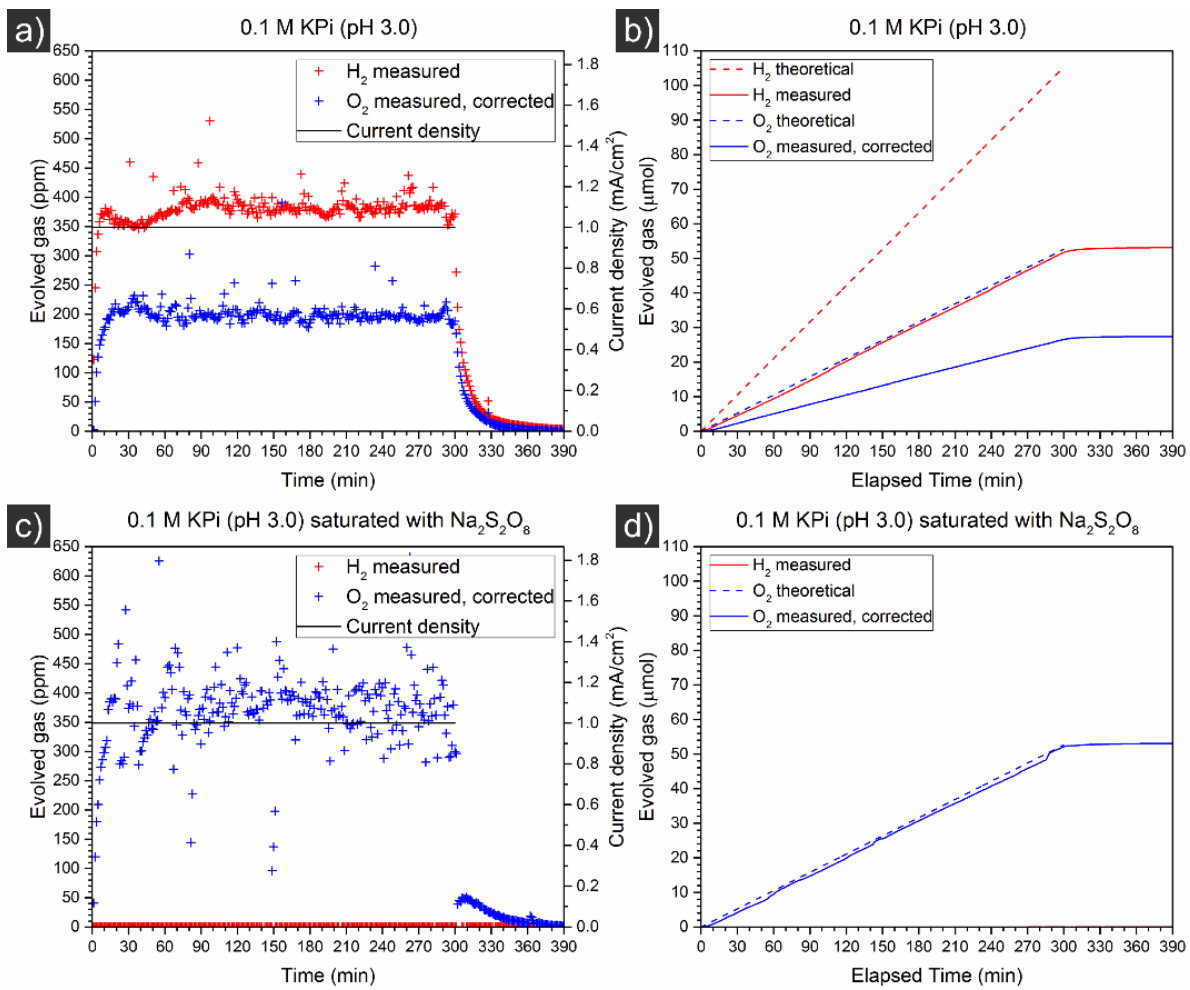

Figure 5.6 Analysis of $\mathrm{H}_{2}$ and $\mathrm{O}_{2}$ gas evolution from water splitting by $\mathrm{Pt}$ anode control experiments operated at $1 \mathrm{~mA} / \mathrm{cm}^{2}$ in a $0.1 \mathrm{M} \mathrm{KPi}$ buffer of $\mathrm{pH} 3.0$ without (Ctrl 1, a, b) and with $(\mathrm{Ctrl} 2, \mathrm{c}, \mathrm{d})$ saturation with sodium persulfate $\left(\mathrm{Na}_{2} \mathrm{~S}_{2} \mathrm{O}_{8}\right)$. a) and c) show the time-resolved evolved amounts and b) and d) the cumulative amounts integrated over time. The leak-in of $\mathrm{O}_{2}$ into the reactor was estimated based on the measured amount of $\mathrm{N}_{2}$ and subtracted from the total $\mathrm{O}_{2}$ amount. Theoretical amounts were calculated from charge passed through the electrodes.

We have chosen to use a KPi buffer based on the publication of Hill et al. ${ }^{[15]}$ who studied the effect of cations and anions and $\mathrm{pH}$ of the electrolyte on the stability of $\mathrm{WO}_{3}$ photoanodes and faradaic efficiencies towards $\mathrm{O}_{2}$ evolution. Best results in their study were obtained in a $\mathrm{Na}_{2} \mathrm{SO}_{4}\left(\mathrm{pH} \mathrm{5)}\right.$ and $\mathrm{KH}_{2} \mathrm{PO}_{4}(\mathrm{pH} 3)$ solutions with photocurrent to oxygen conversion efficiencies of $88 \%$ and $87 \%$ for $1 \mathrm{~h}$ of operation. We made the choice in favor of phosphate because sulfate is well known to be oxidized to persulfate (reversed Eq. 5.5) on the $\mathrm{WO}_{3}$ surface whereas phosphate is more stable. ${ }^{[13,14]}$ Nevertheless, Mi et al. suggested that phosphate can be oxidized to peroxydiphosphate. ${ }^{[14]}$ Furthermore, Augustynki et al. reported that a significant portion of the photon-generated holes oxidize water only partially (Eq. 5.2) and lead to a an accumulation of a few percent $\mathrm{H}_{2} \mathrm{O}_{2}$ in the 
solution and the formation of peroxo species on the surface of $\mathrm{WO}_{3}$, causing the loss of $\mathrm{WO}_{3}$ photoactivity during operation. ${ }^{[13]}$ In order to determine the $\mathrm{H}_{2} \mathrm{O}_{2}$ concentration in our experiments we have analyzed the electrolyte immediately after reaction by two different methods, i.e. the $\mathrm{KMnO}_{4}$ and the LabAssay ${ }^{\mathrm{TM}}$ Glucose method. The permanganate ion is a strong oxidizing agent having a deep purple color and is reduced in strong acidic solutions to colorless $\mathrm{Mn}^{2+}$ and water according to Equation 5.6.

$\mathrm{MnO}_{4}^{-}+8 \mathrm{H}^{+}+5 \mathrm{e}^{-} \rightarrow \mathrm{Mn}^{2+}+4 \mathrm{H}_{2} \mathrm{O} \quad E^{\circ}=1.51 \mathrm{~V}$ (Eq. 5.6)

The permanganate ion reacts with all reagents which are able to reduce it in solution, including $\mathrm{H}_{2} \mathrm{O}_{2}$ (Eq. 5.4). However, since this reaction is not specific, we have performed an additional $\mathrm{H}_{2} \mathrm{O}_{2}$ analysis in parallel with the LabAssay ${ }^{\mathrm{TM}}$ Glucose method, originally designed for quantitative determination of glucose in solutions. During enzymatic glucose oxidation, $\mathrm{H}_{2} \mathrm{O}_{2}$ is developed and further processed by a second enzymatic reaction of a coloring dye and $\mathrm{H}_{2} \mathrm{O}_{2}$ transformation to a red pigment and water (Eq. 5.7). We used only the second part of the LabAssay ${ }^{\mathrm{TM}}$ Glucose kit to determine $\mathrm{H}_{2} \mathrm{O}_{2}$ specifically.

$2 \mathrm{H}_{2} \mathrm{O}_{2}+$ [coloring dye] $\stackrel{\text { enzyme }}{\longrightarrow}$ [red pigment] $+4 \mathrm{H}_{2} \mathrm{O}$

The amounts of $\mathrm{H}_{2} \mathrm{O}_{2}$ in electrolyte solution in our reactions were calculated from the UV-Vis absorption decrease at $525 \mathrm{~nm}$ in the $\mathrm{KMnO}_{4}$ method and its increase at $505 \mathrm{~nm}$ in the LabAssay ${ }^{\mathrm{TM}}$ Glucose method. Figure 5.7a shows measured amounts in comparison to theoretical maximum assuming $100 \%$ faradaic efficiency of water oxidation to $\mathrm{H}_{2} \mathrm{O}_{2}$ and protons (Eq. 5.2). Measured values for $\mathrm{H}_{2} \mathrm{O}_{2}$ range between $-0.26 \mu \mathrm{mol}$ and $0.23 \mu \mathrm{mol}$ for the $\mathrm{KMnO}_{4}$ method and between $-0.03 \mu \mathrm{mol}$ to $0.18 \mu \mathrm{mol}$ in the LabAssay ${ }^{\mathrm{TM}}$ Glucose method. Negative values result when the reference sample which was treated in parallel to the actual sample showed a lower absorption in the $\mathrm{KMnO}_{4}$ method or a higher absorption in the LabAssay ${ }^{\mathrm{TM}}$ Glucose method. We consider the negative values as our experimental error margin. Since positive and negative values fluctuate in the same range, we find that no significant amounts of $\mathrm{H}_{2} \mathrm{O}_{2}$ were produced during the reaction. However, we neither can confirm nor exclude the appearance of $\mathrm{H}_{2} \mathrm{O}_{2}$ in very low amounts of a few percent compared to the theoretical maximum. 
Also, it is well possible that formed peroxides or peroxo-species attach to the surface and do not migrate into the electrolyte. ${ }^{[21]}$

To verify whether $\mathrm{WO}_{3}$ photoanodes suffer from corrosion we analyzed the tungsten content in the electrolyte by inductively coupled plasma optical emission spectrometry (ICP-OES). Degradation was only found in solution at $\mathrm{pH} 7.4$ for all times of photocatalytic operation and a small amount at $\mathrm{pH} 5.0$ after $5 \mathrm{~h}$ of operation (Figure 5.7b). After $5 \mathrm{~h}$ of photocatalytic operation of the $\mathrm{WO}_{3}$ photoanodes in $\mathrm{pH} 7.4,0.27 \mathrm{mg}$ tungsten was dissolved into the electrolyte solution. This is about $30 \%$ of the total amount of tungsten on the photoanode. The total $\mathrm{WO}_{3}$ amount on $1.13 \mathrm{~cm}^{2}$ electrode area was calculated to be $1.13 \mathrm{mg}$ and thus of tungsten $0.90 \mathrm{mg}$, while estimating a $50 \%$ porosity of the $2.8 \mu \mathrm{m}$ thick $\mathrm{WO}_{3}$ layer. These results are consistent with literature indicating $\mathrm{WO}_{3}$ being thermodynamically stable in acidic solutions at a $\mathrm{pH}$ below $4 .{ }^{[25,26]}$ SEM images after photocatalytic activity (Figure 5.8, and in Appendix Figure 5.14, Figure 5.17, Figure 5.20) confirm these findings. $\mathrm{WO}_{3}$ particles showed degradation at $\mathrm{pH} 7.4$, whereas at all other pHs, the particles remained intact. Also, the SEM images show that the $\mathrm{WO}_{3}$ films adhered well and kept contact to the surface after the photocatalytic tests, and that the underlying ITO layer remained stable.

a)

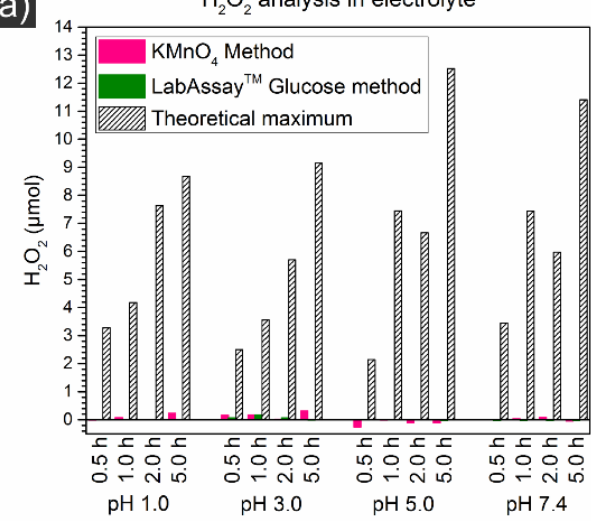

b)

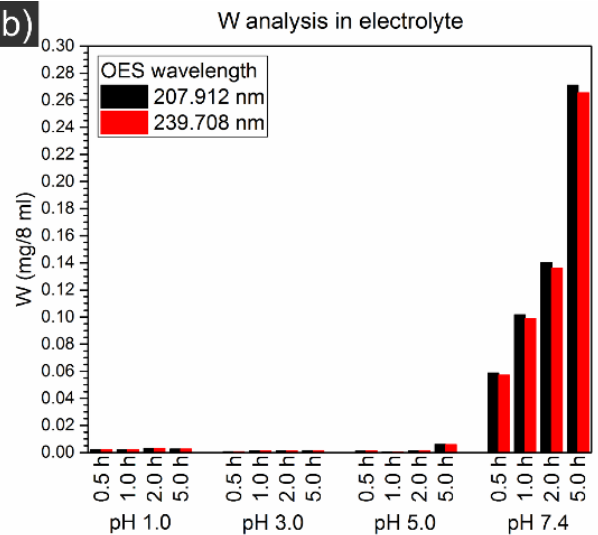

Figure 5.7 Analysis of a) $\mathrm{H}_{2} \mathrm{O}_{2}$ by UV-Vis spectroscopy and b) W by ICP-OES in the electrolyte after photocatalytic operation for $0.5 \mathrm{~h}, 1.0 \mathrm{~h}, 2.0 \mathrm{~h}$ and $5.0 \mathrm{~h}$ of $\mathrm{WO}_{3}$ photoanodes at $1.23 \mathrm{~V} v s$. RHE in $0.1 \mathrm{M} \mathrm{KPi}$ buffer at a pH of 1.0, 3.0, 5.0 and 7.4 under $100 \mathrm{~mW} / \mathrm{cm}^{2}$ AM 1.5 simulated solar illumination. 


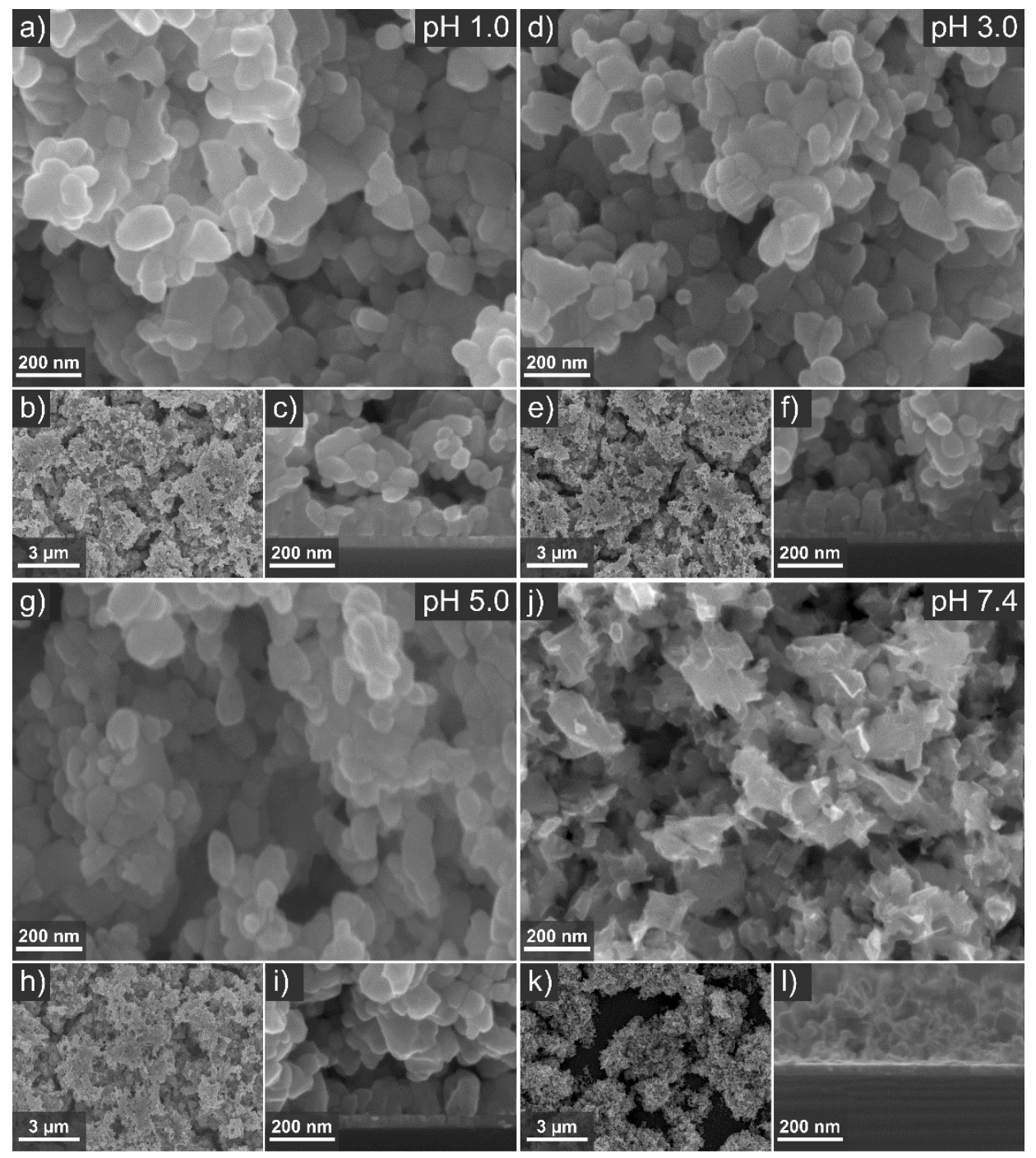

Figure 5.8 Top-view (a, b, d, e, g, h, j, k) and cross sectional (c, f, i, l) SEM images after $5 \mathrm{~h}$ photocatalytic operation of $\mathrm{WO}_{3}$ photoanodes at $1.23 \mathrm{~V} v s$. RHE in $0.1 \mathrm{M} \mathrm{KPi}$ buffer at a pH of $1.0(\mathrm{a}, \mathrm{b}, \mathrm{c}), 3.0(\mathrm{~d}, \mathrm{e}, \mathrm{f}), 5.0(\mathrm{~g}, \mathrm{~h}, \mathrm{i})$ and $7.4(\mathrm{j}, \mathrm{k}, \mathrm{l})$ under $100 \mathrm{~mW} / \mathrm{cm}^{2}$ AM 1.5 simulated solar illumination.

The presence of oxygen vacancies in $\mathrm{WO}_{3}$ is essential for its usage as a photoanode material. These lattice defects, induced by a small fraction of $\mathrm{W}^{5+}$, are responsible for the n-type character, and increase the electrical conductivity and light absorption. ${ }^{[5,6,27-30]}$ Also, $\mathrm{W}^{5+}$ has been reported to improve chemical and photocatalytic long-term stability. ${ }^{[17,28,31]}$ Self-oxidation of $\mathrm{W}^{5+}$ to $\mathrm{W}^{6+}$ and 
a)

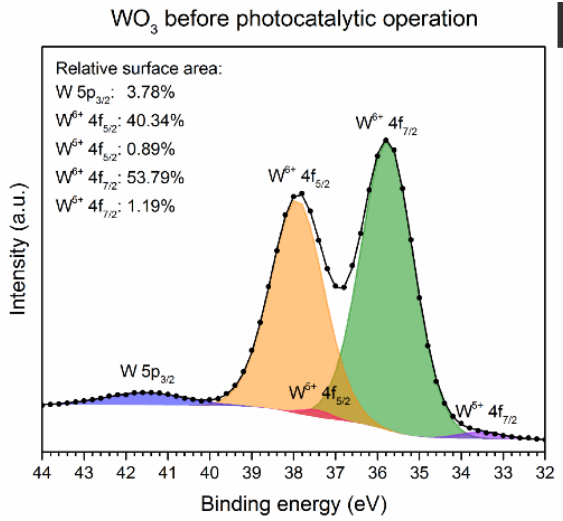

c)

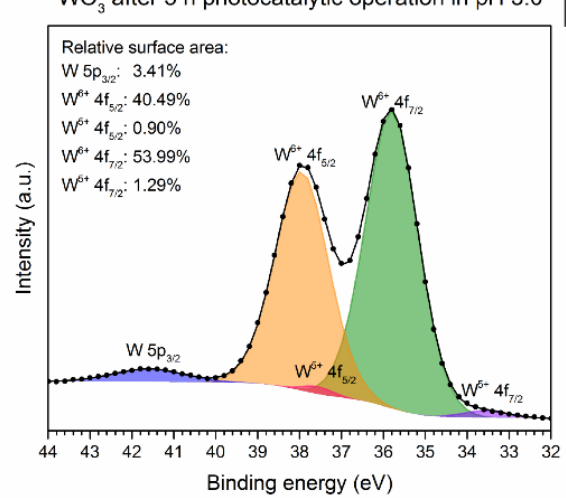

b)

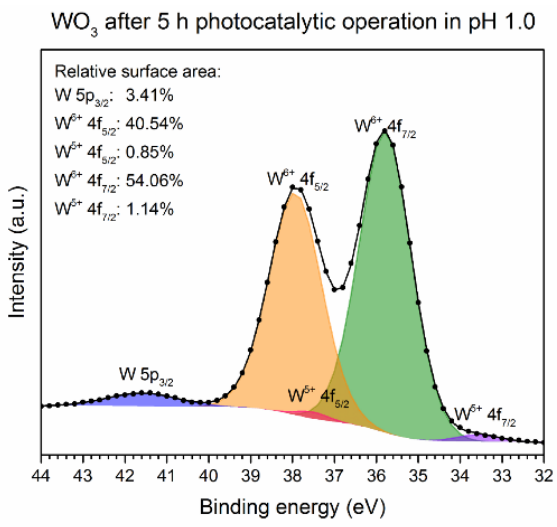

d)

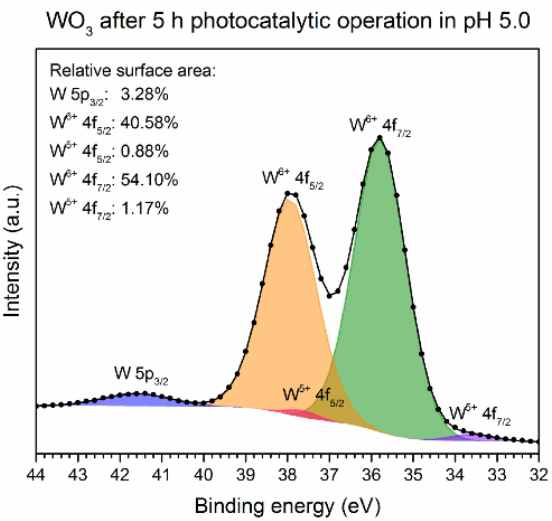

Figure 5.9 W 4f XPS spectra of $\mathrm{WO}_{3}$ photoanodes a) before photocatalytic tests and after $5 \mathrm{~h}$ operation in b) $\mathrm{pH} 1.0, \mathrm{c}) \mathrm{pH} 3.0$ and d) $\mathrm{pH}$ 5.0. The dots represent experimental data, the colored areas deconvoluted peaks and the black line is the sum of all deconvoluted areas. The white area underneath the curves is the subtracted Shirley-type background.

thereby a reduction of oxygen vacancies may cause a gradual loss of photocurrent. Analysis of XPS results before and after $5 \mathrm{~h}$ photocatalytic performance in KPi solutions of $\mathrm{pH}$ 1.0, 3.0 and 5.0 showed changes neither in the overall element spectrum (Figure 5.22, Appendix), nor in the $\mathrm{O}$ 1s spectrum (Figure 5.23, Appendix), nor in the W 4f spectrum (Figure 5.9) in comparison to an unused $\mathrm{WO}_{3}$ photoanode. This indicates that the $\mathrm{WO}_{3}$ surface structure did not change during reaction and that surface morphology changes are not responsible for the decrease in photocatalytic current density. The deconvolution of the $\mathrm{W} 4 \mathrm{f}$ signal shows two pairs of peaks. The first, well resolved doublet with binding energies of $35.8 \mathrm{eV}$ and $37.9 \mathrm{eV}$ corresponds to $\mathrm{W}^{6+} 4 \mathrm{f}_{7 / 2}$ and $4 \mathrm{f}_{5 / 2}$, respectively. ${ }^{[17,32-34]}$ The second doublet with binding energies of $33.5 \mathrm{eV}$ and $37.5 \mathrm{eV}$ is assigned to $\mathrm{W}^{5+} 4 \mathrm{f}_{7 / 2}$ and $4 \mathrm{f}_{5 / 2}$, respectively. ${ }^{[17,33,34]}$ Based on the peak 
areas in XPS, the photoanodes consisted of $2.2 \% \pm 0.1 \% \mathrm{~W}^{5+}$ and $97.8 \% \pm 0.1 \%$ of $\mathrm{W}^{6+}$. The finding of $\mathrm{W}^{5+}$ on the $\mathrm{WO}_{3}$ surface is in agreement with our Raman results (Figure 5.2b). Also, the XPS data confirm that the $\mathrm{WO}_{3}$ surface is free of hydrocarbon impurities. Only traces of adventitious carbon were found (Figure 5.22, Appendix).

Furthermore, to investigate whether the photocatalytic deactivation of $\mathrm{WO}_{3}$ photoanodes over time is permanent or reversible, we have performed tests in which we have run photocatalytic water splitting experiments with two kinds of interruptions. Type 1 interruption was to block the light after $2 \mathrm{~h}$ of operation with a shutter and switch off the applied external bias of $1.23 \mathrm{~V} v s$. RHE for $1 \mathrm{~h}$, and then continue the photocurrent measurements for another $2 \mathrm{~h}$. Type 2 interruption was to remove the electrolyte from the reactor, rinse the sample and reactor well with high-purity water, gently blow the sample and reactor dry, and let it sit for $13 \mathrm{~h}$ or $2 \mathrm{~h}$. Figure 5.10 shows the results in air-saturated $0.1 \mathrm{M} \mathrm{KPi}$ solutions of $\mathrm{pH} 1.0,3.0$ and 5.0. The photoactivity of $\mathrm{WO}_{3}$ at $\mathrm{pH} 1.0$ dropped by $84 \%$ from $0.74 \mathrm{~mA} / \mathrm{cm}^{2}$ to $0.12 \mathrm{~mA} / \mathrm{cm}^{2}$ and did not substantially recover in the dark and no applied bias. Also, the photocurrent did not regain after cleaning the sample with high-purity water and drying. At $\mathrm{pH} 3.0$ the photoanode lost $60 \%$ of the initial photocurrent, from $0.72 \mathrm{~mA} / \mathrm{cm}^{2}$ to $0.29 \mathrm{~mA} / \mathrm{cm}^{2}$, within the first $120 \mathrm{~min}$ of operation. However, it recovered to $0.62 \mathrm{~mA} / \mathrm{cm}^{2}$ after $1 \mathrm{~h}$ type 1 interruption, fell below $0.29 \mathrm{~mA} / \mathrm{cm}^{2}$ after $35 \mathrm{~min}$ of operation and dropped to $0.17 \mathrm{~mA} / \mathrm{cm}$ after $120 \mathrm{~min}$. The photoanode regained to a starting current of $0.56 \mathrm{~mA} / \mathrm{cm}^{2}$ which was $78 \%$ of the initial photocurrent after the first type 2 interruption and then lost photocurrent at a similar rate as before type 2 interruption. The regain of the initial photocurrent after the second type 2 interruption was similar as after the first type 2 interruption but here the photocurrent decay rate was much higher. The photocurrent behavior of $\mathrm{WO}_{3}$ photoanodes at $\mathrm{pH} 5.0$ was similar to $\mathrm{pH} 3.0$ in the first test. The initial photocurrent of $0.76 \mathrm{~mA} / \mathrm{cm}^{2}$ dropped by $71 \%$ to $0.22 \mathrm{~mA} / \mathrm{cm}^{2}$ but regained to $0.60 \mathrm{~mA} / \mathrm{cm}^{2}$ after type 1 interruption. The regains after type 2 interruptions were lower than at $\mathrm{pH} 3.0$ and showed a higher photocurrent loss rate. These observations suggest that the deactivation in $\mathrm{pH} 1.0,3.0$ and 5.0 is due to a mix 

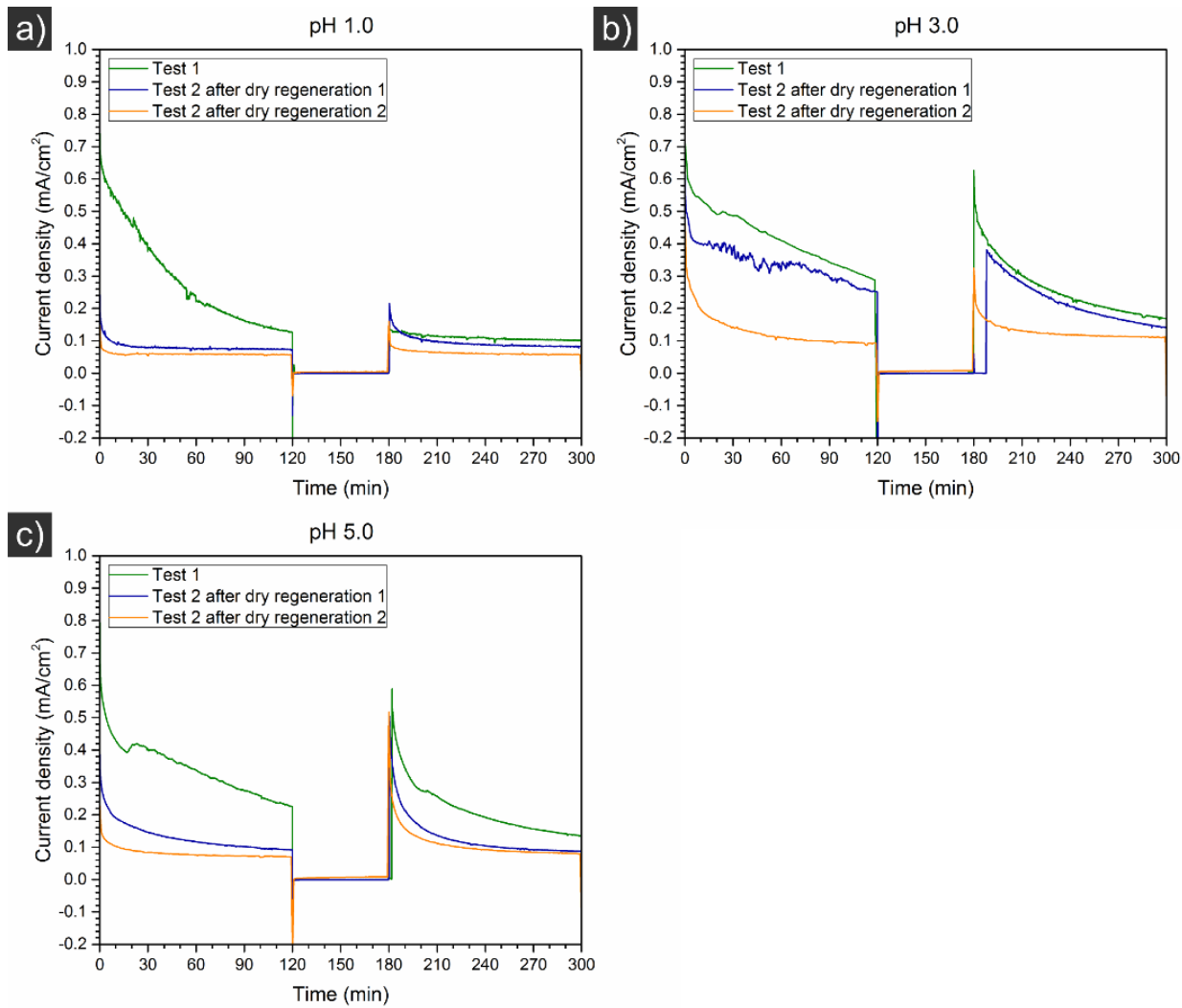

Figure 5.10 Photocurrent regeneration tests of $\mathrm{WO}_{3}$ photoanodes in $0.1 \mathrm{M} \mathrm{KPi}$ buffer at a pH of a) 1.0, b) 3.0 and c) 5.0. In every test the electrode was biased at $1.23 \mathrm{~V} v s$. RHE under $100 \mathrm{~mW} / \mathrm{cm}^{2} \mathrm{AM} 1.5$ simulated solar illumination during the first and last $120 \mathrm{~min}$ of operation. In between these photoactivity tests the electrode was held in the reactor at an open circuit potential in the dark. In between the tests, the reactor was opened and the electrolyte removed. The $\mathrm{WO}_{3}$ sample was rinsed with high-purity water, gently blowdried with air and exposed to air for $13 \mathrm{~h}$ after test 1 and for $2 \mathrm{~h}$ after test 2 .

of two parallel processes of which one is reversible and one irreversible by the two types of interruptions. In $\mathrm{pH}$ 1.0, the irreversible process dominates whereas in $\mathrm{pH} 3.0$ and $\mathrm{pH} 5.0$ both processes occur in parallel. The irreversible process might be the loss of catalytic centers for water oxidation, potentially induced by surface binding of peroxo species as suggested by Augustynski et al. ${ }^{[13]}$ or by other deactivation processes. The formation of peroxo species is supported by the findings of Augustynski et al. that the initial performance of $\mathrm{WO}_{3}$ photoanodes can be regenerated by steps which are able to destroy tungsten peroxides, such as annealing in oxygen atmosphere, a short reductive current pulse or exposure of 
intense UV illumination. ${ }^{[13]}$ Also, the increasing rate of $\mathrm{WO}_{3}$ photoanode deactivation from $\mathrm{pH} 5.0$ to $\mathrm{pH} 3.0$ to $\mathrm{pH} 1.0$ correlates well with the stability of peroxides at different $\mathrm{pHs}$, which increases at decreasing $\mathrm{pH} .{ }^{[35,36]}$ The reversible process is presumably the build-up of a $\mathrm{pH}$ gradient between the electrodes during photocatalytic water electrolysis. A pH gradient is more easily built up at higher pHs, explaining the observed occurrence at $\mathrm{pH} 3.0$ and 5.0 compared to $\mathrm{pH}$ 1.0.

\subsection{Conclusions}

In conclusion, we have studied potential factors which lead to the deactivation of $\mathrm{WO}_{3}$ photoanodes during photocatalytic water splitting in KPi buffer solutions of $\mathrm{pH}$ 1.0, 3.0, 5.0 and 7.4. We found that faradaic efficiencies for oxygen evolution were $100 \%$ when recombination losses of $\mathrm{O}_{2}$ and $\mathrm{H}_{2}$ in the single compartment cell are taken into account. Thus we conclude that no major parallel oxidation reactions, such as the formation of $\mathrm{H}_{2} \mathrm{O}_{2}$, occur, as confirmed by analysis of the electrolyte composition with different $\mathrm{H}_{2} \mathrm{O}_{2}$ assays. The lowest photocurrent stabilities over time were observed at $\mathrm{pH} 1.0$, followed by $\mathrm{pH} 7.4, \mathrm{pH} 3.0$ and $\mathrm{pH}$ 5.0. The photoanodes are chemically instable at $\mathrm{pH} 7.4$ and stable at $\mathrm{pH} 5.0$ only for a few hours. Thus, the optimal $\mathrm{pH}$ for $\mathrm{WO}_{3}$ photoanodes is at around 3 . Our study showed no observable change of the surface of the $\mathrm{WO}_{3}$ photoanode after $5 \mathrm{~h}$ of photocatalytic operation in $\mathrm{pH} 1.0,3.0$ and 5.0. However, as put forward by Augustynski et al., the deactivation may be due to unfavorable formation of surface peroxides on the $\mathrm{WO}_{3}$ surface. This study provides a basis for further in situ studies to fully understand the mechanism of the loss in photocurrent on $\mathrm{WO}_{3}$ photoanodes and analyze the formation of surface peroxides or other species.

\subsection{Acknowledgements}

Gerard Kip is greatly acknowledged for XPS measurements, Caroline Lievens for ICP-OES measurements and Kai Han for the introduction to the GC setup. 
$\mathrm{WO}_{3}$ photoanode deactivation during photoelectrochemical water oxidation

\subsection{References}

[1] A. Kudo, Int. J. Hydrogen Energy 2007, 32, 2673.

[2] P. Dong, G. Hou, X. Xi, R. Shao, F. Dong, Environ. Sci.: Nano 2017, 4, 539.

[3] Z.-F. Huang, J. Song, L. Pan, X. Zhang, L. Wang, J.-J. Zou, Adv. Mater. 2015, 27, 5309.

[4] V. O. Makarov, M. Trontelj, J. Eur. Ceram. Soc. 1996, 16, 791.

[5] W. Sahle, M. Nygren, J. Solid State Chem. 1983, 48, 154.

[6] J. M. Berak, M. J. Sienko, J. Solid State Chem. 1970, 2, 109.

[7] J. Kleperis, J. Zubkans, A. R. Lusis, "Nature of fundamental absorption edge of WO3", 1997, DOI:10.1117/12.266832.

[8] S. Wang, H. Chen, G. Gao, T. Butburee, M. Lyu, S. Thaweesak, J.-H. Yun, A. Du, G. Liu, L. Wang, Nano Energy 2016, 24, 94.

[9] T. Zhu, M. N. Chong, E. S. Chan, ChemSusChem 2014, 7, 2974.

[10] J. R. Bolton, S. J. Strickler, J. S. Connolly, Nature 1985, 316, 495.

[11] R. H. Coridan, M. Shaner, C. Wiggenhorn, B. S. Brunschwig, N. S. Lewis, J. Phys. Chem. C 2013, 117, 6949.

[12] H. Doscher, J. F. Geisz, T. G. Deutsch, J. A. Turner, Energy Environ. Sci. 2014, 7, 2951.

[13] J. Augustynski, R. Solarska, H. Hagemann, C. Santato, Proc. of SPIE 2006, 6340, U140.

[14] Q. Mi, A. Zhanaidarova, B. S. Brunschwig, H. B. Gray, N. S. Lewis, Energy Environ. Sci. 2012, 5, 5694.

[15] J. C. Hill, K.-S. Choi, J. Phys. Chem. C 2012, 116, 7612.

[16] L. Weinhardt, M. Blum, M. Bär, C. Heske, B. Cole, B. Marsen, E. L. Miller, J. Phys. Chem. C 2008, 112, 3078.

[17] G. Wang, Y. Ling, H. Wang, X. Yang, C. Wang, J. Z. Zhang, Y. Li, Energy Environ. Sci. 2012, 5, 6180.

[18] J. A. Seabold, K.-S. Choi, Chem. Mater. 2011, 23, 1105.

[19] J. M. Spurgeon, J. M. Velazquez, M. T. McDowell, Phys. Chem. Chem. Phys. 2014, 16, 3623.

[20] R. Liu, Y. Lin, L.-Y. Chou, S. W. Sheehan, W. He, F. Zhang, H. J. M. Hou, D. Wang, Angew. Chem. Int. Ed. 2011, 50, 499. 
[21] V. M. Daskalaki, P. Panagiotopoulou, D. I. Kondarides, Chemical Engineering Journal 2011, 170, 433.

[22] E. A. Meulenkamp, J. Electrochem. Soc. 1997, 144, 1664.

[23] M. F. Daniel, B. Desbat, J. C. Lassegues, B. Gerand, M. Figlarz, J. Solid State Chem. 1987, 67, 235.

[24] G. L. Frey, A. Rothschild, J. Sloan, R. Rosentsveig, R. Popovitz-Biro, R. Tenne, J. Solid State Chem. 2001, 162, 300.

[25] M. Anik, T. Cansizoglu, J. Appl. Electrochem. 2006, 36, 603.

[26] R. S. Lillard, G. S. Kanner, D. P. Butt, J. Electrochem. Soc. 1998, 145, 2718.

[27] J. Yan, T. Wang, G. Wu, W. Dai, N. Guan, L. Li, J. Gong, Adv. Mater. 2015, 27, 1580.

[28] G. Liu, J. Han, X. Zhou, L. Huang, F. Zhang, X. Wang, C. Ding, X. Zheng, H. Han, C. Li, J. Catal. 2013, 307, 148.

[29] S. K. Deb, Phys. Rev. B 1977, 16, 1020.

[30] R. Chatten, A. V. Chadwick, A. Rougier, P. J. D. Lindan, J. Phys. Chem. B 2005, 109, 3146.

[31] D. Tamboli, S. Seal, V. Desai, A. Maury, J. Vac. Sci. Technol. A 1999, 17, 1168.

[32] R. Sohal, C. Walczyk, P. Zaumseil, D. Wolansky, A. Fox, B. Tillack, H.-J. Müssig, T. Schroeder, Thin Solid Films 2009, 517, 4534.

[33] L. Cheng, Y. Hou, B. Zhang, S. Yang, J. W. Guo, L. Wu, H. G. Yang, Chem. Commun. 2013, 49, 5945.

[34] F. Y. Xie, L. Gong, X. Liu, Y. T. Tao, W. H. Zhang, S. H. Chen, H. Meng, J. Chen, J. Electron Spectrosc. Relat. Phenom. 2012, 185, 112.

[35] Evonik Resource Efficiency GmbH, Stability \& Decomposition, http://h2o2.evonik.com/product/h2o2/en/about-hydrogen-peroxide/basicinformation/stability-and-decomposition/pages/default.aspx, 11. 10. 2017

[36] F. A. Cotton, G. Wilkinson, ADVANCED INORGANIC CHEMISTRY A Comprehensive Text, Third Edition, 1980. 


\subsection{Appendix}

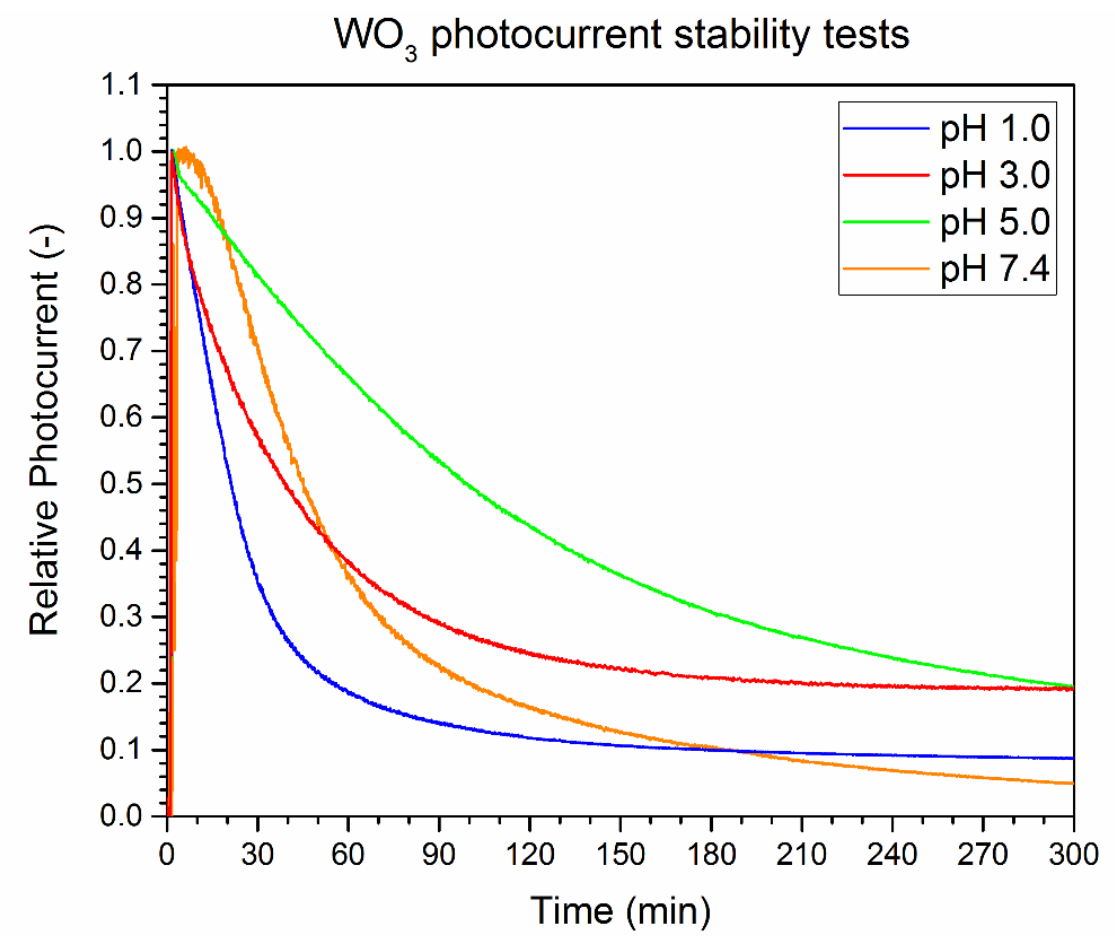

Figure 5.11 Photocurrent stability tests of $\mathrm{WO}_{3}$ photoanodes at $1.23 \mathrm{~V}$ vs. RHE in $0.1 \mathrm{M}$ KPi buffer at a $\mathrm{pH}$ of 1.0, 3.0, 5.0 and 7.4 under $100 \mathrm{~mW} / \mathrm{cm}^{2}$ AM 1.5 simulated solar illumination. Measured photocurrents are divided by their maximum for a current loss comparison at different $\mathrm{pH}$. 

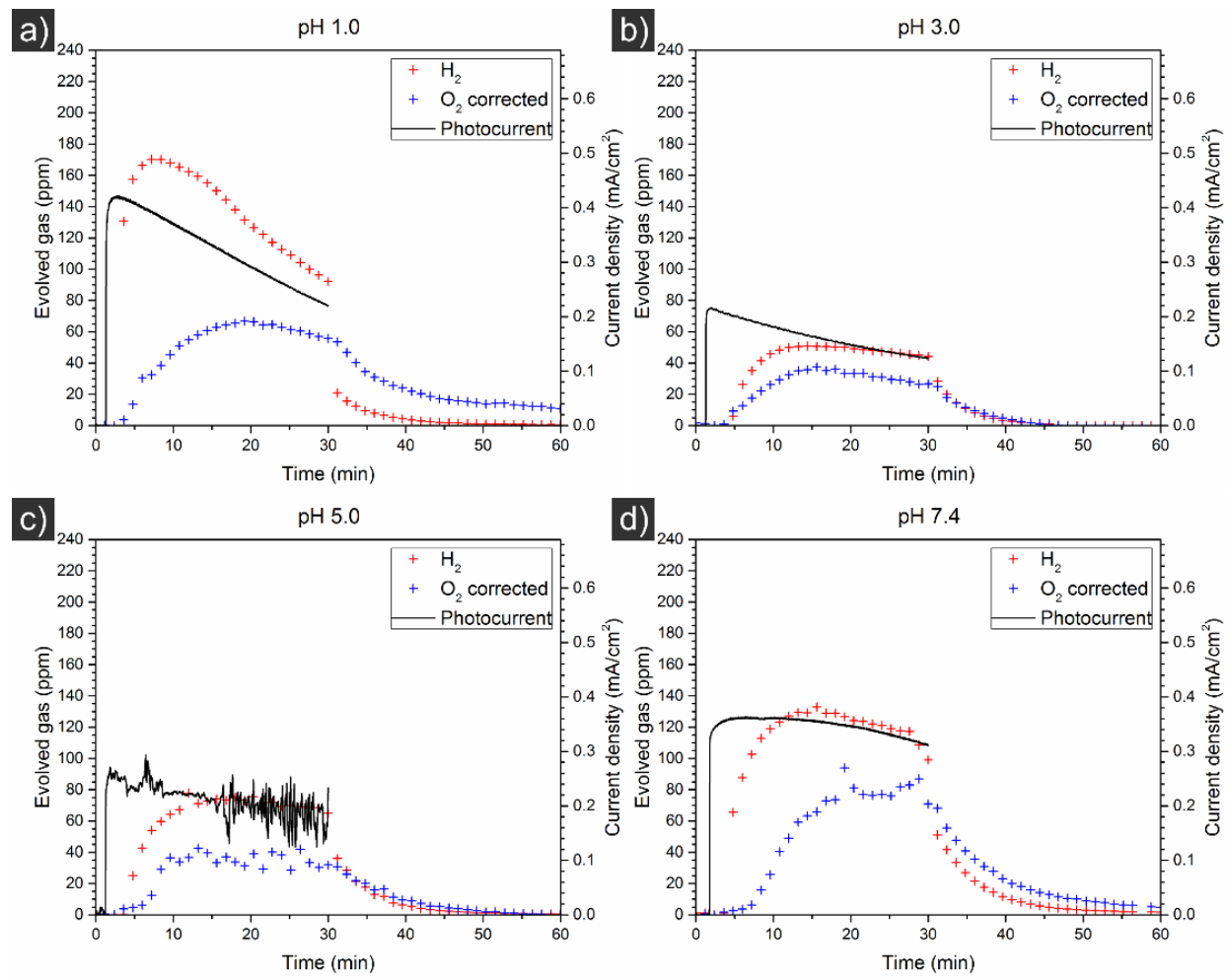

Figure 5.12 Photocurrent stability tests of $\mathrm{WO}_{3}$ photoanodes at $1.23 \mathrm{~V}$ vs. RHE in $0.1 \mathrm{M}$ KPi buffer at a pH of a) 1.0, b) 3.0, c) 5.0 and d) 7.4 under $100 \mathrm{~mW} / \mathrm{cm}^{2}$ AM 1.5 simulated solar illumination. $\mathrm{H}_{2}, \mathrm{O}_{2}$ and $\mathrm{N}_{2}$ gases were collected by a constant He purge of $10 \mathrm{ml} / \mathrm{min}$ through the reactor, separated with a GC and detected with a Pulsed Discharge Detector. The leak-in of $\mathrm{O}_{2}$ into the reactor was estimated based on the measured amount of $\mathrm{N}_{2}$ and subtracted from the total $\mathrm{O}_{2}$ amount. The two vertical axis are aligned in such that the current density represents the theoretical amount of $\mathrm{O}_{2}$ produced at the photoanode assuming $100 \%$ faradaic efficiency. The first minute of the measurement was in dark to illustrate the absence of a dark current. 

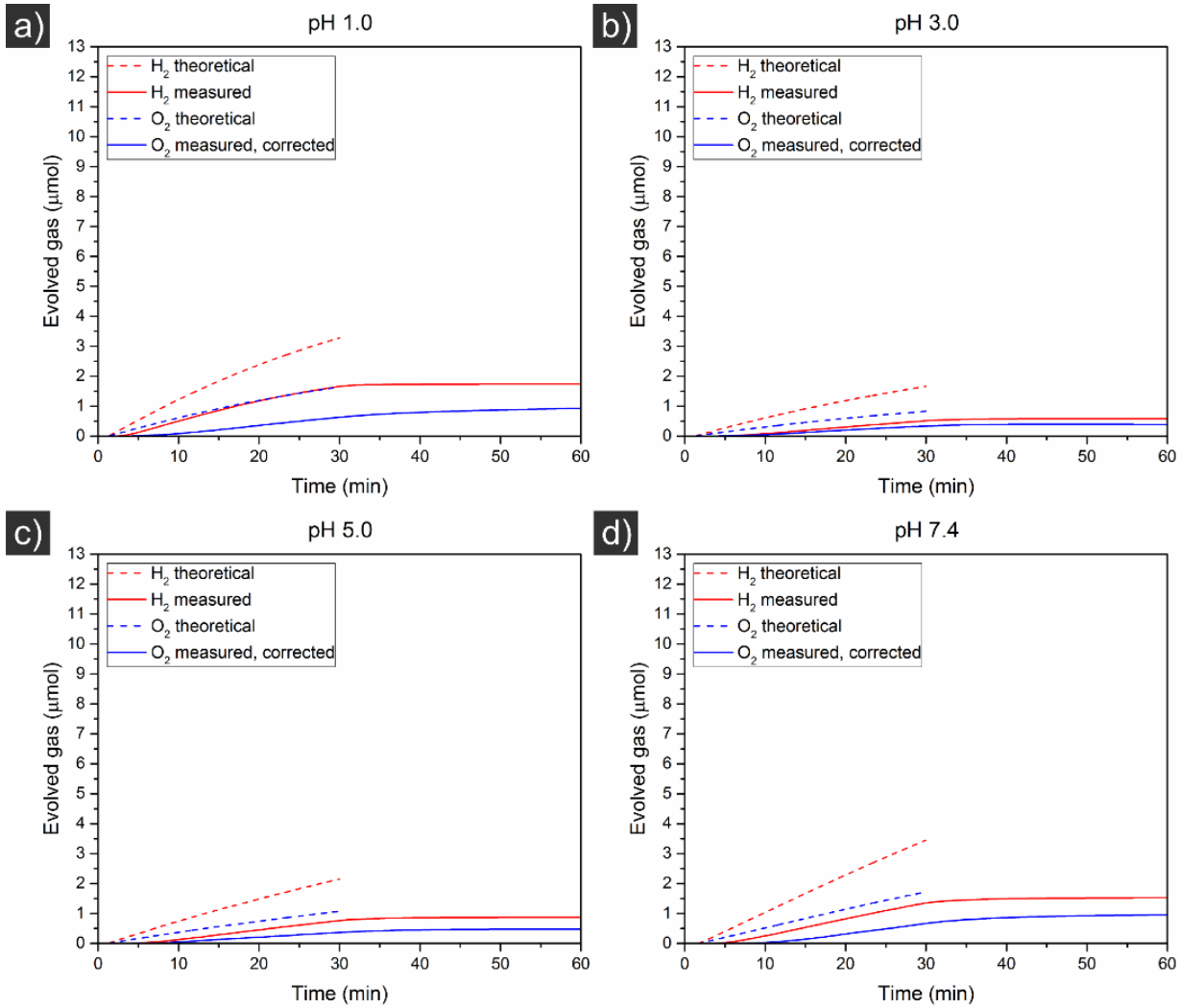

Figure 5.13 Integrated $\mathrm{H}_{2}$ and $\mathrm{O}_{2}$ gas evolution over time of $\mathrm{WO}_{3}$ photoanodes operated at $1.23 \mathrm{~V} v s$. RHE in $0.1 \mathrm{M} \mathrm{KPi}$ buffer at a $\mathrm{pH}$ of a) 1.0, b) 3.0, c) 5.0 and d) 7.4 under $100 \mathrm{~mW} / \mathrm{cm}^{2}$ AM 1.5 simulated solar illumination. The leak-in of $\mathrm{O}_{2}$ into the reactor was estimated based on the measured amount of $\mathrm{N}_{2}$ and subtracted from the total $\mathrm{O}_{2}$ amount. Theoretical amounts were calculated from charge passed through the electrodes. The first minute of the measurement was in dark to illustrate the absence of a dark current. 


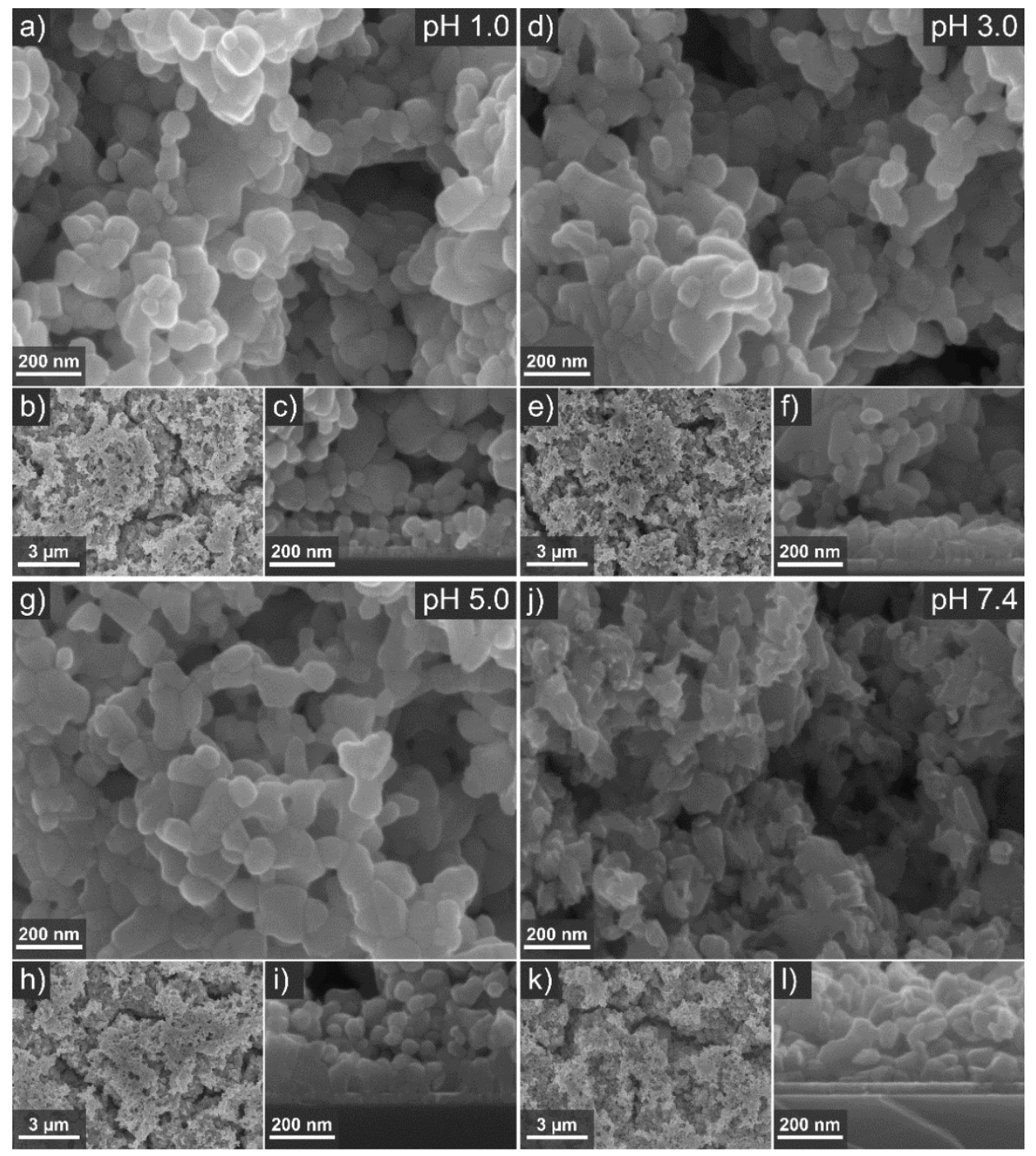

Figure 5.14 Top-view (a, b, d, e, g, h, j, k) and cross sectional (c, f, i, l) SEM images after $0.55 \mathrm{~h}$ photocatalytic operation of $\mathrm{WO}_{3}$ photoanodes at $1.23 \mathrm{~V}$ vs. RHE in $0.1 \mathrm{M} \mathrm{KPi}$ buffer at a pH of $1.0(\mathrm{a}, \mathrm{b}, \mathrm{c}), 3.0(\mathrm{~d}, \mathrm{e}, \mathrm{f}), 5.0(\mathrm{~g}, \mathrm{~h}, \mathrm{i})$ and $7.4(\mathrm{j}, \mathrm{k}, \mathrm{l})$ under $100 \mathrm{~mW} / \mathrm{cm}^{2}$ AM 1.5 simulated solar illumination. 

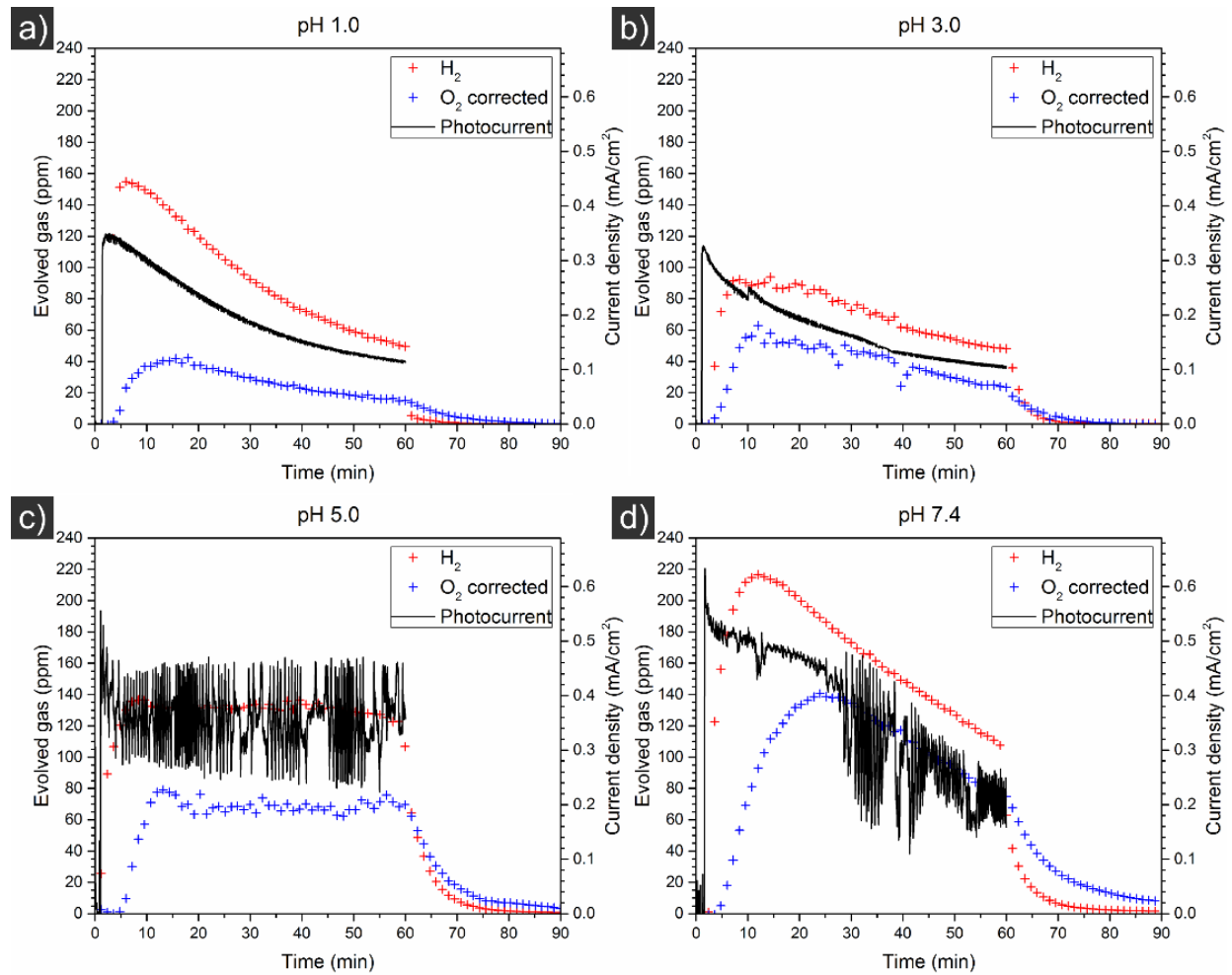

Figure 5.15 Photocurrent stability tests of $\mathrm{WO}_{3}$ photoanodes at $1.23 \mathrm{~V} v s$. RHE in $0.1 \mathrm{M}$ KPi buffer at a pH of a) 1.0 , b) 3.0, c) 5.0 and d) 7.4 under $100 \mathrm{~mW} / \mathrm{cm}^{2} \mathrm{AM} 1.5$ simulated solar illumination. $\mathrm{H}_{2}, \mathrm{O}_{2}$ and $\mathrm{N}_{2}$ gases were collected by a constant He purge of $10 \mathrm{ml} / \mathrm{min}$ through the reactor, separated with a GC and detected with a Pulsed Discharge Detector. The leak-in of $\mathrm{O}_{2}$ into the reactor was estimated based on the measured amount of $\mathrm{N}_{2}$ and subtracted from the total $\mathrm{O}_{2}$ amount. The two vertical axis are aligned in such that the current density represents the theoretical amount of $\mathrm{O}_{2}$ produced at the photoanode assuming $100 \%$ faradaic efficiency. The first minute of the measurement was in dark to illustrate the absence of a dark current. 
a)

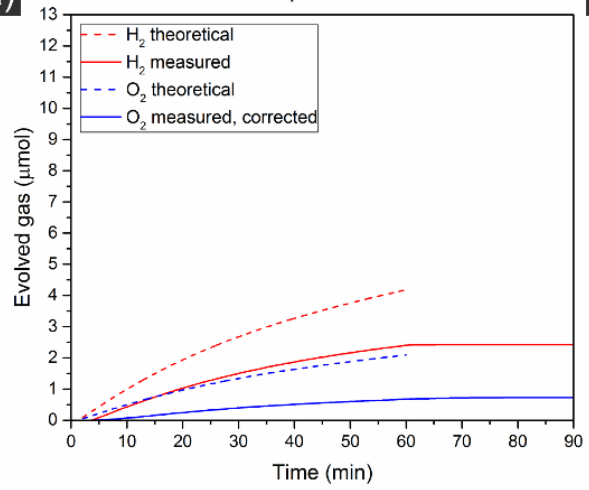

b)
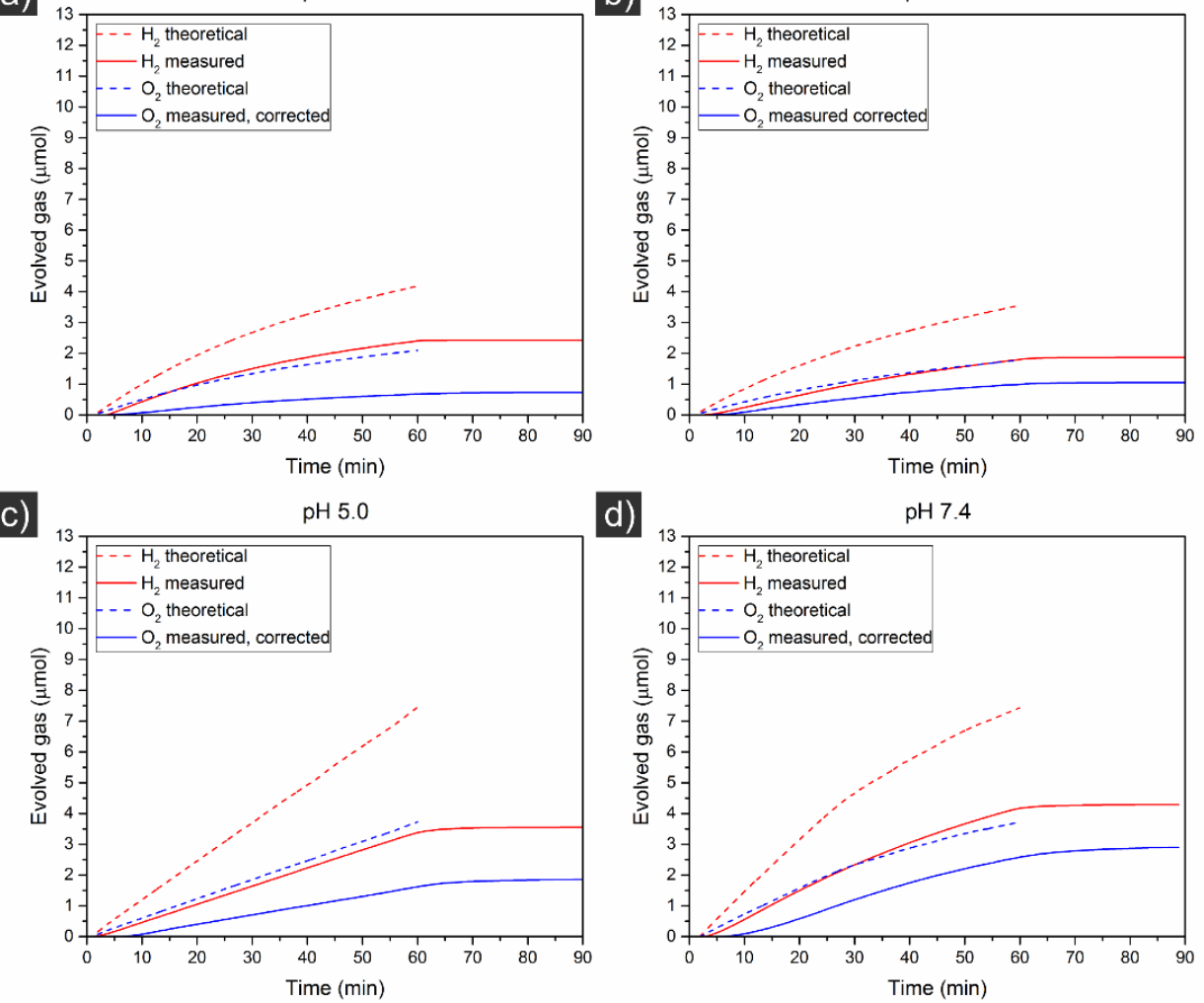

d)

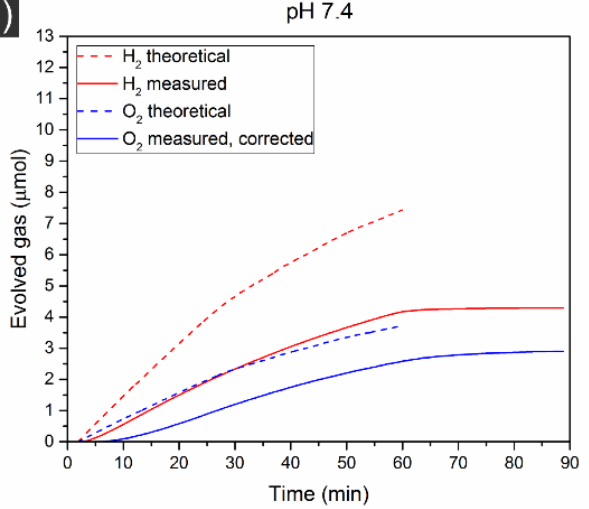

Figure 5.16 Integrated $\mathrm{H}_{2}$ and $\mathrm{O}_{2}$ gas evolution over time of $\mathrm{WO}_{3}$ photoanodes operated at $1.23 \mathrm{~V} v s$. RHE in $0.1 \mathrm{M} \mathrm{KPi}$ buffer at a $\mathrm{pH}$ of a) 1.0 , b) 3.0 , c) 5.0 and d) 7.4 under $100 \mathrm{~mW} / \mathrm{cm}^{2}$ AM 1.5 simulated solar illumination. The leak-in of $\mathrm{O}_{2}$ into the reactor was estimated based on the measured amount of $\mathrm{N}_{2}$ and subtracted from the total $\mathrm{O}_{2}$ amount. Theoretical amounts were calculated from charge passed through the electrodes. The first minute of the measurement was in dark to illustrate the absence of a dark current. 
$\mathrm{WO}_{3}$ photoanode deactivation during photoelectrochemical water oxidation

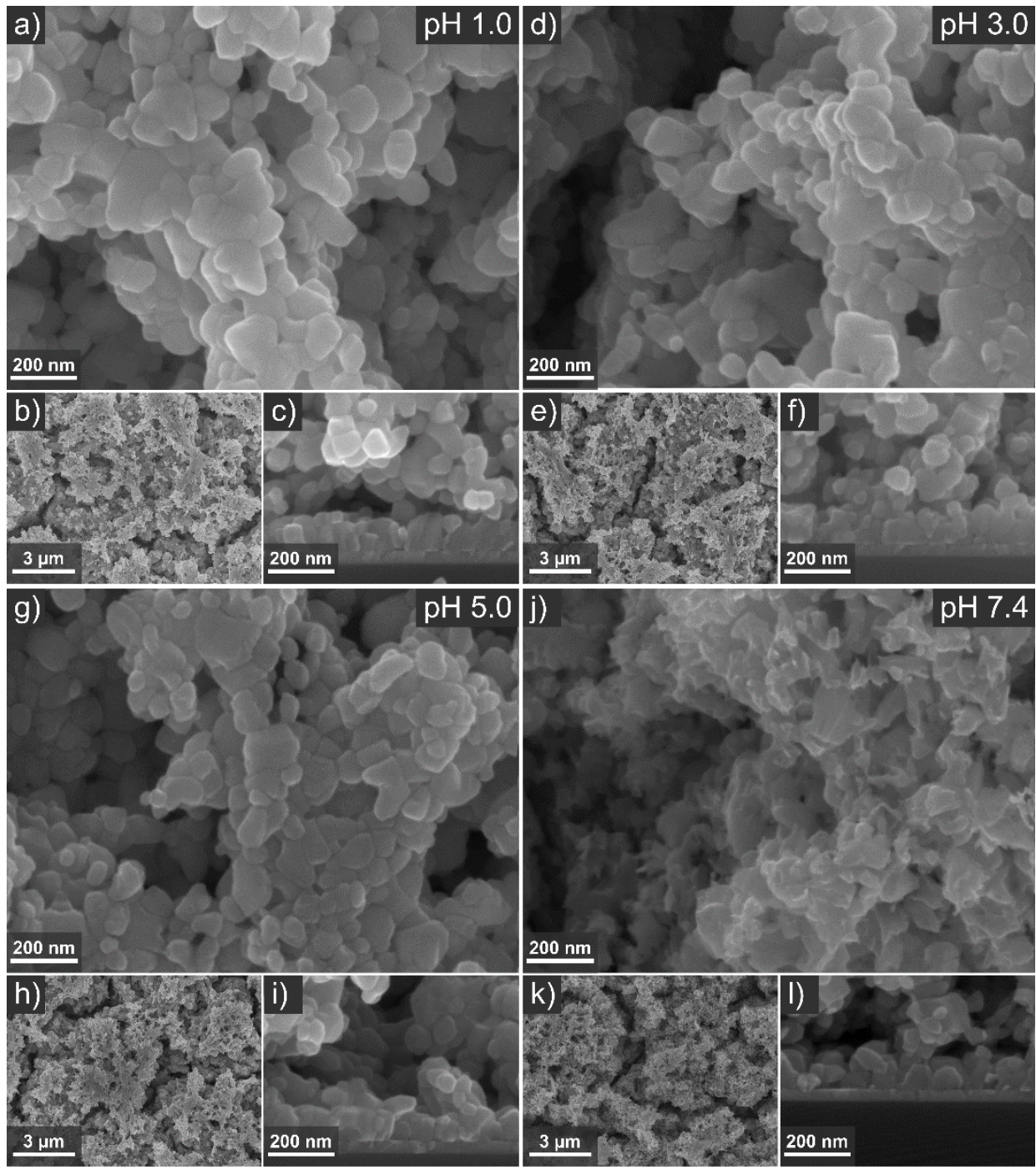

Figure 5.17 Top-view (a, b, d, e, g, h, j, k) and cross sectional (c, f, i, l) SEM images after $1.0 \mathrm{~h}$ photocatalytic operation of $\mathrm{WO}_{3}$ photoanodes at $1.23 \mathrm{~V} v s$. RHE in $0.1 \mathrm{M} \mathrm{KPi}$ buffer at a pH of $1.0(\mathrm{a}, \mathrm{b}, \mathrm{c}), 3.0(\mathrm{~d}, \mathrm{e}, \mathrm{f}), 5.0(\mathrm{~g}, \mathrm{~h}, \mathrm{i})$ and $7.4(\mathrm{j}, \mathrm{k}, \mathrm{l})$ under $100 \mathrm{~mW} / \mathrm{cm}^{2}$ AM 1.5 simulated solar illumination. 

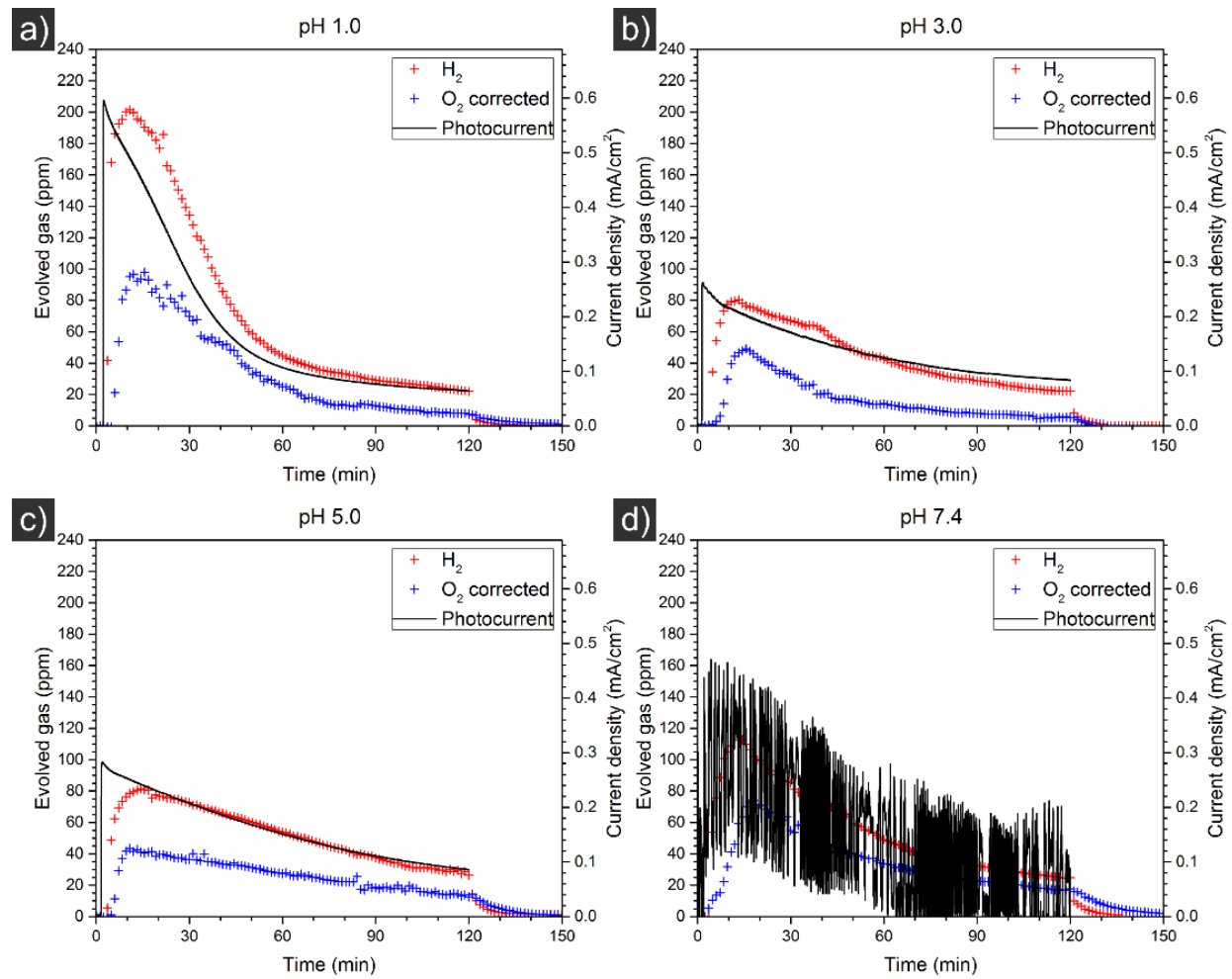

Figure 5.18 Photocurrent stability tests of $\mathrm{WO}_{3}$ photoanodes at $1.23 \mathrm{~V}$ vs. RHE in $0.1 \mathrm{M}$ KPi buffer at a pH of a) 1.0, b) 3.0, c) 5.0 and d) 7.4 under $100 \mathrm{~mW} / \mathrm{cm}^{2}$ AM 1.5 simulated solar illumination. $\mathrm{H}_{2}, \mathrm{O}_{2}$ and $\mathrm{N}_{2}$ gases were collected by a constant He purge of $10 \mathrm{ml} / \mathrm{min}$ through the reactor, separated with a GC and detected with a Pulsed Discharge Detector. The leak-in of $\mathrm{O}_{2}$ into the reactor was estimated based on the measured amount of $\mathrm{N}_{2}$ and subtracted from the total $\mathrm{O}_{2}$ amount. The two vertical axis are aligned in such that the current density represents the theoretical amount of $\mathrm{O}_{2}$ produced at the photoanode assuming $100 \%$ faradaic efficiency. The first minute of the measurement was in dark to illustrate the absence of a dark current. 

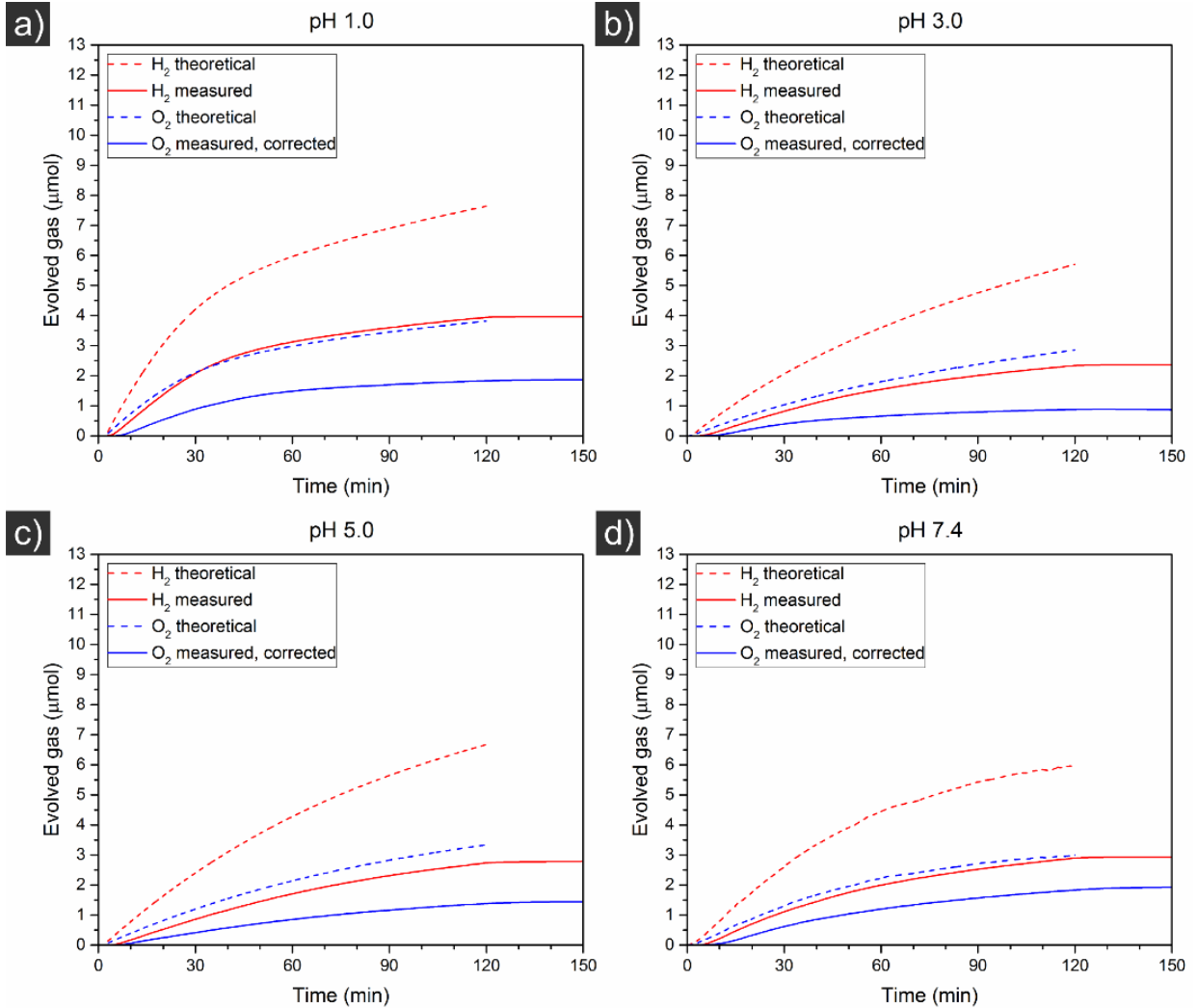

Figure 5.19 Integrated $\mathrm{H}_{2}$ and $\mathrm{O}_{2}$ gas evolution over time of $\mathrm{WO}_{3}$ photoanodes operated at $1.23 \mathrm{~V} v s$. RHE in $0.1 \mathrm{M} \mathrm{KPi}$ buffer at a $\mathrm{pH}$ of a) 1.0, b) 3.0, c) 5.0 and d) 7.4 under $100 \mathrm{~mW} / \mathrm{cm}^{2}$ AM 1.5 simulated solar illumination. The leak-in of $\mathrm{O}_{2}$ into the reactor was estimated based on the measured amount of $\mathrm{N}_{2}$ and subtracted from the total $\mathrm{O}_{2}$ amount. Theoretical amounts were calculated from charge passed through the electrodes. The first minute of the measurement was in dark to illustrate the absence of a dark current. 


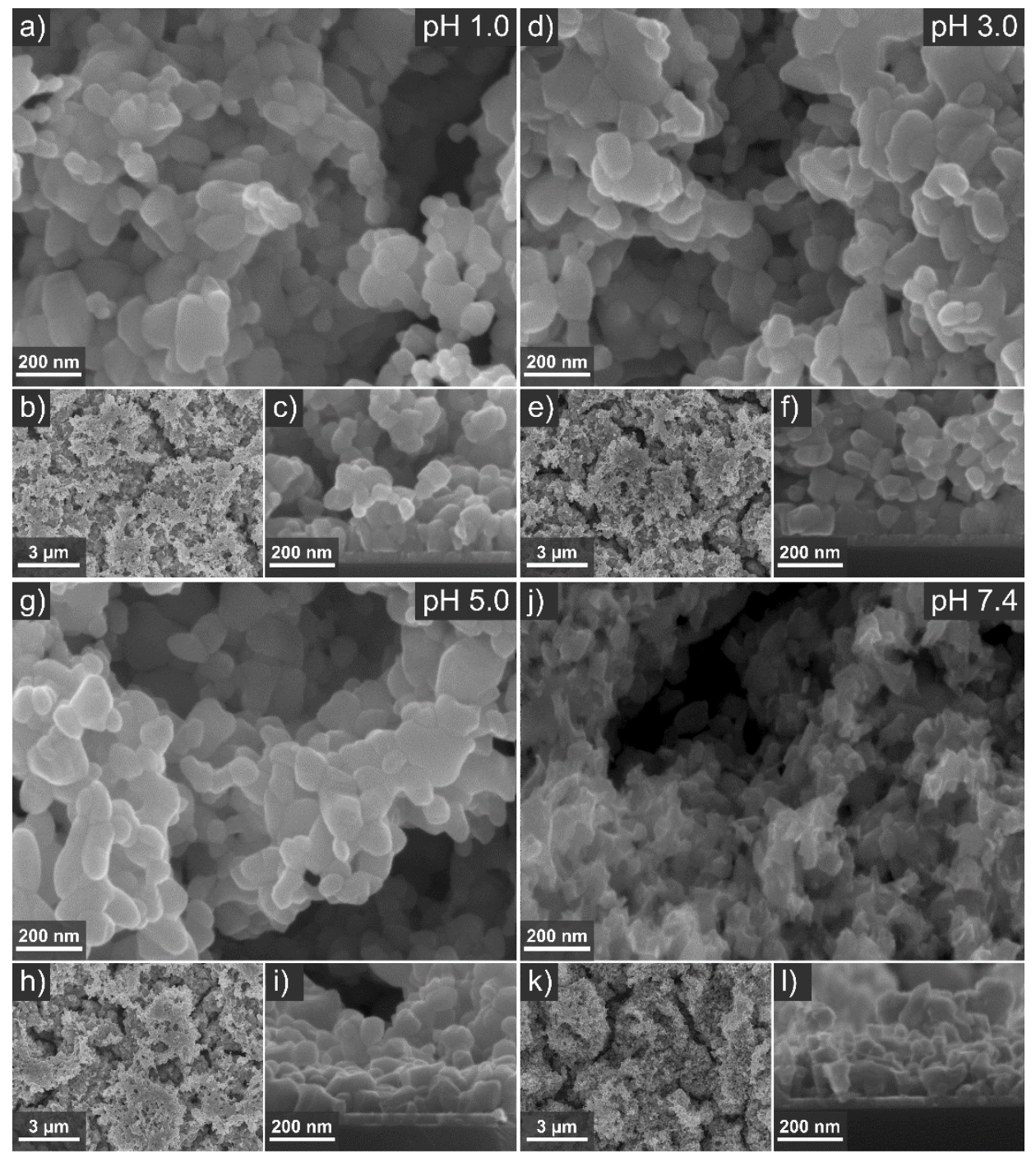

Figure 5.20 Top-view (a, b, d, e, g, h, j, k) and cross sectional (c, f, i, l) SEM images after $2.0 \mathrm{~h}$ photocatalytic operation of $\mathrm{WO}_{3}$ photoanodes at $1.23 \mathrm{~V} v s$. RHE in $0.1 \mathrm{M} \mathrm{KPi}$ buffer at a pH of $1.0(\mathrm{a}, \mathrm{b}, \mathrm{c}), 3.0(\mathrm{~d}, \mathrm{e}, \mathrm{f}), 5.0(\mathrm{~g}, \mathrm{~h}, \mathrm{i})$ and $7.4(\mathrm{j}, \mathrm{k}, \mathrm{l})$ under $100 \mathrm{~mW} / \mathrm{cm}^{2}$ AM 1.5 simulated solar illumination. 

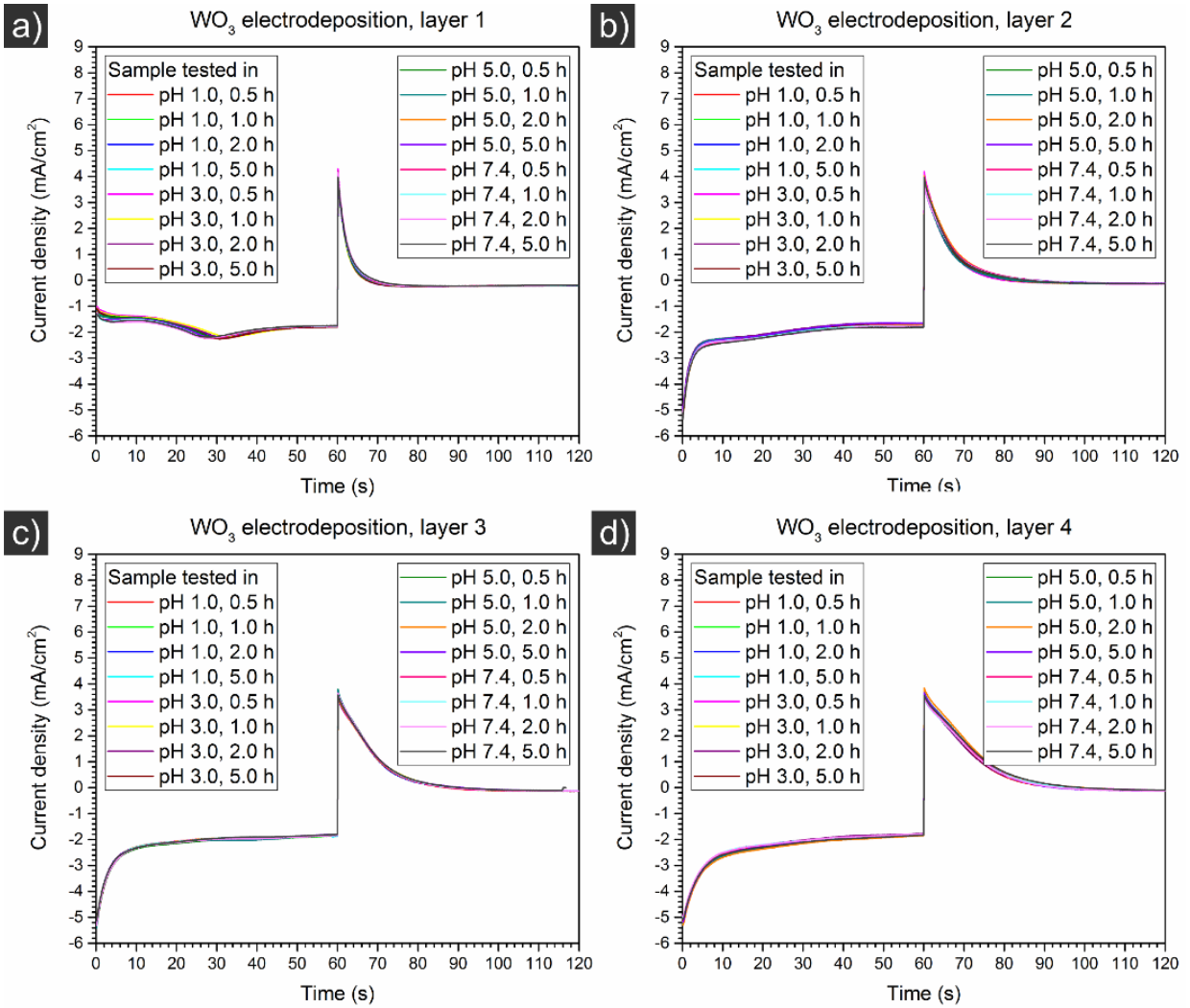

Figure 5.21 Electrodeposition of 4 layers $\mathrm{WO}_{3}$ on ITO coated highly p-type doped silicon from a $0.1 \mathrm{M}$ peroxo-tungstic acid plating solution at $45^{\circ} \mathrm{C}$ and applied potentials of $-0.6 \mathrm{~V}$ and $0.2 \mathrm{~V}$ for $60 \mathrm{~s}$ each versus $\mathrm{Ag} / \mathrm{AgCl}(3 \mathrm{M} \mathrm{NaCl})$ reference electrode. After the deposition of each layer the substrate was rinsed with high-purity water for 2 min, gently blow-dried with an air gun and dried in a preheated oven at $120{ }^{\circ} \mathrm{C}$ for $30 \mathrm{~min}$ after deposition of layer 1 to 3 to prevent crack formation. 
a)

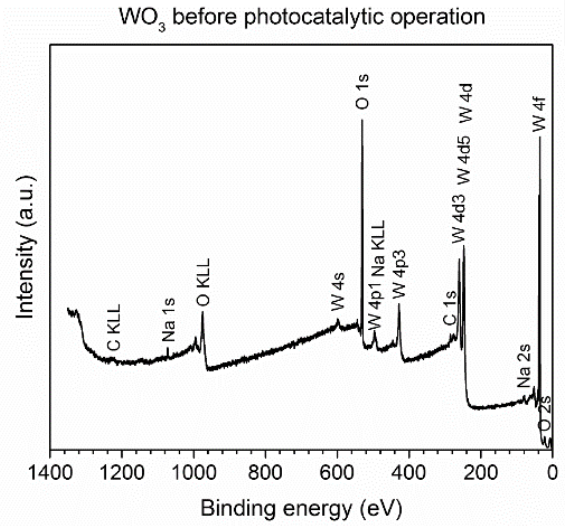

c)
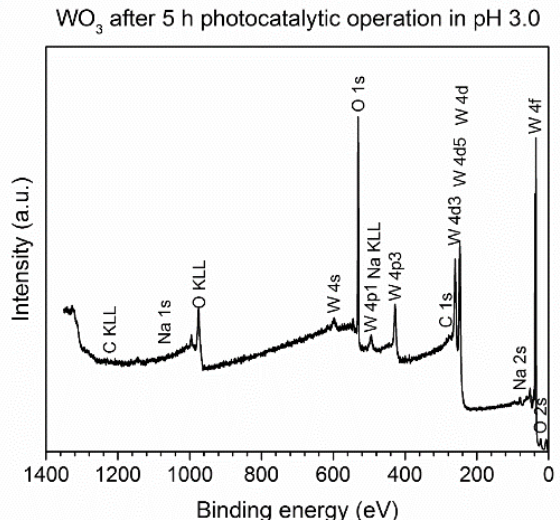

b)

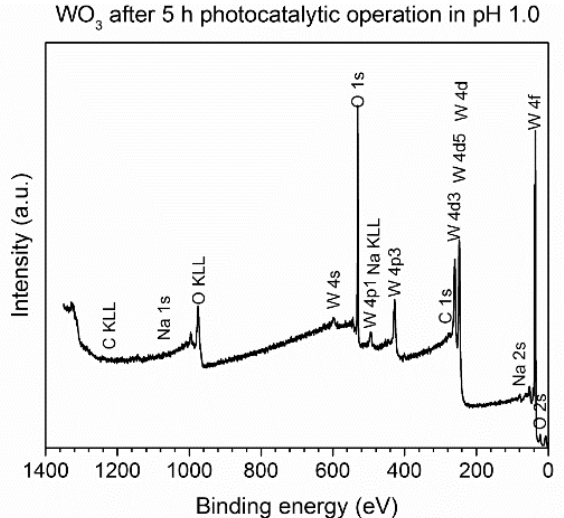

d)

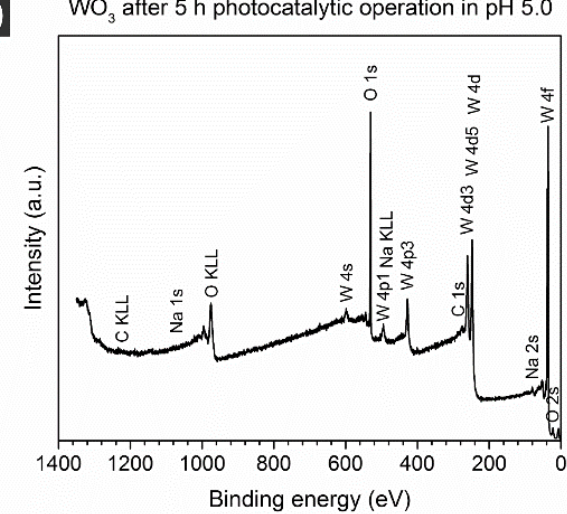

Figure 5.22 XPS survey spectra of $\mathrm{WO}_{3}$ photoanodes a) before photocatalytic tests and after 5 h operation at b) $\mathrm{pH} 1.0, \mathrm{c}) \mathrm{pH} 3.0$ and d) $\mathrm{pH} 5.0$. 


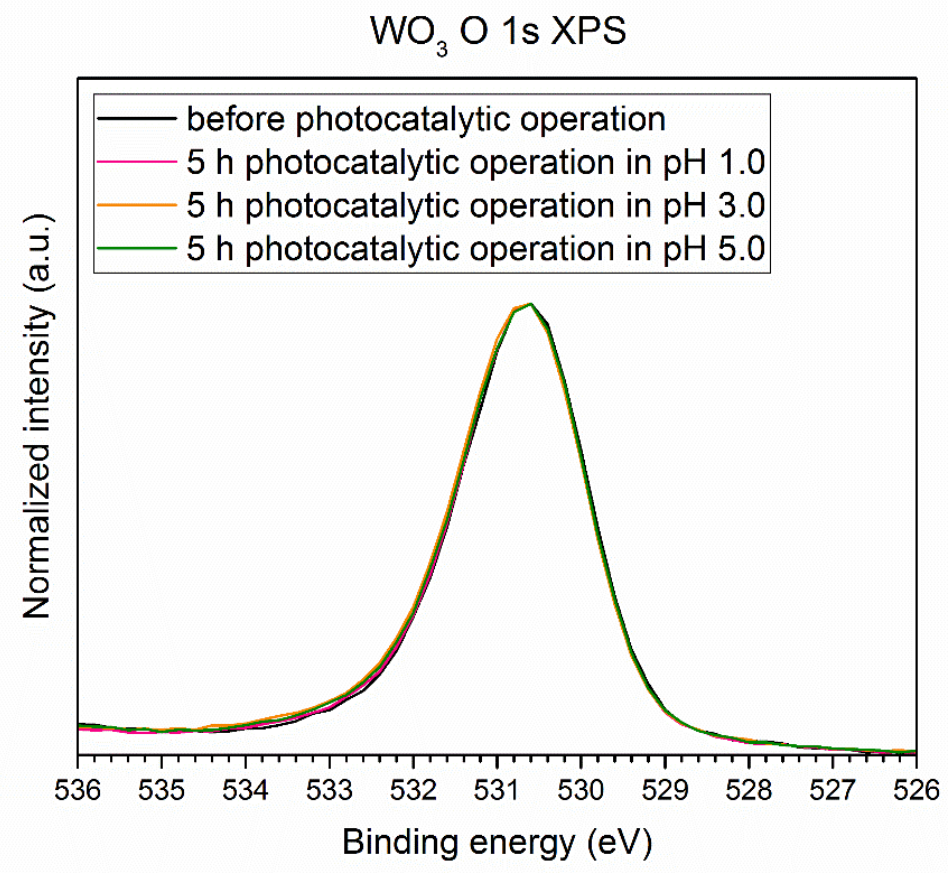

Figure 5.23 O 1s XPS spectra of $\mathrm{WO}_{3}$ photoanodes before photocatalytic tests and after 5 h operation at $\mathrm{pH} 1.0, \mathrm{pH} 3.0$ and $\mathrm{pH} 5.0$. 


\section{Chapter 6}

\section{Integration of molybdenum-doped, hydrogen-annealed $\mathrm{BiVO}_{4}$ on silicon microwires for photocatalytic applications}

$\mathrm{BiVO}_{4}$ is a promising photoanode material for photoelectrochemical water oxidation. However, its short minority-carrier diffusion lengths minimize the allowable thickness of the films, typically below the values required for complete light absorption. In order to increase the amount of deposited material without the limitation of short diffusion length, we have deposited nanoporous molybdenum-doped and hydrogen-annealed $\mathrm{H}_{-} \mathrm{BiVO}_{4-\mathrm{x}} \mathrm{Mo}$ on microwirestructured silicon substrates covered with indium tin oxide (ITO). In this $\mathrm{Si}-\mathrm{BiVO}_{4}$ tandem architecture we aimed to decouple the directions and path lengths of light absorption and charge carrier transport to improve its performance. Mo doping of the $\mathrm{BiVO}_{4}$ was applied to improve the charge carrier diffusion, while hydrogen annealing targets the same by enhancing the formation of oxygen vacancies. High internal surface area of the nanoporous n-type $\mathrm{BiVO}_{4}$ is expected to create a high junction area between semiconductor and electrolyte and thus enhance electron and hole separation. Devices with microwires of $4 \mu \mathrm{m}$ radius, $4 \mu \mathrm{m}$ to $20 \mu \mathrm{m}$ spacing, and $5.3 \mu \mathrm{m}$ to $15.9 \mu \mathrm{m}$ length were prepared, sputtered with ITO, subsequently covered by BiOI in an electrodeposition process and converted to $\mathrm{H}-\mathrm{BiVO}_{4-\mathrm{x}}: \mathrm{Mo}$. While the optical properties of $\mathrm{H}-\mathrm{BiVO}_{4-\mathrm{x}}$ :Mo were favorable as compared to flat surfaces, photocatalytic tests of these devices showed that flat equivalents of $\mathrm{Si}$ substrates outperformed microwire-structured devices in sulfite $\left(\mathrm{SO}_{3}{ }^{2-}\right)$ oxidation in a KPi buffer solution ( $\mathrm{pH}$ 7.0). We attribute this to diffusion limitations of redox species in the internal volume of the microwires. This hypothesis is supported by the observation, during the deposition process, of $\mathrm{BiOI}$ starting to grow at the bottom of the microwires, and additionally faster growth on microwire-structured arrays with a lower spacing. 


\subsection{Introduction}

Bismuth vanadate $\left(\mathrm{BiVO}_{4}\right)$, an n-type semiconductor, is one of the most promising photoanode materials for photoelectrochemical oxidation of water. It is stable in a $\mathrm{pH}$ range between 3 and $11,{ }^{[1]}$ environmentally benign, widely available, non-toxic, inexpensive and is commonly used in industry as a yellow pigment. The valence band edge of the monoclinic phase is located at $2.8 \mathrm{~V} v s$. $\mathrm{NHE}^{[2]}$ and is thus sufficiently positive to oxidize water at a potential of $1.23 \mathrm{~V}$ $v s$. NHE. The conduction band edge is located at $0.3 \mathrm{~V} v s$. NHE, ${ }^{[2]}$ which is near the $\mathrm{H}_{2}$ evolution potential of $0 \mathrm{~V} v s$. NHE, and thus the photocurrent onset potential is relatively low, leading to a high photocurrent generation in the low bias region in comparison to other photoanode materials with a more positive conduction band edge. ${ }^{[3]}$ The direct bandgap of $2.4 \mathrm{eV}$ to $2.5 \mathrm{eV}^{[2,4]}$ allows to absorb up to $11 \%$ of the solar spectrum which equals a theoretically maximal photocurrent of $7.5 \mathrm{~mA} / \mathrm{cm}^{2}$ and a solar to hydrogen efficiency of $9 \%$ when illuminated with an AM 1.5 spectrum. ${ }^{[5]}$ Further efficiency improvement can be achieved by stacking $\mathrm{BiVO}_{4}$ on a lower band gap absorber, such as silicon. ${ }^{[6,7]}$

However, the $\mathrm{BiVO}_{4}$ minority-carrier diffusion length of $70 \mathrm{~nm}^{[8]}$ is below the required thickness for total optical light absorption. This means that the layers in $\mathrm{BiVO}_{4}$ photoanodes cannot be made sufficiently thick to absorb all of the incident photons with energies above $2.5 \mathrm{eV}$. When the layer becomes too thick, the photogenerated charge carriers will not be able to either reach the electrolyte to perform the oxidation reaction, or the conductive layer to be collected and close the circuit in a photo-electrochemical cell.

Several routes have been described in literature to overcome this drawback. Most of them focus on charge transport improvement by doping with for instance molybdenum, ${ }^{[9-11]}$ tungsten $^{[5,12]}$ or nitrogen, ${ }^{[13]}$ or by the creation of oxygen vacancies by annealing in hydrogen atmosphere. ${ }^{[14,15]}$ Others have created $\mathrm{BiVO}_{4}$ layers with a high internal surface area. This was achieved by developing a procedure to create nanoporous $\mathrm{BiVO}_{4}$ from electrodeposited $\mathrm{BiOI}$ sheets. This method of preparation suppressed bulk carrier recombination without additional doping. ${ }^{[3,}{ }^{16]}$ Furthermore, others have created $\mathrm{WO}_{3} / \mathrm{BiVO}_{4}: \mathrm{W}$ core/shell heterostructures which combine the merits of the two semiconductors, i.e., the 
excellent charge transport characteristics of $\mathrm{WO}_{3}$ and the good light absorption capability of $\mathrm{BiVO}_{4} \cdot{ }^{[17-22]}$

A further alternative to improve the activity of $\mathrm{BiVO}_{4}$ photoanodes is to deposit $\mathrm{BiVO}_{4}$ on structured conductive substrates which provide a high internal surface area such as nano- or microwires. They reduce electron and hole recombination by allowing to keep the $\mathrm{BiVO}_{4}$ layers thin, providing short minority carrier diffusion lengths and thus reduce electron and hole recombination. ${ }^{[23]}$ Additionally, these systems have light trapping properties and thus lead to a much higher absorption of incident photons with energies above the semiconductor bandgap..$^{[24-27]}$

Many methods have been developed to deposit $\mathrm{BiVO}_{4}$ on substrates, such as spray pyrolysis, ${ }^{[28,29]}$ chemical bath deposition, ${ }^{[30]}$ chemical vapor deposition, ${ }^{[31]}$ pulsed laser deposition, ${ }^{[32]}$ hydrothermal ${ }^{[33]}$ or $\operatorname{direct}^{[34]}$ and indirect ${ }^{[3,}$ 16, 35] electrodeposition. However, the method has to be compatible with: (i) deposition on 3-dimensional structures, (ii) introduction of dopants, (iii) a high surface area of nanoporous $\mathrm{BiVO}_{4}$, and (iv) favorable pricing and scalability.

Herein we integrate nanoporous, molybdenum-doped, and hydrogen-annealed $\mathrm{H}-\mathrm{BiVO}_{4-\mathrm{x}}$ :Mo on p-type silicon flat surfaces and microwire arrays with an intermediate indium tin oxide (ITO) layer using a two-step synthesis procedure developed by Choi et al ${ }^{[3,16]}$ First, the electrodeposition of BiOI was studied with a focus on the influence of microwire spacing and length (Section 6.3.1). The $\mathrm{BiOI}$ deposition process is triggered by a local $\mathrm{pH}$ change which allows to trace back the formation of $\mathrm{pH}$ gradients in-between the microwire structures through the observation of $\mathrm{BiOI}$ thickness gradients. Then, the transformation to $\mathrm{H}-\mathrm{BiVO}_{4-\mathrm{x}}$ :Mo was evaluated, varying the thickness of $\mathrm{H}-\mathrm{BiVO}_{4-\mathrm{x}}: \mathrm{Mo}$ on microwires of variable length and spacing (Section 6.3.2). The results are evaluated on the basis of sulfite oxidation performance during the photoelectrochemical process (Section 6.3.3). Finally, we evaluate the influence of Mo doping and annealing conditions in our preparation procedure (Section 6.3.4) on performance. 


\subsection{Materials and methods}

\subsubsection{Fabrication of silicon microwire arrays}
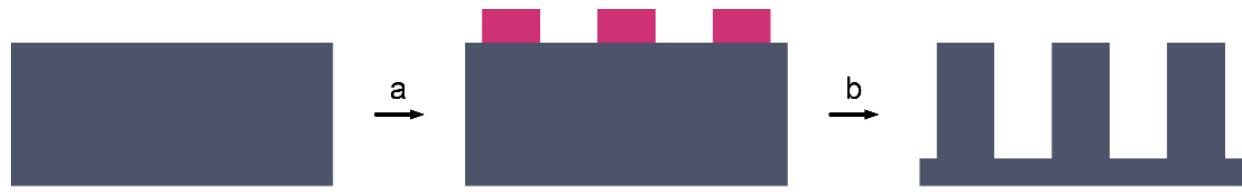

lc
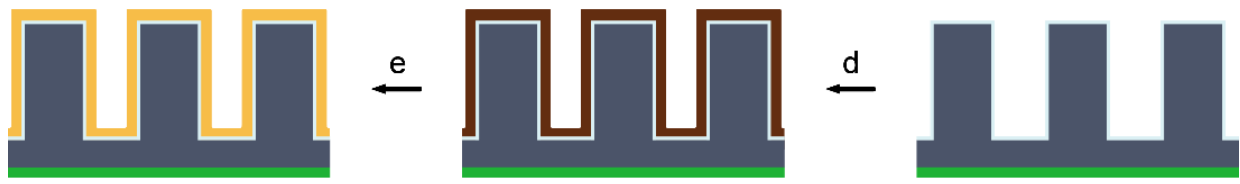

$p^{++}-S i$

photoresist

ITO

Al/Si alloy

BiOI

$\mathrm{BiVO}_{4}$

Figure 6.1 Schematic illustration of the integration of $\mathrm{H}-\mathrm{BiVO}_{4-\mathrm{x}}$ :Mo on silicon microwires as a photoanode. a) Definition of microwire arrays by standard UV lithography. b) Deep reactive ion etching (DRIE) and removal of photoresist. c) HF etching of silicon oxide and sputtering of aluminum/silicon alloy $(99 \% \mathrm{Al}, 1 \% \mathrm{Si})$ on the backside and ITO on the frontside. d) Electrochemical deposition of BiOI from a $\mathrm{KI}$, $\mathrm{Bi}\left(\mathrm{NO}_{3}\right)_{3}$ and p-benzoquinone in water/ethanol solution at $-0.1 \mathrm{~V}$ vs. $\mathrm{Ag} / \mathrm{AgCl}$ $(3 \mathrm{M} \mathrm{NaCl})$. e) Formation of $\mathrm{H}-\mathrm{BiVO}_{4-\mathrm{x}}$ : $\mathrm{Mo}$ by dropcasting $\mathrm{VO}(\mathrm{acac})_{2}$ and $\mathrm{Na}_{2} \mathrm{MoO}_{4}$ in DMSO, evaporation of DMSO at $100{ }^{\circ} \mathrm{C}$, calcination at $450{ }^{\circ} \mathrm{C}$ in air, soaking in $1 \mathrm{M}$ $\mathrm{KOH}$ and reduction in a $5 \% \mathrm{H}_{2} / 95 \%$ Ar atmosphere at $300{ }^{\circ} \mathrm{C}$ for $0.5 \mathrm{~h}$.

Figure 6.1 schematically shows the fabrication process of $\mathrm{BiVO}_{4-\mathrm{x}}$ :Mo coated silicon microwires. Highly boron-doped, p-type silicon substrates (<100>-oriented, resistivity $0.010-0.025 \Omega \mathrm{cm}, 100 \mathrm{~mm}$ diameter, $525 \mu \mathrm{m}$ thickness, single-side polished, Okmetic Finland) were cleaned by immersion in $100 \%$ nitric acid $\left(\mathrm{HNO}_{3}\right)(2 \times 5 \mathrm{~min})$ and in $69 \%$ nitric acid $(10 \mathrm{~min})$, followed by quick dump rinsing in de-mineralized (DI) water, immersion in a $1 \%$ aqueous hydrofluoric (HF) acid for at least 1 min to remove the formed oxide shell and another quick dump rinsing cycle. After spin-drying the wafers, areas with an array of microwires (specifications: diameter $4 \mu \mathrm{m}$, spacing $4 \mu \mathrm{m}-20 \mu \mathrm{m}$, hexagonally stacked, $0.5 \times 0.5 \mathrm{~cm}^{2}$ cell size on a specimen of $\left.2 \times 2 \mathrm{~cm}^{2}\right)$ were defined in photoresist (Olin 907-17), and post-baked for $10 \mathrm{~min}$ at $120^{\circ} \mathrm{C}$ after exposure and development. The photoresist acted as a mask layer during deep reactive ion etching (CF-chemistry, SPTS Pegasus). The height of the wires was determined by the etch duration, which was set to $60 \mathrm{~s}, 120 \mathrm{~s}$ or $180 \mathrm{~s}$, resulting 
in microwire lengths of approximately $5.3 \mu \mathrm{m}, 10.6 \mu \mathrm{m}$ and $15.9 \mu \mathrm{m}$. The surface area enhancement factors between projected and effective surface area for a complete and partially microwire structured area is shown in Table 6.1.

Table 6.1 Total surface area enhancement by microwires of $4 \mu \mathrm{m}$ diameter and sample area enhancement containing $22.1 \%$ microwire-structured area during BiOI deposition and $85.7 \%$ microwire-structured area during photocurrent measurements. The active area is illustrated inside the black frame in the schematic illustrations. The centered square is a microwire-structured area with a projected surface area of $0.25 \mathrm{~cm}^{2}$.

\begin{tabular}{|c|c|c|c|c|}
\hline $\begin{array}{c}\text { Microwire } \\
\text { spacing } \\
(\mu \mathrm{m})\end{array}$ & $\begin{array}{r}\text { Effective a } \\
\text { enhancemen } \\
\text { for } \\
5.3 \mid 10.6 \\
\mu \mathrm{m} \text { long micr }\end{array}$ & $\begin{array}{l}\text { rea } \\
\text { factor } \\
15.9 \\
\text { owires }\end{array}$ & $\begin{array}{c}\text { Effective area } \\
\text { enhancement factor } \\
\text { during BiOI } \\
\text { deposition } \\
\text { for } \\
5.3 \mid 10.6 \text { | } 15.9 \\
\mu \mathrm{m} \text { long microwires }\end{array}$ & $\begin{array}{c}\text { Effective area } \\
\text { enhancement factor } \\
\text { during photocurrent } \\
\text { measurements for } \\
5.3|10.6| 15.9 \\
\text { um long microwires }\end{array}$ \\
\hline 4 & $2.04 \mid 3.08$ & 4.12 & $1.23|1.46| 1.69$ & $1.88|2.80| 3.73$ \\
\hline 6 & 1.67 & 3.00 & $1.15|1.29| 1.44$ & $2.14 \mid 2.73$ \\
\hline 8 & $1.46 \mid 1.93$ & 2.39 & $1.10|1.20| 1.31$ & $1.37|1.78| 2.19$ \\
\hline 10 & $1.34 \mid 1.68$ & 2.02 & \begin{tabular}{l|l|l|} 
& 1.23 \\
\end{tabular} & $1.27|1.57| 1.87$ \\
\hline 15 & \begin{tabular}{l|l|}
1.18 & 1.37
\end{tabular} & 1.55 & $1.04|1.08| 1.12$ & $1.13|1.29| 1.45$ \\
\hline 20 & $1.12 \mid 1.23$ & 1.35 & $1.03|1.05| 1.08$ & $1.07|1.17| 1.27$ \\
\hline $\begin{array}{l}\text { Schematic } \\
\text { illustration } \\
\text { of the } \\
\text { active } \\
\text { area }\end{array}$ & & & & \\
\hline
\end{tabular}

\subsubsection{Sputtering of indium tin oxide (ITO)}

The wafers were treated with oxygen plasma for $20 \mathrm{~min}$ followed by $\mathrm{C}_{4} \mathrm{~F}_{8}$ cleaning for $1 \mathrm{~min}$ to remove fluorocarbon residues (GIGAbatch 360P), and immersed in $100 \%$ nitric acid $\left(\mathrm{HNO}_{3}\right)(2 \times 5 \mathrm{~min})$ and consecutively in $69 \%$ nitric acid (10 min), followed by: a quick dump rinse in DI water to remove any residue from the etching process, immersion in $1 \%$ aqueous $\mathrm{HF}$ for at least 1 min to remove the silicon oxide shell, washing by quick dump rinsing in DI water, and spin-drying. Subsequently, the backside was sputter-coated with a $1 \mu \mathrm{m}$ thick aluminum/silicon alloy (99\% Al, 1\% Si) (Oxford PL 400, $7000 \mathrm{~W}$ ) to create a 
low resistance Ohmic contact. Thereafter, the frontside was coated with ITO in a home-built reactive magnetron sputtering system (TCOater) in direct current (DC) mode, using a $90 \mathrm{wt} \% \mathrm{In}_{2} \mathrm{O}_{3}-10 \mathrm{wt} \% \mathrm{SnO}_{2}$ (99.99\%) target of $4.00 \mathrm{inch}$ diameter. A DC power of $100 \mathrm{~W}$ was applied. The distance between the target and the substrate was kept at $44 \mathrm{~mm}$, and the substrate was rotated at $5 \mathrm{rpm}$ during the whole deposition process. The reactor chamber was pumped down to a base pressure of $5.0 \times 10^{-7}$ mbar prior to sputtering, and a mix of $40 \mathrm{sccm} \mathrm{Ar}$ and $1 \mathrm{sccm}$ $\mathrm{O}_{2}(99.5 \%)$ was introduced as reactive gas and an $\mathrm{Ar}$ (99.99\%) flow of $20 \mathrm{sccm}$ as sputtering gas. The process pressure was $5.0 \times 10^{-7} \mathrm{mbar}$ and the substrate temperature during deposition was maintained at $20^{\circ} \mathrm{C}$. Before ITO was sputtered on the wafer, pre-sputtering was carried out under the same conditions for $1 \mathrm{~min}$ with a shutter covering the substrate. The deposition times were either $5 \mathrm{~min}$ or $20 \mathrm{~min}$ and the ITO deposition rate varied from $7 \mathrm{~nm} / \mathrm{min}$ in the center to $6 \mathrm{~nm} / \mathrm{min}$ at the edge on the horizontal part of the wafer. ITO thicknesses were determined by SEM.

\subsubsection{Electrodeposition of BiOI}

The electrodeposition procedure of $\mathrm{BiOI}$ and the following transformation to $\mathrm{BiVO}_{4}$ was derived from publications of Choi et al. ${ }^{[3,16]} \mathrm{A} 0.4 \mathrm{M}$ potassium iodide (KI) and $0.04 \mathrm{M}$ bismuth(III) nitrate $\left(\mathrm{Bi}\left(\mathrm{NO}_{3}\right)_{3}\right)$ solution was prepared by dissolving KI ( $\geq 99.0 \%$, Sigma-Aldrich) in high-purity water (Millipore, MilliQ, $\mathrm{R}=18.2 \mathrm{M} \Omega \mathrm{cm})$, adjusting the $\mathrm{pH}$ to 1.7 with nitric acid $\left(\mathrm{HNO}_{3}, 70 \%\right.$, ACS reagent, Sigma-Aldrich) and adding $\mathrm{Bi}\left(\mathrm{NO}_{3}\right)_{3} \cdot 5 \mathrm{H}_{2} \mathrm{O}(\geq 98.0 \%$, Sigma-Aldrich). To this solution, a solution of $0.23 \mathrm{M}$ p-benzoquinone ( $\geq 98 \%$, Sigma-Aldrich) in ethanol (99.8\%, AA Chemie B.V.) was added in a ratio of 2:5 (ethanol:aqueous) and stirred vigorously for $1 \mathrm{~h}$. The deposition was performed potentiostatically at $-0.1 \mathrm{~V}$ vs. a $\mathrm{Ag} / \mathrm{AgCl}(3 \mathrm{M} \mathrm{NaCl}$, BioLogic RE-1B) reference electrode in a custom-made Teflon-based reactor with a volume of about $8 \mathrm{ml}$ and a platinum mesh counter electrode. A potentiostat (PAR, VersaStat 3) served as a power source. The active silicon/ITO surface area was $1.13 \mathrm{~cm}^{2}$ as defined by the O-ring, and the deposition times were $30,60,120$ or $300 \mathrm{~s}$. This area covered $0.25 \mathrm{~cm}^{2}$ of the structured, and $0.88 \mathrm{~cm}^{2}$ of a flat surface (see drawing in Table 6.1). All deposition experiments were performed at room temperature and the reactor was open to the environment. The samples were prepared in two batches 
and each sample in each batch was processed consecutively. The data reported in the results paragraph are based on samples from the same batch.

\subsubsection{Synthesis of H-BiVO4-x:Mo}

A solution $(25 \mu \mathrm{l})$ of dimethyl sulfoxide (DMSO, $\geq 99.5 \%$, Sigma-Aldrich) containing $0.4 \mathrm{M}$ vanadyl acetylacetonate ( $\mathrm{VO}(\mathrm{acac})_{2}, 98 \%$, Sigma-Aldrich) with or without $0.004 \mathrm{M}$ sodium molybdate $\left(\mathrm{Na}_{2} \mathrm{MoO}_{4}, \geq 99 \%\right.$, Sigma-Aldrich) was added on top of the BiOI-coated substrate and dried in a preheated drying oven at $100{ }^{\circ} \mathrm{C}$ for $60 \mathrm{~min}$. Samples were calcined immediately at $450{ }^{\circ} \mathrm{C}$ for $2 \mathrm{~h}$ (at a heating rate of $\left.2{ }^{\circ} \mathrm{C} / \mathrm{min}\right)$. Afterwards, the excess of vanadium(III) oxide $\left(\mathrm{V}_{2} \mathrm{O}_{3}\right)$ was removed by placing $500 \mu \mathrm{l}$ of an aqueous (MilliQ) $1 \mathrm{M} \mathrm{KOH} \mathrm{(99.99 \% ,}$ Sigma-Aldrich) solution on top of the sample for $30 \mathrm{~min}$, rinsing with MilliQ water, and drying with compressed air, and repeating this whole procedure. Subsequently, the samples were annealed in a tube furnace at $300{ }^{\circ} \mathrm{C}$ for $0.5 \mathrm{~h}$ at a heating rate of $10{ }^{\circ} \mathrm{C} / \mathrm{min}$ in a $5 \% \mathrm{H}_{2} / 95 \%$ Ar atmosphere at a flow of $500 \mathrm{sccm}$. The microwire-structured samples were prepared in two batches, and all samples in each batch were processed simultaneously. The data reported in the results paragraph are based on samples from the same batch.

\subsubsection{Photoelectrochemical measurements}

Photoelectrochemical measurements of individual electrodes were performed in a custom-made Teflon-based reactor with a volume of about $8 \mathrm{ml}$ which was open to the environment. Illumination occurred through a quartz glass window and $25 \mathrm{~mm}$ electrolyte (front-side illumination), and the incident beam was perpendicular to the specimen surface. A solar simulator (Newport) with a 300 W xenon lamp and an air mass (AM) 1.5 global filter was used as light source. The intensity of the simulated sunlight was adjusted to 1 sun $\left(100 \mathrm{~mW} / \mathrm{cm}^{2}\right)$ with a standard reference silicon solar cell. The $J$ - $V$ photocurrent data were obtained using a standard three-electrode setup with a platinum mesh counter electrode and a $\mathrm{Ag} / \mathrm{AgCl}(3 \mathrm{M} \mathrm{NaCl}, \mathrm{BASi} \mathrm{MF} 2052)$ reference electrode at room temperature. The reference electrode has a potential $\left(E_{\mathrm{Ag} / \mathrm{AgCl}}^{\mathrm{O}}\right)$ of $+0.209 \mathrm{~V}$ with respect to the standard hydrogen electrode (SHE), which was confirmed with a new $\mathrm{Ag} / \mathrm{AgCl}$ (3 M NaCl, BASi MF 2052) master reference electrode before 
measurements. All voltages reported were calculated versus the reversible hydrogen electrode (RHE) using the following Equation 6.1:

$E_{\mathrm{RHE}}=E_{\mathrm{Ag} / \mathrm{AgCl}}^{o}+0.059 \mathrm{~V} \times \mathrm{pH}+E_{\mathrm{Ag} / \mathrm{AgCl}}$

An air-saturated $1 \mathrm{M}$ sodium sulfite $\left(\mathrm{Na}_{2} \mathrm{SO}_{3}\right)$ in $0.5 \mathrm{M}$ potassium phosphate (KPi) buffer solution with a $\mathrm{pH}$ of 7.0 served as the electrolyte. The potential was swept with a scan rate of $10 \mathrm{mV} / \mathrm{s}$ from 0 to $2.0 \mathrm{~V} v \mathrm{~s}$. RHE first in dark and then under illumination. A potentiostat (PAR, VersaStat 4) served as a power source. The active surface area was $0.28 \mathrm{~cm}^{2}$ as determined by the O-ring. This area covered $0.24 \mathrm{~cm}^{2}$ of the structured and $0.04 \mathrm{~cm}^{2}$ of flat surface (see drawing in Table 6.1). These values were incorporated in the determination of the effective surface area calculation. The samples were prepared in two batches, and all samples in each batch were processed consecutively. The data reported in the results paragraph are based on samples from the same batch.

\subsubsection{Scanning electron microscopy (SEM)}

High-resolution scanning electron microscopy (HR SEM) images were taken with a FEI Sirion FEG SEM with a Through the Lens Detector (TLD), operated at acceleration voltages of $10 \mathrm{kV}$. The imaged areas are random, and somewhere around the center of the sample.

\subsubsection{X-ray powder diffraction (XRD)}

X-ray diffraction patterns were determined with a Bruker D2 PHASER XRD using $\mathrm{Cu} \mathrm{K}_{\alpha}$ radiation at an acceleration voltage of $30 \mathrm{kV}$.

\subsubsection{Raman spectroscopy}

Raman spectra were collected at ambient conditions by using a Bruker SENTERRA Raman Spectrometer equipped with a $532 \mathrm{~nm}$ laser and a cooled CCD detector. Measurements were performed at $10 \mathrm{~mW}$ laser power intensity and integration times of $2.0 \mathrm{~s}$. 


\subsection{Results and discussion}

\subsubsection{Electrodeposition of $\mathrm{BiOI}$}

Hexagonally stacked microwires of 5.3, 10.6 and $15.9 \mu \mathrm{m}$ length, $4 \mu \mathrm{m}$ diameter and $4,6,8,10,15$ and $20 \mu \mathrm{m}$ spacing were prepared on areas of $0.5 \times 0.5 \mathrm{~cm}^{2}$ in the center of $2 \times 2 \mathrm{~cm}^{2}$ cells on highly boron-doped $\left(\sim 2 \times 10^{18} \mathrm{~cm}^{-3}-\sim 8 \times 10^{18} \mathrm{~cm}^{-3}\right)$ silicon substrates. High boron doping was chosen because of its high conductivity and thus low series resistance, the possibility to use silicon with $\mathrm{p} / \mathrm{n}$ junctions of which the surface would be highly p-type doped, and the creation of a low resistance ohmic contact to sputtered ITO. A direct contact between p-type silicon and $\mathrm{BiVO}_{4}$ has been shown to be favorable in creating a photovoltage of up to $150 \mathrm{mV}$ under $3.5 \mathrm{eV}$ illumination with $0.3 \mathrm{~mW} / \mathrm{cm}^{2}$ intensity. ${ }^{[36]}$ However, a $\sim 30 \mathrm{~nm}$ intermediate ITO layer was sputtered on top of the (flat and pillared) silicon substrates to prevent the oxidation of the silicon surface which would have

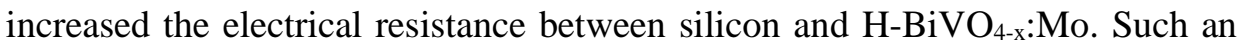
ITO interlayer has been shown to enhance anodic photocurrent densities of $\mathrm{WO}_{3}$ on $\mathrm{p}-\mathrm{Si}^{[37]}$ which can also be expected between $\mathrm{p}-\mathrm{Si}$ and $\mathrm{H}-\mathrm{BiVO}_{4-\mathrm{x}}: \mathrm{Mo}$.

The first step in $\mathrm{H}-\mathrm{BiVO}_{4-\mathrm{x}}:$ Mo preparation is the electrodeposition of $\mathrm{BiOI}$ from a solution of $\mathrm{KI}, \mathrm{Bi}\left(\mathrm{NO}_{3}\right)_{3}$ and p-benzoquinone in aqueous ethanol. BiOI deposits in a two-dimensional crystalline morphology of $\sim 20 \mathrm{~nm}$ thin plates with voids between them. ${ }^{[16]}$ After transformation, this low density structure was shown in the literature to yield high-surface-area nanoporous $\mathrm{BiVO}_{4} \cdot{ }^{[16]}$ Following the literature procedure, a $\mathrm{pH}$ increase near the $\mathrm{Si}$ surface is induced by the electrochemical reduction of p-benzoquinone to hydroquinone (Equation 6.2). ${ }^{[3]}$

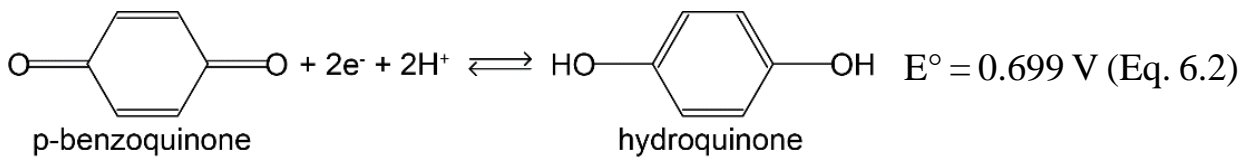



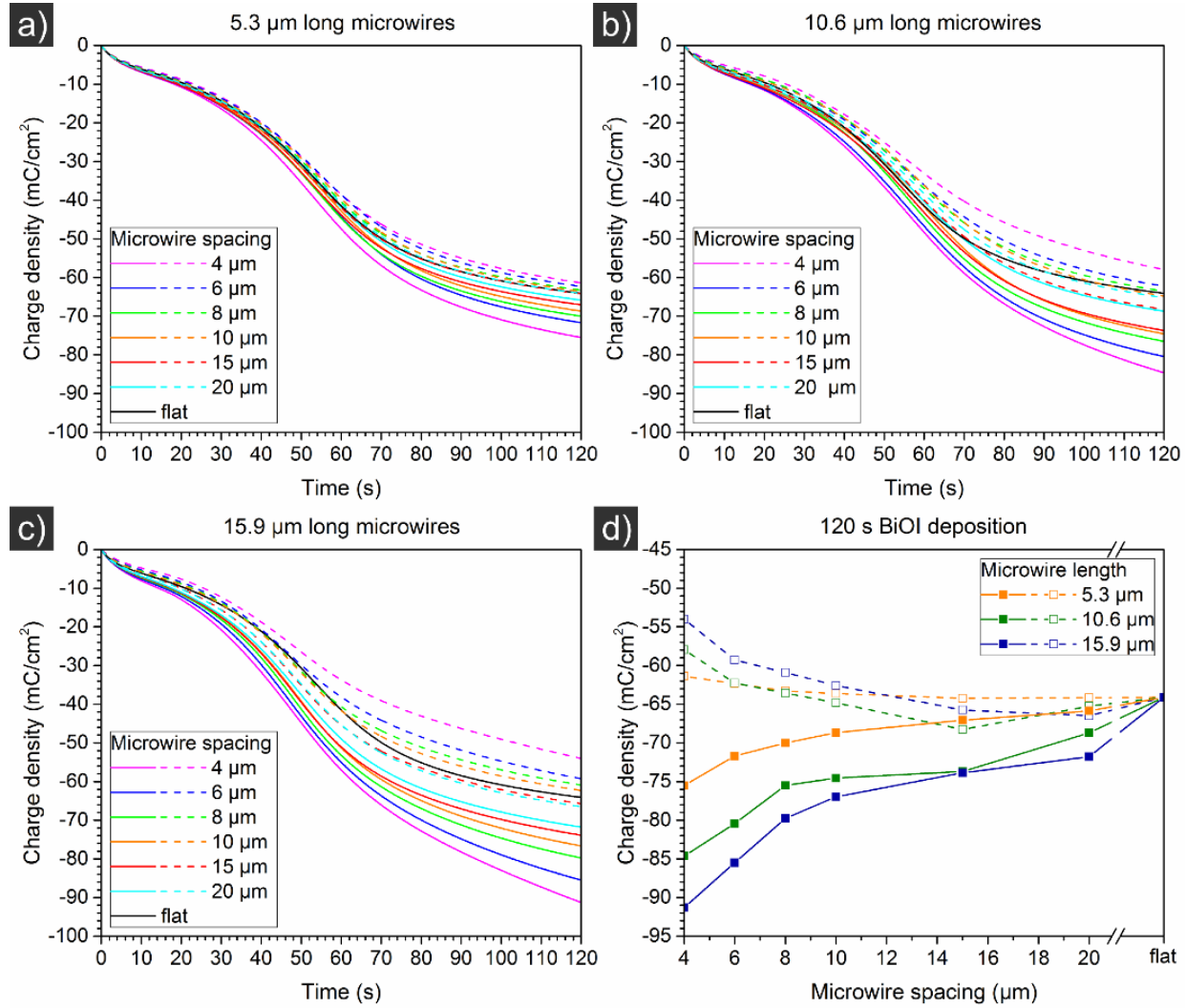

Figure 6.2 Transferred charge densities during electrochemical deposition of BiOI from a solution of $\mathrm{KI}, \mathrm{Bi}\left(\mathrm{NO}_{3}\right)_{3}$ and p-benzoquinone in water/ethanol at $-0.1 \mathrm{~V}$ vs. $\mathrm{Ag} / \mathrm{AgCl}$ $(3 \mathrm{M} \mathrm{NaCl})$ on flat and pillared p-type doped silicon substrates, the latter with $5.3 \mu \mathrm{m}(\mathrm{a})$, $10.6 \mu \mathrm{m}$ (b) and $15.9 \mu \mathrm{m}$ (c) long hexagonally arranged microwire arrays of $4 \mu \mathrm{m}$ diameter and various spacing, with ITO sputtered for $5 \mathrm{~min}$. Solid lines are correlated to the projected surface area and dashed lines are recalculated values scaled to the effective surface area of the same sample. The projected sample area was $1.13 \mathrm{~cm}^{2}$ as defined by the O-ring which contained microwires in a $0.25 \mathrm{~cm}^{2}$ cell. d) Direct comparison of the effect of microwire spacing on charge density, demonstrating increasing charge density (per effective surface area) as a function of decreasing microwire spacing.

To study the influence of microwire length and spacing on $\mathrm{pH}$ gradients, and therefore gradients in BiOI deposition quantities, the deposition time was kept constant at $30 \mathrm{~s}$ or $120 \mathrm{~s}$. Figure 6.2 shows the charge densities passed during the BiOI growth on $1.13 \mathrm{~cm}^{2}$ flat, and $0.25 \mathrm{~cm}^{2}$ structured area containing pillared $\mathrm{Si}$. The curves show the projected surface area (solid lines) and are recalculated to the effective surface area (dashed lines). The values are negative to represent the direction of electron flow towards the working electrode. At all microwire 
lengths, the passed charge densities are higher on structured samples than on flat. The charge densities increase with decreasing microwire spacing, and thus with increased surface area. However, the charge density increase is not proportional to the surface area increase, and the disproportionality increases with smaller microwire spacing and longer length. The effective surface area enhancement by microwires is between 1.12 for microwires with a length of $5.3 \mu \mathrm{m}$ and $20 \mu \mathrm{m}$ spacing and 4.12 for microwires with a length of $15.9 \mu \mathrm{m}$ and $4 \mu \mathrm{m}$ spacing (Table 6.1). During BiOI electrodeposition, $22.1 \%$ of the active surface area was microwire-structured and thus the effective surface areas were enhanced by factors between 1.03 to 1.69 compared to the projected surface area.

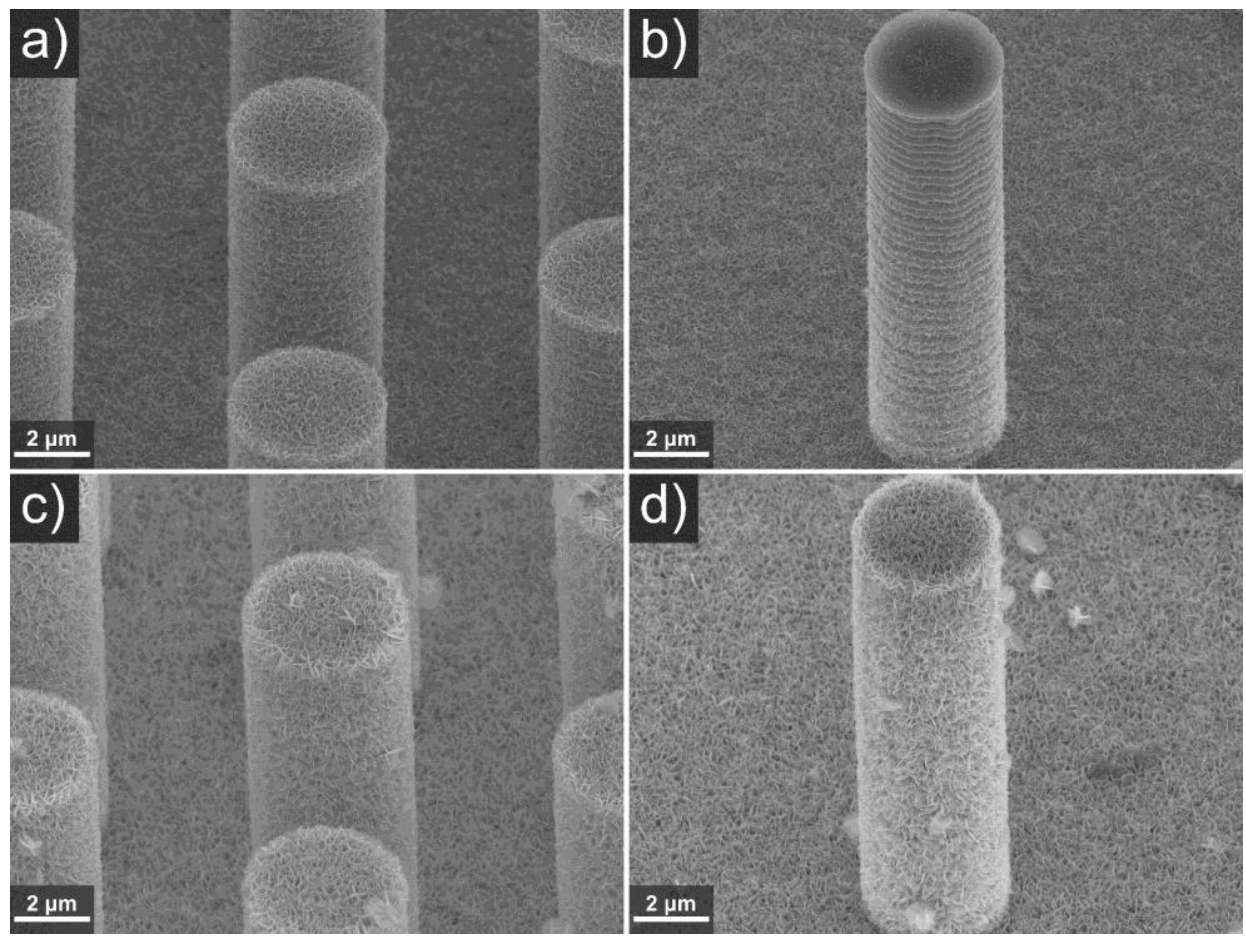

Figure 6.3 SEM images ( $45^{\circ}$ tilted) of electrodeposited BiOI for $30 \mathrm{~s}(\mathrm{a}, \mathrm{b})$ and $120 \mathrm{~s}$ $(\mathrm{c}, \mathrm{d})$ on $15.9 \mu \mathrm{m}$ long hexagonally arranged p-type doped silicon microwire arrays of $4 \mu \mathrm{m}$ diameter and $6 \mu \mathrm{m}(\mathrm{a}, \mathrm{c})$ or $15 \mu \mathrm{m}(\mathrm{b}, \mathrm{d})$ spacing, with ITO sputtered for $5 \mathrm{~min}$.

Figure 6.3 shows selected SEM images of microwire arrays with $6 \mu \mathrm{m}$ and $15 \mu \mathrm{m}$ spacing and $15.9 \mu \mathrm{m}$ length after BiOI deposition. SEM images of all samples coated with BiOI are shown in the Appendix (Figure 6.14, 6.15 and 6.16). It can be seen that the BiOI growth is feasible on three-dimensional surfaces and that 
the microwire surface is covered completely with $\mathrm{BiOI}$ after a deposition time of $120 \mathrm{~s}$ (Figure 6.3c, d). However, at deposition times of $30 \mathrm{~s}$, the samples are either completely (Figure 6.3a) or partially covered (Figure 6.3b) with a thin layer of $\mathrm{BiOI}$. BiOI apparently starts to grow gradually from the bottom to the top, and shows the highest growth rate at the lowest microwire spacing.

Several explanations are possible for this phenomenon. The presence of mass transfer limitations within the microwire system appears the most plausible explanation. The conversion of benzoquinone results in the consumption of protons and an increase of $\mathrm{pH}$. The $\mathrm{pH}$ increase is locally the highest at the base of the microwire arrays, because there protons and p-benzoquinone are not only consumed by electrochemical conversion on the surface of the pillar, but also on the exposed base. Towards the base, the path length for proton and p-benzoquinone transport from the bulk of the solution above the pillared surface is the largest. Since the area over volume ratio of the $\mathrm{Si}$ microwire array increases with decreasing spacing, the $\mathrm{pH}$ increase is also favored by a relatively small microwire spacing. A depletion of p-benzoquinone in between the microwires due to diffusion-limited mass transport explains the disproportionality of charge density of effective surface areas during BiOI deposition. Other reported results strengthen this hypothesis. In Chapter 4, which is based on our publication on spatioselective electrochemical and photoelectrochemical functionalization of silicon microwires with axial $\mathrm{p} / \mathrm{n}$ junctions, ${ }^{[38]}$ we have observed an inversed gradient of electrodeposited Pt particles from a solution containing $\mathrm{H}_{2} \mathrm{PtCl}_{6}$ on an array of microwires with $7 \mu \mathrm{m}$ length, $4 \mu \mathrm{m}$ diameter and $2 \mu \mathrm{m}$ spacing. There, the deposited Pt particle density was higher at the bottom than the top. We have tentatively attributed this to a diffusion limitation of the precursor in between the microwire arrays and have verified this with a control experiment in which we performed the deposition under the same conditions on microwire arrays of $16 \mu \mathrm{m}$ spacing. We have found optically significantly less inhomogeneity. Shaner et al. have electrodeposited $\mathrm{WO}_{3}$ from a tungstic peroxy-acid solution on ITO-coated silicon microwires of $40 \mu \mathrm{m}$ o $70 \mu \mathrm{m}$ length, $\sim 2 \mu \mathrm{m}$ diameter and $4 \mu \mathrm{m}$ spacing in a square lattice. ${ }^{[39]}$ Also they have found a gradient in $\mathrm{WO}_{3}$ thickness over the microwire length for which the $\mathrm{WO}_{3}$ thickness decreased from 
the top to the bottom due to a quicker depletion of the peroxo-tungstic acid at the bottom compared to the top.

We exclude that a voltage drop along the microwires causes the gradient in BiOI during its deposition. Accounting for the highest wafer resistivity of $0.025 \Omega \mathrm{cm}$, $15.9 \mu \mathrm{m}$ length and $4 \mu \mathrm{m}$ diameter of the microwire and a highest current density during $\mathrm{BiOI}$ deposition of $3 \mathrm{~mA} / \mathrm{cm}^{2}$, the maximal potential drop is $1.1 \times 10^{-7} \mathrm{~V}$.

Another potential cause for the area disproportionality in charge density during $\mathrm{BiOI}$ deposition and its inhomogeneous growth, is that the sputtered ITO layer is too thin and does not cover the sides of the microwires completely. Using our recipe, a $\sim 30 \mathrm{~nm}$ film formed on a flat substrate during 5 min sputtering. However, if ITO is truly inhomogeneously distributed at the microwire sides, then we would expect $\mathrm{BiOI}$ growth to be similar on the bottom between the microwires and on the microwire tops, which is not evident. Nevertheless, we have sputtered a fourfold amount of ITO (20 min sputtering time, 120 nm thickness on a flat substrate) on the samples in a second batch of production of microwires. We have constructed microwire arrays with spacings of 6 to $15 \mu \mathrm{m}$, kept the microwire length constant at $10.6 \mu \mathrm{m}$, and deposited BiOI for 30 to 300 s. Figure 6.4 shows the charge densities passed during the BiOI growth on these samples which had an active surface area of $1.13 \mathrm{~cm}^{2}$ including a $0.25 \mathrm{~cm}^{2}$ structured area. The flat samples were prepared two times of which one was further transferred to BiVO4-x:Mo and one used for analysis of the deposited thickness (Figure 6.6).

Also with a thicker ITO layer, BiOI deposited well on microwire-structured surfaces (Figure 6.5). However, more charge passes through the system when thicker ITO layers are sputtered (Figure 6.6). We speculate that this is due to a lower resistance of thicker ITO, which might originate from a different relative oxygen content in ITO or a higher crystallinity. Note that a less pronounced trend in effect of smaller microwire spacing on increasing charge density of Figure 6.2 is observed in Figure 6.4, while a wider spread in absolute values of charge density was obtained when comparing variable BiOI deposition times. A direct control experiment in Figure 6.4 in which we deposited BiOI for $120 \mathrm{~s}$ on microwires with an ITO coating sputtered for $5 \mathrm{~min}$ or $20 \mathrm{~min}$ confirmed this. 
Thus, some effect of ITO uniformity, besides the advocated mass transfer limitation, cannot be excluded.
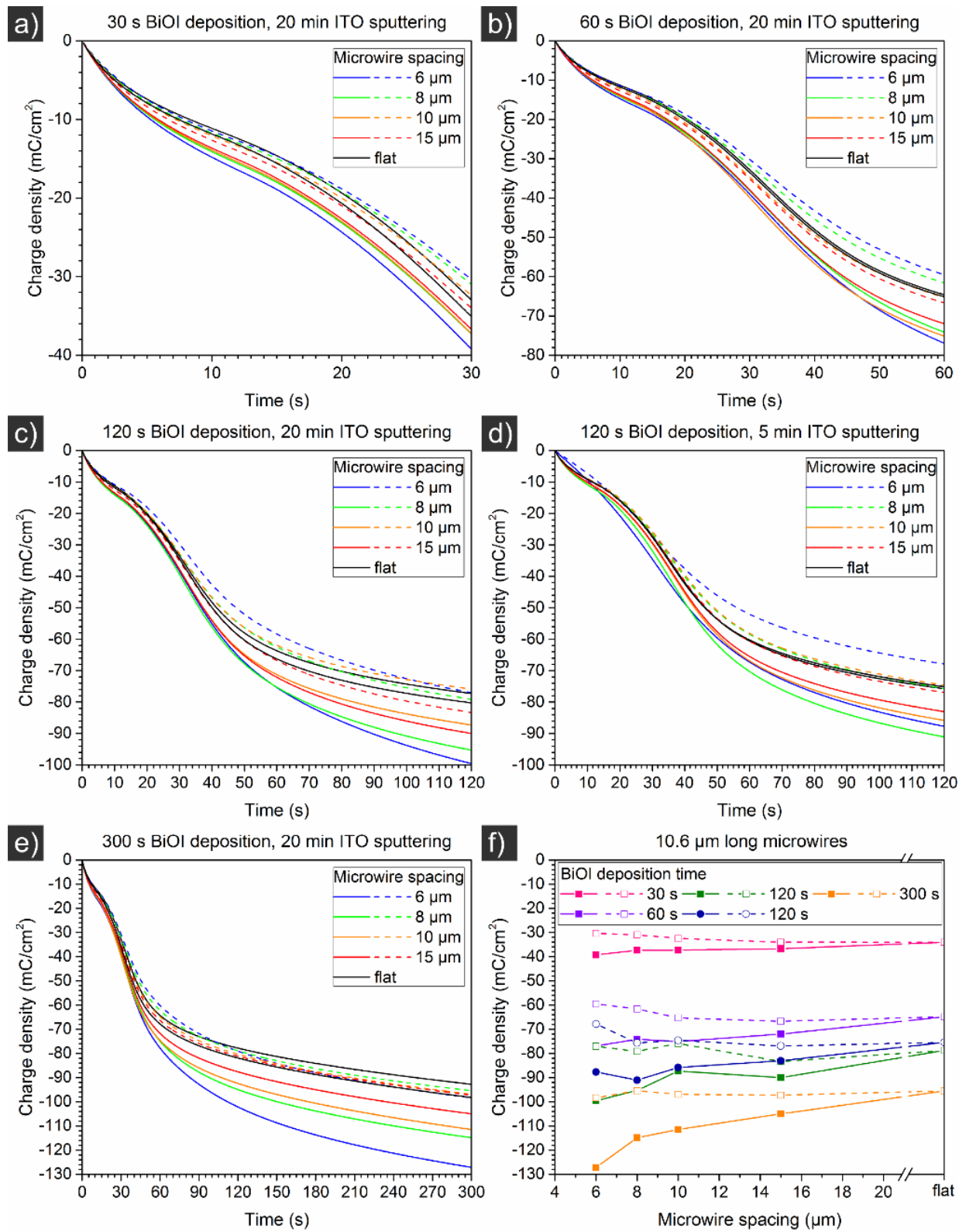

Figure 6.4 Cumulative transferred charge densities during electrochemical deposition of BiOI on $10.6 \mu \mathrm{m}$ silicon microwire arrays with ITO sputtered for $5 \mathrm{~min}$ (d) or $20 \mathrm{~min}$ $(a, b, c, e)$. Solid lines represent projected surface area and dashed lines effective surface area; f) shows a direct comparison of the effect of microwire spacing on transferred charge density. The value for flat is the average of both total cumulative charge densities. 


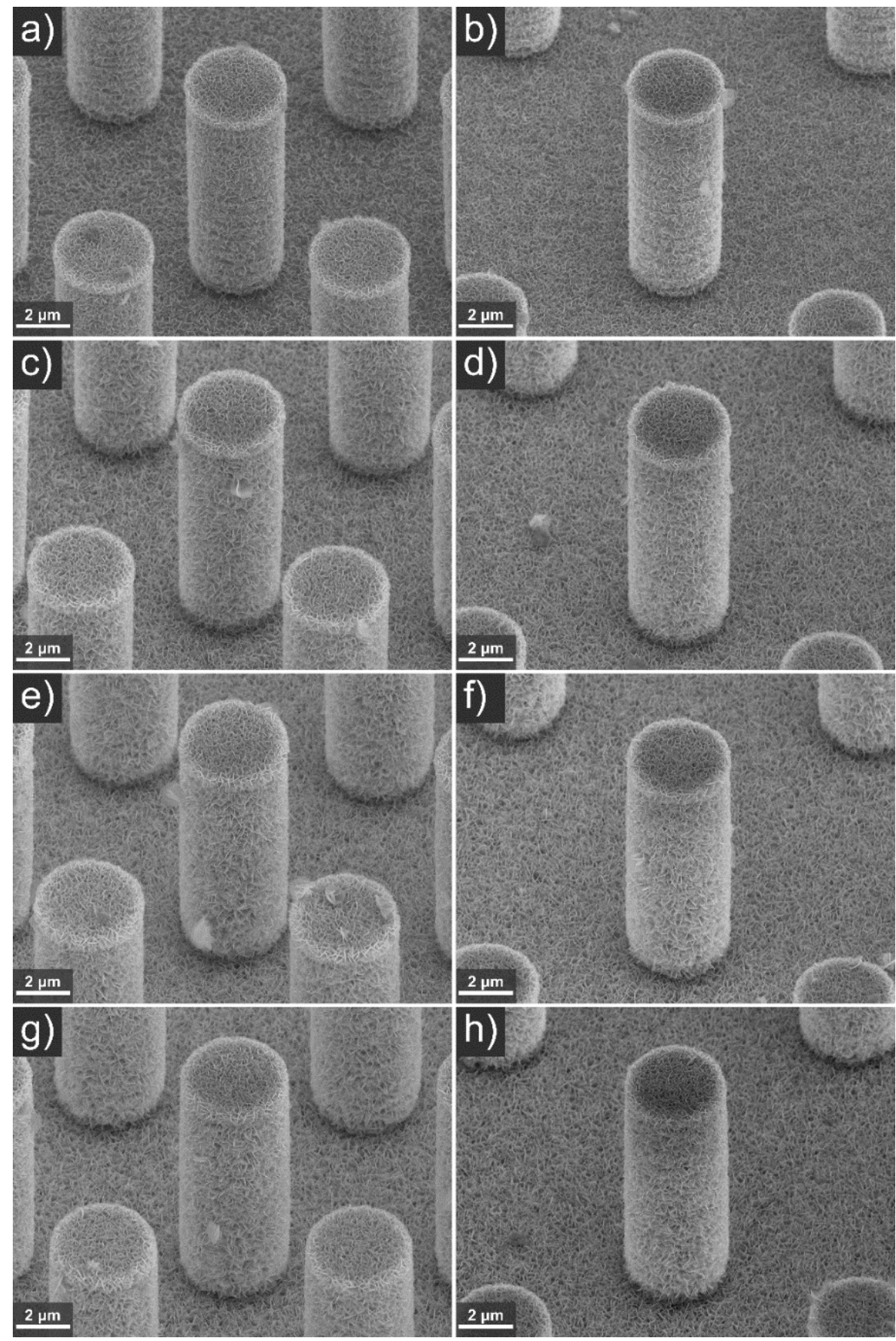

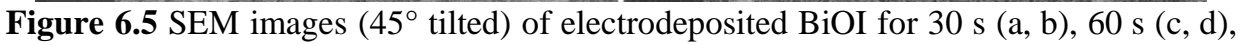
$120 \mathrm{~s}(\mathrm{e}, \mathrm{f})$ and $300 \mathrm{~s}(\mathrm{~g}, \mathrm{~h})$ on $10.6 \mu \mathrm{m}$ long hexagonally arranged p-type doped silicon microwire arrays of $4 \mu \mathrm{m}$ diameter and spacings of $6 \mu \mathrm{m}(\mathrm{a}, \mathrm{c}, \mathrm{e}, \mathrm{g})$ and $10 \mu \mathrm{m}(\mathrm{b}, \mathrm{d}, \mathrm{f}, \mathrm{h})$, with ITO sputtered for $20 \mathrm{~min}$. 


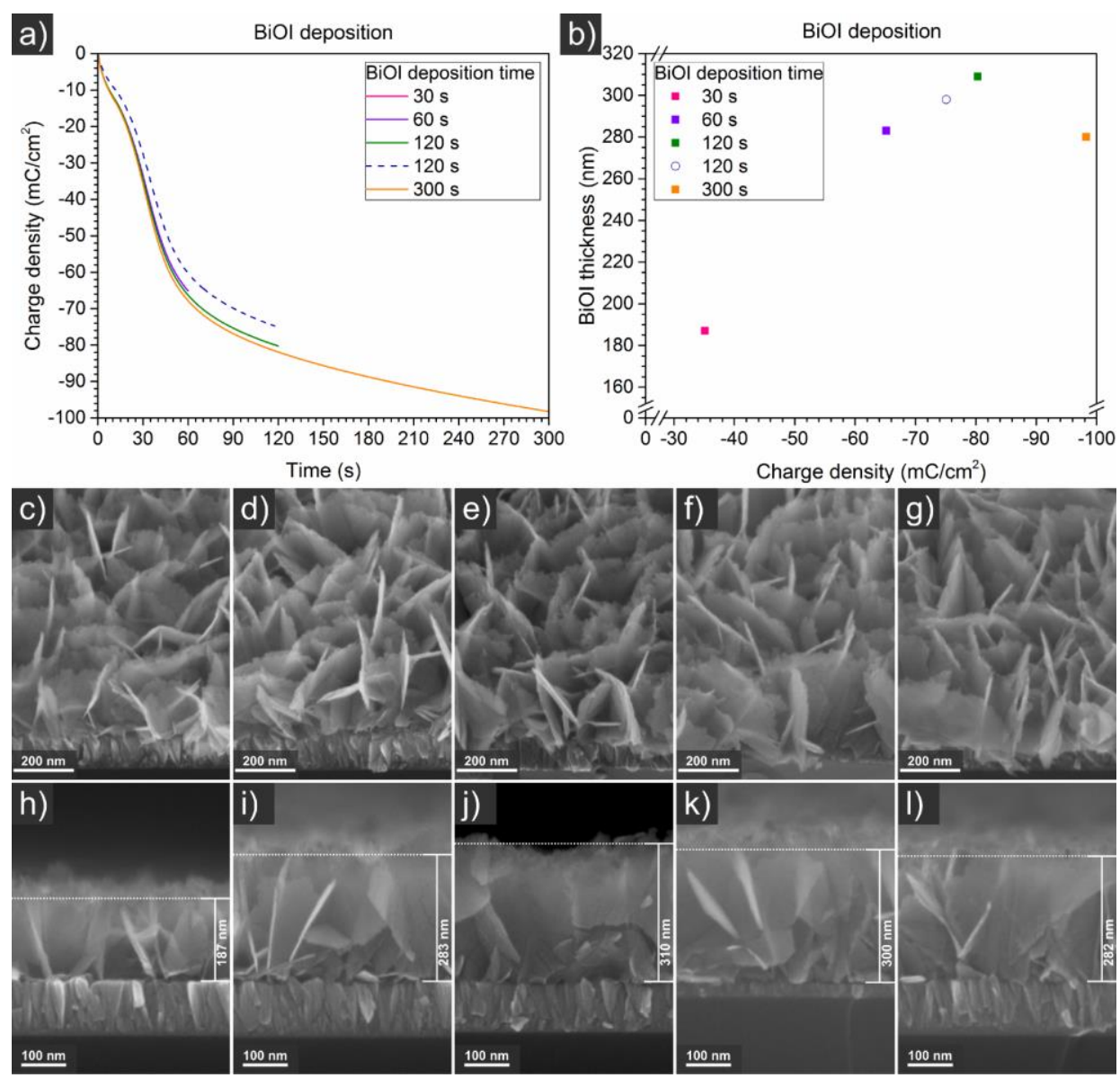

Figure 6.6 Cumulative transferred charge densities (a,b), $45^{\circ}$ tilted (c-g) and cross sectional (k-1) SEM images of BiOI electrochemically deposited from a solution of KI, $\mathrm{Bi}\left(\mathrm{NO}_{3}\right)_{3}$ and p-benzoquinone in water/ethanol at $-0.1 \mathrm{~V} v s$. $\mathrm{Ag} / \mathrm{AgCl}(3 \mathrm{M} \mathrm{NaCl})$ on flat p-type doped silicon with ITO sputtered for 5 min (a dotted line, b circle, f, k) and $20 \mathrm{~min}$ (a solid lines, b squares, c, d, e, g, h, I, j, l). The projected sample area was $1.13 \mathrm{~cm}^{2}$ as defined by the O-ring.

On flat $\mathrm{Si}$ substrates, the BiOI growth rate appeared linear over the passed charge density between a deposition time of $30 \mathrm{~s}$ and $120 \mathrm{~s}$ (Figure 6.6). At a higher deposition time of $300 \mathrm{~s}$, the BiOI thickness decreased. This is due to a decreasing current density over time, evident from Figure 6.6a, which becomes too low to sustain a significant $\mathrm{pH}$ gradient between substrate surface and bulk solution. $\mathrm{BiOI}$ starts to re-dissolve back into solution when the $\mathrm{pH}$ becomes too low at the surface. 


\subsubsection{Transformation of BiOI into H-BiVO4-x:Mo}
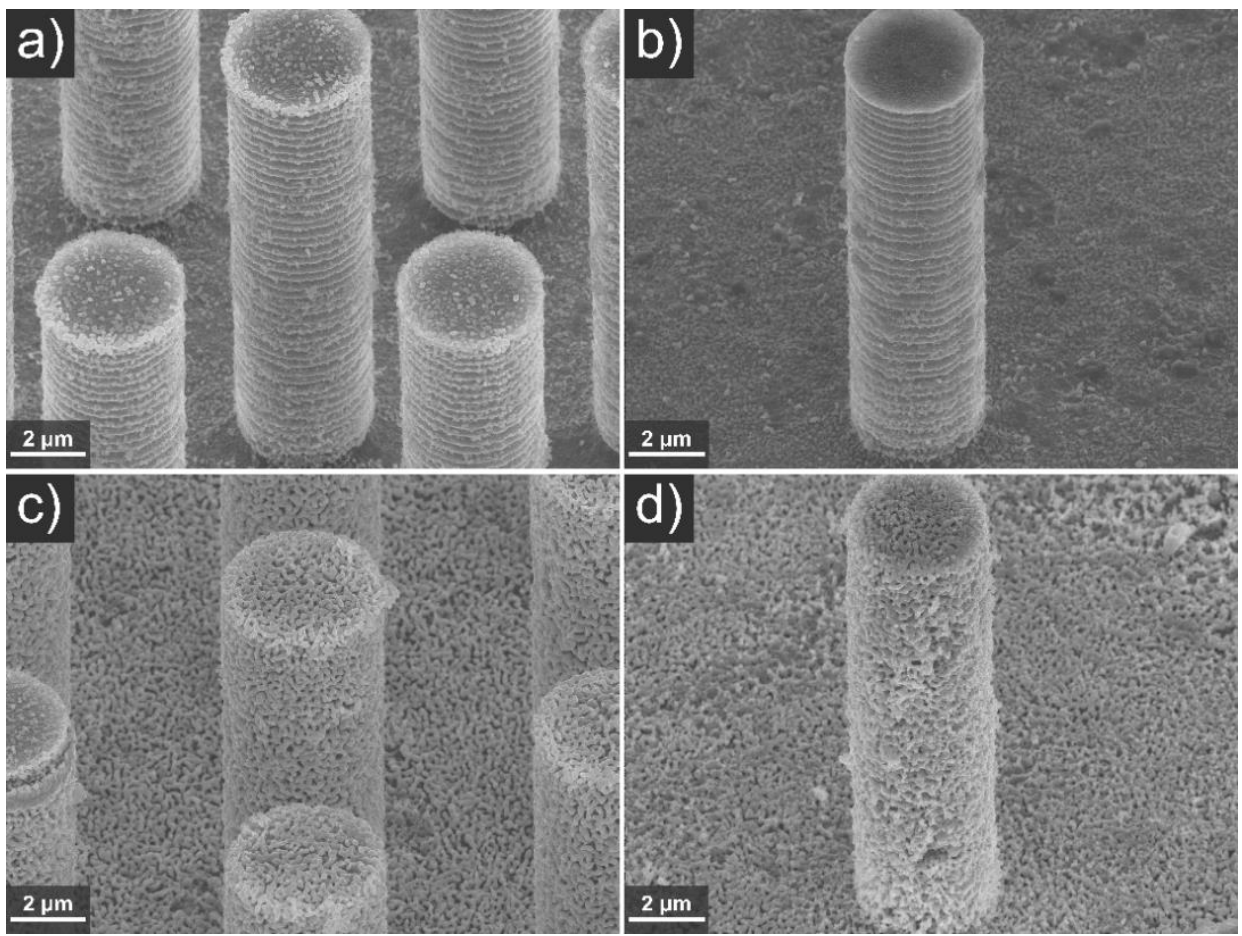

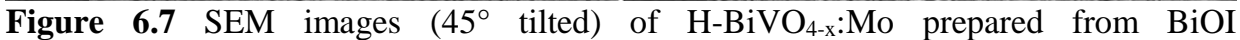
electrodeposited for $30 \mathrm{~s}(\mathrm{a}, \mathrm{b})$ and $120 \mathrm{~s}(\mathrm{c}, \mathrm{d})$ on $15.9 \mu \mathrm{m}$ long hexagonally arranged ptype doped silicon microwire arrays of $4 \mu \mathrm{m}$ diameter and $6 \mu \mathrm{m}(\mathrm{a}, \mathrm{c})$ or $15 \mu \mathrm{m}(\mathrm{b}, \mathrm{d}))$ spacing with ITO sputtered for $5 \mathrm{~min}$.

The transformation of $\mathrm{BiOI}$ into $\mathrm{H}-\mathrm{BiVO}_{4-\mathrm{x}}$ :Mo was performed by dropcasting a DMSO solution with vanadyl acetylacetonate $\left(\mathrm{VO}(\mathrm{acac})_{2}\right)$ and sodium molybdate $\left(\mathrm{Na}_{2} \mathrm{MoO}_{4}\right)$ in a ratio of $100: 1$, evaporating the DMSO at $100{ }^{\circ} \mathrm{C}$ in a drying oven, calcining at $450{ }^{\circ} \mathrm{C}$, removing the excess of vanadium and molybdenum by soaking in a $1 \mathrm{M} \mathrm{KOH}$ solution, and annealing in a reducing $\mathrm{H}_{2} / \mathrm{N}_{2}(1 / 20)$ atmosphere. Figure 6.7 shows selected SEM images of microwire arrays with spacings of 6 and $15 \mu \mathrm{m}$ and a length of $15.9 \mu \mathrm{m}$, sputtered with ITO for $5 \mathrm{~min}$ and coated with $\mathrm{H}-\mathrm{BiVO}_{4-\mathrm{x}}$ :Mo after BiOI deposition times of $30 \mathrm{~s}$ and $120 \mathrm{~s}$. SEM images of all prepared samples of 5.3, 10.6 and $15.9 \mu \mathrm{m}$ length and 4, 6, 8, 10, 15 and $20 \mu \mathrm{m}$ spacing are shown in the Appendix (Figure 6.17, 6.18 and

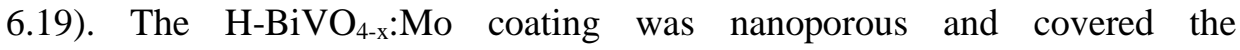
three-dimensional microwire surfaces when $\mathrm{BiOI}$ was deposited for $120 \mathrm{~s}$, but showed defects in the form of cracks (Figure 6.7c, d). These defects are attributed 


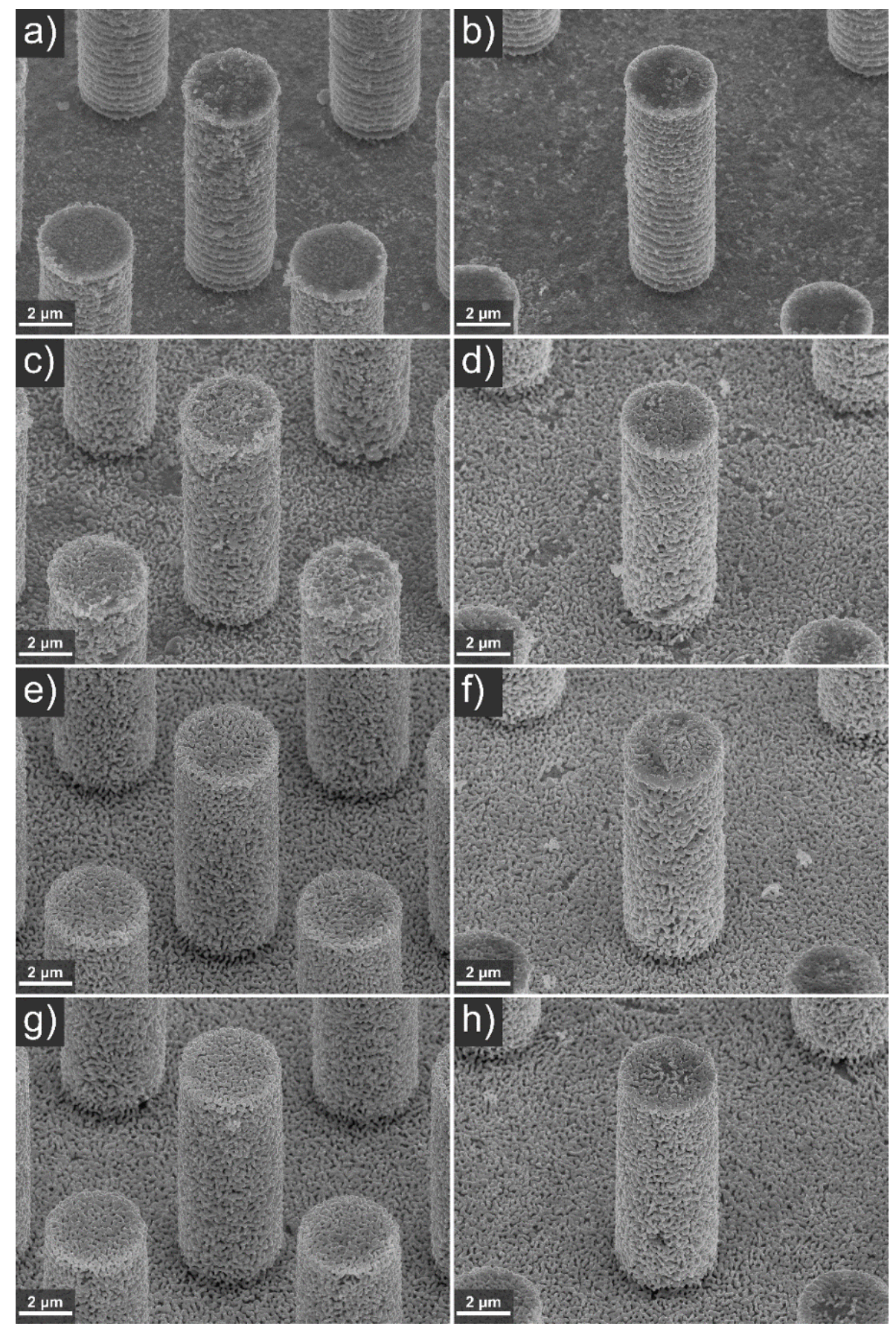

Figure 6.8 $45^{\circ}$ tilted SEM images of $\mathrm{BiVO}_{4-\mathrm{x}}$ :Mo prepared from $\mathrm{BiOI}$ electrodeposited for $30 \mathrm{~s}(\mathrm{a}, \mathrm{b}), 60 \mathrm{~s}(\mathrm{c}, \mathrm{d}), 120 \mathrm{~s}(\mathrm{e}, \mathrm{f})$ and $300 \mathrm{~s}(\mathrm{~g}, \mathrm{~h})$ on $10.6 \mu \mathrm{m}$ long hexagonally arranged p-type doped silicon microwire arrays of $4 \mu \mathrm{m}$ diameter and $6 \mu \mathrm{m}$ (a, c, e, g), or $10 \mu \mathrm{m}(\mathrm{b}, \mathrm{d}, \mathrm{f}, \mathrm{h})$ spacing with ITO sputtered for $20 \mathrm{~min}$. 
to crystallization during the DMSO evaporation process. Microwires on which BiOI was deposited for only $30 \mathrm{~s}$ and thus were not completely covered, were also incompletely covered with $\mathrm{H}-\mathrm{BiVO}_{4-\mathrm{x}}$ :Mo (Figure 6.7a, b). Similar results were achieved when $\mathrm{H}-\mathrm{BiVO}_{4-\mathrm{x}}: \mathrm{Mo}$ was prepared on microwires sputtered with ITO for $20 \mathrm{~min}$ and BiOI deposition times were $30 \mathrm{~s}, 60 \mathrm{~s}, 120 \mathrm{~s}$ and $300 \mathrm{~s}$ (Figure 6.8). Also here, a complete $\mathrm{H}-\mathrm{BiVO}_{4-\mathrm{x}}$ :Mo coating was obtained at $\mathrm{BiOI}$ deposition times greater than $30 \mathrm{~s}$.

\subsubsection{Photoelectrochemical characterization}

Photocurrent measurements were performed by linear potential sweeps from 0 to $2.0 \mathrm{~V} v s$. RHE at a scan rate of $10 \mathrm{mV} / \mathrm{s}$, first in dark and then under simulated AM 1.5 solar illumination. The $0.5 \mathrm{M}$ potassium phosphate (KPi) buffer solution with a $\mathrm{pH}$ of 7.0 contained $1 \mathrm{M}$ sodium sulfite $\left(\mathrm{Na}_{2} \mathrm{SO}_{3}\right)$ as a sacrificial hole acceptor. The intrinsic catalytic water oxidation activity of $\mathrm{BiVO}_{4}$ is relatively poor whereas sulfite oxidation is kinetically fast and also thermodynamically more favorable than the oxidation of water. ${ }^{[34,40,41]}$ Thus, the addition of a hole scavenger allows the investigation of the photoelectrochemical properties of $\mathrm{BiVO}_{4}$ without the necessity of a water oxidation catalyst. ${ }^{[16,42]}$ The resulting photoactivities of $\mathrm{H}-\mathrm{BiVO}_{4-\mathrm{x}}: \mathrm{Mo}$, prepared from BiOI electrodeposited for $120 \mathrm{~s}$, on microwire arrays of various lengths and spacings and $\mathrm{BiOI}$ deposited between $30 \mathrm{~s}$ and $300 \mathrm{~s}$ on microwires of $10.6 \mu \mathrm{m}$ length and various spacings are shown in Figure 6.9 and Figure 6.10, respectively. Linear sweeps are presented in a potential range from 0 to $1.6 \mathrm{~V}$ vs. RHE. Two samples in Figure 6.9, i.e. microwire arrays with a $15 \mu \mathrm{m}$ spacing and $10.6 \mu \mathrm{m}$ length and with a $8 \mu \mathrm{m}$ spacing and $15.9 \mu \mathrm{m}$ length, did not follow the photocurrent trends of the other samples. These samples are considered as outliers, and one of these samples was reproduced in Figure 6.10 and did not show the outlying behavior. For a better comparison, photocurrents at 0.5 and $1.1 \mathrm{~V} v s$. RHE have been plotted as a function of microwire spacing (Figure 6.9d, e and Figure 6.11). The choice of photocurrent comparisons at $0.5 \mathrm{~V}$ and $1.1 \mathrm{~V}$ is arbitrary and serves only to represent a low and a high bias region. The sulfite photooxidation onset potential occurred at $\sim 0.35 \mathrm{~V} v s$. RHE and the dark current onset potential at $\sim 1.10 \mathrm{~V} v s$. RHE. In the low bias region at $0.5 \mathrm{~V} v s$. RHE microwire samples 
a) $5.3 \mu \mathrm{m}$ long microwires, $120 \mathrm{~s}$ BiOl deposition b) $10.6 \mu \mathrm{m}$ long microwires, $120 \mathrm{~s}$ BiOl deposition
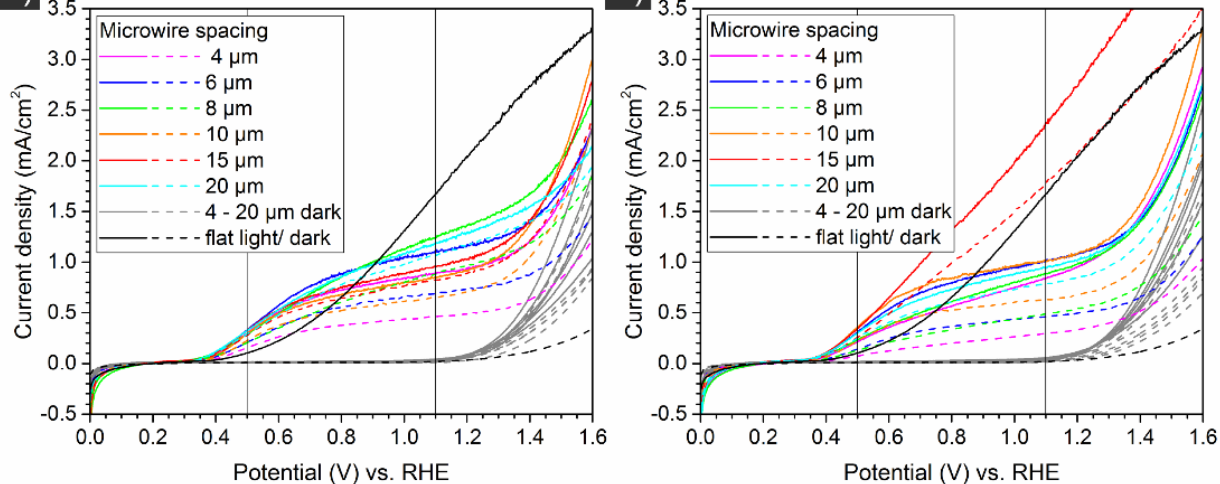

C)

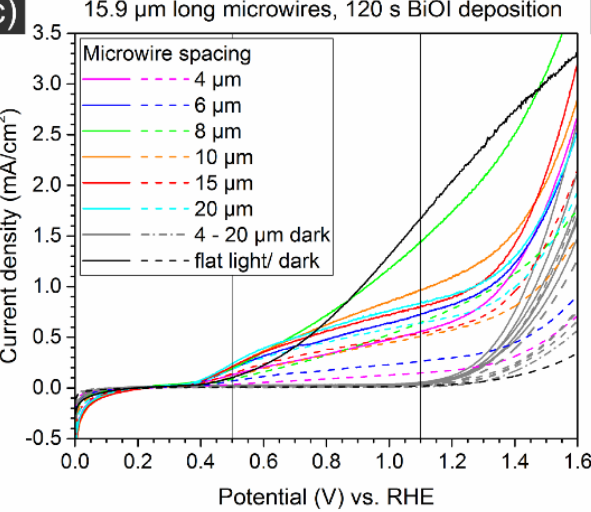

d) Photocurrent at $0.5 \mathrm{~V}$ vs. RHE, $120 \mathrm{~s}$ BiOl deposition

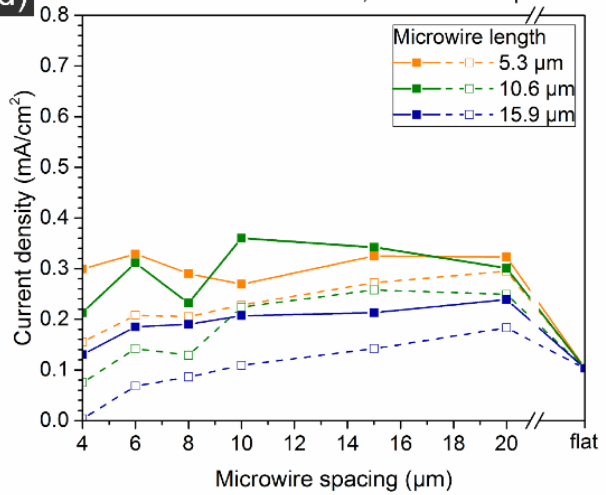

e) Photocurrent at $1.1 \mathrm{~V}$ vs. RHE, $120 \mathrm{~s}$ BiOl deposition

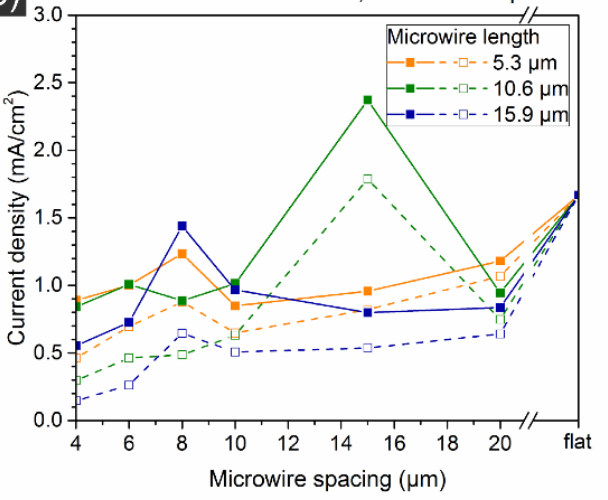

Figure 6.9 a-c) Linear potential sweeps $(10 \mathrm{mV} / \mathrm{s})$ of $\mathrm{H}-\mathrm{BiVO}_{4-\mathrm{x}}: \mathrm{Mo}(120 \mathrm{~s} \mathrm{BiOI}$ deposition) on Si microwires with sputtered ITO (5 min) in a solution of $1 \mathrm{M} \mathrm{Na}_{2} \mathrm{SO}_{3}$ in $0.5 \mathrm{M} \mathrm{KPi}$ buffer ( $\mathrm{pH} 7.0$ ) and current density comparison at $0.5 \mathrm{~V}$ (d) and 1.1 (e) over microwire spacing. Solid lines represent projected and dashed lines effective surface area. 

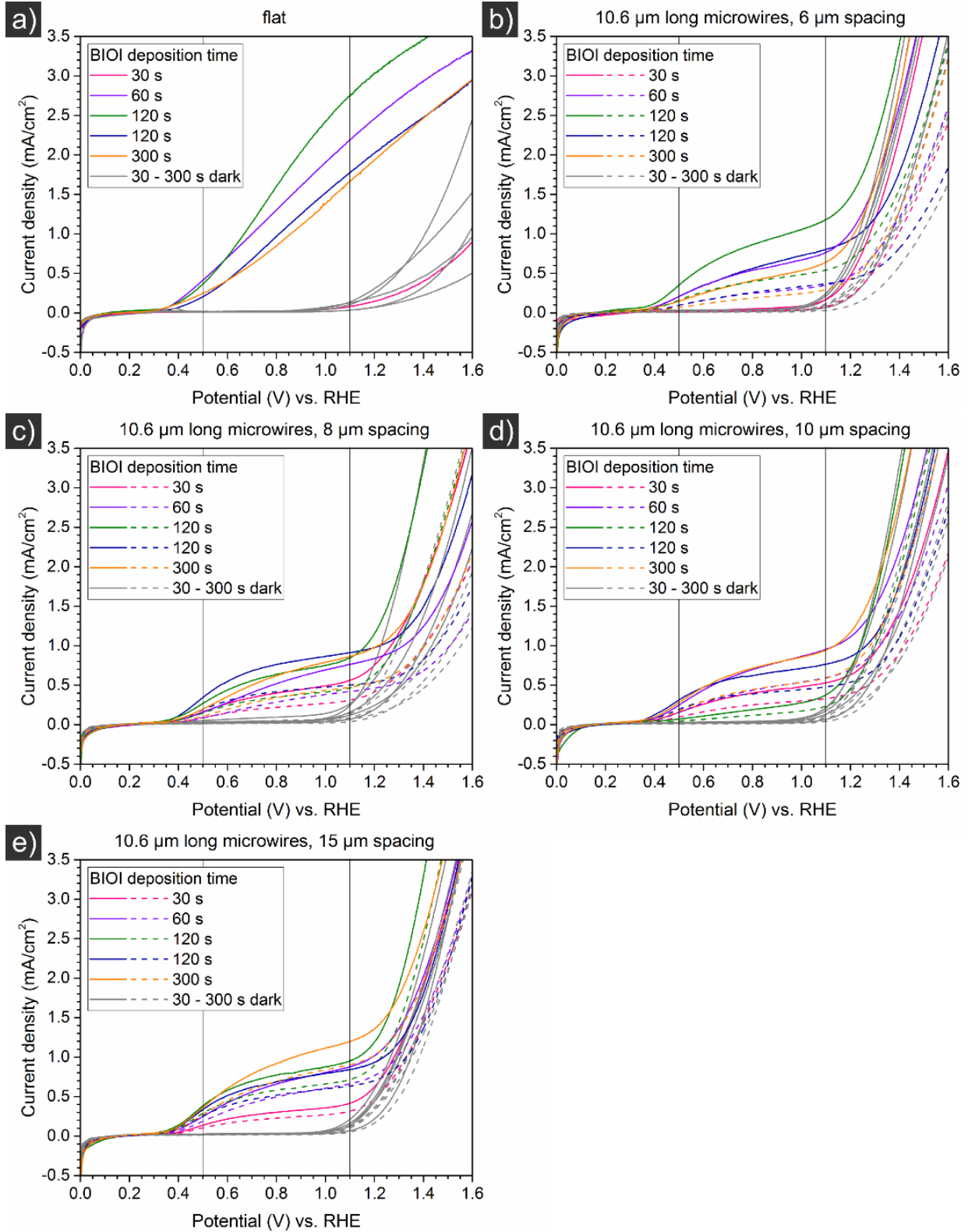

Figure 6.10 Linear potential sweeps $(10 \mathrm{mV} / \mathrm{s})$ of $\mathrm{H}_{-} \mathrm{BiVO}_{4-\mathrm{x}}: \mathrm{Mo}(120 \mathrm{~s}$ BiOI deposition) on flat (a) and Si microwires of $10.6 \mu \mathrm{m}$ length and 6-15 $\mu \mathrm{m}$ (b-e) spacing with sputtered ITO (20 min (various colors), 5 min (blue)) in a solution of $1 \mathrm{M} \mathrm{Na}_{2} \mathrm{SO}_{3}$ in $0.5 \mathrm{M} \mathrm{KPi}$ buffer ( $\mathrm{pH}$ 7.0). Solid lines represent projected and dashed lines effective surface area. 

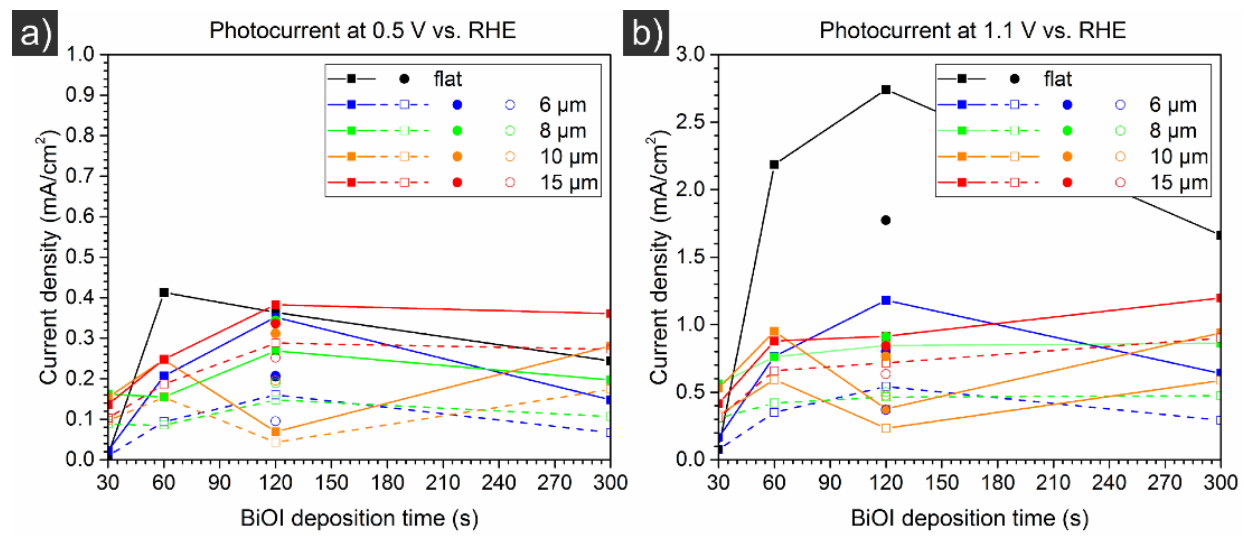

Figure 6.11 Photocurrent densities vs. BiOI deposition time as a function of microwire spacing at $0.5 \mathrm{~V}$ (a) and $1.1 \mathrm{~V}$ (b) for projected (filled symbols, solid lines) and effective (empty symbols, dashed lines) sample areas of $\mathrm{H}-\mathrm{BiVO}_{4-\mathrm{x}}$ :Mo-coated Si microwire arrays of $10.6 \mu \mathrm{m}$ length with sputtered ITO (20 min (squares), $5 \mathrm{~min}$ (circles)). Data is obtained from linear potential sweeps presented in Figure 6.10.

outperformed (Figure 6.9) or slightly underperformed (Figure 6.10 and Figure 6.11) compared to flat samples, while in the high bias region at $1.1 \mathrm{~V} v s$. RHE, $\mathrm{H}-\mathrm{BiVO}_{4-\mathrm{x}}$ :Mo on flat samples outperformed all microwire-structured samples. Several reasons are plausible for this behavior and are addressed in below, i.e. (i) limited mass transfer of the redox species in between the microwires, (ii) suboptimal light absorption, (iii) over-proportional increase in surface recombination of electrons and holes on the microwire-enhanced surface of $\mathrm{H}_{-} \mathrm{BiVO}_{4-\mathrm{x}} \mathrm{Mo}$, (iv) inhomogeneous distribution of the sputtered ITO layer on the microwire sites and thus lack of electrical connection of $\mathrm{H}-\mathrm{BiVO}_{4-\mathrm{x}}$ :Mo to the silicon substrate, and (v) the $\mathrm{H}-\mathrm{BiVO}_{4-\mathrm{x}}:$ Mo thickness is closer to the optimum on flat than on microwire-structured samples.

\section{Mass transfer effects}

Photocurrents of microwire-structured samples increased steeply between the onset potential at $\sim 0.35$ and $\sim 0.70 \mathrm{~V} v s$. RHE and then leveled off until $\sim 1.30 \mathrm{~V}$ $v s$. RHE. This might be due to two reasons: (i) mass transfer limitations of redox species in the internal volume of the microwire array, or (ii) insufficient light absorption and thus depletion of available photoinduced holes in the valence band of $\mathrm{H}-\mathrm{BiVO}_{4-\mathrm{x}}: \mathrm{Mo}$. We used a scan rate of $10 \mathrm{mV} / \mathrm{s}$ in our linear potential sweeps, resulting in a pass time of $\sim 3.5 \mathrm{~s}$ between the photocurrent onset and the 
beginning of the photocurrent leveling off in which $\mathrm{SO}_{3}{ }^{2-}$ ions at the electrode surface can deplete. This is in line with our observations and discussions on the electrochemical BiOI deposition and with literature reports. For instance, Xiang et al. studied the mass transport of $50 \mathrm{mM} / 5.0 \mathrm{mM}$ cobaltocenium ${ }^{+} /$cabaltocene $^{0}$ redox species in $\mathrm{CH}_{3} \mathrm{CN}-1.0 \mathrm{M} \mathrm{LiClO}_{4}$ electrolyte in between p-type microwire arrays of $3 \mu \mathrm{m}$ diameter, $\sim 100 \mu \mathrm{m}$ length, and $4 \mu \mathrm{m}$ spacing in a square lattice. ${ }^{[43]}$ They found that fill factors were low and that the obtainable photocurrent densities were limited to $17.6 \mathrm{~mA} / \mathrm{cm}^{2}$ even under high illumination intensities due to mass transport limitations of the redox species within the internal volume of the silicon microwire arrays. ${ }^{[43]}$ Their simulations with COMSOL Multiphysics showed that the solution-phase reagent concentration decreased to zero over the lower $\sim 70 \%$ of the wire length relative to the bulk concentration above the microwire, implying that more than two thirds of the microwire length only contributed to light absorption but not to the redox process. ${ }^{[43,44]}$ Vijselaar et al. decoupled light absorption and catalytic activity of silicon microwires with radial $\mathrm{p} / \mathrm{n}$ junctions, $4 \mu \mathrm{m}$ diameter, $40 \mu \mathrm{m}$ length and various spacings by depositing a proton reduction catalyst spatioselectively on the microwire tops and achieved similar efficiencies in photoelectrochemical and photoelectrical measurements. ${ }^{[45]}$ Their results strengthen our hypothesis of diffusion limitation of redox species in the internal volume of the microwire array, since in the cited study light trapping properties of the microwire structure were utilized without suffering from mass transfer inside the microwire array because of the placement of the catalyst at the top only.

\section{Light absorption properties}

Various studies have proven that structuring the silicon surface with microwires enhances the photovoltaic performance due to enhanced light absorption and a greater junction area. ${ }^{[25,46]}$ For instance, Elbersen et al. have studied the effects of microwire length on photovoltaic activity of silicon microwires with radial $\mathrm{p} / \mathrm{n}$ junctions and a spacing of $2 \mu \mathrm{m}$ and found that all tested microwires with a length between $10 \mu \mathrm{m}$ and $60 \mu \mathrm{m}$ outperformed flat equivalents under perpendicularly oriented illumination. ${ }^{[4]}$ However, Boettcher et al. prepared similarly sized microwire arrays with a radial $\mathrm{n}^{+} / \mathrm{p}$ junction, deposited platinum on the tops and tested them for photocatalytic hydrogen evolution. ${ }^{[48]}$ They found that the 
efficiencies of silicon microwire photocathodes were $5.8 \%$ and that of planar control samples 9.6\%. In another publication Boettcher et al. tested energy conversion efficiencies of p-type microwires for the reduction of methyl viologen $\left(\mathrm{MV}^{2+}\right) \cdot{ }^{[49]}$ They observed energy conversion efficiencies of 3.6\% for structured and $12.9 \%$ for flat substrates. The authors argue that this is due to minimized optical absorption of the perpendicularly oriented illumination beam to the $\mathrm{Si}$ microwire arrays. By tilting the substrate, the external quantum yield increased from $\sim 0.2$ to close to 0.7 at $60^{\circ}$. Also others have observed similar angledependent photocatalytic behavior on microwires. ${ }^{[50]}$ Vijselaar et al. found that photovoltaic current densities of silicon microwires with a radial $\mathrm{p} / \mathrm{n}$ junction increase with increasing microwire spacing. ${ }^{[45]}$ Our results show predominantly the same trend (Figure 6.9) which indicates that underperformance of devices with a low microwire spacing might be due to limitations in light absorption. This is supported by the study of Chakthranont et al. who published a similar concept as discussed in this chapter, after completion of our study, and obtained higher photocurrents in sulfite oxidation on microwire-structured samples than on flat equivalents. ${ }^{[51]}$ These authors used silicon nanowires instead of microwires, tin oxide $\left(\mathrm{SnO}_{2}\right)$ instead of indium tin oxide as the interlayer between $\mathrm{Si}$ and $\mathrm{BiVO}_{4}$, prepared $\mathrm{BiVO}_{4}$ by spray coating, used $\mathrm{W}$ instead of Mo doping and also annealed their devices in a $\mathrm{H}_{2}$ atmosphere. The biggest difference between their and our study was the dimensions of the silicon structures, i.e. Chakthranont et $a l$. used so-called black silicon which shows a very high light absorption and is composed of needle-shaped (tapered) nanowires, in their case $\sim 3 \mu \mathrm{m}$ length, $\sim 200 \mathrm{~nm}$ average diameter and $\sim 300 \mathrm{~nm}$ spacing. We assume that the microwires in our system do absorb more light than flat equivalents as proven by Elbersen $e t$ $a l .{ }^{[46,47]}$ and Kelzenberg et al. ${ }^{[25]}$ but believe that mass transfer overcompensates this effect and leads to an overall underperformance of the microwire structures compared to flat samples. In contrast, the positive light trapping effect of microwires overcompensated the negative diffusion effect in the system reported by Chakthranont et al. as these authors used smaller microwire dimensions leading to a significantly shorter ion diffusion path length.

\section{Surface recombination}

$\mathrm{BiVO}_{4}$ suffers from surface recombination of photogenerated charges which limit 
the photocurrent of bare $\mathrm{BiVO}_{4}$ in photocatalytic water oxidation. ${ }^{[52]}$ Zachäus $e t$ $a l$. showed that the role of deposited $\mathrm{CoPi}$ on spray-deposited $\mathrm{BiVO}_{4}$ films is mainly the passivation of the surface and thus suppression of surface recombination and not the improvement of charge transfer kinetics. ${ }^{[52]}$ An increase of the surface area in our microwire systems would also increase the amount of $\mathrm{H}-\mathrm{BiVO}_{4-\mathrm{x}}$ :Mo recombination centers and may lower the overall photoactivity in comparison to flat samples. However, due to the addition of sulfite as a hole scavenger to the solution, the loss of holes by surface recombination at the $\mathrm{BiVO}_{4}$-electrolyte interface is negligible ${ }^{[42]}$ and thus we do not expect surface recombination making a significant difference in photoactivity between flat and structured samples in our experiments. In parallel, also the interface areas between $\mathrm{H}-\mathrm{BiVO}_{4-\mathrm{x}}: \mathrm{Mo} / \mathrm{ITO}$ and $\mathrm{ITO} / \mathrm{p}-\mathrm{Si}$ increase with increasing surface area. It is theoretically conceivable that these interfaces were defect-rich and led to an increase in electron and hole recombination. From our experiments, no judgement is possible whether these interfaces limit the performance of microwire structured devices.

\section{ITO layer thickness}

As discussed in the BiOI deposition section above, the ITO layer thickness on the

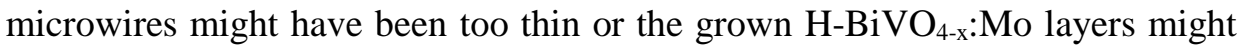
have been closer to the optimal range on the flat samples than on the microwires. Linear potential sweeps in Figure 6.10 and the comparison of photoactivities at $0.5 \mathrm{~V}$ and $1.1 \mathrm{~V} v s$. RHE in Figure 6.11 show that the underperformance of microwire-structured samples in comparison to flat samples is not due to ITO and H-BiVO 4 -x:Mo layer thicknesses since the flat samples also show a better performance than the microwire-structured samples for thicker ITO and

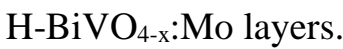

\section{H-BiVO4-x:Mo layer thickness}

The photocurrents of $\mathrm{H}-\mathrm{BiVO}_{4-\mathrm{x}}: \mathrm{Mo}$ (Figure 6.6) on flat substrates and on microwire arrays with a high microwire spacing correlate well with $\mathrm{BiOI}$ and thus $\mathrm{H}-\mathrm{BiVO}_{4-\mathrm{x}}$ :Mo thickness which was found to be thickest at a BiOI deposition time of $120 \mathrm{~s}$ (Figure 6.11). In contrast, microwire-structured samples with a low spacing showed the highest photocurrents at the highest BiOI deposition time 
$(300 \mathrm{~s})$. At a deposition time of $30 \mathrm{~s}$, microwire-structured samples showed higher photocurrents than flat samples. Regarding our findings that BiOI layer growth is fastest at the smallest microwire spacing, it is likely that $\mathrm{H}-\mathrm{BiVO}_{4-\mathrm{x}}: \mathrm{Mo}$ layers became too thick and out of the optimal range on samples with small microwire spacing and long deposition time. Consequently, the layers were closer to the optimal range at the short (30 s) deposition time, explaining the better performance.

\subsubsection{Influence of Mo doping and $\mathrm{H}_{2}$ annealing}

To dope $\mathrm{BiVO}_{4}$ deposited on silicon microwires, $1 \%$ Mo relative to $\mathrm{V}$ was added to the DMSO solution during transformation of $\mathrm{BiOI}$ to $\mathrm{BiVO}_{4}: \mathrm{Mo}$. Subsequently, $\mathrm{BiVO}_{4}$ :Mo was annealed in a $5 \% \mathrm{H}_{2} / 95 \%$ Ar atmosphere at $300{ }^{\circ} \mathrm{C}$ for $0.5 \mathrm{~h}$. To study the effects of Mo addition and hydrogen annealing, reference samples were prepared in which the transformation of $\mathrm{BiOI}$ to $\mathrm{BiVO}_{4}$ was performed without Mo addition and in which $\mathrm{BiVO}_{4}$ :Mo was not annealed in hydrogen atmosphere. X-ray diffractometry (XRD) and Raman spectroscopy revealed that nanoporous doped and undoped $\mathrm{BiVO}_{4}$ is highly crystalline and of purely the monoclinic scheelite phase (Figure 6.12). ${ }^{[3,}$, 54] No detectable diffraction peak shifts were observed in the XRD due to Mo doping or annealing in hydrogen atmosphere which is in agreement with earlier reports. ${ }^{[11,14,15,40,55]}$ The Raman spectra show characteristic $\mathrm{VO}_{4}$ tetrahedron vibrational modes of the monoclinic $\mathrm{BiVO}_{4}$ at around 211, 328, 367, 712 and $826 \mathrm{~cm}^{-1}$. The major band at $826 \mathrm{~cm}^{-1}$ represents the $\mathrm{A}_{\mathrm{g}}$ mode of the symmetric V-O stretching. ${ }^{[33]}$ A shift of this vibrational mode to lower frequency of $822 \mathrm{~cm}^{-1}$ and the appearance of an additional peak at $876 \mathrm{~cm}^{-1}$ confirmed the Mo doping in $\mathrm{BiVO}_{4}$ in these samples. The redshift of the $\mathrm{Ag}_{\mathrm{g}}$ mode frequency in $\mathrm{BiVO}_{4}: \mathrm{Mo}$ and $\mathrm{H}-\mathrm{BiVO}_{4-\mathrm{x}}: \mathrm{Mo}$ is interpreted as an increase of the bond lengths in the tetrahedrons by a substitution of Mo for V, and the peak at $876 \mathrm{~cm}^{-1}$ is due to Mo-O-Mo stretching. ${ }^{[56,57]}$ The exact doping level of Mo in our experiments is not known but it is assumed to be below $6.0 \%$. Mo doping levels higher than $6.0 \%$ should lead to a noticeable change in the XRD pattern due to a structural change from monoclinic to tetragonal phase or precipitation of $\mathrm{V}_{2} \mathrm{O}_{5} \cdot{ }^{[40,42,58]}$ Chen et al. tested $1 \%$ to $5.5 \%$ Mo-doped $\mathrm{BiVO}_{4}$, prepared by reactive co-sputtering, and found that at all doping levels the material performed better than undoped $\mathrm{BiVO}_{4}$ in the photocatalytic 
sulfite oxidation. ${ }^{[40]}$ In their study, the sample with $3.4 \%$ Mo doping showed the best photocatalytic performance. Park et al. have prepared $\mathrm{BiVO}_{4}: \mathrm{Mo}$ with doping levels of $1 \%, 3 \%$ and $6 \%$ via a different electrochemical route. ${ }^{[42]}$ They also found that all doped materials showed higher photocurrents than undoped $\mathrm{BiVO}_{4}$ in the sulfite oxidation. Also here, the sample with a $3 \%$ doping level showed the best performance. ${ }^{[42]}$
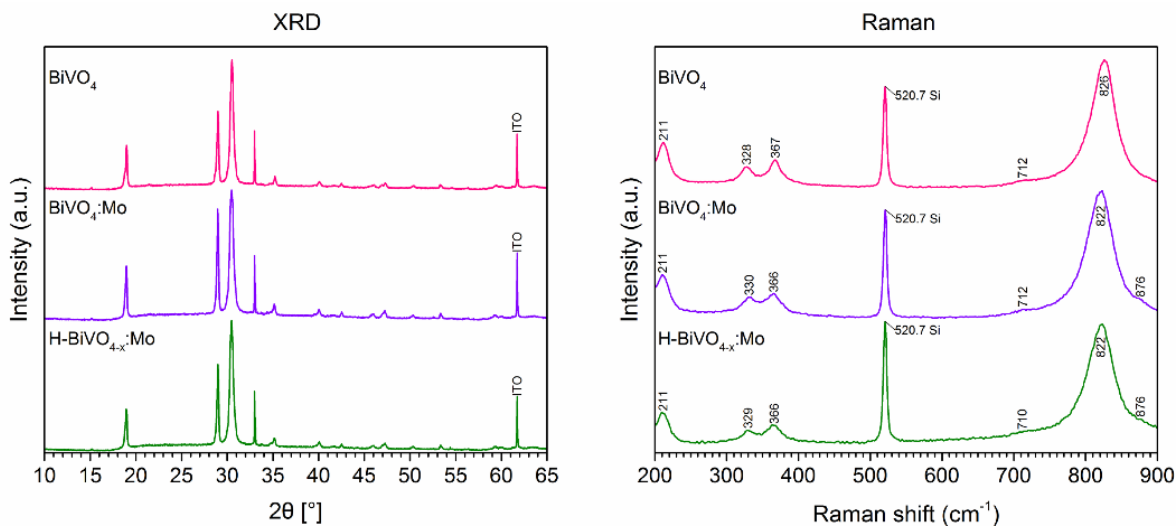

Figure 6.12 a) XRD patterns and b) Raman spectra of $\mathrm{BiVO}_{4}, \mathrm{BiVO}_{4}$ :Mo and $\mathrm{H}-\mathrm{BiVO}_{4}: \mathrm{Mo}$ on flat highly p-type-doped $\mathrm{Si}$ coated with ITO.

The annealing of $\mathrm{BiVO}_{4}$ : $\mathrm{Mo}$ in a $5 \% \mathrm{H}_{2} / 95 \%$ Ar atmosphere was performed according to the publication of Gan et al. ${ }^{[14]}$ These authors prepared $\mathrm{BiVO}_{4}$ via the same route as used in this chapter and compared hydrogen-annealed and unannealed samples. They found that the photocurrent density of $\mathrm{H}-\mathrm{BiVO}_{4-\mathrm{x}}$ in a solution of $1 \mathrm{M}$ sodium sulfite in $0.1 \mathrm{M}$ borate buffer at $\mathrm{pH} 9$ is substantially higher than that of $\mathrm{BiVO}_{4}$. They attribute this to an increase in oxygen vacancies and introduction of hydrogen impurities through hydrogenation. These oxygen vacancies improve photoelectrochemical performance by improving the electrical conductivity which increases the charge transfer and collection in $\mathrm{H}-\mathrm{BiVO}_{4-\mathrm{x}}$. The process shifts the Fermi level position towards the conduction band, thus facilitating charge separation at the semiconductor/electrolyte interface. Moreover, these oxygen vacancies and hydrogen impurities act as shallow donors, which create a new level in the band gap and enhance the charge transfer at the interface between $\mathrm{BiVO}_{4}$ and fluorine-doped tin oxide (FTO). ${ }^{[14]}$ 

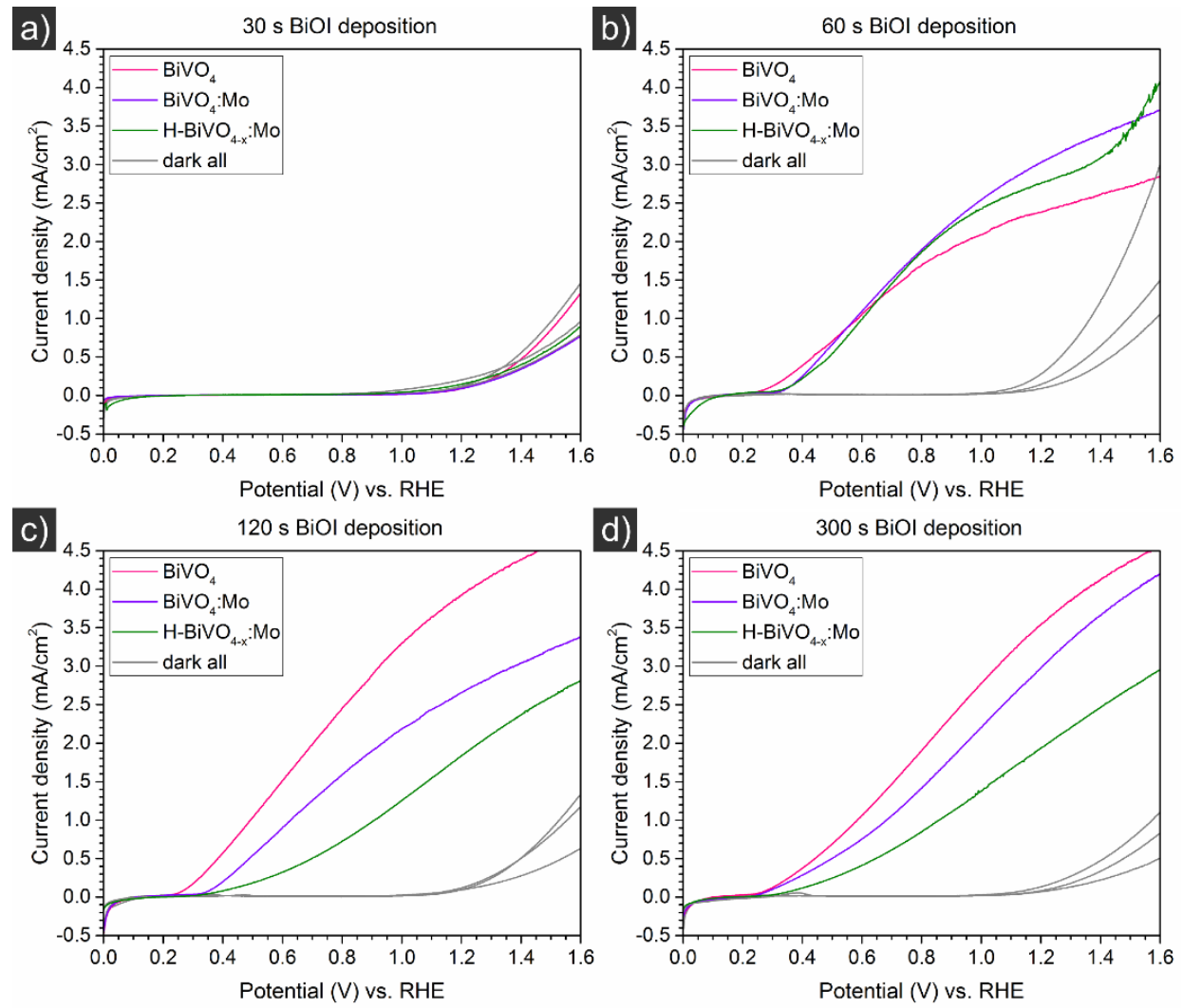

Figure 6.13 Linear potential sweeps at a scan rate of $10 \mathrm{mV} / \mathrm{s}$ for $\mathrm{BiVO}_{4}, \mathrm{BiVO}_{4}: \mathrm{Mo}$ and $\mathrm{H}-\mathrm{BiVO}_{4-\mathrm{x}}$ :Mo obtained from BiOI deposited for $30 \mathrm{~s}(\mathrm{a}), 60 \mathrm{~s}(\mathrm{~b}), 120 \mathrm{~s}(\mathrm{c})$ and $300 \mathrm{~s}(\mathrm{~d})$ on flat p-type silicon in a solution of $1 \mathrm{M}$ sodium sulfite $\left(\mathrm{Na}_{2} \mathrm{SO}_{3}\right)$ and $0.5 \mathrm{M}$ potassium phosphate (KPi) buffer with a $\mathrm{pH}$ of 7.0 under simulated AM 1.5 solar illumination.

Cooper et al. in contrast argue that the improvement of photocurrent of postsynthetically annealed $\mathrm{BiVO}_{4}$ in $100 \%$ hydrogen atmosphere is not due to the introduction of oxygen vacancies but rather to incorporation of hydrogen donors. ${ }^{[15]}$ The authors found that annealing in $\mathrm{H}_{2}$ at temperatures up to $290{ }^{\circ} \mathrm{C}$ led to near-complete elimination of majority carrier transport limitations. ${ }^{[15]}$ In our photocurrent measurements of $\mathrm{BiVO}_{4}, \mathrm{BiVO}_{4}: \mathrm{Mo}$ and $\mathrm{H}-\mathrm{BiVO}_{4-\mathrm{x}}$ :Mo prepared from BiOI deposited for 30 to $300 \mathrm{~s}$ (Figure 6.13) we have observed a slight improvement due to Mo doping and hydrogen annealing only at a BiOI deposition time of $60 \mathrm{~s}$. At BiOI deposition times of $120 \mathrm{~s}$ and $300 \mathrm{~s}$, undoped, unannealed $\mathrm{BiVO}_{4}$ showed the highest photocurrents, followed by $\mathrm{BiVO}_{4}: \mathrm{Mo}$ and then $\mathrm{H}-\mathrm{BiVO}_{4-\mathrm{x}}: \mathrm{Mo}$. The reason for the decrease in photocurrent due to Mo 
doping and hydrogen annealing in these samples, contrary to a positive effect of these procedures reported in the literature ${ }^{[40,42]}$, is not known. We assume that this is, in the case of Mo doping, due to a different preparation procedure, i.e. reactive co-sputtering, and a different electrodeposition route, in comparison to literature. ${ }^{[40,42]}$ As for the hydrogen annealing, the used temperature in the present study might have been too high. While the applied temperature of $300{ }^{\circ} \mathrm{C}$ is below the value of $320^{\circ} \mathrm{C}$ reported by Cooper et al. to induce lower photocurrents of $\mathrm{BiVO}_{4}$ when annealed in pure hydrogen atmosphere due to the formation of metallic species by reduction of $\mathrm{BiVO}_{4},{ }^{[15]} \mathrm{Gan}$ et al. have reported the optimum to be at $250{ }^{\circ} \mathrm{C}$ in a $5 \% \mathrm{H}_{2} / 95 \%$ Ar atmosphere. At higher temperatures, Gan et al. suppose that trap states in the $\mathrm{BiVO}_{4}$ band gap are introduced by the occurrence of defects. ${ }^{[14]}$

\subsection{Conclusions}

In conclusion, molybdenum-doped and hydrogen-annealed $\mathrm{H}-\mathrm{BiVO}_{4-\mathrm{x}}: \mathrm{Mo}$ in different thicknesses was successfully deposited on ITO-coated, highly doped p-type silicon flat surfaces and microwire arrays of $4 \mu \mathrm{m}$ diameter, $4 \mu \mathrm{m}$ to $20 \mu \mathrm{m}$ spacing and $5.3 \mu \mathrm{m}$ to $15.9 \mu \mathrm{m}$ length. At the same time, we encountered several unexpected effects that hampered the efficiency of our devices.

The influence of Mo doping and hydrogen annealing in combination with different preparation methods needs to be further investigated as they decreased the photocatalytic performance of our $\mathrm{H}_{-} \mathrm{BiVO}_{4-\mathrm{x}}: \mathrm{Mo}$ films, which is contrary to literature. Yet, leaving out Mo doping and hydrogen annealing during the preparation may have further increased the observed difference in photocatalytic performance between flat and microwire-structured devices by amplifying the mass transfer phenomena.

Observed photocurrents for the oxidation of sodium sulfite $\left(\mathrm{Na}_{2} \mathrm{SO}_{3}\right)$ on microwire-structured samples were mainly lower than on flat equivalents. We have excluded various hypotheses to explain the differences in photoelectrochemical performance, and our results support the hypothesis that ion diffusion in the internal volume of the microwires overcompensates the positive effect of higher light absorption and $\mathrm{H}-\mathrm{BiVO}_{4-\mathrm{x}}$ :Mo mass loading compared to 
flat equivalents, thus limiting the performance of our microwire-structured devices. This is supported by the findings that during potential sweeps from low to high bias region, microwire-structured devices outperformed flat equivalents in the low bias region and strongly underperformed in the high bias region, since the low bias region is tested before $\mathrm{SO}_{3}{ }^{2-}$ ions could be depleted. When water is oxidized on the microwire-structured anodes instead of sulfite, oxygen and protons evolve which have an effect on mass transport. Protons have a much higher diffusion rate than sulfite ions, and oxygen production could introduce convection. However, the observation of a thickness gradient in BiOI deposition, which is triggered by a local $\mathrm{pH}$ change, showed that either proton or p-benzoquinone diffusion is limited in our microwire system. The light beam was oriented perpendicularly to the samples in the photoelectrochemical experiments, which does not lead to optimal light trapping of the system. To learn more about the influence of light absorption, ion diffusion inside the microwire system and their relative contributions to the overall photocatalytic activity, tests at various tilt angles, different potential scan speeds and chronoamperometry measurements are needed.

In the development of substrates for photocatalysts with the aim to enhance surface area and to create a tandem device for solar water splitting, our results showed unintentionally the limits of (silicon) microwire dimension, structure and architecture. Whereas surface structuring has presumably a positive effect, ion diffusion inside the microwire array has a negative effect on the overall photocatalytic performance. As recent results of Chakthranont et al. ${ }^{[51]}$ have shown, the use of silicon nanowires can increase the photocatalytic performance of $\mathrm{BiVO}_{4}$. However, optimization of silicon wire length, spacing and diameter is needed to obtain maximal photocatalytic device activity.

\subsection{Acknowledgements}

Yuxi Guo is gratefully acknowledged for the input and fruitful discussions regarding BiOI, Wouter Vijselaar for the help in the cleanroom work and discussions, and Bastian Mei for the proofreading of this chapter. 


\subsection{References}

[1] F. F. Abdi, N. Firet, A. Dabirian, R. van de Krol, MRS Proceedings 2012, 1446.

[2] H.-q. Jiang, H. Endo, H. Natori, M. Nagai, K. Kobayashi, Mater. Res. Bull. 2009, 44, 700.

[3] K. J. McDonald, K.-S. Choi, Energy Environ. Sci. 2012, 5, 8553.

[4] S. Tokunaga, H. Kato, A. Kudo, Chem. Mater. 2001, 13, 4624.

[5] F. F. Abdi, N. Firet, R. van de Krol, ChemCatChem 2013, 5, 490.

[6] H. Doscher, J. F. Geisz, T. G. Deutsch, J. A. Turner, Energy Environ. Sci. 2014, 7, 2951.

[7] J. R. Bolton, S. J. Strickler, J. S. Connolly, Nature 1985, 316, 495.

[8] F. F. Abdi, T. J. Savenije, M. M. May, B. Dam, R. van de Krol, J. Phys. Chem. Lett. 2013, 4, 2752.

[9] B. Pattengale, J. Huang, Phys. Chem. Chem. Phys. 2016, 18, 32820.

[10] W. Luo, Z. Yang, Z. Li, J. Zhang, J. Liu, Z. Zhao, Z. Wang, S. Yan, T. Yu, Z. Zou, Energy Environ. Sci. 2011, 4, 4046.

[11] W. Yao, H. Iwai, J. Ye, Dalton Trans. 2008, 1426.

[12] F. F. Abdi, L. Han, A. H. M. Smets, M. Zeman, B. Dam, R. van de Krol, Nat. Commun. 2013, 4.

[13] T. W. Kim, Y. Ping, G. A. Galli, K.-S. Choi, Nat. Commun. 2015, 6.

[14] J. Gan, X. Lu, B. B. Rajeeva, R. Menz, Y. Tong, Y. Zheng, ChemElectroChem 2015, 2, 1385.

[15] J. K. Cooper, S. B. Scott, Y. Ling, J. Yang, S. Hao, Y. Li, F. M. Toma, M. Stutzmann, K. V. Lakshmi, I. D. Sharp, Chem. Mater. 2016, $28,5761$.

[16] T. W. Kim, K.-S. Choi, Science 2014, 343, 990.

[17] S. J. Hong, S. Lee, J. S. Jang, J. S. Lee, Energy Environ. Sci. 2011, 4, 1781.

[18] Y. Pihosh, I. Turkevych, K. Mawatari, T. Asai, T. Hisatomi, J. Uemura, M. Tosa, K. Shimamura, J. Kubota, K. Domen, T. Kitamori, Small 2014, 10, 3692.

[19] Y. Pihosh, I. Turkevych, K. Mawatari, J. Uemura, Y. Kazoe, S. Kosar, K. Makita, T. Sugaya, T. Matsui, D. Fujita, M. Tosa, M. Kondo, T. Kitamori, Sci. Rep. 2015, 5, 11141. 
[20] P. M. Rao, L. Cai, C. Liu, I. S. Cho, C. H. Lee, J. M. Weisse, P. Yang, X. Zheng, Nano Lett. 2014, 14, 1099.

[21] S. K. Pilli, R. Janarthanan, T. G. Deutsch, T. E. Furtak, L. D. Brown, J. A. Turner, A. M. Herring, Phys. Chem. Chem. Phys. 2013, 15, 14723.

[22] J. Su, L. Guo, N. Bao, C. A. Grimes, Nano Lett. 2011, 11, 1928.

[23] C.-J. Chen, P.-T. Chen, M. Basu, K.-C. Yang, Y.-R. Lu, C.-L. Dong, C.-G. Ma, C.-C. Shen, S.-F. Hu, R.-S. Liu, J. Mater. Chem. A 2015, 3, 23466.

[24] E. Garnett, P. Yang, Nano Lett. 2010, 10, 1082.

[25] M. D. Kelzenberg, S. W. Boettcher, J. A. Petykiewicz, D. B. Turner-Evans, M. C. Putnam, E. L. Warren, J. M. Spurgeon, R. M. Briggs, N. S. Lewis, H. A. Atwater, Nat. Mater. 2010, 9, 239.

[26] J. Zhu, Z. Yu, G. F. Burkhard, C.-M. Hsu, S. T. Connor, Y. Xu, Q. Wang, M. McGehee, S. Fan, Y. Cui, Nano Lett. 2009, 9, 279.

[27] E. L. Warren, H. A. Atwater, N. S. Lewis, J. Phys. Chem. C 2013, 118, 747.

[28] Y. Liang, T. Tsubota, L. P. A. Mooij, R. van de Krol, J. Phys. Chem. C 2011, 115, 17594.

[29] F. F. Abdi, R. van de Krol, J. Phys. Chem. C 2012, 116, 9398.

[30] M. C. Neves, T. Trindade, Thin Solid Films 2002, 406, 93.

[31] E. Alarcon-Llado, L. Chen, M. Hettick, N. Mashouf, Y. Lin, A. Javey, J. W. Ager, Phys. Chem. Chem. Phys. 2014, 16, 1651.

[32] A. J. E. Rettie, S. Mozaffari, M. D. McDaniel, K. N. Pearson, J. G. Ekerdt, J. T. Markert, C. B. Mullins, J. Phys. Chem. C 2014, 118, 26543.

[33] Y. Jianqiang, K. Akihiko, Chem. Lett. 2005, 34, 850.

[34] J. A. Seabold, K.-S. Choi, J. Am. Chem. Soc. 2012, 134, 2186.

[35] L. H. Dall'Antonia, N. R. de Tacconi, W. Chanmanee, H. Timmaji, N. Myung, K. Rajeshwar, Electrochem. Solid-State Lett. 2010, 13, D29.

[36] Y. Yang, J. Wang, J. Zhao, B. A. Nail, X. Yuan, Y. Guo, F. E. Osterloh, ACS Appl. Mater. Interfaces 2015, 7, 5959.

[37] R. H. Coridan, M. Shaner, C. Wiggenhorn, B. S. Brunschwig, N. S. Lewis, J. Phys. Chem. C 2013, 117, 6949.

[38] A. Milbrat, R. Elbersen, R. Kas, R. M. Tiggelaar, H. Gardeniers, G. Mul, J. Huskens, Adv. Mater. 2016, 28, 1400.

[39] M. R. Shaner, K. T. Fountaine, S. Ardo, R. H. Coridan, H. A. Atwater, N. S. Lewis, Energy Environ. Sci. 2014, 7, 779. 
[40] L. Chen, F. M. Toma, J. K. Cooper, A. Lyon, Y. Lin, I. D. Sharp, J. W. Ager, ChemSusChem 2015, 8, 1066.

[41] Y. Qiu, W. Liu, W. Chen, W. Chen, G. Zhou, P.-C. Hsu, R. Zhang, Z. Liang, S. Fan, Y. Zhang, Y. Cui, Sci. Adv. 2016, 2.

[42] Y. Park, D. Kang, K.-S. Choi, Phys. Chem. Chem. Phys. 2014, 16, 1238.

[43] C. Xiang, A. C. Meng, N. S. Lewis, Proc. Natl. Acad. Sci. 2012, 109, 15622.

[44] J. R. McKone, N. S. Lewis, Photoelectrochemical Water Splitting: Materials, Processes and Architectures, (Ed: H.-J. Lewerenz), The Royal Society of Chemistry, 2013.

[45] W. Vijselaar, P. Westerik, J. Veerbeek, R. M. Tiggelaar, E. Berenschot, N. R. Tas, H. Gardeniers, J. Huskens, Nat. Energy 2018.

[46] R. Elbersen, R. M. Tiggelaar, A. Milbrat, G. Mul, H. Gardeniers, J. Huskens, Adv. Energy Mater. 2015, 5, 1401745.

[47] R. Elbersen, W. Vijselaar, R. M. Tiggelaar, H. Gardeniers, J. Huskens, $A d v$. Energy Mater. 2016, 6, 1501728.

[48] S. W. Boettcher, E. L. Warren, M. C. Putnam, E. A. Santori, D. TurnerEvans, M. D. Kelzenberg, M. G. Walter, J. R. McKone, B. S. Brunschwig, H. A. Atwater, N. S. Lewis, J. Am. Chem. Soc. 2011, 133, 1216.

[49] S. W. Boettcher, J. M. Spurgeon, M. C. Putnam, E. L. Warren, D. B. TurnerEvans, M. D. Kelzenberg, J. R. Maiolo, H. A. Atwater, N. S. Lewis, Science 2010, 327, 185.

[50] C. W. Roske, E. J. Popczun, B. Seger, C. G. Read, T. Pedersen, O. Hansen, P. C. K. Vesborg, B. S. Brunschwig, R. E. Schaak, I. Chorkendorff, H. B. Gray, N. S. Lewis, J. Phys. Chem. Lett. 2015, 6, 1679.

[51] P. Chakthranont, T. R. Hellstern, J. M. McEnaney, T. F. Jaramillo, Adv. Energy Mater. 2017, 7, 1701515.

[52] C. Zachaus, F. F. Abdi, L. M. Peter, R. van de Krol, Chem. Sci. 2017, 8, 3712.

[53] R. L. Frost, D. A. Henry, M. L. Weier, W. Martens, J. Raman Spectrosc. 2006, 37, 722.

[54] A. W. Sleight, H. y. Chen, A. Ferretti, D. E. Cox, Mater. Res. Bull. 1979, 14, 1571.

[55] S. P. Berglund, A. J. E. Rettie, S. Hoang, C. B. Mullins, Phys. Chem. Chem. Phys. 2012, 14, 7065. 
[56] V. I. Merupo, S. Velumani, A. Kassiba, M. A. García-Sánchez, "Structural and optical properties of molybdenum doped bismuth vanadate powders", presented at 2014 11th International Conference on Electrical Engineering, Computing Science and Automatic Control (CCE), Sept. 29 2014-Oct. 3 2014, 2014, DOI:10.1109/ICEEE.2014.6978299.

[57] L. Sandhya Kumari, P. Prabhakar Rao, A. Narayana Pillai Radhakrishnan, V. James, S. Sameera, P. Koshy, Sol. Energy Mater. Sol. Cells 2013, 112, 134.

[58] H. S. Park, K. E. Kweon, H. Ye, E. Paek, G. S. Hwang, A. J. Bard, J. Phys. Chem. C 2011, 115, 17870. 


\subsection{Appendix}

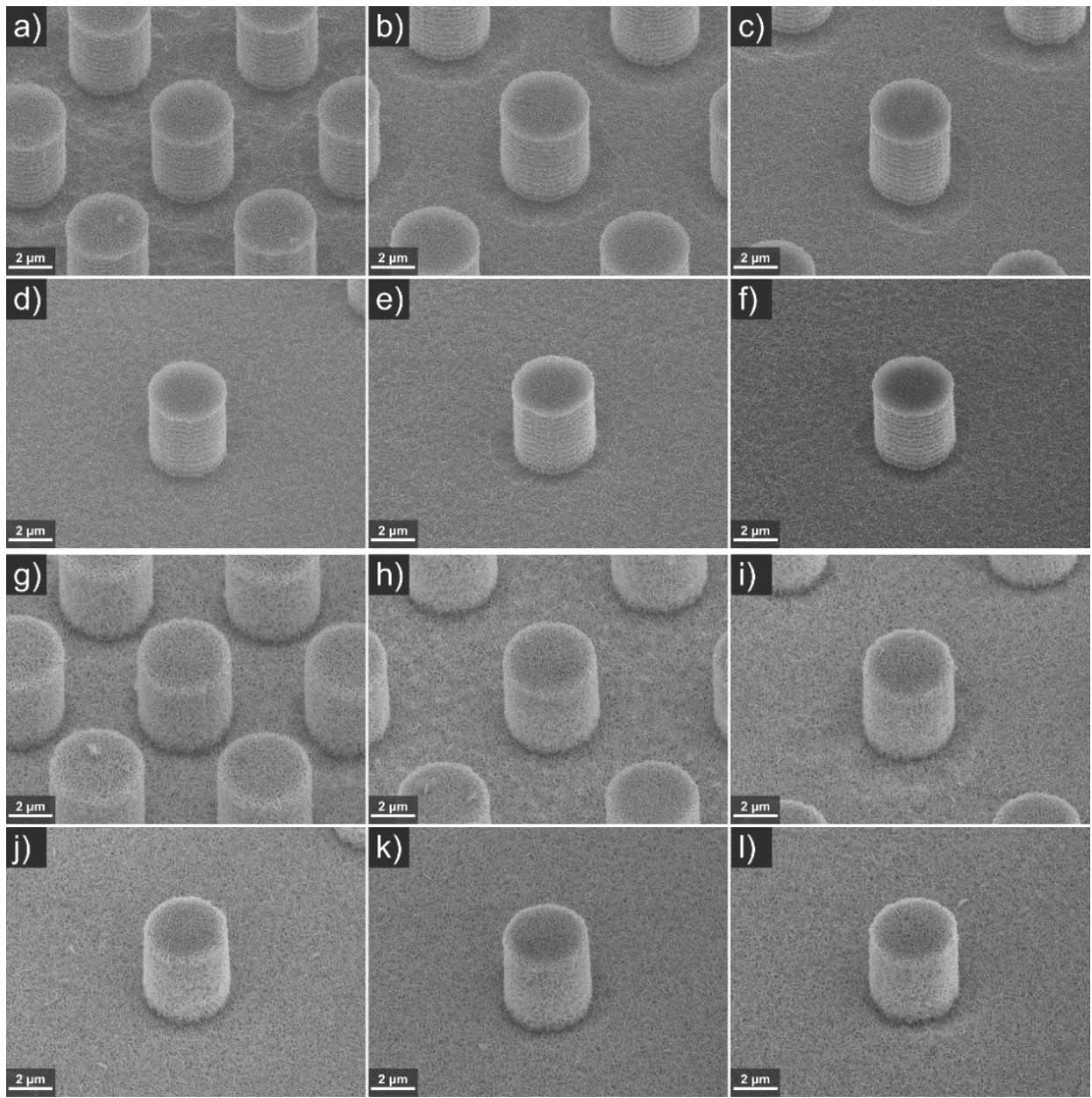

Figure 6.14 $45^{\circ}$ tilted SEM images of electrodeposited BiOI for $30 \mathrm{~s}$ (a-f) and $120 \mathrm{~s}$ (g1) on $5.3 \mu \mathrm{m}$ long hexagonally arranged p-type doped silicon microwire arrays of $4 \mu \mathrm{m}$ diameter and $4 \mu \mathrm{m}(\mathrm{a}, \mathrm{g}), 6 \mu \mathrm{m}(\mathrm{b}, \mathrm{h}), 8 \mu \mathrm{m}(\mathrm{c}, \mathrm{i}), \quad 10 \mu \mathrm{m}(\mathrm{d}, \mathrm{j}), 15 \mu \mathrm{m}(\mathrm{e}, \mathrm{k})$ or $20 \mu \mathrm{m}$ (f, 1) spacing with ITO sputtered for $5 \mathrm{~min}$. 


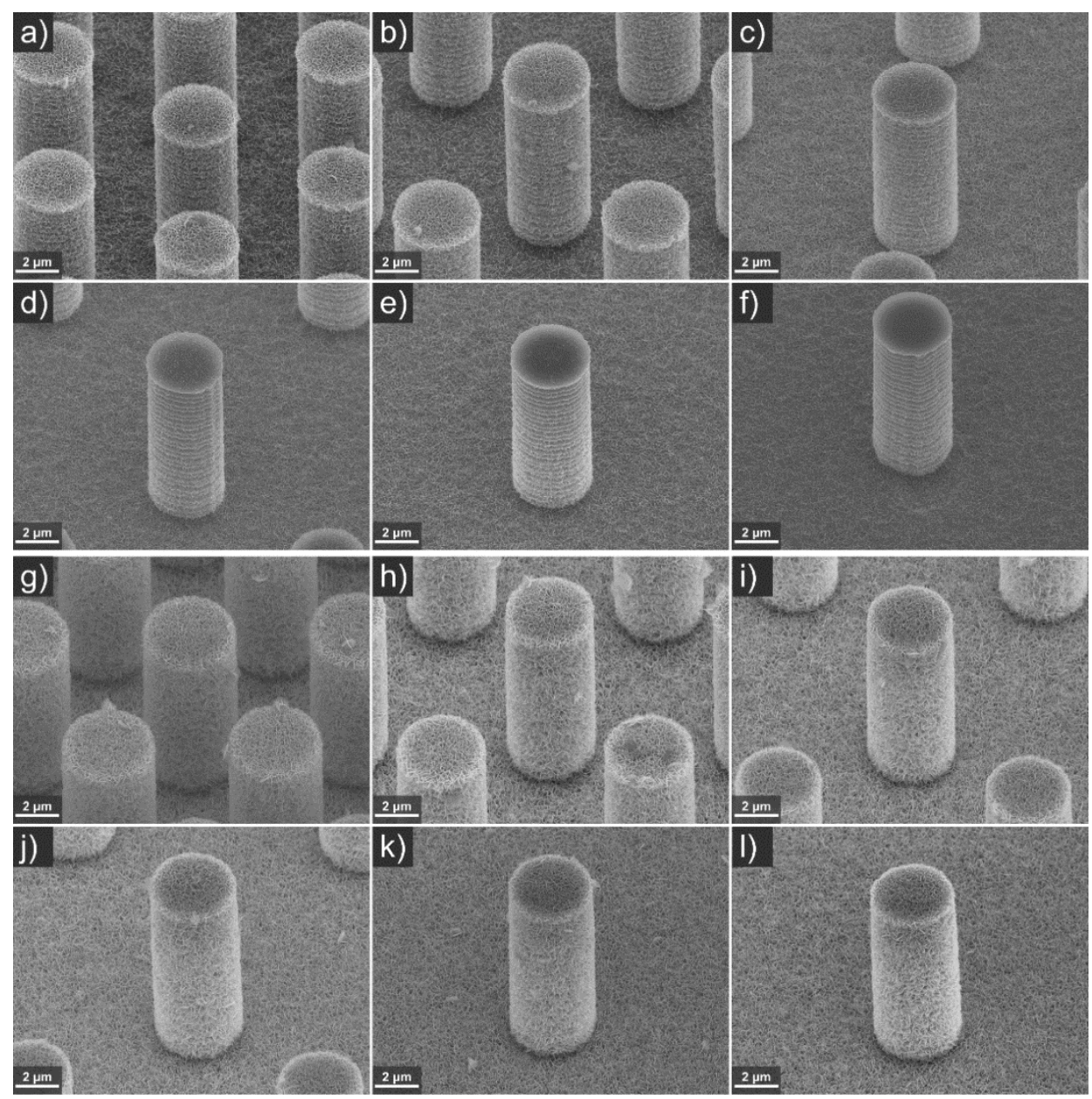

Figure 6.15 $45^{\circ}$ tilted SEM images of electrodeposited BiOI for $30 \mathrm{~s} \mathrm{(a-f)} \mathrm{and} 120 \mathrm{~s}$ (g1) on $10.6 \mu \mathrm{m}$ long hexagonally arranged p-type doped silicon microwire arrays of $4 \mu \mathrm{m}$ diameter and $4 \mu \mathrm{m}(\mathrm{a}, \mathrm{g}), 6 \mu \mathrm{m}(\mathrm{b}, \mathrm{h}), \quad 8 \mu \mathrm{m}(\mathrm{c}, \mathrm{i}), \quad 10 \mu \mathrm{m}(\mathrm{d}, \mathrm{j}), 15 \mu \mathrm{m}(\mathrm{e}, \mathrm{k})$ or $20 \mu \mathrm{m}(\mathrm{f}, 1)$ spacing with ITO sputtered for $5 \mathrm{~min}$. 
Integration of $\mathrm{H}_{-} \mathrm{BiVO}_{4-\mathrm{x}}: \mathrm{Mo}$ on silicon microwires

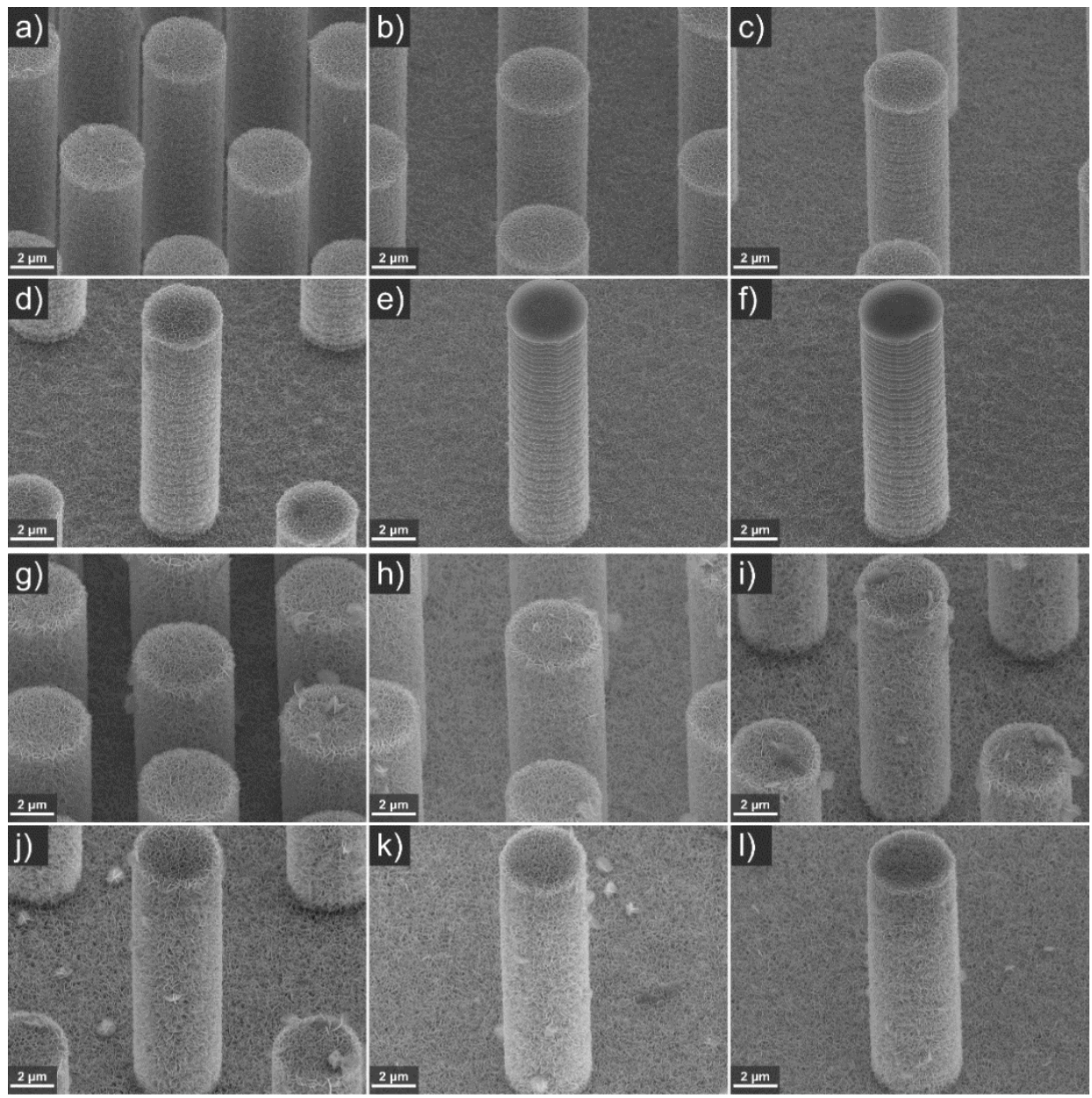

Figure 6.16 $45^{\circ}$ tilted SEM images of electrodeposited BiOI for $30 \mathrm{~s}(\mathrm{a}-\mathrm{f})$ and $120 \mathrm{~s}$ (g1) on $15.9 \mu \mathrm{m}$ long hexagonally arranged p-type doped silicon microwire arrays of $4 \mu \mathrm{m}$ diameter and $4 \mu \mathrm{m}(\mathrm{a}, \mathrm{g}), 6 \mu \mathrm{m}(\mathrm{b}, \mathrm{h}), 8 \mu \mathrm{m}(\mathrm{c}, \mathrm{i}), 10 \mu \mathrm{m}(\mathrm{d}, \mathrm{j}), 15 \mu \mathrm{m}(\mathrm{e}, \mathrm{k})$ or $20 \mu \mathrm{m}$ (f, 1) spacing with ITO sputtered for $5 \mathrm{~min}$. 


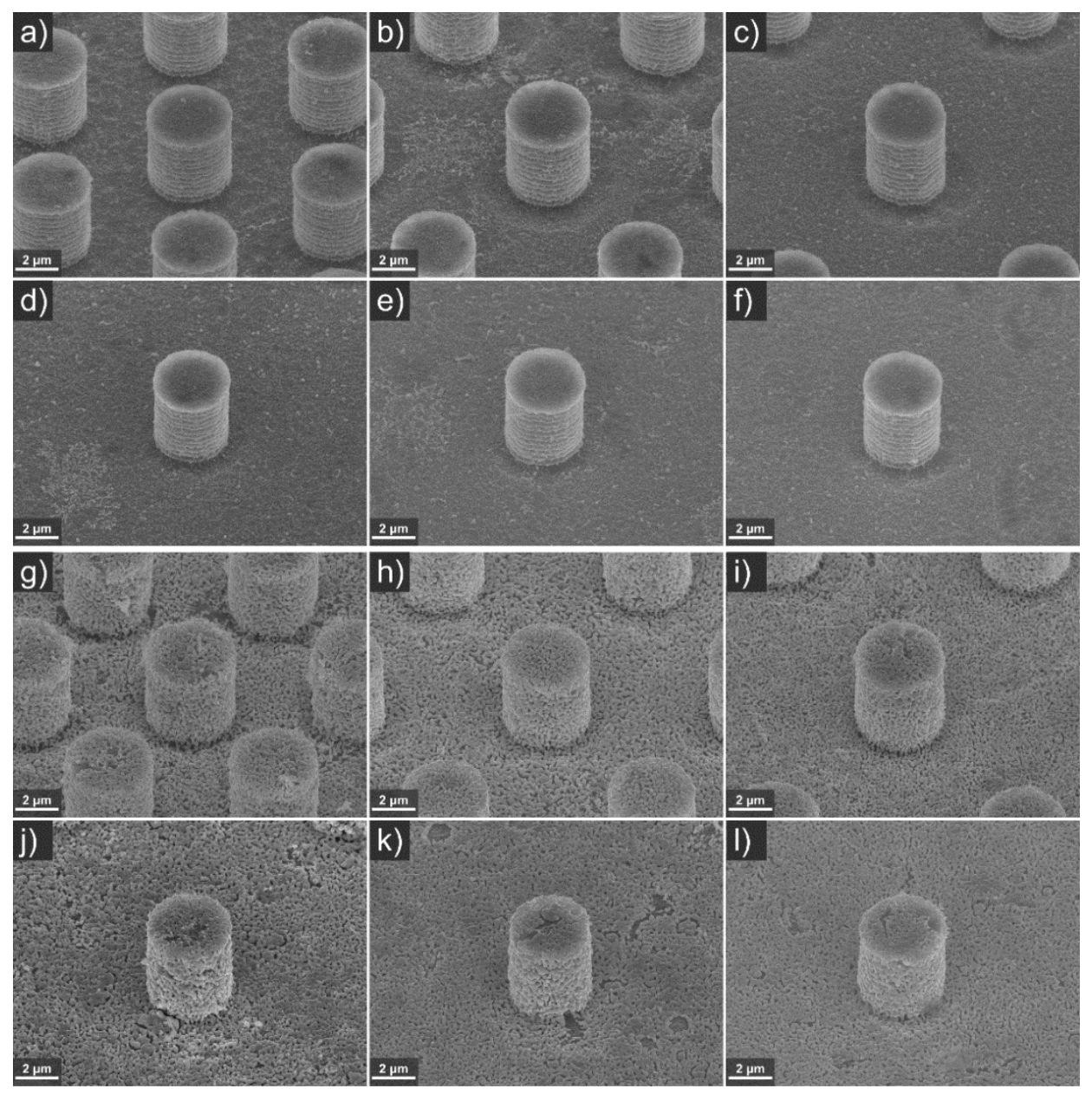

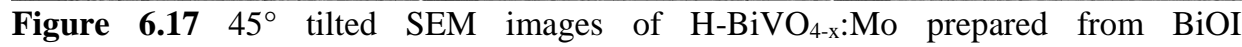
electrodeposited for $30 \mathrm{~s}$ (a-f) and $120 \mathrm{~s}(\mathrm{~g}-\mathrm{l})$ on $5.3 \mu \mathrm{m}$ long hexagonally arranged $\mathrm{p}$ type doped silicon microwire arrays of $4 \mu \mathrm{m}$ diameter and $4 \mu \mathrm{m}(\mathrm{a}, \mathrm{g}), 6 \mu \mathrm{m}(\mathrm{b}, \mathrm{h})$, $8 \mu \mathrm{m}(\mathrm{c}, \mathrm{i}), 10 \mu \mathrm{m}(\mathrm{d}, \mathrm{j}), 15 \mu \mathrm{m}(\mathrm{e}, \mathrm{k})$ or $20 \mu \mathrm{m}(\mathrm{f}, \mathrm{l})$ spacing with ITO sputtered for 5 min. 
Integration of $\mathrm{H}_{-} \mathrm{BiVO}_{4-\mathrm{x}}: \mathrm{Mo}$ on silicon microwires

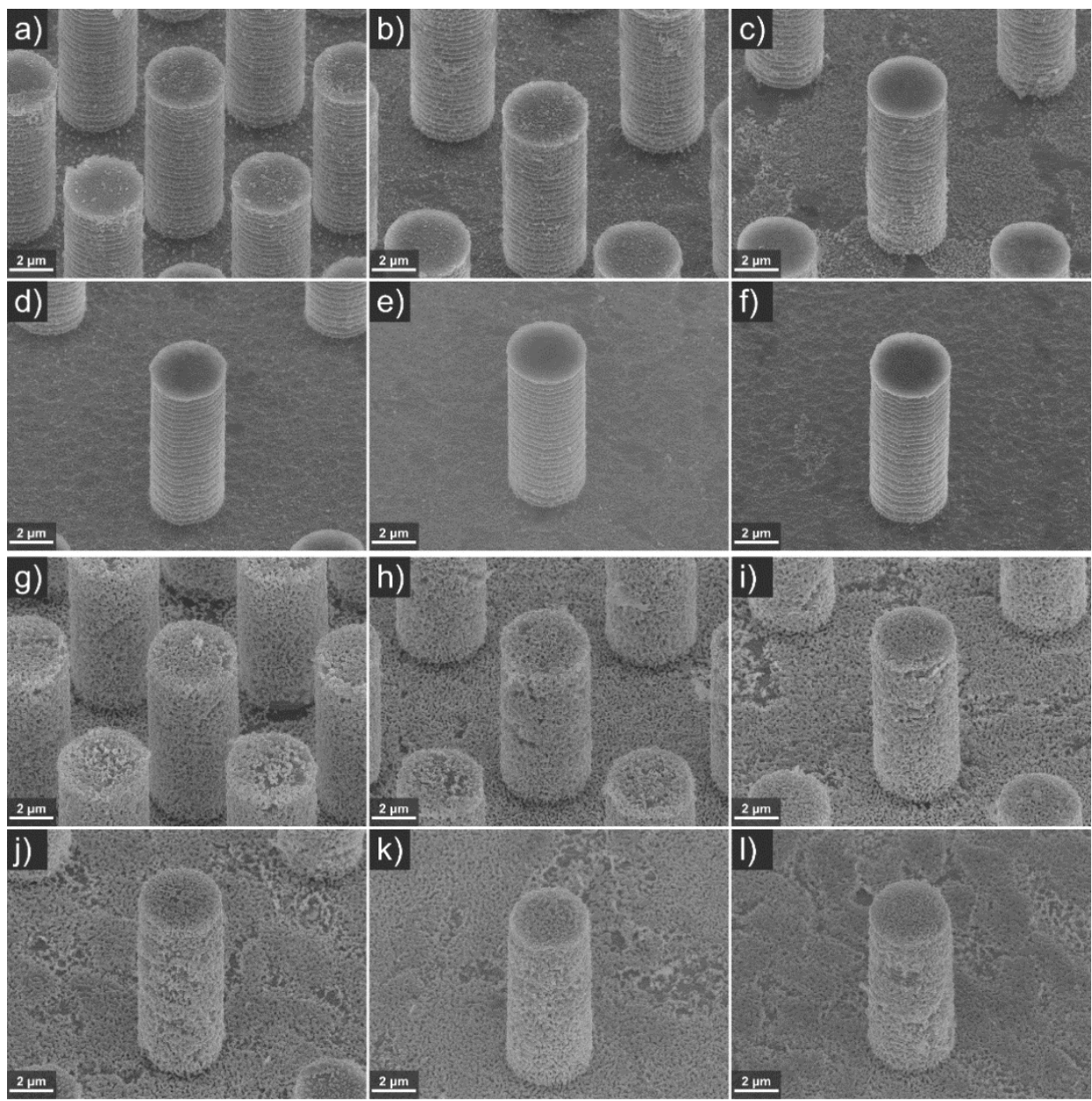

Figure 6.18 $45^{\circ}$ tilted SEM images of $\mathrm{H}_{-} \mathrm{BiVO}_{4-\mathrm{x}}: \mathrm{Mo}$ prepared from $\mathrm{BiOI}$ electrodeposited for $30 \mathrm{~s}(\mathrm{a}-\mathrm{f})$ and $120 \mathrm{~s}(\mathrm{~g}-\mathrm{l})$ on $10.6 \mu \mathrm{m}$ long hexagonally arranged $\mathrm{p}$ type doped silicon microwire arrays of $4 \mu \mathrm{m}$ diameter and $4 \mu \mathrm{m}(\mathrm{a}, \mathrm{g}), 6 \mu \mathrm{m}(\mathrm{b}, \mathrm{h})$, $8 \mu \mathrm{m}(\mathrm{c}, \mathrm{i}), 10 \mu \mathrm{m}(\mathrm{d}, \mathrm{j}), 15 \mu \mathrm{m}(\mathrm{e}, \mathrm{k})$ or $20 \mu \mathrm{m}(\mathrm{f}, \mathrm{l})$ spacing with ITO sputtered for $5 \mathrm{~min}$. 


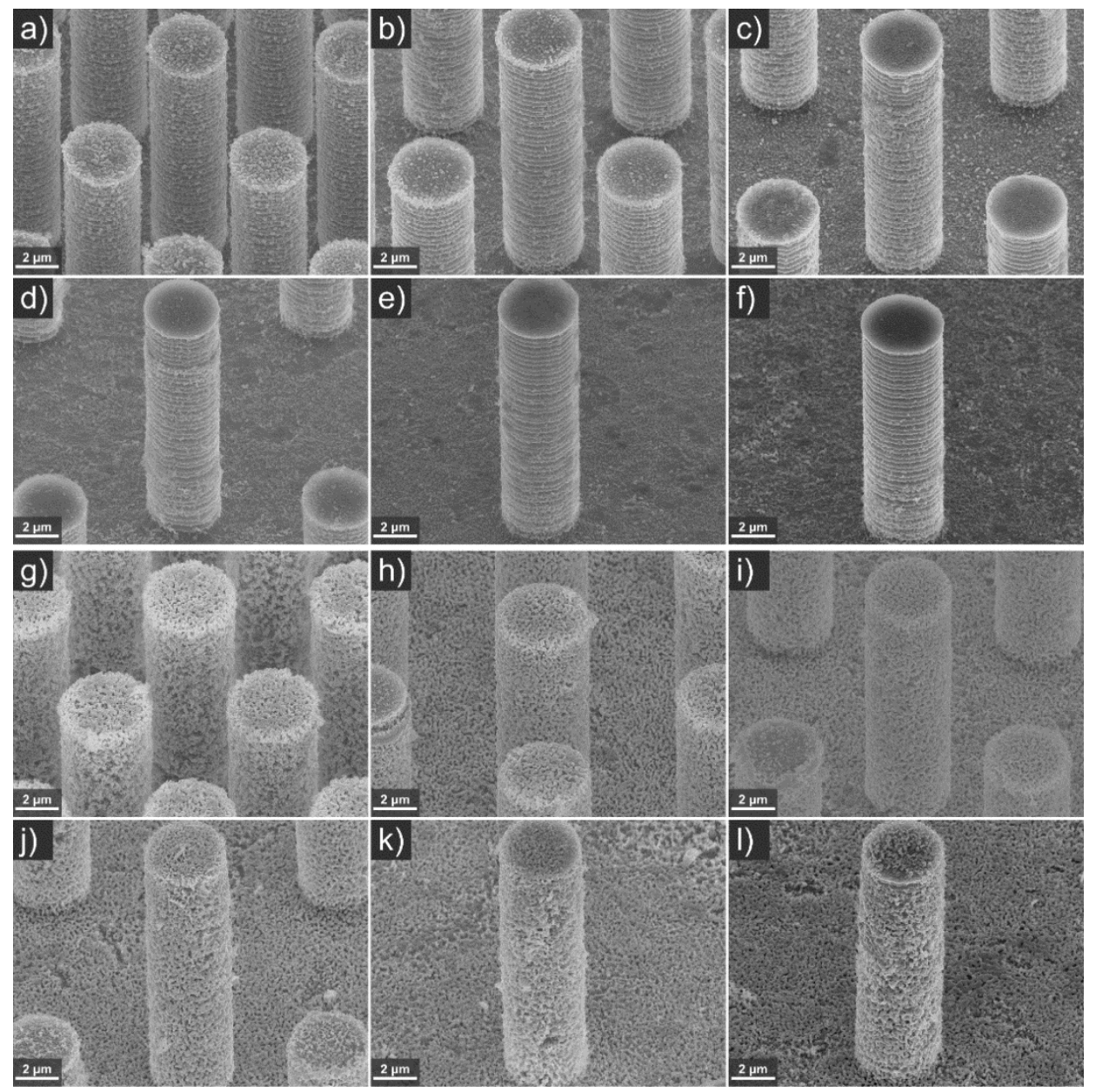

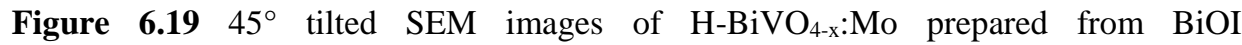
electrodeposited for $30 \mathrm{~s}(\mathrm{a}-\mathrm{f})$ and $120 \mathrm{~s}(\mathrm{~g}-\mathrm{l})$ on $15.9 \mu \mathrm{m}$ long hexagonally arranged $\mathrm{p}$ type doped silicon microwire arrays of $4 \mu \mathrm{m}$ diameter and $4 \mu \mathrm{m}(\mathrm{a}, \mathrm{g}), 6 \mu \mathrm{m}(\mathrm{b}, \mathrm{h})$, $8 \mu \mathrm{m}(\mathrm{c}, \mathrm{i}), 10 \mu \mathrm{m}(\mathrm{d}, \mathrm{j}), 15 \mu \mathrm{m}(\mathrm{e}, \mathrm{k})$ or $20 \mu \mathrm{m}(\mathrm{f}, \mathrm{l})$ spacing with ITO sputtered for 5 min. 


\section{Chapter 7}

Summary and perspective

The transition from a fossil fuel-dependent society towards the use of renewable energies is desirable to reduce pollution, $\mathrm{CO}_{2}$ emission and thus slow down global warming. So far, the focus has been on electricity production from sustainable sources, such as photovoltaics and wind power plants. However, their energy input is fluctuating and does not meet the demand. Whereas short term intermittencies in electricity, under or overproduction, are potentially balanced with pumped hydro storage systems or batteries, solutions for energy storage to deal with long term intermittencies, such as summer and winter cycles, are needed. One of the proposed solutions is to generate hydrogen from water with the energy from the sunlight. This hydrogen could be used as a fuel itself or converted further to hydrocarbons. By replacing the current hydrogen demand, of which around $96 \%$ is produced from fossil fuels, would reduce the total yearly emission of $\mathrm{CO}_{2}$ by about $2 \%$ or 685 million metric tons.

The research described in this thesis has focused on the development of photoelectrochemical devices for solar-driven hydrogen generation from water splitting. For this purpose, silicon was used as a base material as it is nontoxic, abundant, easily available and is being produced in high purity and quantity in industry. Electrochemistry was utilized as the coating and functionalization technique as it provides a versatile range in usable materials and the ability to control the morphology of deposited materials during the deposition process, the possibility to coat structured substrates conformally, a good electrical contact between substrate and deposited material, and compatibility with ambient conditions and scalability.

In Chapters 3 and 5, a metal and a semiconductor, i.e. platinum (Pt) and tungsten oxide $\left(\mathrm{WO}_{3}\right)$, were electrodeposited on flat ITO-coated p-type silicon. Chapter 3 has reported how Pt particle size and density can be controlled and 
tuned to the nano range by the addition of $\mathrm{H}_{2} \mathrm{O}_{2}$ to the electrolyte solution. This is important for the construction of a hydrogen-generating photocathode and allows to cover the p-Si surface by high density Pt particles. At the same time, the method allows to reduce the deposited mass of the precious and expensive metal and to optimize the photocathode for light absorption and hydrogen evolution properties. The Pt particle density was increased 18.5 times by addition of an optimized quantity of $81 \mathrm{mM} \mathrm{H}_{2} \mathrm{O}_{2}$ to the electrolyte solution, while simultaneously decreasing the particle diameter from 302 to $60 \mathrm{~nm}$ at a passed charge density of $20 \mathrm{mC} / \mathrm{cm}^{2}$. At higher $\mathrm{H}_{2} \mathrm{O}_{2}$ concentrations it was observed that the deposited mass decreased upon increasing charge density which we attribute to cathodic dissolution caused by formed hydroxyl radicals. In Chapter 5, a photoanode was created with a $\mathrm{WO}_{3}$ top coating, and its deactivation was studied over time in a phosphate buffer at various $\mathrm{pH} . \mathrm{WO}_{3}$ is a promising, inexpensive, and environmentally benign photoanode material for the oxidation of water but loses its activity after minutes to hours of operation in a photo electrochemical cell. Understanding the deactivation processes is essential in the fabrication of a long-lived device. During device operation, the evolved gases $\mathrm{H}_{2}$ and $\mathrm{O}_{2}$ were measured with high time and concentration resolution. It was found that the rate of deactivation was strongest in a solution of $\mathrm{pH}$ 1.0, followed by $\mathrm{pH} 7.4, \mathrm{pH} 3.0$ and $\mathrm{pH}$ 5.0. At $\mathrm{pH} 7.4$ the photocathode was unstable and dissolved into solution whereas at other $\mathrm{pH}$ values the deactivation might be caused by peroxo-bound species on the $\mathrm{WO}_{3}$ surface, although significant amounts of $\mathrm{H}_{2} \mathrm{O}_{2}$ were not detected in the electrolyte.

In Chapters 4 and 6, microwire-structured silicon substrates were used. These architectures have improved light-trapping properties and provide a high internal surface area, whereby a higher fraction of the incident light is absorbed, current densities at the surface are decreased during photoelectrochemical operation, and a higher loading of semiconductors becomes possible without increasing its thickness. Chapter 4 has shown a novel method to deposit two different materials, i.e. silver $(\mathrm{Ag})$ and platinum $(\mathrm{Pt})$, spatioselectively on the microwire top and bottom sections, respectively without any masking steps. This significantly improves the fabrication of devices which require two different deposits, potentially oxidation and reduction catalysts. For this, an 
axial $\mathrm{p} / \mathrm{n}$ junction was created with a top $\mathrm{n}-\mathrm{Si}$ part and its diode behavior was utilized. The metals were cathodically deposited, and the presence or absence of light steered the deposition. In Chapter 6, p-type silicon microwires with an ITO layer were coated with molybdenum-doped and hydrogen-annealed bismuth vanadate $\left(\mathrm{H}-\mathrm{BiVO}_{4-\mathrm{x}}\right)$ to study its effect on photocatalytic performance. The performance was evaluated by studying the oxidation of the hole scavenger

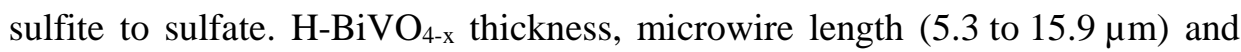
spacing (4 to $20 \mu \mathrm{m}$ ) were varied to optimize the device performance and compare it to flat substrates. It was found that microwires of these geometries did not improve photocatalytic performance, which we attribute to diffusion limitation of redox species in the internal volume of the microwires.

In conclusion, the research on flat substrates in Chapters 3 and 5 on control of Pt particle size and density and $\mathrm{WO}_{3}$ deactivation contributes to the materials development for photocatalytic water splitting. The results from Chapter 3 provide synthetic means for optimizing silicon-based photocathodes for hydrogen evolution. These results may be further extended to other semiconductor types and also for other applications, as Pt is used as a catalyst in many chemical reactions. Moreover, the understanding of $\mathrm{Pt}$ corrosion processes in the presence of $\mathrm{H}_{2} \mathrm{O}_{2}$ may be of use in the development of more stable and long-lived (photo)catalysts. The deactivation of $\mathrm{WO}_{3}$ during photocatalytic water oxidation is still not fully understood and needs further in situ surface studies to make this material viable for practical devices, by for instance tailored surface modification or passivation with protective (mono)layers which do not absorb a significant portion of the incident light.

The research described in Chapters 4 and 6 on spatioselective functionalization and $\mathrm{H}-\mathrm{BiVO}_{4-\mathrm{x}}$ coating contributes to efforts on the utilization and functionalization of microwire-structured silicon. The method presented in Chapter 4 opens up opportunities to create devices that have value also outside of the area of photocatalysis, as micro- to nanowires are used in various applications, such as electronics, sensors, and photonics. The results from Chapter 6 have shown that the microwire dimensions, structure and architecture commonly used in literature may not be suitable for photocatalysis. A very recent study on a similar construction but with the usage of black silicon with 
shorter wire length, did show slight photocatalytic improvements in comparison to flat substrates. Here, more research is needed on the optimization of silicon wire length, spacing and diameter.

Considering that Fujishima and Honda described the first photocatalytic water splitting on a semiconductor electrode almost five decades ago, the field is still in an early stage of development and many challenges remain. Besides the materials development which was tackled in this thesis, the engineering of a device design which includes gas collection and component arrangement is under debate. Furthermore, the vast majority of the experiments reported in the literature so far have been performed under controlled lab conditions, and it is not yet clear how temperature changes, physical impact from wind, rain and hail, day/night and summer/winter cycles will impact the performance and durability of the devices. Especially freezing temperatures might be a hurdle and exclude photocatalytic hydrogen production at many areas on the planet. Also, commonly overlooked is the fact that hydrogen would be evolved on a large surface area which makes the sealing of the device difficult as hydrogen is the lightest molecule and diffuses through many materials. All these points raise doubts whether photocatalytic water splitting will ever see the light of the day on a large scale that is relevant for solving the energy problem. Nevertheless, past research was and further research is needed as generation and storage of sustainable energy is one of the key challenges of this century and all viable approaches need to be explored. 


\section{Hoofdstuk 7}

Samenvatting en perspectief

De overgang van een samenleving die afhankelijk is van fossiele brandstoffen, naar één die gebruik maakt van duurzame energie, is wenselijk om $\mathrm{CO}_{2}$-emissies, en daarmee de opwarming van het klimaat, tegen te gaan. Tot nu toe heeft de nadruk gelegen op de productie van elektriciteit uit duurzame bronnen, zoals fotovoltaïsche panelen en windmolens. De energieproductie daarvan schommelt echter en voldoet meestal niet aan de vraag. Onderbrekingen in de productie van elektriciteit op de korte termijn, kunnen mogelijkerwijs opgevangen worden door waterkrachtaccumulatie of batterijen, maar energieopslag is ook nodig voor de langere termijn om zo seizoensfluctuaties te compenseren. Eén van de voorgestelde oplossingen voor lange-termijnfluctuaties, is om waterstof te maken uit water, met energie uit zonlicht. Deze waterstof kan zelf als brandstof of energiebron gebruikt worden, of omgezet worden naar koolwaterstoffen. Momenteel wordt $96 \%$ van alle waterstof vanuit fossiele brandstoffen gemaakt. Daarom zou de $\mathrm{CO}_{2}$-uitstoot jaarlijks met $2 \%$, of 685 miljoen ton, verminderd kunnen worden indien deze waterstof met behulp van duurzame energie uit water wordt gevormd.

Het onderzoek dat in dit proefschrift is beschreven, is gericht op de ontwikkeling van foto-elektrochemische systemen voor de vorming van waterstof uit water. Als basismateriaal is silicium gebruikt omdat het niet giftig is, maar wel ruimschoots beschikbaar en makkelijk te verkrijgen, en al in grote hoeveelheden en hoge zuiverheid geproduceerd wordt in de halfgeleiderindustrie. Elektrochemie is toegepast om coatings en functionaliteiten toe te voegen. Deze techniek biedt diverse opties, zoals een brede materiaalkeuze, controle over de morfologie van de gedeponeerde materialen, de mogelijkheid om gestructureerde oppervlaktes gelijkmatig te bedekken, een goed elektrisch contact tussen 
substraat en het gedeponeerde materiaal, normale procesomstandigheden en opschaalbaarheid.

In de hoofdstukken 3 en 5 zijn een metaal en een halfgeleider, te weten platina $(\mathrm{Pt})$ en wolfraamoxide $\left(\mathrm{WO}_{3}\right)$, door middel van elektrodepositie aangebracht op p-gedoteerd silicium, dat voorzien was van een laag ITO (indium-gedoteerd tinoxide). Hoofdstuk 3 beschrijft hoe de grootte en dichtheid van Pt-deeltjes kan worden gecontroleerd en dat de grootte een functie is van de hoeveelheid $\mathrm{H}_{2} \mathrm{O}_{2}$ die wordt toegevoegd aan het elektrolyt. Dit is belangrijk voor de constructie van een fotokathode die waterstof genereert en maakt het mogelijk het silicium met een hoge dichtheid aan Pt-deeltjes te bedekken. Tegelijkertijd staat deze methode ook toe om de totale gedeponeerde massa van dit dure en kostbare metaal te verminderen, en de lichtabsorptie en waterstofgeneratie van de kathode te optimaliseren. De dichtheid van de Pt-deeltjes werd 18.5-voud verhoogd door de optimale hoeveelheid $\mathrm{H}_{2} \mathrm{O}_{2}$ toe te voegen aan het elektrolyt, en daarmee werd ook de diameter van de deeltjes teruggebracht van 302 naar $60 \mathrm{~nm}$ bij een ladingsdichtheid van $20 \mathrm{mC} / \mathrm{cm}^{2}$. Bij hogere concentraties $\mathrm{H}_{2} \mathrm{O}_{2}$ werd geconstateerd dat de gedeponeerde massa verminderde bij toenemende ladingsdichtheid; dit werd toegeschreven aan de vorming van hydroxylradicalen.

In hoofdstuk 5 werd een fotoanode gemaakt met een $\mathrm{WO}_{3}$-coating, en de deactivering van de elektrode werd bestudeerd in een fosfaatbuffer bij verschillende $\mathrm{pH} . \mathrm{WO}_{3}$ is een veelbelovend, goedkoop, en milieuvriendelijk fotoanodemateriaal voor wateroxidatie, maar verliest haar activiteit na verloop van tijd in een fotoelektrochemische cel. Begrip van het deactiveringsproces is essentieel om een systeem met een lange levensduur te kunnen maken. De gevormde gassen, $\mathrm{H}_{2}$ en $\mathrm{O}_{2}$, werden in bedrijf gemeten met goede tijds- en concentratieresolutie. Het bleek dat de deactivering het snelst plaatsvond in een oplossing van $\mathrm{pH} 10$, gevolgd door $\mathrm{pH} 7.4$, dan $\mathrm{pH} 3.0$ en het langzaamst bij $\mathrm{pH}$ 5.0. Bij pH 7.4 was de fotoanode niet stabiel, en loste op; bij de ander $\mathrm{pH}$-waardes zou de deactivering veroorzaakt kunnen worden door peroxo-gebonden moleculen op het $\mathrm{WO}_{3}$-oppervlak, hoewel geen significante hoeveelheden $\mathrm{H}_{2} \mathrm{O}_{2}$ in het elektrolyt werden gevonden. 
In hoofdstukken 4 en 6 werden siliciumsubstraten met micropilaren gebruikt. De architectuur hiervan zorgt voor een verbeterde lichtinvang en een groot intern oppervlak, waardoor een grotere fractie van het invallende licht geabsorbeerd kan worden, en efficiënter gebruik van halfgeleiders mogelijk is zonder de dikte ervan te vergroten. Hoofdstuk 4 laat een nieuwe methode zien om twee verschillende materialen te deponeren, te weten zilver $(\mathrm{Ag})$ en platina $(\mathrm{Pt})$, respectievelijk op de onder- en bovenkant van de pilaren, zonder gebruik van enig masker. Dit is een significante verbetering van het productieproces van elektroden die twee verschillende functies nodig hebben, zoals bv. katalysatoren die oxidatie en reductie kunnen bewerkstelligen. Hiertoe werd een axiale pn-overgang gemaakt, waarvan de bovenkant n-gedoteerd silicium is. De metalen werden kathodisch gedeponeerd, en de aan- of afwezigheid van licht bepaalde de plaats van depositie.

In hoofdstuk 6 werden p-gedoteerde, silicium-micropilaren bedekt met ITO, en vervolgens met bismutvanadaat $\left(\mathrm{H}-\mathrm{BiVO}_{4-\mathrm{x}}\right)$. Bismutvanadaat werd vervolgens gedoteerd met molybdeen en behandeld in waterstofatmosfeer, om het effect hiervan op de fotokatalytische prestatie te bestuderen. Evaluatie van de fotokatalytische activiteit werd uitgevoerd met de oxidatie van sulfiet naar sulfaat en de reductie van protonen naar waterstof. De dikte, lengte (5.3 tot $15.9 \mu \mathrm{m})$ en tussenruimte (4 tot $20 \mu \mathrm{m}$ ) van de micropilaren voorzien van $\mathrm{H}-\mathrm{BiVO}_{4-\mathrm{x}}$ werden gevarieerd, om de prestatie van de elektrode te optimaliseren en te vergelijken met één met een vlakke geometrie. De micropilaarstructuur bleek de fotokatalytische prestatie niet te verbeteren, hetgeen toegeschreven kan worden aan de beperkte diffusie van redoxmoleculen in de ruimte tussen de micropilaren.

Concluderend heeft het onderzoek op vlakke substraten beschreven in hoofdstukken 3 en 5 bijgedragen aan de ontwikkeling van materialen voor het fotokatalytisch splitsen van water. De resultaten van hoofdstuk 3 bieden een synthesemethode om fotokathodes, gebaseerd of silicium, te optimaliseren voor waterstofproductie. Deze resultaten kunnen nog verder uitgebreid worden naar andere soorten halfgeleiders alsook andere toepassingen, aangezien $\mathrm{Pt}$ wordt gebruikt in vele chemische reacties. Bovendien is het begrip met betrekking tot de corrosie van $\mathrm{Pt}$ in de aanwezigheid van $\mathrm{H}_{2} \mathrm{O}_{2}$ cruciaal voor de ontwikkeling 
van stabiele (foto)katalysatoren met een lange levensduur. De deactivering van $\mathrm{WO}_{3}$ wordt nog altijd niet volledig begrepen en behoeft verder in-situ onderzoek om praktisch gebruik van dit materiaal rendabel te maken, bijvoorbeeld door specifieke structuren op het oppervlak aan te brengen, of door het te beschermen met (mono)lagen van een ander materiaal, zonder daarbij een significante hoeveelheid licht te absorberen.

Het onderzoek beschreven in hoofdstukken 4 en 6 , over plaatsgebonden depositie en de $\mathrm{H}-\mathrm{BiVO}_{4-\mathrm{x}}$-film, draagt bij aan beter begrip van de functionalisatie en de toepassing van silicium met micro-pilaren. De methode uit hoofdstuk 4 is ook toepasbaar voor de fabricage van systemen buiten de fotokatalyse, aangezien micropilaren gebruikt worden in vele toepassingen, zoals elektronica, sensoren, en fotonische systemen. De resultaten van hoofdstuk 6 tonen aan dat de dimensies, structuur en architectuur van veelgebruikte micropilaren misschien niet geschikt is voor fotokatalyse. Een recente studie, die een vergelijkebare constructie beschrijft die gemaakt is van zwart silicium met korte micropilaren, laat echter wel een bescheiden verbetering van de fotokatalyse zien in vergelijking met een vlakke geometrie. Meer onderzoek is nodig om de lengte, tussenruimte en diameter van de micropilaren te optimaliseren.

Aangezien Fujishima en Honda pas 50 jaar geleden voor het eerst fotokatalytisch water wisten te splitsen op een halfgeleidende electrode, is het veld momenteel nog in een pril stadium van ontwikkeling en er zijn dan ook nog veel aspecten die moeten worden onderzocht. Naast het ontwikkelen van materialen, zoals in dit proefschrift is beschreven, is het ontwikkelen van een apparaat, compleet met gasopvang en de organisatie van de verschillende onderdelen, noodzakelijk. Bovendien zijn verreweg de meeste experimenten in gecontroleerde laboratoriumomstandigheden gedaan, en het is nog niet duidelijk hoe variaties in temperatuur, de fysieke invloed van wind, regen en hagel, en dag/nacht- en seizoens-cycli de prestatie en levensduur van dit soort apparaten zullen beïnvloeden. Met name temperaturen onder het vriespunt kunnen een struikelblok vormen en de toepassing van deze apparaten verhinderen. Een ander onderbelicht feit is dat waterstof op een groot oppervlak gegenereerd zal worden, waardoor het afsluiten van het apparaat een uitdaging zal worden: waterstof is het lichtste molecuul en diffundeert door vele materialen heen. Al deze punten leiden tot 
twijfel over de haalbaarheid van het fotokatalytisch splitsen van water, ook omdat een benadering van het rendement op een grote schaal nodig is om een relevante bijdrage te leveren aan het oplossen van het energieprobleem. Desalniettemin was, is en blijft onderzoek noodzakelijk, aangezien de productie en opslag van energie één van de grootste vraagstukken van deze eeuw is, en alle mogelijke benaderingen uitgeprobeerd moeten worden. 


\section{Acknowledgements}

Doing research described in this thesis was an exciting and magnificent as well as challenging and instructive experience to me. The work required a very broad and interdisciplinary skillset and would hardly be possible without precious support of many personalities. I want to thank you all who accompanied and helped me during this time. Here is a small tribute to a few of these people:

Foremost I would like to thank sincerely my supervisors Guido Mul and Jurriaan Huskens for giving me the freedom to develop and follow my ideas and constantly supporting me throughout all activities. I am really glad that I was part of both of your research groups even though people asked me a couple of times if it is not difficult to satisfy two professors. To me, having you both as my supervisors was an advantage and gave me the chance to discuss the topics in more detail by getting feedback from sometimes different points of view. I enjoyed your cheerful enthusiasm and ever friendly nature and could learn a lot from your individual working styles.

Special thanks are also given to Thomas Jüstel, my mentor from one of the first days of my studies. Thomas, even though you had no direct input to the research of this thesis, your indirect contribution is tremendous. A big part of the basic knowledge in inorganic chemistry, materials science and interaction of light with matter, which was needed for this thesis, was taught to me by you in Bachelor and Master courses and during my work as a student research assistant on tailored optical materials in your group.

I am grateful to Rick, Janneke, Wouter and Pieter who also worked on silicon related topics and contributed to a great team. Together we found solutions to our specific problems quicker, helped each other in experiments and made an efficient use of resources, such as expensive cleanroom hours. I cannot imagine a better collaboration as with you all. Rick, you were my contact person and mentor from my first day as I came to UTwente to work on my Master 
assignment. Thanks for helping me in all paper work in Dutch. Besides, our work together led to two publications and even a shared chapter (Chapter 4 in this thesis) by combining your experience in microwire fabrication and my idea in spatioselective deposition. Janneke, I had a lot of fun in the lab and laughed with many people but never so much and so hard during experiments as with you. I remember that we even had to take a deep breath and focus on changing the samples one day.

Recep, also with you we had a very close collaboration and many discussions on electrochemistry. Additionally, you made me thinking very often about other topics from your philosophical questions. I learned many things from you. Thanks for all of that.

Thank you, Annemarie, my office mate during the writing period, for our discussions, your tips on writing and providing a quiet and focused atmosphere.

During the work on my promotion, I mentored Jan-Niklas, Han, Thimo during the Bachelor and Robert during the Master assignment. I experienced you as highly motivated, fast learning and hardworking students who were able to discuss detailed scientific questions after a short period of time. Thank you all for your input. All of your work was of high quality and part of the experimental work performed in Thimo's assignment is even used in Chapter 3 of this thesis.

I am also very grateful to the secretaries of the PCS and MnF groups Lidy, Nicole and Izabel for the help in organization and paper work. Big thanks also to the technical staff of the NanoLab and both research groups, especially to Robert who helped me the most in my experiments.

I enjoyed the time at the university, our group trips, coffee + cake breaks and our "borrels". Thanks a lot, to every PCS and MnF group member for providing a great atmosphere.

Thank you, Kai and Vera, my paranymphs, for all of your support, our scientific and non-scientific conversations, help in and outside of the lab, your great humor and all the laughs we had. Vera, thank you very much for translating Chapter 7 into Dutch. 
I also gratefully acknowledge the committee members for reviewing my thesis and being present at my defense.

Last but not least, thanks to all of my family and friends. My deepest gratitude and love receive to my parents Irina and Waldemar Milbrat for their dedication and support during all my life.

Alexander, April 2018 


\section{About the author}

Alexander Milbrat studied Bachelor and Master Chemical Engineering at Münster University of Applied Sciences (Germany) with the specialization in Applied Chemistry. He received his Bachelor of Science in October 2010 after a 6-month exchange at Juniata College (USA) where he did an internship and performed the research for his Bachelor thesis. During this time, he worked on the preparation and characterization

bis-diazomethylketones as chelate ligands under the supervision of Prof. Richard R. Hark (Juniata College) and Prof. Hermann Büttner (Münster

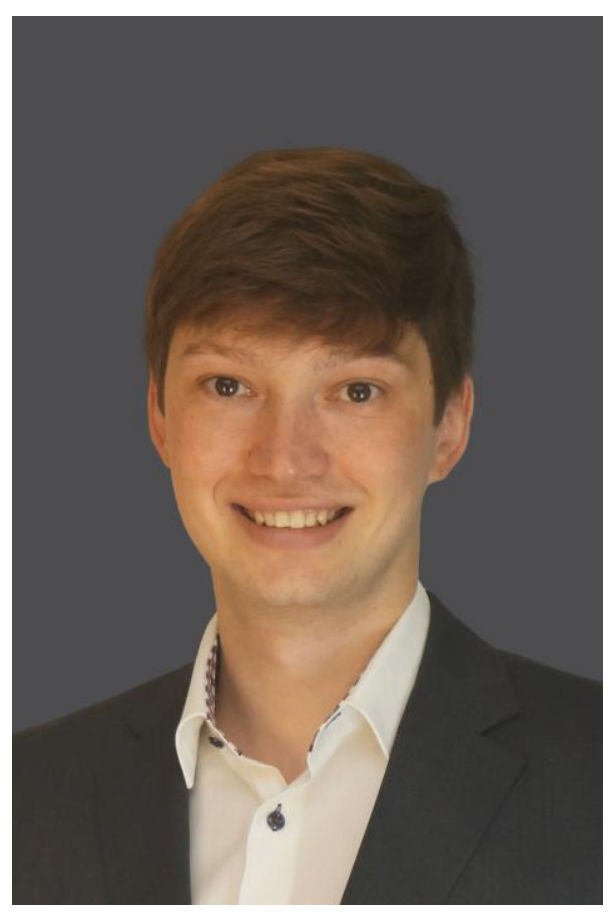
University of Applied Sciences).

Alexander received his Master of Science in December 2012. He focused in his Master assignment on the preparation of silicon nanowires for photocatalytic applications. The project was carried out at the University of Twente (The Netherlands) in the Photocatalytic Synthesis (PCS) and Molecular Nanofabrication $(\mathrm{MnF})$ groups under the supervision of Prof. Guido Mul, Prof. Jurriaan Huskens (both University of Twente) and Prof. Thomas Jüstel (Münster University of Applied Sciences).

Apart from his study, Alexander also worked as a Research Assistant in the Tailored Optical Materials (TOM) group at Münster University of Applied 
Sciences between November 2009 and February 2012 where he researched novel afterglow phosphors.

Between April 2011 and April 2012, Alexander was an elected member of the faculty council Chemical Engineering at Münster University of Applied Sciences. During this time, he represented over 500 Chemical Engineering students together with three other students in the council.

Since January 2013, Alexander has been working as a Ph.D. candidate under the supervision of Prof. Guido Mul (PCS) and Prof. Jurriaan Huskens (MnF) at the University of Twente. The results of this research are described in this thesis. 